\title{
III. Krisenbewältigung im Zeichen von Großer Koalition und Ermächtigungsgesetzen
}

Mit der Regierung Stresemann wurde die von Teilen der bürgerlichen Mitte und der SPD seit Jahren angestrebte Große Koalition im August 1923 erstmals in die Realität umgesetzt. Nach dem Regierungsaustritt der SPD Anfang November, dem Sturz Stresemanns und der Bildung des Kabinetts Marx Anfang Dezember blieb das breite Bündnis noch als parlamentarisches Kooperationsmodell erhalten. $\mathrm{Da}$ in jenen Monaten der Ruhrkampf beendet, die Währung stabilisiert und die akuten extremistischen Gefahren im Inneren zurückgedrängt werden konnten, bedeutete die vorläufige Rettung der parlamentarischen Republik als verfassungsmäßiges Regierungssystem. Erhebliche Bedeutung kam dabei als Grundlage eines ausgedehnten Verordnungsregimes den beiden großen Ermächtigungsgesetzen vom Oktober und Dezember 1923 zu. Es erscheint daher sinnvoll, die Zeit der Regierungen Stresemann und Marx bis zur Reichstagsauflösung im März 1924 als eine unter dem Signum von Großer Koalition und Ermächtigungsgesetzen stehende Einheit zu betrachten.

\section{Bildung der Großen Koalition und Antritt der Regierung Stresemann}

Sofort nach der Rücktrittsankündigung Cunos nahm der Reichspräsident Kontakt zu den wichtigsten Fraktionen auf und empfing am Nachmittag des 12. August hintereinander die Vertreter von DDP, Zentrum, BVP und SPD. Da Stresemann während der letzten Monate in Parlament und Öffentlichkeit mit wachsendem Zuspruch eine politische Führungsrolle ausgefüllt hatte ${ }^{1}$, war es keine Überraschung, daß der DVP-Vorsitzende hier einhellig als künftiger Kanzler vorgeschlagen wurde ${ }^{2}$. Erst nach dieser informellen Klärung reichte Cuno wie vereinbart ${ }^{3}$ sein Demissionsgesuch ein. Ebert, der Stresemann ursprünglich mit einigen Vorbehalten gegenübergestanden hatte 4 , jetzt aber de facto keinen Spielraum für eine andere Entscheidung besaß, erteilte diesem daraufhin den Auftrag zur Kabinettsbildung.

Darüber, daß die neue Reichsregierung von einer Großen Koalition getragen sein würde, bestand im Augenblick von Cunos Rücktritt kaum ein Zweifel. Vermutlich erfolgten bereits in den Gesprächen am 12. August von allen beteiligten Parteien konkrete Bereitschaftsbekundungen. Auch im größten Teil der politischen Öffentlichkeit herrschte angesichts der dramatischen Krisensituation und

1 Absolut unglaubwürdig ist Stresemanns spätere Behauptung in einem Presseartikel, er habe nicht daran gedacht, "damals als Reichskanzler berufen zu werden“. Zitiert nach Stresemann, Vermächtnis 1, S. 89. Zur „selbstverständlichen“ Betrauung Stresemanns vgl. auch Arns, Regierungsbildung, S. $156 \mathrm{f}$.

2 So Stresemann am Abend des 12. 8. 1923 in der erwähnten Pressekonferenz. Vgl. VZ, 13. 8. 1923 ab, S. 2, „Reichskanzler Stresemann über die Regierungsbildung“. Text aus der Pressekonferenz auch in Stresemann, Vermächtnis 1, S. 88. Allgemein zur Regierungsbildung Stresemanns vgl. v.a. Arns, Regierungsbildung, S. 155-159; Morsey, Zentrumspartei, S. 516-518; AdR Stresemann, S. XXI$\mathrm{XXV}$.

$3 \mathrm{Zu}$ den Abmachungen zwischen Cuno und der bürgerlichen Arbeitsgemeinschaft vgl. oben S. 232.

4 Vgl. oben S. $173 \mathrm{f}$. zur Nichtberücksichtigung als möglicher Kanzler im November 1922. 
der Dimension der anstehenden Aufgaben Einigkeit darüber, daß für eine breite parlamentarische Mehrheit zu sorgen sei5.

Die Voraussetzungen für eine Große Koalition hatten sich im Vergleich zum gescheiterten Anlauf vom November 1922 erheblich gewandelt: Zumindest im Augenblick gab es keine akuten politischen Differenzen zwischen SPD und DVP, denn der offene Konflikt in der Währungsfrage war längst von der rasenden Hyperinflation überrollt worden und auch in der DVP bestand nun weitgehende Klarheit über die Notwendigkeit einer möglichst raschen Währungsstabilisierung. Für die SPD hatte sich die Situation auch insofern geändert, als während der vergangenen Monate wohl ein gewisses Vertrauen zu Stresemann gewachsen war und die DVP den Nimbus einer "Stinnes-Partei“ wieder etwas verloren hatte. Über eine baldige Beendigung des Ruhrkampfes wurde öffentlich zwar wenig gesprochen, wie der Lauf der Ereignisse zeigen sollte, gab es aber auch in dieser Frage innerhalb der Großen Koalition wenig grundlegende Differenzen. Taktisch war es für alle beteiligten Parteien sinnvoll, die Beendigung des passiven Widerstandes auf eine breite Grundlage zu stellen und damit die Gefahr einer erneuten Dolchstoßlegende zu begrenzen 6 .

Trotz dieser Rahmenbedingungen blieb in DVP und SPD jeweils eine relativ starke Minderheit erhalten, die ein derartiges Bündnis prinzipiell ablehnte. Die vom rechten Flügel der DVP anvisierte Option eines bürgerlichen Blocks unter Beteiligung der DNVP war zu diesem Zeitpunkt aber ebenso irreal wie die am linken Flügel der SPD gepredigte Lösung einer „Arbeiterregierung“ mit Duldung oder Beteiligung der Kommunisten. Während in einer Sitzung der DVP-Fraktion am 13. August noch unklar blieb, wie groß das ablehnende Lager eigentlich war, und nur Reinhold Quaatz und Albert Vögler gegen eine Große Koalition Stellung nahmen', kam es in der SPD-Fraktion am 13. August zu einer offenen Abstimmung. Nach den Aufzeichnungen Giebels sprachen sich 83 Abgeordnete für und 39 gegen einen Regierungseintritt aus ${ }^{8}$. Da nicht bekannt ist, wie viele der 173 sozialdemokratischen Abgeordneten an dieser Sitzung teilnahmen und wie viele sich der Stimme enthielten, fällt eine Bewertung dieses Ergebnisses schwer. Wie dann auch die spätere Abstimmung über die Vertrauensfrage Stresemanns zeigen sollte, scheint der Anteil der Koalitionsgegner aber tatsächlich bei etwa einem Drittel der Fraktionsmitglieder gelegen zu haben.

Die BVP, die in den letzten Monaten in den informellen Verbund der bürgerlichen Arbeitsgemeinschaft einbezogen worden war und deren Fraktionsvorsitzender Leicht auch an den Parteiführerbesprechungen im Vorfeld der Ablösung Cunos teilgenommen hatte, wurde kein integraler Bestandteil der Großen Koalition und lehnte insbesondere eine ministerielle Beteiligung ab. Die formelle Mitarbeit der BVP an einer Koalition mit der Sozialdemokratie war von Anfang an

5 Vgl. z. B. FZ, 13. 8. $1923 \mathrm{mo} / 1$, S. 1, Frankfurt, 13. August: „Eine Selbstverständlichkeit ist es, daß diese Wendung die Große Koalition zur Folge hat."

6 Winkler, Von der Revolution zur Stabilisierung, S. 592.

7 So Turner, Stresemann, S. 116.

8 ASD Bonn, Nl. Giebel, Kassette II, Mappe 3, Bl. 243f. Vgl. auch Kastning, Sozialdemokratie, S. 115; Winkler, Von der Revolution zur Stabilisierung, S. $602 \mathrm{f}$. 
unwahrscheinlich gewesen, wobei die Verweigerung weniger von Leicht ausging als von der Münchner Parteileitung?.

Die Bildung einer Großen Koalition hatte zur Folge, daß es im Reichstag keine nennenswerte systemloyale Opposition mehr gab. Die parlamentarische Alternativfunktion war dadurch nahezu vollständig suspendiert. Im Unterschied zur Amtszeit Cunos stand der Regierung jetzt zudem nicht mehr nur eine kleine, allerdings überaus aktive linke Systemopposition in Form der KPD gegenüber, sondern auch die in eine fundamentale Oppositionshaltung zurückfallende DNVPFraktion.

Über die kurzen Koalitionsverhandlungen ist wenig bekannt ${ }^{10}$. Nach dem Bericht Severings, der - vermutlich auf Ersuchen Stresemanns - bei der SPD-Fraktion auf Kompromißbereitschaft drängte, gab es Schwierigkeiten in der „Frage einer durchgreifenden Finanzreform auf der Grundlage der Heranziehung der Wirtschaft und der Belastung ihrer Sachwerte"11. Inwieweit hier konkrete Vereinbarungen getroffen und ob weitere Sachprobleme erörtert wurden, bleibt unklar. Auf ein bindendes Programm, wie dies Stresemann Anfang August in einem Brief selbst gefordert hatte, wurde verzichtet ${ }^{12}$. Differenzen über die Zusammensetzung der Ministerliste, die nach Stresemanns Tagesnotizen am Nachmittag des 13. August zu „größter Spannung “ führten, wurden rasch beseitigt. Die SPD hatte zunächst Einspruch gegen die erneute Besetzung des Wehrministeriums mit Otto Geßler (DDP) erhoben, der aus sozialdemokratischer Sicht für das Erstarken reaktionärer Tendenzen in der Reichswehr verantwortlich war ${ }^{13}$. Offenbar kam es daraufhin zu einer gewissen Kompensation, indem der rheinische Sozialdemokrat Wilhelm Sollmann, der dem rechten Parteiflügel angehörte ${ }^{14}$, das umkämpfte Innenministerium erhielt. Das Zentrum hatte hier ebenfalls Ansprüche angemeldet und präsentierte als Kandidaten den von den Franzosen aus dem besetzten Gebiet ausgewiesenen rheinischen Oberpräsidenten Johannes Fuchs ${ }^{15}$. Nach kurzem Konflikt lenkte das Zentrum ein, und Fuchs wurde mit dem neugeschaffenen Ministerium für die besetzten Gebiete betraut ${ }^{16}$.

9 Leicht hatte schon am 12.8. 1923 in einer Parteiführerbesprechung signalisiert, daß es vermutlich keine Beteiligung seiner Partei an einer Großen Koalition geben werde. AdR Cuno, Nr. 248, S. 743. Vgl. zur Haltung der BVP auch Maga, Prälat Johann Leicht, S. $113 \mathrm{f}$.

10 Vgl. aus der Literatur v.a. AdR Stresemann, S. XXV-XXX; Hirsch, Stresemann, S. 143 f.; Baechler, Stresemann, S. 349-351; Arns, Regierungsbildung, S. 156-158; Morsey, Zentrumspartei, S. 516518.

1 Severing, Lebensweg 1, S. 424 f. Nach ebd. kam die Bitte von Leidig, einem preußischen Landtagsabgeordneten der DVP, der in engem Kontakt zu Stresemann stand.

12 In seiner Regierungserklärung lehnte es der neue Kanzler ausdrücklich ab, ein Regierungsprogramm zu präsentieren. Vgl. unten S. 242. Zu Stresemanns ursprünglicher Forderung vgl. Brief vom 1. 8. 1923 an Jänecke; Stresemann, Vermächtnis 1, S. $74 \mathrm{f}$.

13 Zur ursprünglichen Ablehnung Geßlers in der SPD-Fraktion vgl. auch die Bemerkungen Ledebours am 14.8. 1923 im Reichstag; Verh. RT 361, S. 11854.

14 Als Chefredakteur der Rheinischen Zeitung hatte er eine harte Haltung gegen Frankreich gezeigt. Vgl. AdR Stresemann, S. XXVIII.

15 Vgl. VZ, 13. 8. 1923 ab, S. 1, „Die Regierung der Großen Koalition“.

16 Vgl. Stresemann, Vermächtnis 1, S. 88, unter Tagesnotizen 13.8. 1923: „Verhandlungen wegen Kabinettsbildung. Größte Spannung/ Nachmittag betreffend Geßler und Minister des Innern. 730 Kabinettsbildung/ Ernennung zum Kanzler/ Abschied Cunos." Nach dem Erinnerungsbericht 1923 von Marx wäre wegen des Konflikts um Ministerien und v.a. um das Innenressort beinahe die gesamte Regierungsbildung gescheitert. Vgl. Nachlaß des Reichskanzlers Wilhelm Marx 1, S. 286. 
Bereits am Abend des 13. August war damit die Kabinettsbildung abgeschlossen, und Ebert konnte Stresemann zum Reichskanzler ernennen. Besonders auffallend ist, daß dieser für die Besetzung des Wirtschafts- und Finanzministeriums eine personell harmonische Lösung im „Doppelgespann Raumer-Hilferding“ anstrebte und so auch die Gegensätze zwischen DVP und SPD zu mindern glaubte. Der ehemalige unabhängige Sozialdemokrat und bekannte Finanztheoretiker Hilferding und der unkonventionelle DVP-Politiker und Interessenvertreter der Elektroindustrie Raumer, 1918 einer der wesentlichen Architekten der Zentralarbeitsgemeinschaft ${ }^{17}$ und neben Stresemann die treibende Kraft für eine Große Koalition innerhalb der DVP, pflegten nicht nur gute persönliche Beziehungen, sondern hatten Ende Oktober/Anfang November 1922 in dem von Wirth eingesetzten überparteilichen Ausschuß auch erfolgreich politisch zusammengearbeitet $^{18}$.

Die weiteren Posten im ersten Kabinett Stresemann wurden wie folgt besetzt: Minister für Wiederaufbau und zugleich Vizekanzler wurde der Sozialdemokrat Robert Schmidt, der bereits über Erfahrungen als Ernährungs- und Wirtschaftsminister verfügte, die Justiz übernahm - wie bereits im Kabinett Wirth II - Gustav Radbruch von der SPD, das Verkehrsressort ging an den DDP-Politiker Rudolf Oeser, der unter Cuno Innenminister gewesen war. Neben Geßler blieben aus der Regierung Cuno auch der parteilose, allerdings der DVP nahestehende Ernährungsminister Hans Luther sowie Arbeitsminister Heinrich Brauns vom Zentrum in ihren Ämtern. Vakant blieb vorerst das Postministerium, das nach Presseberichten Karl Stingl von der BVP hätte weiterführen sollen ${ }^{19}$. Ende August übertrug der Kanzler das Ministerium dann auf Vorschlag von Marx dem Zentrumsabgeordneten Anton Höfle ${ }^{20}$. Das Außenamt übernahm Stresemann in Personalunion mit der Kanzlerschaft, eine spätere separate Besetzung wurde jedoch vage in Aussicht gestellt.

Unter den insgesamt zwölf Ministern waren demnach vier Vertreter der SPD, drei des Zentrums, je zwei der DVP und der DDP sowie ein parteiloser Politiker. Die Stellung der DVP im Kabinett wurde insofern noch verstärkt, als Stresemann seine Parteifreunde Arnold Kalle zum Reichspressechef und Werner Freiherr von Rheinbaben zum Leiter der Reichskanzlei berief ${ }^{21}$ und damit eine dem modernen parlamentarischen System durchaus adäquate parteipolitische Anpassung vornahm. Daß die SPD mit mehreren wichtigen Ministerien vertreten war, übertraf zwar die im Vorfeld von Stresemann innerhalb seiner Partei angekündigte Einbin-

$17 \mathrm{Vgl.} \mathrm{Feldman/Steinisch,} \mathrm{Industrie} \mathrm{und} \mathrm{Gewerkschaften} \mathrm{1918-1924,} \mathrm{S.} 30$ f.

$18 \mathrm{Vgl}$. Bemerkungen in Stresemann, Vermächtnis 1, S. 144, über das Zusammenwirken. Raumer machte den Kabinettseintritt von einer Aussprache mit Hilferding abhängig. Vgl. hierzu Baechler, Stresemann, S. 349.

19 Vgl. VZ, 13. 8. 1923 ab, S. 1, „Die Regierung der Großen Koalition“.

20 Da die BVP eine Regierungsbeteiligung ablehnte, fiel das Ressort dem Zentrum zu. Dessen erster Kandidat Johannes Giesberts, der das Amt bereits unter Wirth eingenommen hatte, wurde jedoch von Stresemann abgelehnt, möglicherweise weil Giesberts als Exponent des linken Zentrumsflügels galt. So die plausible Vermutung in Arns, Regierungsbildung, S. 158. Nach dem Erinnerungsbericht 1923 von Marx hatte sich die Zentrumsfraktion schon am 13.8. auf Höfle geeinigt. Vgl. Nachlaß des Reichskanzlers Wilhelm Marx 1, S. 286.

21 Vgl. zur Begründung durch Stresemann Protokoll der Kabinettssitzung vom 14.8. 1923; AdR Stresemann, Nr. 1, S. 2. 
dung von lediglich ein bis zwei sozialdemokratischen Ministern in ein bürgerlich dominiertes Kabinett ${ }^{22}$. Die parlamentarischen Kräfteverhältnisse innerhalb der Regierungsfraktionen (SPD 173, DDP 39, Zentrum 68 und DVP 66 Mandate) wurden damit aber nicht in vollem Umfang widergespiegelt. Die SPD stellte zwar die Hälfte der Abgeordneten des Regierungsbündnisses, aber nur ein Drittel der Minister. Auffallend ist, daß Stresemann wohl nicht einmal den Versuch unternommen hat, den rechten Flügel seiner eigenen Partei in das Kabinett zu integrieren. Die Ablösung von Wirtschaftsminister Becker durch Raumer symbolisierte die zeitweise Verlagerung des von Stresemann bestimmten Kurses der DVP hin zur politischen Mitte.

Insgesamt bedeutete die für Weimarer Verhältnisse ungewöhnlich rasche Einigung auf ein neues Kabinett eine Reaktivierung der regierungsbildenden Funktion des Reichstags. Eine während der Kanzlerschaft Cunos stockend angebahnte Entwicklung fand so unter akutem Krisendruck doch noch einen konsequenten $\mathrm{Ab}$ schluß. Entgegen der Ankündigung Stresemanns in einer Pressekonferenz am 12. August, daß die "Zusammenstellung des Kabinetts", „wie die Verfassung es vorsieht, Sache des neuen Kanzlers" sei23, hatten die Parteiführungen bei der Nominierung der einzelnen Minister eine wesentliche Mitsprache ausgeübt ${ }^{24}$. Im Widerspruch zu dem von weiten Bereichen der Öffentlichkeit und auch von Stresemann selbst getragenen Wunsch, den Einfluß der Parteien und Fraktionen ${ }^{25}$ zu reduzieren, gelangte somit die Logik des parlamentarischen Systems erneut zum Durchbruch. Entscheidend für die weitere Entwicklung war nun aber, ob die in der Regierungsbildung praktizierte enge Zusammenarbeit auch zu einer erfolgreichen Kooperation in der Regierungsarbeit und damit zu einer stabilen parlamentarischen Regierungsstützung führen würde.

Eine erste Probe hierfür bildete die Präsentation der neuen Regierung im Reichstag am 14. August. Im Gegensatz zu seinen eindrucksvollen Auftritten während der Amtszeit Cunos hielt Stresemann diesmal nur eine kurze Rede ${ }^{26}$. Aufschlußreich sind vor allem die Ausführungen zum Charakter seines Kabinetts, in denen der Kanzler die Existenz einer "parlamentarische[n] Basis“ ebenso wie die Notwendigkeit zur Großen Koalition betonte. Die anstehenden „großen Entscheidungen " verlangten "den Zusammenschluß aller den verfassungsmäßigen Staatsgedanken bejahenden Kräfte". Letztlich wies Stresemann der Großen Koalition damit einen paradoxen Ausnahmestatus zu. Der Staat werde, so führte er weiter aus, „den Ansturm von außen und innen“ nur bestehen können, „wenn Regierung und eine staatsbejahende Opposition sich in der Sorge um die deutsche

22 Brief Stresemann vom 1. 8. 1923 an Jänecke (Verleger des Hannoverschen Kuriers); Stresemann, Vermächtnis 1, S. $74 \mathrm{f}$.

23 Zitiert nach VZ, 13. 8. 1923 ab, S. 2, "Reichskanzler Stresemann über die Regierungsbildung“.

24 Allerdings klagte der Abgeordnete Franz Feilmayr in der Sitzung vom 14.8. 1923 in der Zentrumsfraktion, „daß der Fraktion zu wenig Gelegenheit gegeben worden sei, zu den vorgeschlagenen Ministern Stellung zu nehmen“. Protokolle Zentrumspartei, Nr. 252, S. 472. Feilmayr enthielt sich dann beim Vertrauensvotum.

25 Letzteres spiegelte sich zum Beispiel auch in der Bemerkung Stresemanns, es sei „selbstverständlich“, daß ein Kabinett der Großen Koalition einen stark politischen Charakter trage, keineswegs aber würden die Mitglieder von den Fraktionen präsentiert. VZ, 13.8. 1923 ab, S. 2, „Reichskanzler Stresemann über die Regierungsbildung“.

26 Verh. RT 361, S. 11839-11841. 
Zukunft zusammenfinden“. Ausdrücklich verzichtete der Kanzler auf eine Konkretisierung seiner politischen Absichten und forderte einen Vertrauensvorschuß für seine Regierung: „Programme helfen uns nicht weiter, wenn nicht schnellstens Maßnahmen zur Heilung getroffen werden. [...] Wir brauchen zu unserer Arbeit ihr Vertrauen. Bekunden Sie durch dieses Vertrauen nach außen und innen, daß das deutsche Parlament sich in schwerer Zeit zusammenschließt.“

Die inhaltliche Unbestimmtheit dieser Ausführungen, die in gewisser Weise an Cunos Antrittsrede erinnerte, war zumindest in der Frage des Ruhrkonflikts wohl auch ein Ausdruck politischer Strategie. Stresemann beschränkte sich auf vorsichtige Andeutungen über eine mögliche Beendigung des passiven Widerstandes, wobei er die Hoffnung auf ein internationales Schiedsgericht zum Ausdruck brachte ${ }^{27}$. Ebenso allgemein blieben die Hinweise zur „Währungsfrage“. Die Aussage, daß es in dieser "keine Parteimeinungen“ gebe, bediente sich der bekannten Kriegsrhetorik und kontrastiert geradezu frappierend mit den bisherigen parteipolitischen Differenzen über das Ob und das Wie einer Stabilisierung. Die wichtigste Botschaft, die von Stresemanns Rede ausging, war die optimistisch gestimmte Bereitschaft zu politischer Aktivität und damit zur Überwindung der weithin als lethargisch empfundenen Politik Cunos.

Auf die Regierungserklärung folgten, wie zweifellos im Ältestenrat vereinbart, lediglich kurze Stellungnahmen der Fraktionsführer der Regierungsparteien sowie der DNVP und BVP. Dem Verzicht auf die Entfaltung eines Regierungsprogramms entsprach somit der Verzicht auf eine Aussprache. Der gemeinsame Tenor der Auftritte von Müller, Marx, Petersen und Scholz, dem Nachfolger Stresemanns als Vorsitzender der DVP-Fraktion, lag in der pauschalen Vertrauensbekundung gegenüber der neuen Regierung und in der allgemeinen Forderung nach aktiver deutscher Politik ${ }^{28}$. Einen gewissen inhaltlichen Akzent setzte lediglich Müller mit seiner nachdrücklichen Forderung, die anstehende Währungsstabilisierung durch eine Heranziehung der Sachwerte in die Wege zu leiten. Die Vertreter der bürgerlichen Regierungsparteien beschränkten sich dagegen auf extrem knappe Stellungnahmen ${ }^{29}$. Alles in allem nahm sich so das parlamentarische Regierungslager stark zurück und überließ demonstrativ der neuen Regierung die Initiative.

Ein Blick sei auch auf die wichtigsten Redner der nicht in der Regierung vertretenen Parteien geworfen. Während Prälat Leicht für die BVP eine diffuse Position bezog und zwischen einer grundsätzlich positiven Reaktion auf Stresemanns Kanzlerschaft und einer kritischen Beurteilung der „Zusammensetzung des Kabinetts“ lavierte ${ }^{30}$, signalisierte der DNVP-Vorsitzende trotz eines relativ modera-

27 Übertrieben ist die Darstellung bei Turner, Stresemann, S. 115, der Kanzler habe die Fortführung des passiven Widerstands angekündigt. Zur anfänglichen Haltung des Kanzlers Stresemann gegenüber dem Ruhrkonflikt vgl. v.a. Baechler, Stresemann, S. 354-362.

28 Verh. RT 361, S. 11842 f. (Müller); 11843 (Marx; vgl. hierzu auch Morsey, Zentrumspartei, S. 518); 11844 (Petersen und Scholz).

29 Auffallend bei Scholz und gleichermaßen Ausdruck eines extrem dualistischen Parlamentarismusverständnisses wie einer gewissen eigenen Distanz zur Regierungsbildung ist die Ansicht, die Kanzlerschaft Stresemanns bedeute das „größte Opfer [...] das eine Partei dem Vaterlande bringen kann“. Ebd.

30 Ebd., S. 11844 f. Vgl. auch Maga, Prälat Johann Leicht, S. 114 f. 
ten Tones eindeutige Ablehnung. Hergt forderte eine Intensivierung des Ruhrkampfes und prophezeite, daß die neue Regierung „unter den beherrschenden Einfluß der Sozialdemokratie geraten" werde. Grundsätzlich kritisierte er die „Rückkehr zum System der Parteiregierung“. Diese würde „nicht zur Zusammenfassung aller Kräfte, also auch nicht zur Erweiterung, sondern zur Verengerung der Regierungsgrundlagen und damit zur Schwäche “ führen ${ }^{31}$. Schroffe Gegnerschaft zur Regierung verkündeten die Vertreter der übrigen systemfeindlichen Fraktionen und Gruppen ${ }^{32}$, die den Konsens zur Kürze unterliefen und erheblich längere Reden hielten. Gewisse Wirkung auf den linken Flügel der SPD-Fraktion gewann möglicherweise die eindringliche Kritik Ledebours (USPD) an der Koalitionspolitik der SPD im allgemeinen und an der Akzeptanz von Geßler als Wehrminister im besonderen ${ }^{33}$. Um so wichtiger war es, daß mit Breitscheid noch ein zweiter Redner der SPD vor das Plenum trat, der - relativ ausführlich - für die ursprünglichen Gegner einer Großen Koalition in der SPD sprach. Der ehemalige Unabhängige führte aus, daß auch bei ihm „Bedenken“ blieben, daß er aber unter den gegebenen Umständen keine andere Möglichkeit sehe. Breitscheid, der das Verhalten der KPD im Ruhrkonflikt scharf attackierte und auch der These, der kommunistisch inspirierte Generalstreik hätte die Regierung Cuno gestürzt, vehement widersprach, ging es dabei sicher nicht nur um eine Einwirkung auf die Fraktionslinke, sondern auch um die Vermittlung der Koalitionsentscheidung gegenüber der skeptischen SPD-Basis ${ }^{34}$.

Der von den Regierungsparteien eingebrachte Vertrauensantrag enthielt erstmals seit 1920 wieder eine explizite Bekundung: „Der Reichstag billigt die Erklärung der Reichsregierung und spricht ihr das Vertrauen aus. “35 Das Ergebnis der namentlichen Abstimmung ergab mit $239 \mathrm{Ja}$ - zu 76 Nein-Stimmen bei 25 Enthaltungen eine deutliche Mehrheit ${ }^{36}$. Gegen den Antrag stimmten weitgehend die DNVP ${ }^{37}$, die KPD, die kleinen Gruppen der Deutschvölkischen und der USPD sowie einzelne Abgeordnete anderer Splittergruppen. Die BVP-Fraktion enthielt sich der Stimme. Als Beweis für eine stabile parlamentarische Stützung der neuen Regierung kann dieses Vertrauensvotum allerdings kaum gewertet werden, denn die eigentliche Besonderheit war die hohe Zahl von 97 fehlenden Abgeordneten, was über einem Fünftel aller Parlamentarier entspricht. Darunter waren 53 Sozialdemokraten ${ }^{38}$, 19 Volksparteiler, 11 Zentrums- und 6 DDP-Abgeordnete. Von den Flügelparteien der Koalition, SPD und DVP, blieb damit jeweils ein knappes Drittel der Abgeordneten der Abstimmung fern und insgesamt etwa ein Viertel

31 Verh. RT 361, S. $11843 \mathrm{f}$.

32 Frölich für die KPD, Wulle für die Deutschvölkische Freiheitspartei und Ledebour für die Splitter-USPD. Ebd., S. 11845-11855.

33 Ebd., S. 11853-11855.

34 Ebd., S. 11855-11857. Den Druck der SPD-Basis beklagt v.a. Winkler, Von der Revolution zur Stabilisierung, passim. Vgl. auch die Kritik bei Feldman, Von Krise zu Krise, S. 635.

35 Verh. RT 361, S. 11843.

36 Ergebnis der namentlichen Abstimmung ebd., S. 11871-11873.

37 Lediglich der Abgeordnete Spahn stimmte mit Ja. Ebd.

38 Zurückzuweisen ist die in der Literatur teilweise verbreitete Auffassung, es hätte aus den Reihen der SPD auch zwei Nein-Stimmen gegeben. So etwa Arns, Regierungsbildung, S. 159; Winkler, Von der Revolution zur Stabilisierung, S. 603. 
des Regierungslagers ${ }^{39}$. Die Fraktionskohärenz erreichte somit für deutsche Verhältnisse ungewöhnlich schlechte Werte.

Tab. 7: Votum des Reichstags am 14. 8. 1923: Investitur Regierung Stresemann I40

\begin{tabular}{|c|c|c|c|c|c|c|c|}
\hline $\begin{array}{l}\text { Fraktion oder } \\
\text { Gruppe }{ }^{41}\end{array}$ & Abg. & $\mathrm{ja}$ & nein & $\begin{array}{l}\text { ent- } \\
\text { halten }\end{array}$ & fehlend & $\begin{array}{l}\text { beurl. } \\
\text { krank } \\
\text { entsch. }\end{array}$ & $\begin{array}{l}\text { Kohä- } \\
\text { renz }{ }^{42}\end{array}$ \\
\hline
\end{tabular}

\begin{tabular}{lrrrrrrc}
\hline KPD & 16 & - & 10 & 1 & 3 & 2 & $(71 \%)$ \\
USPD & 2 & - & 2 & - & - & - & - \\
SPD & 171 & 115 & - & - & 53 & 3 & $68 \%$ \\
DDP & 39 & 33 & - & - & 6 & - & $85 \%$ \\
Zentrum & 65 & 46 & - & 2 & 11 & 6 & $78 \%$ \\
DVP & 66 & 44 & - & - & 19 & 3 & $70 \%$ \\
BBMB & 4 & - & - & 3 & 1 & - & - \\
BVP & 20 & - & - & 16 & 2 & 2 & $89 \%$ \\
DHP & 4 & - & - & 3 & 1 & - & - \\
DNVP43 & 66 & 1 & 59 & - & 1 & 5 & $97 \%$ \\
DVFP & 3 & - & 3 & - & - & - & - \\
fraktionslos & 2 & - & 2 & - & - & - & - \\
\hline Gesamt & 458 & 239 & 76 & 25 & 97 & 21 & - \\
\hline
\end{tabular}

Hinzu kam, daß jeweils eine größere Gruppe innerhalb der DVP und der SPD auf informelle Weise ihr Mißtrauen bekundete. „Mehr als ein Dutzend Mitglieder“ der DVP-Fraktion gab, so bemerkte Stresemann später in einem Zeitschriftenartikel, „durch Entfernung aus dem Saal ihrem Protest gegen die Bildung des Kabinetts Ausdruck “44. Den Anlaß für diese Demonstration, die nach der Fraktionssitzung vom 13. August noch nicht absehbar gewesen war, bildete höchstwahrscheinlich die erst sehr spät bekannt gewordene ministerielle Stärke der Sozialdemokratie ${ }^{45}$.

39 Anzumerken ist, daß nicht jeder Abwesende auch ein Dissident gewesen sein muß. Das Fehlen einiger DDP-Abgeordneter besaß wohl keine politische Signifikanz. Auffällig ist hingegen die Zahl von 11 abwesenden Parlamentariern sowie einer Enthaltung aus den Reihen des Zentrums, insgesamt immerhin ein knappes Fünftel der Fraktion. Es gibt Indizien dafür, daß hier weniger eine grundsätzliche politische Distanz zum Ausdruck kam als vielmehr Verstimmungen über die mangelhafte Einbindung der Fraktion bei der Benennung von Ministern. Vgl. Anm. 24 zur Kritik Feilmayrs. Zu berichtigen ist das Urteil bei Morsey, Zentrumspartei, S. 518, die Fraktion habe "geschlossen " für den Vertrauensantrag gestimmt.

40 Nach Verh. RT 361, S. 11871-11873.

41 Einschließlich Hospitanten.

42 Anteil der von der Mehrheit der Fraktion abgegebenen Stimmen bezogen auf die Zahl der verfügbaren Abgeordneten (d.h. Zahl der Abgeordneten minus Beurlaubte, Kranke und Entschuldigte). Nur bei Gruppen über 10 Abgeordnete berechnet. - Im Falle der KPD ist die Angabe der Kohärenz fragwürdig, da hier das Fehlen kein Zeichen möglicher Divergenzen mit der Fraktionslinie war, sondern - im Gegensatz zur Propagandaarbeit im Lande - den relativ geringen Stellenwert der parlamentarischen Präsenz spiegelte. Vgl. hierzu auch Mergel, Parlamentarische Kultur, S. 184.

43 Einschließlich eines Abgeordneten der Bayerischen Mittelpartei.

${ }_{44}$ Nach Arns, Regierungsbildung, Anmerkungen, S. 77. Nach dem Herausgeberkommentar in Stresemann, Vermächtnis 1, S. 90, haben 13 Abgeordnete „absichtlich und zum Ausdruck ihrer Unzufriedenheit mit der personellen Zusammensetzung des Kabinetts" nicht am Votum teilgenommen.

45 So Turner, Stresemann, S. 116. 
Zum harten Kern einer Rechts- „Fronde“ innerhalb der DVP dürften jene 12 Parlamentarier gehören, die bereits bei der Abstimmung über das erste Republikschutzgesetz am 18. Juli 1922 gefehlt oder mit „Nein“ gestimmt hatten ${ }^{46}$. Darunter waren so bedeutsame Namen wie Curtius, Quaatz und Vögler. Auch die beiden Unterhändler vom 13. November 1922, Becker(-Hessen) und Zapf, die damals ihren Beitrag zum Scheitern einer Großen Koalition geleistet hatten ${ }^{47}$, standen nun im Lager der Koalitionsgegner. Bemerkenswert ist, daß Stinnes mit "Ja" stimmte, eine Haltung, die seiner im Vorfeld signalisierten Unterstützung für eine Große Koalition entsprach ${ }^{48}$. Die Einbindung des unberechenbaren Wirtschaftsführers entfaltete aber keinerlei Breitenwirkung in die Fraktion, und die zuletzt erkennbaren Bemühungen Stresemanns, den Koalitionskurs in der Fraktion abzusichern, hatten offenbar nicht ausgereicht, um den rechten Flügel für sich einzunehmen.

Noch deutlicher zeigte sich eine die Koalition ablehnende Minderheit in der SPD-Fraktion, wo es ja bereits während der Regierungsbildung zu einer kontroversen Abstimmung gekommen war ${ }^{49}$. Vor dem Vertrauensvotum veröffentlichten 43 Abgeordnete eine Erklärung, die sich deutlich gegen eine Große Koalition aussprach, statt dessen den „Kampf gegen die Bourgeoisie“ forderte und den Beschluß der Fraktionsmehrheit als „schwere Belastung“ für die SPD bezeichnete. Gleichzeitig enthielt die Erklärung aber auch einen Appell an alle Unzufriedenen, trotz der Koalitionsentscheidung in der SPD zu bleiben ${ }^{50}$. Von den fehlenden $\mathrm{Ab}-$ geordneten gehörten 34 der ehemaligen USPD an - darunter als prominenteste Namen Artur Crispien und Paul Levi - und 20 der ehemaligen MSPD.

Auf die „Debatte“ zur Regierungserklärung folgten im Reichstag Beratungen, die an die Steuervorlagen während der Plenartagungen vom 8. bis 10. August anknüpften. Den höchsten Stellenwert hatte das Projekt einer Goldanleihe, das am 14. August in zweiter und dritter Lesung behandelt und mit großer Mehrheit in der Fassung des Steuerausschusses gebilligt wurde ${ }^{51}$. Für den nächsten Tag lag ein SPD-Gesetzentwurf über „finanzpolitische Vollmachten der Reichsregierung vor", der eine enge Ermächtigung zur zwangsweisen Deviseneintreibung enthielt und gleichzeitig eine auf eidesstattliche Erklärungen gestützte Devisenkontrolle vorsah, falls die Goldanleihe unzureichend gezeichnet werden sollte. Diese Vorlage war allerdings im Steuerausschuß auf die Ablehnung der bürgerlichen Koalitionspartner gestoßen 52 . Es wurde daher nun eine im Ausschuß gebilligte Resolu-

46 Damals hatten insgesamt 23 DVP-Abgeordnete gefehlt bzw. sich enthalten und drei mit Nein gestimmt. Vgl. oben S. 135.

47 Vgl. oben S. $161 \mathrm{f}$.

48 AdR Stresemann, S. XXIII, ordnet hier Stinnes fälschlicherweise der Oppositionsgruppe zu. Übernommen z.B. von Baechler, Stresemann, S. 342. Zutreffend auch Wulf, Stinnes, S. 443 f.

49 Vgl. oben S. 238.

so Text der Erklärung und Liste der Unterzeichner in Arns, Die Linke in der SPD-Reichstagsfraktion, S. 195-199.

51 Beratung in Verh. RT 361, S. 11859-11862. „Entwurf eines Gesetzes über die Sicherung und die steuerliche Behandlung einer wertbeständigen Anleihe des Deutschen Reichs“ in Verh. RT 379, Drucks. Nr. 6142.

52 Extrem knappes Protokoll in den Akten des Steuerausschusses: BA Berlin, R 101, Nr. 1513, Bl. 340. Dagegen detailliertes Protokoll in Vo, 15. 8. 1923 ab, S. 3, „Beratungen im Steuerausschuß". 
tion der Koalitionsparteien eingebracht, die eine allgemein gefaßte Aufforderung zur Währungsstabilisierung und zur „Belastung der Vermögenswerte der Wirtschaft" enthielt ${ }^{53}$.

In diesem Zusammenhang kam es zur einzigen währungspolitischen Plenardiskussion während der Amtszeit Stresemanns. In einer scharfen Intervention wandte sich Helfferich gegen eine Stabilisierung allein auf der Basis „Erfassung der Sachwerte" und forderte die politische Beteiligung der "wirtschaftlichen Berufsstände" ${ }^{44}$. Der promovierte Finanzwissenschaftler und führende DNVP-Parlamentarier nahm dabei für sich in Anspruch, im Steuerausschuß mit einem Änderungsantrag die informelle Billigung der bürgerlichen Ausschußmitglieder gefunden zu haben, welche die jetzt eingebrachte Resolution nur wegen „einer Vereinbarung mit der Sozialdemokratie" unterstützt hätten ${ }^{55}$. Finanzminister Hilferding gab hierauf eine kurze, Entgegenkommen andeutende, wenngleich unverbindliche Antwort, was nur ein neues Insistieren Helfferichs auslöste, der freilich mit seinem Antrag an der Reichstagsmehrheit scheiterte. Schlaglichtartig zeigte sich in dieser Szene die Grundkonstellation der in den folgenden Wochen stattfindenden Stabilisierungsdiskussion: ein überaus aktiver und aggressiver Helfferich und ein sofort in die Defensive gedrängter Hilferding. Hier deutete sich erstmals an, wie brüchig die Basis der Großen Koalition in der entscheidenden Währungsfrage war und wie prekär damit auch die Voraussetzung für eine stabile parlamentarische Stützung der neuen Regierung.

Am Ende der Sitzung vom 15. August billigte der Reichstag ohne Widerspruch den Vorschlag seines Vizepräsidenten Bell, „die neue Tagesordnung und Anberaumung der neuen Sitzung dem Präsidenten zu überlassen" 56 . Tatsächlich sollte es schließlich bis zum 27. September, also etwa sechs Wochen, dauern, bis das Parlament wieder zusammentrat. Explizite Vereinbarungen der Parteien über diese Abstinenz in einer Zeit höchster politischer Anspannung lassen sich nicht finden, die Intention der Regierungsparteien steht aber außer Zweifel: Gerade angesichts des enormen Krisendrucks und des hohen politischen Handlungsbedarfs überließ man nun der aus den eigenen Reihen geformten Regierung das Feld. Der breite Vertrauensbeweis für das Kabinett Stresemann erscheint so als ein pauschaler Akt, der eine weitgehende Suspendierung von der parlamentarischen Praxis und von der dabei zu leistenden konkreten Unterstützung der Regierung nach sich zog. Die parlamentarische Reaktivierung in der Endphase der Regierung Cuno und während der Bildung des Kabinetts Stresemann war sofort in einen weitgehenden Funktionsverzicht des Reichstags umgeschlagen.

53 Beratung in Verh. RT 361, S. 11878-11881. Positive Bewertung in Vo, 16. 8. 1923 mo, „Der erste Schritt".

54 Verh. RT 361, S. 11880 f.; ebd. Hinweise auf Verhandlungen im Steuerausschuß. Zu den Hintergründen aus sozialdemokratischer Sicht vgl. ausführlich Vo, 16. 8. 1923 mo, „Der erste Schritt“.

55 Verh. RT 361, S. 11880.

56 Ebd., S. 11896. 


\section{Parlamentarische Abstinenz und diffuse Erosion des Regierungslagers}

Die ersten Wochen der Kanzlerschaft Stresemanns waren erfüllt von dem Bemühen, Auswege aus dem perspektivlos gewordenen Ruhrkonflikt und aus der rasenden Hyperinflation zu finden. Der politische Erwartungsdruck war angesichts der geradezu absurden Geldentwertung sowie der daraus resultierenden sozialen Folgen - Arbeitslosigkeit, Einkommenseinbußen, Nahrungsmittelknappheit und öffentliche Proteste - dramatisch gestiegen ${ }^{57}$. Erfolg oder Mißerfolg der Regierungspolitik wurden unter diesen Umständen für die junge Republik zu einer Existenzfrage.

Stresemann ging es, wie er in einer Parteiführerbesprechung am 22. August erläuterte, zunächst darum, „mit rasch wirkenden Mitteln“ - gemeint waren in erster Linie Maßnahmen der Devisenerfassung - im Prozeß des Währungsverfalls „eine Atempause zu sichern, die außenpolitisch zur ehrenvollen Liquidation der Ruhrfrage ausgenutzt werden müsse" 58 . Das Sondieren des Kanzlers nach einer Begrenzung der Niederlage im Ruhrkonflikt hatte freilich zur Folge, daß die Hyperinflation über Wochen hinweg weiter angeheizt wurde.

Die letzten außenpolitischen Bemühungen, zumindest einige symbolische $\mathrm{Zu}$ geständnisse Frankreichs im Ruhrkonflikt zu erreichen, sowie die sich anbahnende Einstellung des passiven Widerstands, der in den besetzten Gebieten ohnehin mehr und mehr kollabierte, brauchen hier im einzelnen nicht dargestellt zu werden ${ }^{59}$. Entscheidend ist in unserem Zusammenhang, daß dieses Streben nach einem „ehrenvollen“ Ende des Ruhrkampfes zwar führende Parteivertreter aus den besetzten Gebieten einbezog ${ }^{60}$, aber völlig am vertagten Reichstag vorbeiging.

Die Suspendierung der parlamentarischen Kontrollfunktion beim Abbruch des Ruhrkampfes läßt sich noch halbwegs nachvollziehen, da in dieser Frage im Regierungslager eine weitgehende informelle Übereinstimmung herrschte und eine vom Reichstag mit einem klaren Vertrauensvotum eingesetzte Regierung amtierte. Anders liegt der Fall hinsichtlich der währungspolitischen Thematik. Hier standen extrem wichtige und langfristig für die wirtschafts- und sozialpolitischen Verhältnisse in Deutschland maßgebliche Entscheidungen über die Art und Weise der Stabilisierung an, die ein umfangreiches legislatives Handeln erforderten.

Dennoch wurden die wesentlichen Fragen der Finanzlage und der Währungsstabilisierung kaum parlamentarisch diskutiert. Soweit dies aus den vorliegenden Quellen erkennbar ist, betreffen diese Defizite nicht nur das suspendierte Plenum, sondern - mit einzelnen Ausnahmen - auch die übrigen parlamentarischen Instanzen und Gremien. Fraktionssitzungen erfolgten offenbar nur vereinzelt ${ }^{61}$, bis

57 Vgl. exemplarisch zu München und Bayern Geyer, Verkehrte Welt, S. 321-328; Sperl, Wirtschaft und Staat, S. 490-501.

58 AdR Stresemann, Nr. 14, S. 59.

59 Vgl. hierzu v.a. Kamper, Die Rheinlandkrise des Herbstes 1923, S. 33-49; Ruck, Die freien Gewerkschaften im Ruhrkampf 1923, S. 434-463; Favez, Le Reich devant l'occupation franco-belge, S. 310-315; Jeannesson, Poincaré, S. 283-285, 293-297.

60 So fiel eine gewisse Vorentscheidung zur Einstellung des Ruhrkampfes am 6.9.1923 in Berlin in einer Konferenz mit Vertretern von Rhein und Ruhr. Vgl. knappes Protokoll in AdR Stresemann, Nr. 43, S. 197, sowie ebd., Anm. 2. Vgl. auch Kamper, Rheinlandkrise, S. 36-38.

61 Zwischen dem 15.8. und 7.9. 1923 ist keine Sitzung der Zentrumsfraktion überliefert. Vgl. auch Protokolle Zentrumspartei, S. $473 \mathrm{f}$. Das nächste Treffen folgte dann am 26.9. Sitzungen der DVP 
zum 25. September kam es nur zu einer Parteiführerbesprechung 62 , und auch der Ausschußbetrieb wurde auf ein Minimum reduziert: Zwischen dem 15. August und 26. September gab es nur fünf Sitzungen, drei des Haushalts- und zwei des Steuerausschusses ${ }^{63}$. Die Beratungen des Steuerausschusses vom 15. August „über wertbeständige Zahlungsmittel" wurden wegen des Konflikts über die zwangsweise Deviseneintreibung abgebrochen ${ }^{64}$. Eine offene parlamentarische Auseinandersetzung über die Stabilisierungsfrage ist seit diesem Tag, an dem auch die geschilderte Konfrontation zwischen Helfferich und Hilferding im Plenum stattgefunden hatte, nicht mehr zu erkennen. Die Diskussion vollzog sich statt dessen weitgehend im Bereich des Kabinetts, des Finanz-, Wirtschafts- und Ernährungsministeriums, aber auch des Reichswirtschaftsrats, der in Sachen Währungsstabilisierung schon seit längerem eine bedeutsame Rolle spielte und damit indirekt zur funktionalen Schwächung des Reichstags beitrug.

Daß der weitgehende Verzicht auf eine parlamentarische Sachdebatte im Einvernehmen zwischen der Regierung und den Spitzen der Regierungsparteien erfolgte, steht außer Frage. Neben der Grundhaltung der Koalitionsparteien, der Regierung weitgehend freie Hand zu lassen, spielte möglicherweise auch die Absicht mit, koalitionsinterne Konflikte um Sachfragen, die sich am 15. August ja schon angedeutet hatten, zu vermeiden. Darüber hinaus ging es aber auch darum, eine gewisse Geheimhaltung zu wahren. Bezeichnend hierfür ist die Parteiführerbesprechung vom 22. August: Hilferding gab einen Überblick über den Stand der Reichsfinanzen, der „die schlimmsten Erwartungen“ übertraf, und fügte sogleich hinzu, die einzelnen Ziffern dürften „aus außenpolitischen und innenpolitischen Gründen dem Haushaltsausschuß zur Zeit nicht mitgeteilt werden"65. Gertrud Bäumer, die für die DDP an der Besprechung teilgenommen hatte, informierte hierüber ihre Fraktion ohne jede Mißbilligung dieses Vorgehens und riet sogar davon ab, wie bei anderen Parteien eine Fraktionssitzung abzuhalten ${ }^{66}$. Daß eine offene Diskussion der finanziellen Lage des Reichs und der daraus zu ziehenden Konsequenzen, insbesondere bezüglich der Einstellung des passiven Widerstands, aus Regierungsperspektive die letzten Chancen auf französische Konzessionen gefährdet hätte, liegt auf der Hand. Ebenso fürchtete man offensichtlich, daß diejenigen Kräfte in Deutschland, die sich immer mehr zu einer "nationalen“, vor allem von der DNVP und der ihr nahestehenden Presse getragenen Opposition formierten ${ }^{67}$, Anknüpfungspunkte für ihre Agitation finden könnten. Selbst die

fanden nach der Presse am 12.9. und 25.9. statt. Bemerkenswert ist der gemeinsame „ständige Ausschuß" der DNVP-Fraktionen des Reichstags und des Preußischen Landtags, „der während der Parlamentsferien ständig in Berlin tagt, um im Sinne der bekannten Einstellung der Partei die nationalen Interessen nachdrücklich zu wahren“. Vgl. DT, 21. 9. 1823 mo, S. 1, „Ständiger Ausschuß der deutschnationalen Fraktionen".

62 Am 22. 8. 1923. Vgl. unten auf dieser Seite.

63 Ausschußsitzungen nach Weimar-Index, S. $95 \mathrm{f}$.

64 Protokoll der 159. Sitzung; BA Berlin, R 101, Nr. 1513, Bl. 340. Vgl. auch oben S. 245.

65 AdR Stresemann, Nr. 14, S. 58.

66 Protokoll Bäumers in BA Koblenz, Nl. Erkelenz, Nr. 27, Bl. 127-130 (neue Zählung); zitiert in AdR Stresemann, Nr. 14, S. 56.

67 Vgl. z.B. DT, 21. 9. 1923 mo, S. If., „Opposition-Defaitismus“, wo ein Gegensatz zwischen einer "nationalen Opposition, die sich in weitesten Kreisen des deutschen Volkes gegen eine Politik regt, von welcher man eine mehr oder weniger verschleierte Kapitulation vor Frankreich befürchtet", 
Haushaltskommission, die im Ersten Weltkrieg als „Hauptausschuß“ die Funktion eines vertraulichen Ersatzparlaments gewonnen hatte ${ }^{68}$, galt nun anscheinend nicht mehr als vertrauenswürdiges Forum. Anzunehmen ist, daß sich die Befürchtungen in diesem Falle vor allem auf die KPD und die DNVP bezogen, die beide im Haushaltsausschuß vertreten waren ${ }^{69}$. Unter den Bedingungen des kriegsähnlichen außenpolitischen Konflikts und der gleichzeitigen Konfrontation einer Großen Koalition mit den erstarkenden systemfeindlichen Kräften kam es so zu einer massiven Einschränkung der parlamentarischen Kontrolle.

In der Frage der Währungsstabilisierung dürfte es noch eine weitere Ursache dafür gegeben haben, daß die Fraktionen kaum an der politischen Diskussion beteiligt wurden: Schon seit längerem hatte sich die für den finanzpolitischen Laien nur sehr schwer verständliche Thematik in die Sphäre der konkurrierenden Sachverständigen, aber auch der großen Interessengruppen verlagert, und allem Anschein nach machten die Fraktionsführungen nicht einmal den Versuch, mehr Mitwirkung zu erlangen. Kritik an der Ausschaltung der parlamentarischen Instanzen kam lediglich aus den Reihen der Opposition, gegen das vereinte Regierungslager blieb diese freilich chancenlos. So scheiterte am 13. September ein Vorstoß von KPD und DNVP zur sofortigen Einberufung des Reichstags, „nachdem die Regierung hatte wissen lassen, daß die außenpolitischen Verhandlungen und die finanzpolitischen Verhandlungen im Innern noch im Fluß sind, so daß eine abschließende Mitteilung sich noch nicht machen läßt" ${ }^{\text {"70 }}$.

Der Rückzug aus der Sachdiskussion spiegelt, neben dem weitgehenden Verzicht auf Ausübung der Kontrollfunktion, auch die grundsätzliche Bereitschaft der Regierungsfraktionen, bei der Überwindung der Hyperinflation auf die legislative Kompetenz des Reichstags zu verzichten. Von Anfang an und nach den Erfahrungen aus der Regierungszeit Cunos wie selbstverständlich kam dabei das Instrument legislativer Verordnungen ins Spiel. Im parlamentarischen Regierungslager und in der politischen Öffentlichkeit war die Thematik sofort mit dem Regierungswechsel präsent, wobei zwischen dem Einsatz des Artikels 48 und einer legislativen Ermächtigung wenig Unterschiede gemacht wurden. So hatte beispielsweise Georg Bernhard in der Vossischen Zeitung noch vor der Beauftragung Stresemanns mit der Regierungsbildung „weitgehende Vollmachten “ für die neue Regierung gefordert ${ }^{71}$. Von der zurückgezogenen sozialdemokratischen Ge-

und einem „defaitistischen Feldzug“ der Presse des Regierungslagers konstruiert wird. Vgl. allgemein auch Klein, Die Herbstkrise 1923, S. 39.

$68 \mathrm{Vgl}$. Schiffers, Hauptausschuß.

69 Allerdings fand offenbar eine gewisse Einbindung der DNVP statt. Nach der Besprechung mit den Spitzen der Regierungsparteien wurden die DNVP-Vertreter am 22.8. gesondert zu Stresemann bestellt. Vgl. Einleitung zu Protokoll Bäumers in AdR Stresemann, Nr. 14, S. 56.

70 So Leipziger Volkszeitung, 14. 9. 1923, S. 1, „Keine sofortige Einberufung des Reichstages“.

71 VZ, 13. 8. 1923 mo, S. 1f., "An die Arbeit“, hier S. 2: "Jetzt heißt es, so schnell wie möglich die neuen Männer zu finden und ihnen so schnell wie möglich das Feld für eine energische Arbeit frei zu machen. Man muß ihnen die Möglichkeiten geben, ungehemmt durch parteitaktische Rücksichten ihre Programme durchzuführen. Sie müssen weitgehende Vollmachten bekommen, für deren Benutzung sie sich vor dem Parlament zu verantworten haben, während deren Ausübung abcr alle Sonderparteiwünsche schweigen müssen.“ 
setzesvorlage über eine Spezialermächtigung zur zwangsweisen Deviseneinziehung war bereits die Rede ${ }^{72}$.

In einer Kabinettssitzung, die am 20. August unter dem Vorsitz von Reichspräsident Ebert stattfand, kam dann erstmals seit dem Februar 1923 wieder der Gedanke einer breiteren Ermächtigung zur Sprache ${ }^{73}$. Vizekanzler Schmidt verlangte mit Blick auf die wirtschaftlichen Probleme, aber auch auf das kommunistische und völkische Erstarken sowie auf Eigenmächtigkeiten mehrerer Reichsländer, daß „ein Stück Diktatur seitens der Reichsregierung ausgeübt werden müsse, um dieser Schwierigkeiten Herr zu werden "74. Stresemann wurde konkreter und betonte die "große Schnelligkeit“, mit der die zur finanziellen Sanierung geplanten Maßnahmen verwirklicht werden müßten. Es sei daher „zweckmäßig, daß man die Devisenzwangsanleihe im Wege der Verordnung ohne Mitwirkung des Reichstags erlasse“75. Offenbar zielte der Kanzler zunächst lediglich auf einen raschen Einsatz des Artikels 48. Die Ausführungen Stresemanns wurden vom Kabinett und vom Reichspräsidenten ohne Widerspruch gebilligt. Am selben Tag war man sich im Haushaltsausschuß über ein schnelles Agieren per Notstandsmaßnahmen einig, wobei Otto Wels für die SPD vehement eine weite Fassung der geplanten Devisennotverordnung forderte ${ }^{76}$. In der Kabinettssitzung vom 23. August brachte dann erneut ein Sozialdemokrat umfassendere Vorstellungen ins Spiel. So merkte Innenminister Sollmann angesichts der bevorstehenden Beendigung des Ruhrkampfes an, daß „eine gewisse Diktatur [...] unter Umständen nicht zu vermeiden sein" werde"

Bereits am 25. August wurde die von Stresemann in Aussucht gestellte Verordnung verkündet. Die Ablieferung ausländischer Vermögensgegenstände war darin auf weniger rigide Weise geregelt, als dies der Gesetzentwurf der SPD vom 15. August vorgesehen hatte. Bedeutsamer aber war, daß mit der Verordnung wie auch in der ursprünglichen Vorlage geplant - ein weiterer Schritt hin zur Ausdehnung des Artikels 48 auf den Bereich der wirtschaftspolitischen Gesetzgebung erfolgte. Zwei weitere Verordnungen nach Artikel 48 modifizierten und ergänzten Anfang September die Verordnung vom 25. August, wobei unter anderen ein „Reichskommissar für die Devisenerfassung“ eingesetzt wurde ${ }^{78}$. Treibende Kraft all dieser Maßnahmen war - stärker noch als Hilferding - die auf eine harte Devisenpolitik setzende SPD-Fraktion ${ }^{79}$. Damit wurde gerade jene Partei zum Vorreiter einer sozioökonomischen Ausdehnung des Artikels 48, in der im Prinzip noch

72 Vgl, oben S. 245.

73 AdR Stresemann, Nr. 13, S. 42-55, Protokoll Stockhausens; Parallelüberlieferung zu erstem Punkt „Allgemeine Finanzlage“ durch Reichssparkommissar Saemisch. Vgl. ebd., S. 43. Zurückzuweisen ist die Auffassung Baechlers, Stresemann, S. 372, der behauptet, die „idée des pleins pouvoirs“ sei durch Brauns am 30. 9. 1923 vorgebracht worden.

74 AdR Stresemann, Nr. 13, S. 45.

75 Ebd., S. 49. In der Mitschrift von Saemisch heißt cs: „Stresemann warnt vor Hoffnung auf ausländische Anleihe. Zuerst muß Selbsthilfe kommen. Also für Vorschlag Raumer-Hilferding. Gegen Beschreitung des gesetzlichen Weges im Reichstag, vielmehr Verordnung. “

76 BA Berlin, R 101, Nr. 1364, Bl. 240-244.

77 AdR Stresemann, Nr. 18, S. 82.

78 RGBI. 1923 I, S. 833-835; „Verordnung des Reichspräsidenten über die Ablieferung ausländischer Vermögensgegenstände“; ebd., S. 865-869.

79 Dies zeigte sich v.a. in der Stellungnahme von Wels in der erwähnten Parteiführerbesprechung; AdR Stresemann, Nr. 14, S. 58 f. 
am meisten Bewußtsein von der notwendigen Wahrung der parlamentarischen Prärogative entwickelt war. $\mathrm{Daß}$ es unter diesen Umständen in der politischen Öffentlichkeit nicht einmal ansatzweise zu einer kritischen Diskussion über die Mittel der legislativen Funktionsabgabe kam, ist kaum verwunderlich.

$\mathrm{Da}$ die bürgerlichen Koalitionspartner der sozialdemokratischen Devisenpolitik skeptisch bis ablehnend gegenüberstanden, baute sich in dieser Frage eine gewisse Spannung innerhalb des Regierungslagers auf. Dies zeigte sich auch in der einzigen größeren parlamentarischen Beratung der Stabilisierungsthematik, die am 23. August im Haushaltsausschuß des Reichstags stattfand. Hilferding gab hier eine allgemeine Darstellung der finanziellen Lage, rechtfertigte die auf große Einkommen und Vermögen zielenden Zwangsmaßnahmen zur Schaffung eines Devisenfonds und setzte sein Vertrauen in die Kooperationsbereitschaft der Wirtschaft ${ }^{80}$. Die Vertreter der bürgerlichen Koalitionspartner und auch der DNVP äußerten ihre Bedenken gegen die weitere Verschärfung der Devisenpolitik; der Einsatz des Artikels 48 und auch das Vorhaben einer parlamentarischen Ermächtigung fanden aber breite Billigung ${ }^{81}$. Eine Diskussion über Mittel und Methoden einer dauerhaften Währungsstabilisierung erfolgte auch in dieser Sitzung des Haushaltsausschusses nicht.

Die entscheidenden währungspolitischen Auseinandersetzungen entwickelten sich gleichsam im Schatten der vordergründigen Debatte um Devisenmaßnahmen. Die verwirrende Vielfalt von Akteuren, Positionen und Interessen soll und kann hier nur andeutungsweise dargestellt werden ${ }^{82}$. Sie bildet gleichsam den Hintergrund, vor dem eine Analyse der parlamentarischen Implikationen zu erfolgen hat. Um die fortschreitende Erosion des Regierungslagers verstehen zu können, muß zunächst ein Blick auf die divergierenden Grundansätze geworfen werden, die sich mit den Namen Helfferich und Hilferding verbinden. Die einzige parlamentarische Konfrontation der beiden Antagonisten ist ja bereits angesprochen worden ${ }^{83}$. Helfferich, ein Vertreter der traditionellen Geldwerttheorie, setzte auf eine berufsständisch getragene und dem staatlichen Einfluß weitgehend entzogene Währungsbank, auf die Deckung einer wertbeständigen Währung durch eine fiktive Belastung des landwirtschaftlichen Grundbesitzes auf der Basis des Roggenpreises und auf eine Minimierung der steuerlichen Belastung von Sachwerten. Die Anfänge dieser Pläne zur „Roggenmark“ liegen noch in der Amtszeit Cunos, den der führende deutschnationale Finanzexperte als Ratgeber unterstützt hatte, wäh-

80 Gedrucktes Protokoll in BA Berlin, R 101, Nr. 1476; Abdruck in Teilen der Presse, z. B. BT, 24. 8. 1923 mo, S. 3f., „Der Reichsfinanzminister über die Devisenabgabe“. Vgl. auch Dittmann, Erinnerungen 2, S. 860 f.: „Als Hilferding in einer im Reichshaushaltsausschuß gehaltenen Rede die katastrophale Lage enthüllte, in die der ,passive Widerstand" an der Ruhr die Reichsfinanzen gestürzt hatte, und Vorschläge für eine scharfe steuerliche Heranziehung der großen Einkommen und Vermögen machte, kam es darüber zu einem Konflikt mit dem Stinnes-Flügel der Volkspartei und am 4. Oktober 1923 zur Demission des ganzen Kabinetts Stresemann.“

81 So meinte Florian Klöckner (Zentrum): „Man müsse der Reichsregierung dic notwendigen Vollmachten geben, um möglichst schnell die besprochenen Maßnahmen durchzuführen." Auch Wels (SPD) billigte den eingeschlagenen Weg. Gedrucktes Protokoll; BA Berlin, R 101, Nr. 1476.

82 Instruktiver Überblick in Einleitung zu AdR Stresemann, S. LXXV-LXXX. Vgl. auch Feldman, Great Disorder, S. 698-736; Morsey, Zentrumspartei, S. 524-526; Winkler, Von der Revolution zur Stabilisierung, S. 608-612; Wolff-Rohé, Reichsverband, S. 346-354. Auch zum folgenden.

83 Vgl. oben S. 246. 
rend er gleichzeitig als Mitglied des Steuerausschusses des Reichstags und des Reichswirtschaftsrates mit dem Thema befaßt war ${ }^{84}$. Hilferding, der sich auf neuere finanzwissenschaftliche Ansätze im Umfeld von Keynes stützte, strebte einen Währungsschnitt durch eine drastische Geldverknappung an, verbunden mit der Schaffung einer staatlichen Goldnotenbank und einer rigiden Haushaltssanierung, die im wesentlichen über eine steuerliche Belastung von Sachwerten erfolgen sollte ${ }^{85}$. Zumindest erwähnt sei, daß es in der zeitgenössischen Diskussion eine Reihe weiterer Konzepte gab, die teilweise Elemente beider Planungen kombinierten. Insbesondere gilt dies für den vom RDI vertretenen Vorschlag einer privaten Goldnotenbank.

Daß sich die mehrfach modifizierte Konzeption Helfferichs schließlich in Form der an die Goldrechnung gebundenen Rentenmark weitgehend durchgesetzt hat, ist bekannt, und der Stabilisierungserfolg scheint ihr letztlich Recht zu geben. Allerdings ist damit über die finanzpolitische Qualität des unterlegenen Ansatzes noch nichts gesagt, und im Rahmen der vorliegenden Arbeit soll hier auch kein Urteil gefällt werden. Tatsache ist, daß Hilferding zwar wesentlich zur Goldbindung der Rentenmark beigetragen hat, aber mit jenen Vorstellungen, die auf eine stärkere Belastung des Sachbesitzes und auf eine klare Dominanz des Staates im Stabilisierungsprozeß zielten, gescheitert ist. Sein Ausscheiden aus dem Kabinett Anfang Oktober bildete die logische Konsequenz dieser Niederlage. Die Ursachen des Widerstands gegen Hilferding waren im übrigen keineswegs nur fachlicher Art, vielmehr schlugen dem marxistischen Finanztheoretiker und ehemaligen unabhängigen Sozialdemokraten, der vielfach den Eindruck eines theorielastigen "cunctators" hinterließ, ungeachtet seines pragmatischen und kompromißbereiten Vorgehens grundsätzliche Ablehnung führender Wirtschaftskreise und erhebliches Mißtrauen im bürgerlichen Spektrum entgegen ${ }^{86}$.

Bemerkenswert ist, daß mit Helfferich ein Politiker wesentlichen Einfluß gewann, der Cuno nahegestanden hatte und der jetzt als führender Vertreter einer Partei agierte, die trotz einer strategisch bedingten Mäßigung ${ }^{87}$ keinen Zweifel an der Gegnerschaft zur Regierung „Stresemann-Hilferding“ ließ88. Es spricht für die Offenheit Stresemanns und auch Hilferdings, ist aber auch ein gewisses Indiz

84 Allgemein zu Helfferichs Rolle in der Stabilisierungsplanung vgl. auch Krohn, Helfferich contra Hilferding, S. 62-92; Williamson, Helfferich, S. 383-394.

${ }^{85} \mathrm{Vgl}$. Krohn, Helfferich contra Hilferding; S. 86. Zu Hilferding v.a. Vogt, Rudolf Hilferding als Finanzminister; Smaldone, Rudolf Hilferding, S. 160-168.

86 Vgl. auch ebd., S. 161 f., 168; Vorbehalte gab es auch in Teilen der SPD, vgl. Schulze, Otto Braun, S. $436 \mathrm{f}$.

${ }^{87}$ Nach einer Mitteilung von Scholz in der Fraktionssitzung der DVP am 25. 9. 1923 hat Hergt am 14.8. „seiner Presse Direktiven gegeben: kein Kampf gegen den Kanzler und keine Polemik gegen die D.V.P." PA AA Berlin, Nl. Stresemann, Nr. 87, H171326.

88 Vgl. z. B. Bericht in DT, 23. 9. 1923, S. 3, „Hergt über die deutschnationale Opposition“ über einen Auftritt Hergts beim Landesverband Mecklenburg-Schwerin; ebd. auch Zitat. Obwohl die DNVP-Fraktion die noch von der Regierung Cuno eingebrachten Steuergesetze vom 10.8. mitgetragen hatten, führte die Partei nun eine regelrechte Steuerverweigerungskampagne. Vgl. auch Nationalliberalismus, S. 474, Anm. 3. Eine Sitzung der Landesverbandsvorsitzenden, an der unter anderem auch Hergt und Helfferich teilnahmen, verabschiedete bereits am 29.8. ein breites Oppositionsprogramm, das eine konfrontative Reparationspolitik und die Wiedereinführung der allgemeinen Wehrpflicht vorsah und eine zeitweise Diktatur forderte, die sich bei Verweigerung des Parlaments auf eine „Entscheidung des Volkes“ stützen sollte. Vgl. Bericht in Vo, 30. 8. 1923, S. 1, "Dcutschnationale in Kampfstellung". 
für die von der eigenen parlamentarischen Basis abgelöste Regierungspraxis, daß Helfferich am 18. August in einer Besprechung mit Regierungsvertretern Gelegenheit bekam, seine Pläne einer Roggenwährung zu entwickeln und dabei erneut eine kontroverse Diskussion mit Hilferding zu führen ${ }^{89}$. Wenige Tage später wurde der Plan Helfferichs dann schriftlich der Regierung vorgelegt ${ }^{90}$. Zweifellos bemühte sich das Finanzministerium fortan um enge Kontakte nicht nur zu Helfferich, der in den folgenden Wochen in die fachlichen Beratungen des Ministeriums einbezogen wurde ${ }^{91}$, sondern auch zum Reichswirtschaftsrat und zum Währungsausschuß des RDI, dessen Pläne am 8. September vorlagen ${ }^{92}$.

Am 10. September stellte schließlich Hilferding, der bereits deutlich auf eine Beendigung des Ruhrkampfes als Voraussetzung für eine Währungsreform drängte ${ }^{93}$, im Reichskabinett ein Stabilisierungskonzept vor, das auf Planungen des Reichswirtschaftsrates beruhte. In Verbindung mit der Reichsbank sollte demnach eine staatliche Goldnotenbank errichtet werden. Im Kabinett erfuhr der Minister zunächst eine überraschend breite Zustimmung94. Zwei Tage später ging Hilferding dann in einer gemeinsamen Sitzung des wirtschafts- und des finanzpolitischen Ausschusses des Reichswirtschaftsrats in die Offensive. Dabei forderte er in einer aufsehenerregenden Rede nicht allein große Einsparungen, sondern auch den Abbruch des Ruhrkampfes ${ }^{95}$.

Daß das vom Kabinett abgesegnete Konzept Hilferdings doch noch scheiterte, ist das Ergebnis hartnäckiger und im Hintergrund auch von Helfferich unterstützter industrieller Interessenpolitik, die offensichtlich vor allem die Schaffung einer selbständigen Goldnotenbank sowie die in Aussicht gestellte hohe steuerliche Belastung von Sachwerten verhindern wollte. Nur vereinzelt läßt sich erkennen, daß der Entscheidungsprozeß auch Wendungen in den informellen parlamentarischen Raum nahm. So hatte ten Hompel, der führende Vertreter der Schwerindustrie innerhalb der Zentrumsfraktion, Clemens Lammers - Mitglied des Vorstands, des Präsidiums und des „engeren Währungsausschusses“ des $\mathrm{RDI}^{96}$ - davon überzeugt, ihn am 13. September in eine gemeinsame Sitzung des Fraktionsvorstands und der Zentrumsminister zu begleiten ${ }^{97}$. Lammers und ten Hompel gelang es hier, einen stabilisierungspolitischen Kurswechsel der Zentrumsfraktion einzuleiten.

89 AdR Stresemann, Nr. 9, S. 23-29. Vgl. auch Feldman, Great Disorder, S. 710 f.

90 AdR Stresemann, Nr. 9, S. 28, Anm. 22. Zur Einsetzung einer Kommission vgl. Feldman, Great Disorder, S. 711.

91 Vgl. AdR Stresemann, Nr. 9, S. 28, Anm. 22.

92 Morsey, Zentrumspartei, S. 524.

${ }_{93}$ So am 30. 8. 1923 im Kabinett: „Wertbeständige Zahlungsmittel lösen das Problem nicht. Mit technischen Mitteln allein ist überhaupt nichts getan. Wenn ihm vorgeworfen worden ist, daß er keine Vorschläge gemacht habe, so beruht dies darauf, daß er der Überzeugung ist, in der augenblicklichen Situation kann nur eine Operation im Wege der Außenpolitik helfen. “ AdR Strcsemann, Nr. 33, S. 164.

94 Protokoll ebd., Nr. 51, S. 224-228.

95 Vgl. Vo, 15. 9. 1923, S. 1, „Vorbedingungen der Währungsgesundung“.

96 Nach den Maiwahlen 1924 wurde Lammers dann auch Mitglied des Reichstags.

97 Ten Hompel, „Aus den Erinnerungen cines Reichstagsabgeordneten aus der Zeit 1920 bis $1928^{\text {“; }}$ Protokolle Zentrumspartei, Nr. 255, S. 476f. - Der Vorgang scheint bislang in der Literatur nicht beachtet worden zu sein. 
Die Art und Weise, wie dies geschah, ist bezeichnend für die Verworrenheit der Entscheidungsfindung und letztlich wohl auch für die fachliche Überforderung der meisten Regierungsmitglieder und Parlamentarier. Trotz der dringenden Bitte ten Hompels, ,in Anbetracht der Wichtigkeit und Dringlichkeit der Sache" sofort gehört zu werden, dauerte es über eine Stunde, bis sich der Fraktionsvorstand der Stabilisierungsfrage zuwandte und bis der ungeduldig wartende Lammers zugelassen wurde. Inzwischen hatten mehrere Vorstandsmitglieder sowie Arbeitsminister Brauns die Sitzung bereits wieder verlassen, so daß schließlich „nur noch fünf oder sechs Herren anwesend“ waren. Nachdem sich dann zur „maßlosen Überraschung" ten Hompels und Lammers auch noch gezeigt hatte, „daß die Minister nur ganz oberflächlich von der ganzen Sache wußten“, gelang es dem „eingehenden klaren Vortrag von Lammers“, "das Interesse der beiden Minister und der Vorstandsmitglieder in hohem Maße zu wecken "98.

Die beiden Interessenvertreter hatten letztlich Erfolg: In der Kabinettssitzung am Abend des 13. September war es vor allem der Zentrumsminister Höfle, der wesentlich zur Revidierung des Beschlusses einer Goldnotenbank beitrug99. Inzwischen hatten Stinnes und Vögler bei Stresemann vorgesprochen und auch die Reichsbank Bedenken angemeldet ${ }^{100}$. Dem vereinten Widerstand gegen die Hilferdingschen Pläne gelang es so, die Planungen Helfferichs als „Zwischenlösung“ wieder ins Spiel zu bringen ${ }^{101}$. De facto war damit eine Umsetzung des ministeriellen Konzepts blockiert und eine neue Weichenstellung für die Währungsstabilisierung vorgenommen. Zur weiteren Planung, an der Helfferich und Luther ${ }^{102}$ maßgeblichen Anteil nahmen, wurde ein ministerieller Ausschuß unter dem Vorsitz Hilferdings eingesetzt. Am 26. September, parallel zur Aufgabe des passiven Widerstands an der Ruhr, billigte das Kabinett dann einen Kompromißplan und leitete ihn Reichsrat und Reichstag zu ${ }^{103}$. Helfferichs Konzept, insbesondere der Gedanke einer berufsständischen Stabilisierungsbank, war in diesen Gesetzentwurf eingeflossen, wenngleich als Basis einer wertbeständigen Währung noch eine Golddeckung vorgesehen war.

Im Verlauf dieser hier nur angedeuteten Vorgänge fand eine schleichende Entmachtung des Finanzministers statt; gleichzeitig wurde die Konzeption eines führenden Oppositionspolitikers wesentlicher Bestandteil der Regierungsvorlage. Mitentscheidend für diese Entwicklung war wohl auch, daß Hilferding wenig Unterstützung durch seine eigene Partei erfuhr. Statt dessen wuchs in der SPD ein

98 Ebd.

99 Darauf läßt eine Aussage von Lammers über den Verlauf der Sitzung schließen, die wiedergegeben wird in einem Bericht ten Hompels "Erinnerungen zur Einführung der Rentenmark“. BA Koblenz, Nl. ten Hompel, Nr. 1. Das Protokoll der Sitzung in AdR Stresemann, Nr. 55, hier S. 256-262, bleibt in dieser Frage unklar. Zur Rolle Höfles vgl. auch Vogt, Rudolf Hilferdering als Finanzminister, S. 150.

100 Mitteilung Stresemanns in Kabinettssitzung; AdR Stresemann, Nr. 55, S. 258.

101 Ebd., Nr. 55, S. 256-262.

$102 \mathrm{Vgl}$. aus dessen Sicht den Bericht in Luther, Politiker, S. 113-118.

103 „Entwurf eines Gesetzes über die Errichtung der Währungsbank“, Reichstags-Drucks. Nr. 6216; Verh. RT 380 (nicht Teil der Seitenzählung). Protokoll der Kabinettssitzung in AdR Stresemann, Nr. 82, hicr S. 375 f. Zuvor hatten Verhandlungen zwischen dem Finanzminister und Wirtschaftsvertretern stattgefunden. Vgl. Ramhorst, Die Entstehung der Deutschen Rentenbank, S. 29. 
Unwille gegen das vermeintliche Zaudern des Finanzministers ${ }^{104}$, während es an Verständnis für die währungspolitischen Zusammenhänge fehlte und auch Hilferdings Drängen auf Abbruch des Ruhrkampfes wenig Resonanz fand.

Ein offener, parteimäßig strukturierter Dissens läßt sich daher für diese erste Phase der Großen Koalition kaum erkennen, zumal der parlamentarisch entrückte Stabilisierungskonflikt keine Tiefenwirkung in die Fraktionen entfaltete ${ }^{105}$. Dennoch kann von einer diffusen Erosion des Regierungslagers gesprochen werden. Neben der Demontage Hilferdings ist hier die bei den bürgerlichen Koalitionspartnern wachsende Mißstimmung gegenüber der sozialdemokratischen Fixierung auf eine harte - und wenig erfolgreiche - Devisenpolitik anzuführen ${ }^{106}$. Vor allem aber wurde seitens der Wirtschaftsgruppen und der DVP nach und nach das Reizthema "Verlängerung der Arbeitszeit" in die Stabilisierungsdebatte getragen 107 , - ein Thema, das bereits 1922 seine Brisanz bewiesen hatte und das während der Regierungszeit Cunos aus Gründen der nationalen Geschlossenheit gleichsam zu Seite gestellt worden war. Jetzt, im Vorfeld der Währungsstabilisierung ließ sich der Konflikt freilich nicht mehr umgehen, zumal der Rückgang der deutschen Steinkohleförderung und die wachsende Einfuhr von Importkohle zusätzliche Devisenprobleme schufen ${ }^{108}$. So wies Scholz am 6. September während einer Tagung des Reichsausschusses der DVP nachdrücklich auf die Notwendigkeit einer "Steigerung der Produktion" hin und berichtete von einem entsprechenden Beschluß der Fraktion. In dem Parteigremium bestand offenbar Einigkeit, daß eine Stabilisierung primär auf diesem Wege zu erreichen sei, was „wiederum die „Beseitigung aller hemmenden Maßnahmen“ erfordere ${ }^{109}$. In gewohnt provokativer Manier wiederholte Stinnes in der Deutschen Allgemeinen Zeitung sofort seine Forderung nach zweistündiger Mehrarbeit im Vergleich zur Vorkriegszeit, was wiederum eine scharfe Reaktion des Vorwärts hervorrief 110 . Eine Zündschnur zur Sprengung der Großen Koalition war damit bereits gelegt. Auf Regierungsebene kam es in der Arbeitszeitfrage erstmals am 22. September in einer Chefbesprechung im Reichsarbeitsministerium zu Unstimmigkeiten: Brauns hatte detaillierte Vorschläge zu einer Neuregelung der Arbeitszeit vorgelegt, die

104 Vgl. z. B. Radbruch, Der innere Weg, S. 170: Hilferding sei „von der Bedenklichkeit des theoretischen Menschen allzusehr behindert" worden.

105 In der Zentrumsfraktion herrschte teilweise Mißstimmung, daß sie so wenig in die Diskussion eingebunden war. Vgl. Josef Andre nach dem Protokoll der Fraktionssitzung vom 26.9. 1923: „Brauns ist unser Zentrumsminister. - Pfeift auf Fraktionsstimmung. Fraktionsleitung. Habe den Eindruck, daß Führung der Regierung nicht beikommt [?]. Kommen unsere Gedanken zur Regierung?" Protokolle Zentrumspartei, Nr. 257, S. 480.

106 Vgl. etwa den Abgeordneten Lange-Hegermann am 7. 9. 1923 in der Fraktionssitzung des Zentrums: „Devisenverordnung läßt alle Devisen verschwinden. Bürgerliche müssen zusammenstehen, [um] den Soz[ialdemokraten] zu sagen: Bis hierher und nicht weiter." Protokolle Zentrumspartei, Nr. 254, S. 476.

107 Allgemein zur Thematik im Herbst 1923 vgl. v.a. Steinisch, Arbeitszeitverkürzung, S. 464-489; Oltmann, Reichsarbeitsminister Heinrich Brauns, S. 188-213.

108 Zur Stcinkohleförderung vgl. Oltmann, Reichsarbeitsminister Heinrich Brauns, S. $197 \mathrm{f}$.

109 Bericht der Nationalliberalen Correspondenz 83, 17. 9. 1923; BA Berlin, R 8034 II, Nr. 9106, Bl. 196.

110 Vgl. Oltmann, Reichsarbeitsminister Heinrich Brauns, S. 196 f. zu DAZ, 8. 9. 1923, und Vo, 8. 9. 1923. Kurz zuvor hatte am 7. 9. 1923 eine Resolution des Bundesausschusses des ADGB für den Fall des Abbruchs des passiven Widerstands „die Aufrechterhaltung der sozialen Errungenschaften" gefordert; nach ebd., S. $196 \mathrm{f}$. 
zwar grundsätzlich am Achtstundentag festhielten, aber weitgehende Möglichkeiten der Durchbrechung vorsahen, und traf damit auf den Widerspruch Hilferdings ${ }^{111}$. Einen weiteren Belastungsfaktor für die Koalition bildete der in der DVP-Fraktion herrschende Unmut über die Passivität der Regierung gegenüber den kommunistischen Aktionen in Sachsen und Thüringen ${ }^{112}$.

Insgesamt ist für die ersten Wochen der Regierung Stresemann ein markanter Bedeutungsverlust des Reichstags zu erkennen. Von einer aktiven regierungstragenden Funktion kann angesichts der weitgehenden Lahmlegung des parlamentarischen Betriebes und der vom Reichstag weg verlagerten Diskussion um Währungsstabilisierung und Aufgabe des Ruhrkampfes keine Rede sein. Die Alternativfunktion war unter den Bedingungen der Großen Koalition ohnehin suspendiert. Mit diesen Entwicklungen verband sich zum einen der Verzicht auf parlamentarische Kontrolle; zum anderen deutete sich im Bereich der Gesetzgebung bereits eine Krisenlösung mittels eines zeitweisen Verordnungsregimes an.

\section{Nach Abbruch des Rubrkampfes: Von der Regierungs- zur Systemkrise}

Mit der bedingungslosen Beendigung des Ruhrkampfes am 26. September durch eine gemeinsame Proklamation von Reichskanzler und Reichspräsident ${ }^{113}$ fand ein langer Prozeß der Desillusionierung ein schmerzhaftes Ende. Selbst der realitätsbewußte Stresemann hatte sich noch wochenlang der Hoffnung hingegeben, eine derartige Kapitulation verhindern zu können. Nachdem dann am 19. September das Treffen des britischen Premierministers Baldwins mit Poincaré ein letztes Signal für die Aussichtslosigkeit gegeben hatte, Frankreich zumindest zu gewissen Konzessionen zu bewegen, herrschte im Reichskabinett weitgehende Einigkeit über die Notwendigkeit, den passiven Widerstand formell einzustellen ${ }^{114}$. Am 24. folgten Besprechungen Stresemanns mit Vertretern der führenden Parteien und Wirtschaftsverbände aus den besetzten Gebieten ${ }^{115}$, am 25. eine Unterredung mit den deutschen Ministerpräsidenten ${ }^{116}$, und erst danach wurde in einer Parteiführerkonferenz beim Kanzler, zu der neben den Regierungsparteien auch die BVP und DNVP zugezogen wurde, eine informelle parlamentarische Billigung für diesen Schritt eingeholt ${ }^{117}$. Dabei zeigte sich die in dieser Frage erkennbare Kluft zwischen der Regierung und der Rechtsopposition der DNVP. Während die Vertreter der Koalitionsparteien den Abbruch des passiven Widerstandes billigten, plädierte Hergt „für etwas Stärkeres“ als passiven Widerstand ${ }^{118}$ und zielte damit

111 Nach ebd., S. 198-200.

112 Protokoll in PA AA Berlin, Nl. Stresemann, Nr. 87, H171304-171311. Besonders scharf äußerte sich hier Stinnes.

113 Text in Ursachen und Folgen 5, S. $203 \mathrm{f}$.

114 Dies wird mehr oder minder implizit deutlich aus dem Protokoll der Sitzung vom 20. 9. 1923; AdR Stresemann, Nr. 71, S. 319-325.

115 Protokolle cbd., Nr. 76, S. 334-338, Nr. 77, S. 339-345.

116 Ebd., Nr. 79, S. 349-356.

117 Ebd., Nr. 80, S. 356-361.

118 Vgl. Niederschrift von Marx über eine Besprechung mit Stresemann am 25.9. 1923; Nachlaß des Reichskanzlers Wilhelm Marx 2, S. 7. Nach dem Protokoll in AdR Stresemann, Nr. 80, S. 358, plädierte Hergt für „neue Maßnahmen“. Vgl. auch Stresemann am 25.9. im Kabinett: „Hergt will stärkeren Trumpf, Bruch!“ Ebd., Nr. 81, S. 361. 
auf eine demonstrative Kündigung des Versailler Vertrages ${ }^{119}$. Unumstritten war der Schritt der Regierung aber auch in Teilen des Regierungslagers nicht. So gab es am 21. September in der DDP-Fraktion ${ }^{120}$, am 25. bei der DVP und und einen Tag später beim Zentrum durchaus kontroverse Meinungen zur "Liquidation“ des passiven Widerstandes ${ }^{121}$. Auch einzelne Parlamentarier der DVP traten für eine Aufkündigung des Versailler Vertrages ein, die parallel zur Einstellung des passiven Widerstandes erfolgen sollte ${ }^{122}$. Am 26 . September wurde dann erstmals eine formelle parlamentarische Instanz eingeschaltet, als Stresemann die Aufhebung des Ruhrkampfes im Auswärtigen Ausschuß begründete ${ }^{123}$.

Das parlamentarische Leben der folgenden Wochen stand ganz unter dem Eindruck der Staatskrise, die sich an das Ende des Ruhrkonflikts anschloß. Diese Vorgänge, insbesondere der Konflikt zwischen Bayern und dem Reich sowie die Aktionen separatistischer und extremistischer Kräfte124, werden hier - soweit sie nicht die parlamentarische Sphäre im engeren Sinne betreffen - als bekannt vorausgesetzt. Mit besonderer Aufmerksamkeit sollen hingegen jene Entwicklungen im Bereich der regierungstragenden und legislativen parlamentarischen Funktion betrachtet werden, die von einer akuten Bedrohung des parlamentarischen Systems überschattet wurden und die zunächst zum Bruch und dann zur Neubildung der Koalitionsregierung sowie zum ersten großen Ermächtigungsgesetz der Weimarer Republik führten ${ }^{125}$.

Ein wesentlicher Impuls für die nun aufbrechenden Klüfte im Regierungslager war die Verhängung des bayerischen und reichsweiten Ausnahmezustands. Als die bayerische Regierung Knilling, die selbst unter dem Druck der immer aggressiver auftretenden „Vaterländischen Verbände“ stand, am Abend des 26. September den Abbruch des Ruhrkampfes mit der Verhängung des Ausnahmezustands und mit der Übertragung der vollziehenden Gewalt an den rechtslastigen ehemaligen Ministerpräsidenten von Kahr beantwortete, war dies eine offene Herausforderung der Autorität der Reichsregierung ${ }^{126}$. Brisanter noch als das separatisti-

119 In diesem Sinne wiedergegeben von Scholz in der DVP-Fraktionssitzung vom 25. 9. 1923. Protokoll in PA AA Berlin, Nl. Stresemann, Nr. 87, H171326.

120 Vgl. tagebuchartige Notizen Koch-Wesers vom 21.9. 1923; BA Koblenz, Nl. Koch-Weser, Nr. 139, Bl. 162.

121 Protokolle in PA AA Berlin, Nl. Stresemann, Nr. 87, H 171326-171331; Protokolle Zentrumspartei, Nr. 256, S. 478-480.

122 Vgl. v.a. Reinhold Quaatz zur Frage, ob die Fraktion die Kapitulation „decken“ könne: „Die mindeste Voraussetzung ist für mich: Kündigung des Friedensvertrages und Vorbereitung des Kampfes, den wir heute noch nicht führen können." Protokoll der DVP-Fraktionssitzung; PA AA Berlin, Nl. Stresemann, Nr. 87, H 171328.

${ }_{123}$ Resümee in Horkenbach, Das Deutsche Reich, S. 175.

${ }^{124}$ Erwähnt seien nur die Separatistendemonstration am 30.9. 1922 in Düsseldorf, bei der es 17 Tote gab, der Putschversuch der "schwarzen Reichswehr“ unter Major Bruno Buchrucker in Küstrin am 1.10. sowie der gescheiterte Oktoberaufstand der KPD in Hamburg. Die Entwicklung gipfelte dann im Münchner Hitlerputsch.

125 Vgl. generell zum folgenden: Arns, Krise, S. 181-216; ders., Regierungsbildung, S. 159-171; Baechler, Stresemann, S. 371-387; Turner, Stresemann, S. 119-123; Winkler, Von der Revolution zur Stabilisierung, S. 605-669; Hehl, Marx, S. 238-240; Huber, Verfassungsgeschichte 7, S. 341373. - V.a. Arns, Krise, hat auf die systemgefährdende Dimension aufmerksam gemacht; allerdings kann die These einer akut drohenden Rechtsdiktatur nicht völlig überzeugen. Vgl. hierzu unten S. 284.

126 Text der gleichzeitig auf Art. 48 Abs. 4 der Weimarer Reichsverfassung und $\$ 64$ der Bayerischen Verfassungsurkunde gestützten Verordnung in Ursachen und Folgen 5, S. $388 \mathrm{f}$. - Allgemein zu 
sche Potential dieses Vorgangs war das reichspolitische Fanal. Der auf der starken republikfeindlichen Rechten in Bayern unter dem Eindruck der Hyperinflation besonders laut ertönende Ruf nach einem Ende der "sozialistischen“ Regierung Stresemann und nach einem "Diktator" ${ }^{127}$ war auch anderswo zu hören. Eine autoritäre Wende in Bayern, so war zu befürchten, konnte daher leicht Vorbildwirkung für das Reich gewinnen. Stresemann reagierte sofort, rief noch am späten Abend des 26. September zu einer - unvollständig besetzten - Kabinettsrunde zusammen 128 und erwirkte bei Reichspräsident Ebert die Verhängung eines auf Artikel 48 Absatz 2 gestützten militärischen Ausnahmezustands, womit die Exekutivgewalt im Reich an Reichswehrminister Geßler überging ${ }^{129}$. Die Eigenmächtigkeit Bayerns wurde so mit einem primär symbolischen Akt beantwortet, für den auf dem Feld der inneren Sicherheit zu diesem Zeitpunkt noch kein akuter Anlaß vorlagi30.

Der seit 1919 expandierende Gebrauch des Ausnahmezustands wurde mit der Verordnung vom 26. September, die bis Ende Februar 1924 in Kraft bleiben sollte, auf einen neuen Höhepunkt geführt: Erstmals und in der Weimarer Geschichte das einzige Mal erfolgte nun eine reichsweite Ausdehnung des militärischen Ausnahmezustands, erstmals waren alle Elemente einer 1919 für den regionalen Einsatz entworfenen Musterverordnung einschließlich drakonischer Strafverschärfungen und Sondergerichte vertreten. Erstmals fehlte auch der bislang in Ausnahmezustands-Verordnungen übliche Hinweis auf das Schutzhaftgesetz von 1916, der angesichts der pauschalen Grundrechtssuspendierung zumindest die wesentlichen Habeas-Corpus-Rechte eines Verhafteten schützte131. Zeitgenössisch wurde dieser Präzedenzfall anscheinend überhaupt nicht wahrgenommen - auch dies ein Symptom für die bestehenden Defizite an parlamentarischer Kontrolle.

Die SPD, von der in dieser Frage noch am ehesten Aktivität zu erwarten war, trug als Regierungspartei den Ausnahmezustand selbst mit, wenngleich von den sozialdemokratischen Ministern wohl nur Sollmann an der nächtlichen Kabinettsrunde beteiligt war ${ }^{132}$. Während an der Parteibasis zum Teil heftige Empörung über den in früheren Jahren oftmals scharf kritisierten militärischen Ausnahme-

dem Vorgang: Winkler, Von der Revolution zur Stabilisierung, S. 612-619; Lange, Bayern, S. 203205.

127 Vgl. Feldman, Bayern und Sachsen, S. 596.

${ }^{128}$ Hierzu liegt kein Protokoll vor. Vgl. Tagebuchnotizen von Seeckts Adjutanten Oberstleutnant von Selchow nach AdR Stresemann, Nr. 83, S. 380f., Anm. 10. Demnach fand die Kabinettssitzung um Mitternacht statt.

129 RGBl. 1923 I, 905; auch in Dokumente zur deutschen Verfassungsgeschichte 4, Nr. 268, S. $322 \mathrm{f}$. Allgemein zum militärischen Ausnahmezustand in der Amtszeit Stresemanns vgl. Hürten, Reichswehr und Ausnahmezustand, S. 33-48; Eilers, Ermächtigungsgesetz und militärischer Ausnahmezustand, S. 166-200.

130 Allerdings hatte es schon Vorgespräche für den Fall eines Ausnahmezustands gegeben. Vgl. AdR Stresemann, Nr. 83, S. 381, Anm. 11.

131 Die Hintergründe sind bislang nicht geklärt. Drei Monate später wurde der Verweis auf das Schutzhaftgesetz von 1916 mit einer Verordnung vom 23. 12.1923 nachgetragen. Bei Hitlers „Verordnung zum Schutz von Volk und Staat" vom 28. 2.1933 fehlte der Hinweis dann erneut. Hierzu sowie zur Entwicklung des Ausnahmezustands in den Anfangsjahren der Weimarer Republik vgl. Raithel/Strenge, „Reichstagsbrandverordnung“.

132 So Radbruch, Der innere Weg, S. 170. Daß Radbruch fehlte, belegen auch seine Proteste am folgenden Tag. 
zustand herrschte ${ }^{133}$, war die Parteiführung bemüht, die Notwendigkeit der Verordnung und ihre republikschützende Intention $\mathrm{zu}$ betonen ${ }^{134}$. Innerhalb des $\mathrm{Ka}$ binetts legte allerdings Justizminister Radbruch am folgenden Tag Protest gegen die Bestimmungen zur Strafverschärfung und insbesondere gegen die Schaffung von Sondergerichten ein ${ }^{135}$.

Bedeutete somit die Verordnung an sich eine Erschütterung der stärksten Regierungspartei und damit auch der Koalition, entwickelte sich die Frage, wie die Reichsverordnung in Bayern durchgesetzt werden könne, zu einem Spaltpilz innerhalb des Regierungslagers. Gerade weil der reichsweite militärische Ausnahmezustand an der Parteibasis zumeist auf Unwillen stieß, wäre es für die SPDFührung notwendig gewesen, seine Durchsetzung gegen den autoritären Sonderweg Bayerns zu erreichen. Die SPD-Fraktion forderte daher sofort, die bayerische Staatsregierung formell um Aufhebung des bayerischen Ausnahmezustands zu ersuchen. Ein entsprechender Antrag für den Wiederzusammentritt des Reichstags am 27. September war offenbar geplant ${ }^{136}$. Radbruch und vor allem Innenminister Sollmann, der seine Fraktion nach eigenen Aussagen von einer sofortigen parlamentarischen Initiative abgehalten hatte, waren in der Kabinettssitzung vom 27. September nachdrücklich bemüht, die Regierung zu einem entsprechenden Vorgehen zu bewegen ${ }^{137}$. Daß sich die SPD-Minister hier nicht gegen Stresemanns dilatorische Haltung gegenüber Bayern durchsetzen konnten, bildete den Auftakt zu einer Kette sozialdemokratischer Mißerfolge in der bayerischen Frage.

Obwohl das Reichstagsplenum am 27. und 28. September erstmals seit Installation der Regierung Stresemann wieder zusammentrat und obwohl nach Abbruch des Ruhrkampfes genug Anlaß für eine öffentlichkeitswirksame Regierungserklärung und für eine parlamentarische Debatte vorgelegen hätte, vermied die Koalition weiterhin die offene Thematisierung der akuten politischen Fragen. Neben der Verabschiedung einiger dringender finanzpolitischer Vorlagen ${ }^{138}$ stand in der Reichstagssitzung vom 27. eine Geschäftsordnungsdebatte im Mittelpunkt, in der sich die Regierungsparteien gegen das Verlangen der radikalen linken und rechten Oppositionskräfte nach einer großen Aussprache zur Wehr setzten ${ }^{139}$. Daß auch die regierungsinternen Differenzen in Sachen Ausnahmezustand und Währungsstabilisierung Anlaß dafür waren, einer Plenardiskussion aus dem Weg zu gehen, ist anzunehmen. Mindestens ebenso bedeutsam aber war eine in der bürgerlichen Mitte zum Durchbruch kommende Grundhaltung, die ein von „Reichstagsreden“

133 Dic Proteste reichten bis hin zu Forderungen nach einem Parteiausschluß von Reichspräsident Ebert. Vgl. Geßler, Reichswehrpolitik, S. 272.

134 Vgl. die Rechtfertigung in Vo, 27. 9. 1923 ab, S. 1, „Ausnahmezustand über Deutschland“, als Mittel, „um die republikanische Staatsform und die Einheit des Reiches zu sichern“.

135 Protokoll der Kabinettssitzung vom 27. 9. 1923, 17.30; AdR Stresemann, Nr. 83, S. 381 f. Mit Geßler wurde schließlich vereinbart, daß Sondergerichte „nur im Benehmen“ mit dem Justizminister gebildet werden dürfen.

136 Vgl. die Bemerkung Sollmanns in der Kabinettssitzung zum Aufhebungsersuchen an die bayerische Regierung; AdR Stresemann Nr. 83, S. 384.

137 Ebd., S. $383 \mathrm{f}$.

138 Verh. RT 361, S. 11905-11909.

139 Ebd., S. 11898-11905. 
ungestörtes „Handeln“ forderte ${ }^{140}$. Je mehr sich die innenpolitische Krise zuspitzte, desto mehr wuchs auch die Bereitschaft, den parlamentarischen Betrieb zurückzufahren, um dadurch der Regierung vermeintlich bessere Bedingungen für tatkräftiges Agieren zu schaffen. Als Termin für eine Regierungserklärung wurde schließlich der 2. Oktober vorgesehen, nachdem es den vereinten Regierungskräften gelungen war, einen kommunistischen und einen deutschnationalen Antrag auf Außerkraftsetzung des Ausnahmezustands zu vertagen ${ }^{141}$.

Ebenfalls am 27. September sollte das am Vortag im Kabinett gebilligte Kompromißkonzept zur Währungsreform in erster Lesung behandelt werden ${ }^{142}$. Hilferding ließ hierzu mit Datum vom 1. Oktober dem Reichstag eine zuvor noch im Reichsrat modifizierte Gesetzesvorlage „über die Gründung einer Währungsbank " zukommen ${ }^{143}$. Trotz der seit Wochen im Raum stehenden Option einer weitgehenden Ermächtigung hatte der Finanzminister somit zunächst eine reguläre legislative Bewältigung der Hyperinflation in Gang gesetzt. Dieses nun vorliegende Konzept zur Einführung der "Neumark“, das von Hilferding als Zwischenlösung angesehen wurde, enthielt auch bedeutsame Elemente aus den Planungen Helfferichs, wodurch es freilich nicht gegen die scharfe Kritik führender Wirtschaftskreise geschützt war ${ }^{144}$.

Die weitere legislative Behandlung fiel jedoch der eskalierenden Krise im Regierungslager zum Opfer. Erneut zeigte sich nun, und diese Entwicklung sollte sich bis Ende des Jahres 1923 auf spektakuläre Weise fortsetzen, daß der legislative Funktionsverlust des Reichstags auch wesentlich durch Probleme der parlamentarischen Regierungsstützung verursacht wurde. Hilferding hatte die koalitionsbedrohende Sprengkraft regulärer Gesetzgebungsverfahren offenbar bereits zum Zeitpunkt seiner eben erwähnten Vorlage erkannt. So bewertete er in der Kabinettssitzung vom 30. September die Vorgänge in Bayern als Indiz für die wachsende Beliebtheit des „Gedanke[ns] einer Rechtsdiktatur" auch im übrigen Reich. „Es sei“, so führte er weiter aus, „eine Gefahr, daß bei einer Besprechung der Frage im Reichstag die Koalition auseinandergehe, und man müsse sich daher fragen, ob bei einer Beibehaltung des Reichstags die Situation noch zu beherrschen sei. Es sei erforderlich, vom Parlament die Vollmacht zu erbitten, in finanzieller und politischer Hinsicht das Notwendige zu veranlassen und im übrigen den Reichstag zu vertagen. Dies sei der einzige Weg, das Reich zu erhalten. " ${ }^{145}$ Die bereits in den ersten Wochen der Regierung Stresemann zu erkennende und - wie sich in einer Fraktionssitzung der DDP am 21. September zeigte ${ }^{146}$ - im unmittel-

140 Vgl. z. B. oben S. 92 im Kontext der Parlamentarismusbewertung eine entsprechende Äußerung von Koch-Weser am 27. 11.1923 im Reichstag.

141 Vgl. Diskussion in Verh. RT 361, S. 11917-11930.

$142 \mathrm{Zu}$ den Stationen Ramhorst, Entstehung, S. 29-31. Vgl. auch Löbe zur vorgesehenen Tagesordnung: Verh. RT 361, S. 11930.

143 Drucks. Nr. 6216 in Verh. RT 380, S. 1-8 (mit Begründung); Abdruck in Ramhorst, Entstehung, S. 32-35. In BA Koblenz, Nl. ten Hompel, Nr. 28, findet sich eine Fassung mit Änderungsvorschlägen des RDI. Zu der Vorlage auch Elster, Von der Mark zur Reichsmark, S. 229-231. Zur Besprechung im Reichswirtschafts- und Reichsrat vgl. Ramhorst, Entstehung, S. 30-32.

$1+4$ Vgl. vorige Anm.

${ }^{145}$ AdR Stresemann, Nr. 94, hier S. 413.

${ }^{146}$ So sprachen sich Haas und Dietrich für eine "Diktatur" aus. Tagebuchartige Notizen KochWesers vom 21. 9. 1923; BA Koblenz, Nl. Koch-Weser, Nr. 139, Bl. $162 \mathrm{f}$. 
baren Vorfeld der Ruhrkapitulation offenbar verstärkte Neigung innerhalb der Regierungsparteien, auf das Mittel der Verordnungspolitik zu setzen, fand nun deutlichen Ausdruck. Auch Brauns, Sollmann und Geßler sprachen in dieser Kabinettssitzung direkt oder indirekt die Notwendigkeit einer Ermächtigung an, wenngleich die Begründungen hier diffuser blieben. Bezeichnend für weite Teile des bürgerlichen Spektrums erscheint vor allem das von Brauns vertretene Postulat „entschiedenen Handelns“, welches man dem Parlament offenbar grundsätzlich nicht zutraute ${ }^{147}$.

Die Hauptverantwortung für den nun ausbrechenden Konflikt innerhalb des Regierungslagers ist trotz der im Detail kaum mehr aufzuklärenden Vorgänge relativ eindeutig auszumachen: Der rechte Flügel der DVP nutzte die akute innenpolitische Krise, um einen Sprengsatz gegen die ungeliebte Große Koalition zu legen. Die durch ein ausführliches Protokoll gut belegte Fraktionssitzung vom 25. September, in der primär über den kontrovers bewerteten Abbruch des Ruhrkampfes beraten wurde, bildete den Auftakt ${ }^{148}$. Scholz berichtete hier über „Besprechungen" mit Hergt ${ }^{149}$ und stellte die Loyalität zu Stresemann unverblümt in Frage ${ }^{150}$. Zwar blieb die Diskussion in der DVP-Fraktion noch relativ unbestimmt, doch die Hauptstoßrichtung zielte klar auf das vermeintlich zu große $\mathrm{Ge}-$ wicht der SPD. Dabei reichten die Vorstellungen von einer Ausbalancierung durch einen Regierungseintritt der DNVP151 über die Reduzierung der sozialdemokratischen Vertretung im Kabinett auf einzelne Persönlichkeiten ohne festen Auftrag der Partei ${ }^{152}$ bis zur offenkundig auch von Scholz vertretenen Forderung nach einem "sozialistenfreien Kabinett" ${ }^{153}$. Vier Tage später erfuhr dann Zentrumsfraktionsführer Marx "ganz vertraulich“ von dem Ruhrindustriellen und Zentrumsabgeordneten Klöckner, daß „in der Deutschen Volkspartei ein Krach ausgebrochen sei. Man wolle zu einem großen Teil der Fraktion die Koalition mit den Sozi aufheben." 154

147 So meinte Brauns, daß „es sich möglicherweise als notwendig erweisen werde, vom Reichstag große Vollmachten zu fordern. Die Erregung im Volke über das Verhalten Frankreichs und über die schwere innere Wirtschaftskrisis sei so groß, daß nur ein nach klaren Richtlinien eingestelltes, entschiedenes Handeln die Situation noch retten könnte. "Sollmann rechnete damit, daß das Parlament eine Ermächtigung erteilen werde, allerdings sei dazu ein Programm nötig. Geßler sprach von einer „Zeit eines Direktoirs, unter dem auch ein klares Wirtschaftsprogramm gemacht werden müsse". AdR Stresemann, Nr. 94, S. 411 f., 414.

148 Protokoll in PA AA Berlin, Nl. Stresemann, Nr. 87, H171326-H171331.

${ }^{149}$ Ebd. wird laut Protokoll als weiterer Gesprächspartner auch „Schulz (BVP)“ erwähnt. Ein gleichnamiger BVP-Politiker ließ sich nicht ermitteln. Auch über Kontakte zur BVP ist nichts bekannt. Vermutlich handelt es sich um eine Verwechslung mit MdR Georg Schultz (Bromberg) von der DNVP.

150 Ebd., H $171326 \mathrm{f}$.: „Wie soll sich unsere Fraktion einstellen? Wir stehen in der Koalition am weitesten rechts. Ob wir soweit gehen sollen, dem Kanzler nicht weiter in seiner Politik zu folgen, das ist eine Frage, die ich, um Ihnen nicht vorzugreifen, offen lassen möchte."

151 So Alfred Gildemeister: „An der Balancierstange Stresem. hängt an einem Ende das schwere Gewicht der Sozialdemokratie, will er Balance halten, muss er auf der anderen Seite das dtschn. Gewicht einschalten." Ebd., H171329.

152 So Otto Thiel: „In einem kommenden Kabinett Stresem. müssten Sozialdemokraten nur als Persönlichkeiten, nicht als Vertreter ihrer Partei sitzen." Ebd., H171329f.

153 Ebd., H171327. Auch von Kardorff gebrauchte diese Wendung; ebd., H171328.

154 HA Köln, Nl. Marx, Nr. 55, Erinnerungsbericht „Das Jahr 1923 (Ergänzungen)“, Bl. 27. Vgl. auch Hehl, Marx, S. 238. 
Dieses Vorhaben erscheint in mehrfacher Hinsicht als geradezu logische Konsequenz der Kapitulation im Ruhrkampf. Die Vermutung liegt nahe, daß sich in dem Angriff gegen die SPD auch ein diffuser Unmut über die nationale Demütigung Luft machte. Vor allem aber war das wichtigste Argument für eine sozialdemokratische Regierungsbeteiligung, die Aufrechterhaltung einer nationalen Einheitsfront gegen Frankreich, nun weitgehend außer Kraft gesetzt. Der „marxistischen" SPD konnte vielmehr die Rolle eines Sündenbocks für die Niederlage an der Ruhr zugeschoben werden. Hinzu kam, daß die SPD in weiten Bereichen der bürgerlichen Rechten als politisches Hindernis für einen politischen Neuansatz galt: Dies betraf - selten ausgesprochen - offenbar auch Fragen der Außen- und Militärpolitik ${ }^{155}$; in erster Linie aber ging es darum, daß mit der Aufgabe des passiven Widerstandes der Weg frei war für eine Währungsstabilisierung, die führende Kreise der Schwerindustrie an eine sozialpolitische Kurswende und insbesondere an die Aufhebung des Achtstundentages koppeln wollten. Ein Kabinettseintritt der DNVP, die hierfür als Bundesgenosse in Betracht kam, war nun von der Bürde befreit, die Beendigung des Ruhrkampfes mittragen zu müssen. In Anbetracht der herrschenden Empörung im nationalistischen Spektrum der Öffentlichkeit ist aber auch jenes Motiv ernst zu nehmen, das Scholz in der eben erwähnten Fraktionssitzung anführte: Gerade weil im Augenblick die „stärkere“ innenpolitische "Gefahrenquelle“ auf der Rechten liege, müsse „die Politik der Regierung [...] darauf gerichtet sein, diese Gefahr zu vermindern und eine „Versöhnung" mit den Deutschnationalen anzustreben ${ }^{156}$.

Die Vorstellungen darüber, was an die Stelle der bisherigen Koalition zu setzen sei, blieben verschwommen. Die wichtigste Option der DVP-Fronde war wohl eine bürgerliche Rechtsregierung unter Einschluß der DNVP, mit der es zu diesem Zweck konspirative Verhandlungen gab ${ }^{157}$. Allerdings waren die Auffassungen über einen Regierungseintritt innerhalb der DNVP geteilt, da sich hier die pragmatische Bereitschaft zur Mitarbeit im parlamentarischen System und die Hoffnung auf ein Kollabieren dieses Systems gegenüberstanden ${ }^{158}$. Welche Positionen die deutschnationalen Unterhändler in ihren Gesprächen mit der DVPFraktionsführung eingenommen und welche konkreten Forderungen sie erhoben haben, erscheint unklar ${ }^{159}$.

155 Vgl. Koch-Wesers Bericht vom 4. 10. 1923: „[...] Brauns insbesondere ist so verzweifelt über das pacifistische Getue der Sozialdemokraten und ihre wirtschaftliche Unentschlossenheit, dass er sich offenbar bemüht hat ihr ein Joch aufzurichten, unter das sie nicht hindurchgehen könnte." BA Koblenz, Nl. Koch-Weser, Nr. 139, Bl. 179.

156 PA AA Berlin, Nl. Stresemann, Nr. 87, H171326.

157 Die schärfsten Gegner Stresemanns in der Fraktion konspirierten mit der DNVP, durch Maretzky und Quaatz gelangten Indiskretionen an die Hugenberg-Presse. So kommentierend in Stresemann, Vermächtnis 1, S. 145. Zu den Verhandlungen von Scholz mit der DNVP vermerkt das Protokoll der Sitzung des Fraktionsvorstands vom 3.10. 1923 nur knapp Bericht und Aussprache. BA Koblenz, R 45 II, Nr. 66, Bl. 6.

158 Vgl. Hertzman, DNVP, S. 200. Demnach war Heydebrand sogar für einen Regierungseintritt unter SPD-Beteiligung, Westarp jedoch dagegen.

${ }^{159}$ Eine spezielle Untersuchung wäre hier sicher sinnvoll. Die Quellenlage ist allerdings sehr dürftig. Möglicherweise würde eine detaillierte Auswertung der konservativen Parteipresse zu Ergebnissen führen. 
Die Frage, inwieweit einzelne Akteure aus DNVP und DVP und insbesondere auch der im Hintergrund wirksame Hugo Stinnes ${ }^{160}$ weitergehende Ziele verfolgten und den Bruch der Koalition letztlich zu einem Staatsstreich und zur Errichtung einer Rechtsdiktatur nutzen wollten ${ }^{161}$, kann hier nicht verfolgt werden. Diese vor allem von Arns vertretene und an zeitgenössische Vermutungen anknüpfende ${ }^{162}$ These bedürfte einer detaillierten Überprüfung, die den parlamentarismusgeschichtlichen Rahmen der vorliegenden Arbeit sprengen würde. Generell sei allerdings angemerkt, daß Arns und auch andere Autoren dazu neigen, den Begriff „Diktatur“ zu sehr aus seinem historischen Kontext zu lösen. Wie bereits angedeutet, war mit „Diktatur" oftmals nicht mehr als ein zeitweises Verordnungsregime gemeint und somit eine vorübergehende Suspendierung der üblichen parlamentarischen Verfahrensweisen. Die Hoffnung auf eine dauerhafte Systemveränderung lag aber zweifellos nahe. Möglicherweise zielten die Erwartungen der „Verschwörer" auf eine mittels Artikel 48 gestützte „Diktatur“ des nationalen Hoffnungsträgers General von Seeckt. Dieser war seit dem 26. September de facto auch schon der Inhaber der militärischen Ausnahmegewalt, führte mehrfach Gespräche mit der deutschnationalen Parteispitze und bereitete sich wohl ernsthaft auf eine Regierungstätigkeit vor ${ }^{163}$. Ein gewisses Vorbild konnten die bayerischen Verhältnisse mit dem dort herrschenden Regiment des "Generalstaatskommissars" von Kahr abgeben. Ein weitergehender Zusammenhang mit dem Putschversuch der Schwarzen Reichswehr in Spandau und Küstrin am 1. Oktober, der

160 Zur Beteiligung an der Verschwörung vgl. Arns, Krise, S. 207-209. Allgemein zur Haltung von Stinnes vgl. auch Wulf, Stinnes, S. 444; ohne konkrete Angaben Feldman, Stinnes.

161 So die Bewertung in Arns, Krise; ebd. auch zu den Kontakten zwischen DVP und DNVP und zur Involvierung von Seeckt. Zu Seeckt auch Meier-Welcker, Seeckt, S. 389-396; Kessel, Seeckts politisches Programm von 1923. Zu Diktaturplänen Seeckts vgl. auch „Materialsammlung des Generalleutnants z. V. Lieber über die Beziehungen der Heeresleitung zum Kabinett Stresemann und ihre Einstellung zur deutschen Innenpolitik vom September bis November 1923“; AdR Stresemann, S. 1176-1203, Anhang, Nr. 1.

162 Vgl. v.a. PA AA Berlin, Nl. Stresemann, Nr. 2, H 154142, Durchschlag einer maschinenschriftlichen Notiz vom 29. 9. 1923 (ohne Angabe über Verfasser): „Es scheint, als wenn insbesondere der Abgeordnete Hugo Stinnes sich lebhaft für eine Rechtsdiktatur ausgesprochen hat, wobei hin [sic!] im Wesentlichen wirtschaftliche Erwägungen geleitet haben müssen, indem er von diesem Rechtsdiktator die sofortige Lösung der Frage der Arbeitszeit, die Aufgabe der Demobilmachungsvorschriften erwartet. Diese rein aus kapitalistisch wirtschaftlichen Erwägungen heraus geforderte Rechtsdiktatur findet aber kaum über die nähere Umgebung des Herrn Stinnes hinaus volle Zustimmung." Erwähnt auch bei Arns, Krise, S. 207. Entsprechende Gerüchte gingen auch durch die Presse. Vgl. z. B. Ge, 4.10. 1923 (Nr. 275), S, 1, „Ein nichtparlamentarisches Kabinett“, über ein "Gerücht, das mit großer Bestimmtheit auftritt“. Demnach habe ,in der vorigen Woche eine Konferenz bei Herrn Stinnes“ stattgefunden, „, in der die Liste für ein kleines Kabinett mit diktatorischen Vollmachten aufgestellt worden sein soll. Es zirkuliert auch bereits die Ministerliste dieser sogenannten nationalen Diktatur, an deren Spitze ein bekannter General stehen soll und die Herrn Helfferich als Finanzminister und einen bekannten Gewerkschaftler als Arbeitsminister nennt." - Wulf, Stinnes, S. 458, folgt dieser Interpretation nicht und hält die Germania-Meldung für unglaubwürdig, erwähnt allerdings nicht die Notiz aus dem Stresemann-Nachlaß. Ohne Angaben hierzu Feldman, Stinnes; ebd., S. 887-889 aber allgemein zu Diktaturerwartungen von Stinnes. Vgl. hierzu auch Rheinbaben, Viermal Deutschland, S. 190.

163 Offenbar wartete Seeckt auf Ebert. Besprechungen Seeckts mit führenden DNVP-Parlamentariern fanden ab dem 23.9. statt, so am 23. mit Hergt und Westarp. Vgl. Namensliste in IfZ München, Nl. Seeckt, Stück 51, „Tagebuchartige Aufzeichnungen“ 16. 3. 1923-25. 6. 1924“. Vgl. Meier-Welcker, Seeckt, S. 374 f., 393; Carsten, Reichswehr, S. 186. Im Kontext dieser Ereignisse steht vermutlich auch das berühmte "Regierungsprogramm“ Seeckts (handschriftliche Fassung in IfZ München, Nl. Seeckt, Stück 153), das nach Meier-Welcker, Seeckt, S. 390-393, wahrscheinlich am 25. 9. 1923 verfaßt wurde. Carsten, Reichswehr, S. 187 f., nimmt hingegen eine Entstehung im Oktober an. 
durch Eingreifen der Reichswehr rasch beendet wurde, ist unwahrscheinlich, kann aber nicht ganz ausgeschlossen werden ${ }^{164}$.

Die Wendung der DVP gegen die Große Koalition wurde vorbereitet von einer Kampagne der "nationalen“ Presse gegen das Kabinett Stresemann und gegen die SPD, die angeblich ihren Einfluß auf die Massen verloren habe ${ }^{165}$. Auf diese Weise sollte offensichtlich dem Argument der Boden entzogen werden, daß eine an der Regierung beteiligte SPD in der zugespitzten sozialen Krise ein Ordnungsfaktor sei. Besonderes Aufsehen erregte ein Artikel im Tag vom 29. September, in dem der DVP-Reichstagsabgeordnete Oskar Maretzky, dessen Auffassungen in einer redaktionellen Vorbemerkung als charakteristisch für die DVP-Fraktion dargestellt wurden, ein düsteres Bild des nationalen Verfalls malte. Angesichts der „hemmenden und volksverderbenden Einflüsse einer übertriebenen Demokratie und eines innerlich schon längst zusammengebrochenen Marxismus" übte der Parlamentarier scharfe Kritik an der vermeintlichen Tatenlosigkeit des Reichskanzlers und forderte das Ende der Großen Koalition ${ }^{166}$. Als Hauptursache für das Scheitern des Kampfes an der Ruhr galt, wie auch ein Manifest der DNVPParteiführung vom 28. September verkündete, „der Marxismus“, der „die deutsche Widerstandskraft unterhöhlt und die deutsche Wirtschaft zerrüttet" habe ${ }^{167}$. Der Versuch, eine erneute Dolchstoßlegende zu begründen, ist hier unverkennbar. Das Manifest forderte das deutsche Volk auf, sich „bereit" zu halten; bald sei „die Stunde der nationalen Regierung da, die mit starkem Willen, komme, was da wolle, den Weg der Rettung gehen wird“. Auf welchem Wege diese radikale Alternative einer "nationalen Regierung" an die Macht kommen sollte, ließ der Appell freilich offen.

Anfang Oktober kam es schließlich zur Eskalation innerhalb des Regierungslagers. In der fünfstündigen Kabinettssitzung am Nachmittag des 1. Oktober, die unter Anwesenheit des Reichspräsidenten der Vorbereitung auf die für den folgenden Tag geplante Plenardebatte diente, war von der koalitionspolitischen $\mathrm{Zu}$ spitzung noch wenig zu spüren ${ }^{168}$. Zunächst besprach man die außenpolitische Lage, die Situation in Bayern und den Putschversuch von Küstrin. Bemerkenswert ist, daß das Vorhaben des sozialdemokratischen Justizministers Radbruch, gegen Bayern den Klageweg vor dem Reichsgericht zu beschreiten, nicht zuletzt durch eine persönliche Intervention Eberts zu Fall gebracht wurde. Der Reichspräsident schloß sich damit der Auffassung von Reichsarbeitsminister Brauns an,

164 Zum ursprünglichen Plan, Regierungsgebäude in Berlin zu besetzen, vgl. Carsten, Reichswehr, S. 188.

165 Vgl. zusammenfassenden Bericht ohne Verfasserangabe von Anfang Oktober 1923 in PA AA Berlin, Nl. Stresemann, Nr. 87, hier H171339. Ebd. wird insbesondere die Hugenberg-Presse genannt. Allgemein zur Kampagne auch Arns, Krise, S. 210.

166 Der Tag, 29. 9. 1923, S. 1, „Handeln, nicht reden!“ Maretzky war schon wiederholt als Anhänger einer Rechtskoalition aufgetreten. Vgl. auch Arns, Krise, S. $183 \mathrm{f}$., 210.

167 Vgl. im Kontext: „Wieder einmal hat der Marxismus die deutsche Widerstandskraft unterhöhlt und die deutsche Wirtschaft zerrüttet, wieder einmal führt eine sozialdemokratisch-bürgerliche Koalition, mehr vertrauend auf den Feind als auf eigene Kraft, das deutsche Volk dem Elend neuer Kapitulationen entgegen.“ Zitiert nach: NPZ, 29.9. 1923, S. 1, „Die Anklage wider den Marxismus".

168 AdR Stresemann, Nr. 97, S. 417-431. Ebd., S. 418, Anm. 2 auch Abdruck stichwortartiger Notizen Stresemanns. Zum Konfliktpotential vgl. aber die Bemerkung Kempners zu Stockhausen, zitiert ebd., S. 417, Anm. 1. 
der davor gewarnt hatte, den Konflikt zwischen Bayern und dem Reich noch zu "vertiefen“. Man einigte sich schließlich auf die Ankündigung eines Briefes „an die bayerische Regierung über das Verhältnis des Bayer. Ausnahmezustands zum Reichsausnahmezustand"169. Im Anschluß standen Fragen der Wirtschafts- und Finanzpolitik und insbesondere auch der Arbeitszeit zur Debatte. Auch Stresemann erwähnte nun die Notwendigkeit eines Ermächtigungsgesetzes; dieses sollte dem Ziel dienen, „die für die Erhaltung der Wirtschaft notwendigen Maßnahmen auf finanzpolitischem, sozialpolitischem und wirtschaftspolitischem Gebiete zu ergreifen" 170 . In der Arbeitszeitfrage nahm der Kanzler eine moderate Position ein: „Die Reichsregierung müsse“, so schlug er als Formulierung für die Regierungserklärung vor, „die Möglichkeit haben, in lebenswichtigen Betrieben eine Verlängerung der Arbeitszeit vorzusehen durch behördliche Regelung." Kritik hieran gab es von den bürgerlichen Ministerkollegen Brauns und Raumer, denen der Begriff „lebenswichtiger Betrieb“ als zu eng gefaßt erschien. Brauns hatte schon vor Stresemann sein Programm des „sogenannten sanitären Maximalarbeitstages" dargelegt, eine komplexe Kompromißformel für den Bergbau, die den "Achtstundentag in der bestehenden Form" aufhob und die Einführung einer achtstündigen Schicht einschließlich Ein- und Ausfahrt vorsah ${ }^{171}$. Vizekanzler Schmidt gab sich in der Arbeitszeitfrage durchaus kompromißbereit. Er konzedierte die Notwendigkeit einer Arbeitszeitverlängerung im Bergbau und schlug vor, "gerade in dieser Frage [zu] handeln, ohne viel zu reden"172. Radbruch verlas darauf den nicht überlieferten Entwurf eines Ermächtigungsgesetzes. Offenbar fehlte darin der sozialpolitische Themenbereich, denn abschließend billigte es das Kabinett - also auch die sozialdemokratischen Minister - auf Antrag von Geßler, "die Ermächtigung auch auf soziale Maßnahmen auszudehnen“173.

Im Lichte der späteren Ereignisse entsteht der Eindruck, als hätten die sozialdemokratischen Minister einer Arbeitszeitregelung innerhalb eines Ermächtigungsgesetzes zunächst vorbehaltlos zugestimmt ${ }^{174}$ und als seien sie erst infolge der Reaktionen aus Fraktion und Partei sowie aus dem ADGB von ihrer anfänglichen Haltung abgewichen. Dem ist entgegenzuhalten, daß es zu diesem Zeitpunkt noch keineswegs klar war, worum es bei der Neuregelung der Arbeitszeit überhaupt gehen würde. Daß die Formulierung Stresemanns bei den zu großem Entgegenkommen bereiten sozialdemokratischen Ministern keinen Widerspruch hervorrief,

169 Ebd., S. 425.

170 Ebd., S. 430.

171 Ebd., S. 429. Später schriftlich ausformuliert; Anlage zu Kabinettsprotokoll ebd., S. 431. Zu Brauns vgl. auch Oltmann, Reichsarbeitsminister Heinrich Brauns, S. 194-213, allerdings mit einseitiger Perspektive.

172 AdR Stresemann, Nr. 97, S. 429. Vgl. auch Winkler, Von der Revolution zur Stabilisierung, S. $626 f$., zum weiten Entgegenkommen der SPD-Minister in der Arbeitszeitfrage. Winkler nimmt an, daß die sozialdemokratischen Minister eine Arbeitszeitregelung auf der Basis eines Ermächtigungsgesetzes ursprünglich befürwortet hätten, da „es ihrer Fraktion leichter fallen würde, indirekt, auf dem Weg über ein Ermächtigungsgesetz, ihre Zustimmung zu einem derart einschneidenden sozialen Verzicht zu geben“.

173 AdR Stresemann, Nr. 97, S. 431.

174 So etwa Oltmann, Reichsarbeitsminister Heinrich Brauns, S. 200. Stockhausen spricht rückblikkend von der „starke[n] Nachgiebigkeit der soz. Mitglieder des Kabinetts gegenüber gewissen Forderungen, insbesondere des Reichsarbeitsministers"; Notiz aus Nl. Stockhausen vom 13. 10. 1923, AdR Stresemann, Nr. 97, S. 417, Anm. 1. 
liegt auf der Hand. Und auch die weitergehenden, freilich noch sehr vorläufigen Braunsschen Vorschläge besaßen noch nicht den Symbolwert, den diese Frage am folgenden Tag gewinnen sollte. Nicht auszuschließen ist allerdings auch, daß die Kabinettsvertreter der SPD die Brisanz einer Arbeitszeitregelung per Ermächtigungsgesetz noch gar nicht erkannt hatten.

Offenbar kam es noch am selben Tag zu Gesprächen des Kanzlers mit den Fraktionsspitzen, in denen dann das Konfliktpotential klarer zutage trat. So bemerkte Stresemann am 1. Oktober in seinen Tagesnotizen: „Besprechung mit Fraktionen/ Kabinett in Schwierigkeiten wegen E[rmächtigungs]gesetz/ Großer Wirrwarr! Große Koalition oder bürgerliches Kabinett?" 175 Da Protokolle nicht vorliegen und auch andere Quellen wenig Konkretes überliefern, kann über den Inhalt dieser Unterredung freilich nur spekuliert werden.

Möglicherweise deuteten sich hier bereits jene Gegensätze an, die dann in einer breit besetzten und gut dokumentierten Parteiführerbesprechung am Morgen des 2. Oktobers hart aufeinanderprallten ${ }^{176}$. Scholz, der Fraktionsvorsitzende der DVP, führte nun die entscheidende Attacke und verband die Frage eines Ermächtigungsgesetzes sowohl mit der Zusammensetzung der Regierung als auch in sehr offensiver Form mit dem Thema „Arbeitszeit“, bei dem man jetzt nicht „bei den Bergleuten [...] stehen bleiben " könne. Ein Ermächtigungsgesetz dürfe es nur für eine umgestaltete Regierung geben. Scholz forderte zum einen als „conditio sine qua non" personelle Umbesetzungen im Kabinett, zum anderen als Zeichen nationaler Geschlossenheit und zur Regelung der „Ernährungsfrage“ den Regierungseintritt der DNVP177. Ausdrücklich verlangte Scholz auch eine „soz. Ermächtigung zum Zweck Verlängerung der Arbeitszeit" ${ }^{178}$. Provozierend war dabei nicht allein der Inhalt der Forderungen, sondern - wie verschiedene Quellen belegen auch der aggressive Ton. So bewertete Koch-Weser in seinen tagebuchartigen Notizen den Auftritt des DVP-Vertreters als "ganz schlimm“; dieser habe die Verhandlungen eingeleitet, „etwa wie ein Corpsstudent einen Tusch mit einem anderen Corps herbeiführt" 179 .

Müller, der zuvor noch vor einer Arbeitszeitdiskussion gewarnt hatte, bezog gegen seine sonstige Gewohnheit denn auch sofort eine klare Gegenposition und ließ keinen Zweifel daran, daß er eine Koalitionserweiterung ablehne und daß die Haltung der DVP Zugeständnisse seiner eigenen Partei nahezu unmöglich mache. Es sei „ausgeschlossen“, daß die SPD-Fraktion einem Ermächtigungsgesetz in der

175 Stresemann, Vermächtnis 1, S. 137.

176 Vgl. Protokolle aus den Nachlässen Kempner und Erkelenz in AdR Stresemann, Nr. 99, S. 436444. Vgl. auch BA Koblenz, Nl. Wissell, Nr. 120, hs. Protokoll der SPD-Fraktionssitzung vom 2. 10. 1923 .

177 Nach maschinenschriftlicher Fassung; AdR Stresemann, Nr. 99, S. 439. Vgl. ebd.: „Die Ruhe im Lande sei von der Ernährung abhängig. Die Ernährungsfrage könne aber nur geregelt werden, wenn die Deutschnationalen mitarbeiteten."

178 Vgl. Protokoll der SPD-Fraktionssitzung vom 2. 10. 1923 in BA Koblenz, Nl. Wissell, Nr. 120.

179 BA Koblenz, Nl. Koch-Weser, Nr. 139, Bericht vom 3. 10. 1923, Bl. 174-178, hier Bl. 175. KochWeser meint, Scholz habe hier "mehr aus Tapsigkeit als aus Bosheit gehandelt“. Er habe "offenbar beweisen wollen, dass man mit der Sozialdemokratie nur energisch zu reden brauche, um alles bei ihr durchzusetzen. Noch gestern abend war er im Gespräch mit mir siegesgewiss und liess sich von Kempkes, dem Intimus Stresemanns bestärken, dass die Sozialdemokratie zur Zeit so klein sei, dass man nur von ihr zu fordern brauche, um bewilligt zu erhalten." 
von Scholz geforderten Form zustimme. Auf die Beiträge der übrigen Parteiführer-Marx, Leicht ${ }^{180}$, Koch-Weser und Petersen - kann hier im Detail nicht eingegangen werden. Wie vermutlich auch Stresemann wurden sie offenbar durch die Vehemenz des Vorstoßes von Scholz überrascht ${ }^{181}$, denn klare Stellungnahmen zu dessen Forderungen blieben aus. Vor allem Marx und Petersen betonten geradezu beschwörend die Notwendigkeit, „Parteistreit“ zu vermeiden. Das Parlament sei „in Gefahr abzuwirtschaften“, warnte der Fraktionsvorsitzende des Zentrums und forderte im gleichen Atemzug die "Selbständigkeit" des Kabinetts.

Die Situation war vor allem insofern überraschend, als das geplante Ermächtigungsgesetz, das den Parteienkonflikt ja gerade verhindern sollte ${ }^{182}$, jetzt selbst zum Zankapfel wurde. Hinzu kamen die Infragestellung der Regierungszusammensetzung sowie die im Laufe der Unterredung ebenfalls thematisierten Differenzen hinsichtlich der Behandlung Bayerns. Die meisten Teilnehmer waren sich gegen Ende offensichtlich darin einig, daß unter den gegebenen Umständen die für den Nachmittag geplante Regierungserklärung nicht stattfinden könne und daß zunächst eine Klärung innerhalb der Fraktionen herbeigeführt werden müsse. Lediglich Koch-Weser riet dazu, sofort die offene Konfrontation im Reichstag zu wagen ${ }^{183}$, ein Vorschlag, der einem klassisch-individualisierenden Parlamentarismusbild entsprach. Während Breitscheid grundsätzlichen Widerspruch im Sinne eines parteienstaatlichen Parlamentarismusverständnisses einlegte, konnte ein derartiges Vorgehen, das auf eine Zerreißprobe für die DVP hinausgelaufen wäre, von Stresemann aus rein pragmatischen Gründen kaum akzeptiert werden ${ }^{184}$. Der Kanzler setzte schließlich einen Termin bis $19 \mathrm{Uhr}$, damit die Fraktionen Klarheit über ihre Haltung zu den umstrittenen Fragen schaffen könnten.

Die Frage der Arbeitszeit war der entscheidende Hebel, den die DVP-Fraktionsführung im Einklang mit den Interessengruppen der Montan- und Schwerindustrie gegen die Große Koalition ansetzte ${ }^{185}$. Die Beteiligten wußten sehr genau, daß hier der empfindlichste Punkt der Sozialdemokratie lag, die eine demonstrative Demontage der wichtigsten sozialen Errungenschaft der Revolutionszeit nicht akzeptieren konnte. Nachdem sich die politischen Fronten bereits seit Mitte September aufgebaut hatten, wurde das Thema nun innerhalb weniger Tage zum beherrschenden Konflikt in der Stabilisierungsdiskussion. Ein deutliches Signal

180 Vgl. auch Maga, Prälat Johann Leicht, S. $117 \mathrm{f}$.

181 Nach Hehl, Marx, S. 240, gab es keine Absprache in der Arbeitsgemeinschaft. Die Rolle Stresemanns bleibt aber letztlich unklar. Vgl. Bericht Koch-Wesers vom 3. 10. 1923: „Ob Stresemann tatsächlich so unklug gewesen ist, diesen Vorstoss Scholz's zu fördern - Scholz selbst deutete mir das nachher sehr deutlich an - weiss ich nicht." BA Koblenz, Nl. Koch-Weser, Nr. 139, Bl. 174-178, hier Bl. 175.

${ }^{182}$ Vgl. die Beiträge von Marx und Petersen in der Parteiführerbesprechung (s. Anm. 176).

183 „Er soll heute sprechen! Abwarten, ob Reichstag Regierung stürzt!“ AdR Stresemann, Nr. 99, S. 443.

${ }_{184}$ Instruktiv hierzu die Notizen Koch-Wesers vom 3. 10. 1923; BA Koblenz, Nl. Koch-Weser, Nr. $139, \mathrm{Bl} .176 \mathrm{f}$

${ }^{185}$ Auch in der bürgerlichen Öffentlichkeit wurde dies teilweise so wahrgenommen. Vgl. die Analyse der KV, 5. 10. 1923, S. 1, „Klärung!“: Interessenpolitiker der Schwerindustrie und des Landbundes wollten eine „Diktatur der Rechten“. „Man stellte die Forderung nach einer Produktionssteigerung nicht um ihrer selbst willen, sondern um die Sozialdemokratie, die bei jedem Nachgeben dieser Forderung in einen Gegensatz mit ihrer eigenen Agitation und infolgedessen mit ihren Anhängern geraten mußte, aus der Regierung zu beseitigen. Zu diesem Zweck wurden Minen gelegt“”. 
hatte bereits am 30. September in Unna der Beschluß der Zechenbesitzer des Ruhrgebiets gesetzt, ab dem 8. Oktober die Schichtzeit im Bergbau von sieben auf achteinhalb Stunden zu verlängern und somit durch offenen Bruch des geltenden Rechts wieder die vor dem Ersten Weltkrieg geltende Arbeitszeitregelung einzuführen ${ }^{186}$.

Der weitere Verlauf der Koalitionskrise bis zum Rücktritt der Regierung Stresemann I am Abend des folgenden Tages bietet ein komplexes und in manchen Fragen auch widersprüchliches Bild. Insgesamt besteht zu den Entscheidungsprozessen nur eine unzureichende Quellenbasis. So ist wenig bekannt über die Fraktionssitzung der DVP am 2. Oktober, in der es Stresemann offenbar gelang, einen Teilerfolg gegen die Rechtsfronde zu erlangen, seine Partei von der Forderung nach einer Regierungserweiterung um die DNVP abzubringen und zu einer formellen Erklärung für den Fortbestand der Großen Koalition zu bewegen ${ }^{187}$. Das provokative Ziel eines Ermächtigungsgesetzes, das auch eine Neuregelung der Arbeitszeit betreffen sollte, blieb allerdings unverändert im Raum. Auch scheint hier der Ruf nach personellen Veränderungen im Kabinett insofern bekräftigt worden zu sein, als nun die Ablösung von Hilferding, Radbruch und Raumer gefordert wurde ${ }^{188}$. Daß der Finanzminister zur Symbolfigur für eine aus Sicht führender Wirtschaftskreise verfehlte Stabilisierungspolitik geworden war, ist bereits ausgeführt worden. Wahrscheinlich glaubte man in der DVP zudem, über eine Rücktrittsforderung gegen Hilferding und Radbruch und eine eventuelle Solidarisierung der SPD mit ihren Ministern einen weiteren Hebel gegen die Regierungsbeteiligung der Sozialdemokratie ansetzen zu können. Der Vorstoß der eigenen Fraktion gegen Raumer, der bereits Mitte September in einer Fraktionssitzung von Otto Hugo, dem Syndikus der Bochumer Industrie- und Handelskammer, scharf kritisiert worden war ${ }^{189}$, ist in ihren Ursachen nicht eindeutig zu erklären. Möglicherweise spielte hier auch die taktische Überlegung eine Rolle, eine gewisse parteipolitische Parität im ministeriellen Revirement herzustellen und so die Ablösung Hilferdings zu erleichtern. Vermutlich hatte die Rücktrittsforderung aber auch eine spezifisch gegen Raumer gerichtete Dimension: Dem Wirtschaftsminister wurden gute Beziehungen zu Hilferding nachgesagt, er widersetzte sich den Wünschen des Rheinisch-Westfälischen Kohlensyndikats ${ }^{190}$, und er war - zusammen mit Stresemann - einer der entschiedensten Befürworter einer Großen Koali-

186 Die siebenstündige Schicht war in einem Reichsgesetz vom Juli 1922 festgelegt worden. Nach Winkler, Von der Revolution zur Stabilisierung, S. 626, „zielte der Vorstoß von Unna denn wohl auf einen Regierungswechsel“. Vgl. zum Kontext auch Feldman/Steinisch, Weimarer Republik, S. 389 f.; Wulf, Stinnes, S. 443f.; Feldman, Stinnes, Iron and Steel, S. 393-444.

${ }_{187}$ Nach Bericht in VZ, 3. 10.1923 mo, S. 1, "Die Fraktionssitzungen“. Vgl. auch Arns, Krise, S. $188 \mathrm{f}$. ${ }^{188}$ Herausgeberkommentar in Stresemann, Vermächtnis 1, S. 140.

189 Protokoll in PA AA Berlin, Nl. Stresemann, Nr. 87, H 171310. Die Kritik zielte wohl nur vordergründig v.a. auf die schlechte Erreichbarkeit von Raumer, der "seinen volksparteilichen Adjutanten beseitigt und sich dafür einen sozialdemokratischen Beamten ins Vorzimmer gesetzt" habe.

190 Dahinter stand ein Konflikt zwischen der Schwerindustrie und der verarbeitenden Industrie in der DVP. So eine Analyse des französischen Journalisten Camille Loutre in L'Europe Nouvelle, 13. 10. 1923, S. 1299-1301, „Le duel Stinnes-Stresemann, ou ,Charbonnier veut être maître chez soi“ “. Hierzu auch Arns, Krise, S. 202. Vgl. allgemein auch Dittmann, Erinnerungen 2, S. 860: Raumer sei ein „Mann der Elektrizitätsindustrie, [...], der von dem schwerindustriellen StinnesFlügel der Partei argwöhnisch betrachtet wurde, da er ihm zu stark mit Hilferding zu harmonieren schien". 
tion innerhalb der DVP-Fraktion. Die Attacke galt damit letztlich wohl auch dem Kanzler selbst ${ }^{191}$.

Im Anschluß an die Fraktionssitzung reichte Raumer in einem Schreiben an den Reichskanzler seine Demission ein und führte als Begründung den „Verlauf der gestrigen Kabinettssitzung“ an. Diese habe ihn zur „Überzeugung gebracht, $\mathrm{da} ß$ ich in diesem Kabinett keine Aussicht habe, in den mit meinem Ressort zusammenhängenden wirtschaftlichen und sozialpolitischen Fragen eine Politik zu führen, die meinen Überzeugungen von den für unser Vaterland erforderlichen Maßnahmen entspricht" ${ }^{192}$. Trotz gewisser Differenzen in der fraglichen Kabinettssitzung dürfte außer $Z$ weifel stehen, daß dies weitgehend eine vorgeschobene Begründung war, die vom eigentlichen Hintergrund, der Rücktrittsforderung der eigenen Fraktion, ablenken sollte ${ }^{193}$.

Auch die Vorgänge in den anderen Fraktionen sind nur noch bruchstückhaft zu erfassen. Für das Zentrum ist bemerkenswert, daß ein Teil der Fraktion, darunter vor allem Stegerwald und wohl auch Brauns, am 2. Oktober die Zusammenarbeit mit der SPD beenden wollte und dem Regierungseintritt der DNVP durchaus aufgeschlossen gegenüberstand ${ }^{194}$. Die Attacke der DVP-Fraktion gegen die Große Koalition hatte somit bedeutsame Verbündete gefunden. In der SPD-Fraktion, wo angesichts des Putschversuchs von Küstrin und der Vorgänge in Bayern offenbar eine geradezu fatalistische Furcht vor einem reichsweiten Rechtsputsch herrschte, läßt sich eine gewisse Bereitschaft zur pragmatischen Steigerung der Arbeitszeit erkennen ${ }^{195}$. Eine diesbezügliche Ermächtigung scheint aber - im Gegensatz zu einer eingeschränkten finanzpolitischen - auf einhelligen Widerstand gestoßen zu sein.

Die nächste Parteiführerbesprechung sollte am Abend des 2. Oktober Klarheit über das weitere Vorgehen schaffen ${ }^{196}$. Müller forderte für die SPD eine Aufhebung der bayerischen Ausnahmezustandsverordnung, warnte davor, das Thema Arbeitszeit „aufzurollen“, und bekräftigte, daß es eine Ermächtigung „nur für Finanz und Währung, nicht für Sozialpolitik und Arbeitszeit" geben dürfe ${ }^{197}$. Ein

191 Nach FZ, 5. 10. 1923 mo/2, „Die Fortsetzung der Krise“, hatte der rechte Flügel in der DVP-Fraktion „das politische Übergewicht erlangt" und trete für eine Annäherung an die DNVP ein. Man wolle lieber eine Trennung von Stresemann, als den bisherigen Kurs weiterverfolgen. Vgl. auch Arns, Krise, S. 199.

192 AdR Stresemann, Nr. 101, S. 446.

193 Vgl. auch den generellen Widerspruch Stresemanns hinsichtlich der Begründung des Rücktrittsgesuchs zu Beginn der Kabinettssitzung vom Abend des 2. 10. 1923. AdR Stresemann, Nr. 102, S. 447.

194 Brauns und Höfle trugen in der Sitzung konträre Standpunkte vor. Der eine sprach „für eine bürgerliche Regierung“, der andere „für Beibehaltung der bisherigen Mitgliedschaft der Sozialdemokraten“. Zusammenfassendes Protokoll der Sitzungen vom 2. und 3.10. aus Nl. ten Hompel in Protokolle Zentrumspartei, Nr. 259, S. 482f. Vgl. auch KV, 3. 10. $1923 \mathrm{mo} / 1$, S. 1, „Knistern im Gebälk“: Auch ein Teil der Zentrumsfraktion, v.a. Stegerwald, glaube, „daß ein Zusammenarbeiten mit der Sozialdemokratie auf wirtschaftlichem und sozialem Gebiet kaum noch möglich sein werde“. Brauns als treibende Kraft sehen auch Koch-Weser in seinem Bericht vom 4. 10. 1923, BA Koblenz, Nl. Koch-Weser, Nr. 139, Bl. 179, und Radbruch, Der innere Weg, S. 170. Vgl. knapp auch Hehl, Marx, S. 238.

195 Vgl. Notizen in BA Koblenz, Nl. Wissell, Nr. 120, Bl. 18338-18345. Vgl. auch Notizen in ASD Bonn, Nl. Giebel, Kassette II, Mappe 3, Bl. 246f. Winkler, Von der Revolution zur Stabilisierung, S. 629, geht auf diese Fraktionssitzung nicht ein.

196 Protokoll aus Nl. Erkelenz, AdR Stresemann, Nr. 100, S. $444 \mathrm{f}$.

197 Ebd., S. 445. 
Ausweg aus dem Konflikt um die Breite des Ermächtigungsgesetzes war daher noch nicht in Sicht ${ }^{198}$. Eine Annäherung erfolgte aber hinsichtlich der Ausgestaltung einer Arbeitszeitverlängerung, da Scholz die Bereitschaft zur Übernahme des Braunsschen Vorschlags signalisierte. In der Frage einer personellen Veränderung des Kabinetts scheint die DVP ihre Forderung nach Rücktritt Hilferdings zu einem „Wunsch" umformuliert zu haben ${ }^{199}$. Dennoch wurde nun offenbar bereits mit der Demission Stresemanns gerechnet ${ }^{200}$.

Eine gewisse Entspannung setzte sich dann aber in einer am späten Abend stattfindenden Kabinettssitzung fort ${ }^{201}$. Hilferding äußerte dabei erstmals den Verdacht, daß das Ziel der DVP „die Herausdrängung der Sozialdemokraten aus dem Kabinett" sei202, was Stresemann dementierte ${ }^{203}$. Unter dem Eindruck der akuten Krise kam es nun zu einem schrittweisen Nachgeben der sozialdemokratischen Kabinettsmitglieder ${ }^{204}$. So deutete Hilferding bereits zu Beginn Kompromißbereitschaft in den Themen „Bayern“, „Arbeitszeit" und "Ermächtigungsgesetz" an ${ }^{205}$. Bei der Diskussion des bayerischen Ausnahmezustands verzichteten die SPD-Minister wohl bewußt auf ein weiteres Insistieren und akzeptierten stillschweigend die dilatorische Haltung Stresemanns. In Sachen Arbeitszeit wurde nach einigem Hin und Her eine komplizierte und inhaltlich vage Kompromißformel zu Protokoll gegeben. „In der Urproduktion“, so heißt es darin in Anlehnung an die am Vorabend von Brauns formulierte Erklärung, sei „die Arbeitszeit auf das Maß zu erhöhen, das gesundheitlich tragbar erscheint". "Insbesondere [sei] im Bergbau unter Tage eine Arbeitszeit von 8 Stunden einschließlich Ein- und Ausfahrt unentbehrlich." 206 Aber auch hinsichtlich des geplanten Ermächtigungsgesetzes kam man zu einer gewissen Verständigung. Der entscheidende $₫ 1$ des vom Kabinett gebilligten Entwurfs lautete: „Die Reichsregierung kann die Maßnahmen anordnen, welche sie auf finanziellem und wirtschaftlichem Gebiet für

198 Erneut sind „starke Divergenzen“ zwischen den Parteien zu erkennen. Zitat aus Mitschrift Giebels in SPD-Fraktionssitzung; ASD Bonn, Nl. Giebel, Kassette II, Mappe 3, Bl. 248 (Zitat in AdR Stresemann, Nr. 100, S. 445, Anm. 7); Protokoll der Parteiführerbesprechung in AdR Stresemann, Nr. 100, S. $444 \mathrm{f}$.

199 Nach Mitschrift Giebels „nicht ultimative Forderung, sondern nur Wunsch“. Zitiert nach AdR Stresemann, S. 446, Anm. 7.

200 Abends um 20.30 Uhr fand nochmals eine SPD-Fraktionssitzung statt. Gicbel notierte u.a. über den Bericht Müllers: „Situation sehr ernst! - Stresem. ging zum Präsidenten!“ Zitiert nach AdR Stresemann, S. 446, Anm. 7. Vgl. auch Begriff „Demissionssitzung“ im resümierenden Protokoll für die Fraktionssitzungen vom 2. und 3. 10. 1923; Protokolle Zentrumspartei, Nr. 259, S. 484.

201 AdR Stresemann, Nr. 102, S. 447-452. Die Sitzung begann gegen 21.30 Uhr. Vgl. zur Diskussion auch Winkler, Von der Revolution zur Stabilisierung, S. $630 \mathrm{f}$.

202 AdR Stresemann, Nr. 102, S. 448.

203 Ebd., S. 449f. Vgl. aber hierzu ebd., Anm. 14, das Zitat aus einem Anfang Oktober 1923 verfaßten Rundschreiben an die DVP-Generalsekretäre.

204 Vgl. auch den Bericht, den Brauns und Höfle am folgenden Tag in der Zentrumsfraktion gegeben haben. Beide hatten den „Eindruck [...], daß die Sozialdemokraten sich durch die feste Stellungnahme der bürgerlichen Minister nach und nach hätten von Position zu Position zurückdrängen lassen“. Resümierendes Protokoll für die Sitzungen vom 2. und 3. 10.; Protokolle Zentrumspartei, Nr. 259, S. 484.

205 AdR Stresemann, Nr. 102, S. 450. Allerdings blieb unklar, wie die Kompromißbereitschaft in der „bayerischen Frage“ konkret aussah. In diesem Sinne auch Winkler, Von der Revolution zur Stabilisierung, S. 630 .

206 AdR Stresemann, Nr. 102, S. 451. Vgl. auch Arns, Krise, S. 190; Oltmann, Reichsarbeitsminister Heinrich Brauns, S. 203. 
notwendig und dringend erachtet. Die Verordnungen sind dem Reichstag unverzüglich zur Kenntnis zu bringen. "207 Die SPD-Minister hatten demnach ihren Widerstand gegen eine wirtschaftspolitische Ermächtigung aufgegeben und zudem akzeptiert, daß - wie Stresemann am Ende der Kabinettssitzung feststellte darunter auch „soziale Maßnahmen“ zu verstehen seien ${ }^{208}$.

Der Hauptgrund für dieses erstaunliche sozialdemokratische Zurückweichen erscheint relativ klar: Die SPD-Minister waren zu fast jedem Preis bereit, einen Bruch der Koalition zu vermeiden ${ }^{209}$. Die Alternative eines Rechtskabinetts sei, so wiederum Hilferding, „nämlich undenkbar, insbesondere im Hinblick auf die Arbeiterschaft im besetzten Gebiete, welche einem solchen die Gefolgschaft ver-

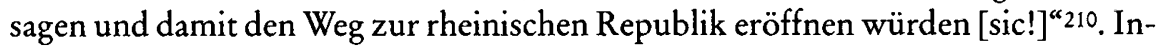
wieweit eine derartige Befürchtung, die vor dem Hintergrund des erstarkenden Separatismus gesehen werden muß, realistisch war, mag hier dahingestellt bleiben. Als Motiv für die sehr weitreichende Kompromißbereitschaft spielte die existentielle Furcht um den Bestand des Nationalstaates und um die Staatsform der Republik aber eine wichtige Rolle. Unabhängig von ihrem realen Gehalt beeinflußte so die im Raum stehende Gefahr eines Rechtsputsches das Verhalten der SPD.

Am nächsten Tag, dem 3. Oktober, mußte sich erweisen, inwieweit die inhaltliche Annäherung im Kabinett auch parlamentarisch gedeckt werden würde. In der DVP-Fraktion fand die vereinbarte Arbeitszeitformel mit Ausnahme von Stinnes einstimmige Billigung211. Die weitgehenden Zugeständnisse der sozialdemokratischen Minister stießen in der SPD-Fraktion hingegen auf Widerstände. Während die absehbare Ablösung Hilferdings kaum für Reaktionen sorgte und es in der bayerischen Frage keinen ernsthaften Widerspruch gegen die passive Linie Stresemanns gab, zeichnete sich rasch $a b$, daß ein sozialpolitisch unbeschränktes Ermächtigungsgesetz und somit eine Neuregelung der Arbeitszeit per Verordnung mit der SPD nicht zu machen war ${ }^{212}$. In der ersten Kabinettssitzung des Tages am Nachmittag teilte dann auch Stresemann mit, daß sowohl Müller als auch er selbst „zur Zeit hier keinen Ausweg mehr“ sähen ${ }^{213}$. Stresemann, der unter diesen Umständen keine Aussicht auf eine verfassungsdurchbrechende Zweidrittelmehrheit im Reichstag hatte ${ }^{214}$, lehnte erneut den während der Vortage mehrfach diskutierten Vorschlag ab, „als Kabinett vor den Reichstag zu treten und,

207 Protokoll der abendlichen Kabinettsitzung vom 2. 10. 1923; AdR Stresemann, Nr. 102, S. 452.

208 Ebd.

209 Winkler, Von der Revolution zur Stabilisierung, S. 630, spricht mit positiverer Wertung davon, daß die SPD-Minister „in der für sie besonders heiklen Arbeitszeitfrage zum zweiten Mal innerhalb weniger Tage über ihren Parteischatten gesprungen" seien und kontrastiert die Kompromißbereitschaft der Minister mit der Haltung der Fraktion.

210 AdR Stresemann, Nr. 102, S. 448.

211 Nach einem Rundschrciben an die DVP-Generalsekretäre (zwischen 3. und 6.10. 1923), zitiert ebd., S. 452, Anm. 20.

212 Vgl. auch Zitat aus Die Zeit, 4. 10. 1923, in AdR Stresemann, S. 454, Anm. 3.

213 Protokoll der gegen 16.30 Uhr beginnenden Fraktionssitzung; ebd., Nr. 104, S. 104; vgl. auch ebd.: „Der Abgeordnete Müller-Franken habe ihm zweimal ausdrücklich erklärt, daß die sozialpolitischen Fragen durch das Parlament geregelt werden müßten." Zentrum und DVP hätten sich demgegenüber „ablehnend“ gegenüber einer Regelung „sozialpolitische[r] Dinge“ „auf parlamentarischem Wege" geäußert.

${ }^{214}$ Eine Prüfung im Innenministerium Anfang Oktober erbrachte das Ergebnis, daß eine derartige Mehrheit notwendig sei. BA Berlin, R 1501, Nr. 17100, Bl. 2-4, Schreiben an Stresemann vom 4. 10. 1923 mit Gutachten. 
ohne Fraktionsbeschlüsse einzuholen, das vom Reichstag zu verlangen, was das Kabinett für nötig halte" 215 .

In dieser Situation rückte plötzlich ein in der Literatur weithin übersehener Kompromißvorschlag in den Mittelpunkt, wonach die Arbeitszeitfrage auf der Grundlage eines älteren Entwurfs des Arbeitsministeriums ${ }^{216}$ auf regulärem legislativen Wege gelöst werden solle, während andere soziale Maßnahmen in den Geltungsbereich des Ermächtigungsgesetzes fallen sollten ${ }^{217}$. Urheber war offenbar die DDP-Fraktion, aber auch im Zentrum fand dieser Ansatz Unterstützung ${ }^{218}$. Damit war im Prinzip bereits jene Formel auf dem Tisch, nach der dann zwei Tage später die Erneuerung der Großen Koalition gelang.

Vizekanzler Schmidt von der SPD versicherte in der für den Abend anberaumten Kabinettssitzung, daß „diese Lösung [...] für die Sozialdemokratie tragbar“ sei $^{219}$. Offenbar schwebte den SPD-Ministern vor, daß ihre Fraktion die Chance zu Abänderungsanträgen und damit auch zu einer Demonstration ,ihre[r] grundsätzliche[n] Anschauung "220 erhalten, dann jedoch die Schlußfassung eines Arbeitszeitgesetzes billigen werde. Die übrigen in die Diskussion eingreifenden Regierungsmitglieder, insbesondere auch der Kanzler sowie Arbeitsminister Brauns, der hier nicht der Linie der Zentrumsfraktion folgte, blieben freilich skeptisch. Stresemann hielt es sogar „für ausgeschlossen, daß seine Fraktion dem Herausbrechen [der Arbeitszeitfrage] zustimme“, erklärte sich aber dazu bereit, „es zu versuchen"221. Näheres zum Entscheidungsprozeß innerhalb der DVP und zum Verhalten Stresemanns ist nicht bekannt. Besonderen Einsatz für das Zustandekommen einer Einigung hat der DVP-Vorsitzende zu diesem Zeitpunkt nach dem Urteil Koch-Wesers freilich nicht gezeigt ${ }^{222}$. Möglicherweise gibt es hier einen $\mathrm{Zu}$ sammenhang mit dem Vertrauensvotum, das Stresemann am selben Tag von seiner Fraktion erhalten hat ${ }^{223}$.

Nach der Kabinettsberatung kam es zu einer bewegten Fraktionssitzung der SPD224. Die Frage, ob es auch eine "Ermächtigung in soz.pol. Dingen“ geben

215 Dieser Weg - so Stresemann - habe sich als ungangbar erwiesen. Protokoll der Kabinettssitzung; AdR Stresemann, Nr. 104, hier S. 455. Nach VZ, 4. 10. 1923 mo, S. 1f., „Wie es kam“ (Georg Bernhard), hier S. 2, wurde ein derartiges Vorgehen von den SPD-Ministern abgelehnt.

216 Vgl. Erläuterung in AdR Stresemann, S. 455, Anm. 1.

217 Vgl. auch Bericht Koch-Wesers vom 4. 10. 1923; BA Koblenz, Nl. Koch-Weser, Nr. 139, Bl. $179 \mathrm{f}$.

Demnach war eine Art von Mantelgesetz geplant. Die Zustimmung von Ebert und Marx, werde aber „vermutlich an Brauns und der Volkspartei scheitern“. Vgl. auch VZ, 4. 10. 1923 mo, S. 1, "Die Verhandlungen der Fraktionen“.

218 Vgl. Ge, 4. 10. 1923 (Nr. 275), S. 1, „Die frivole Krise“. Hier als Vermittlungsvorschlag der Zentrumsfraktion bezeichnet, der gegen vier Stimmen beschlossen worden sei. Kein Hinweis im Protokoll der Fraktionssitzung vom 3. 10.; Protokolle Zentrumspartei, Nr. 259, S. 482-485.

${ }_{219}$ AdR Stresemann, Nr. 105, S. 455.

220 So Sollmann. Ebd., S. 456.

221 Ebd., S. 458: „Der Reichsminister der Finanzen: Der Weg der gesetzlichen Regelung der Arbeitszeit sei also ungangbar, weil die Deutsche Volkspartei ihn nicht mitmache. - Der Reichskanzler: Er sei bereit, es zu versuchen."

222 Vgl. Bericht vom 4. 10. 1923: „Unverständlich aber ist es, wie leichten Herzens Stresemann von dem Versuche der Einigung mit der Sozialdemokratie sich hat abdrängen lassen und jetzt plötzlich der Kanzler einer bürgerlichen Mehrheit zu werden für möglich hält." BA Koblenz, Nl. KochWeser, Nr. 189, B. 181.

${ }^{223}$ AdR Stresemann, S. 458, Anm. 6.

224 Wichtigste Quelle ist ein Protokoll Giebels in ASD Bonn, Nl. Giebel, Kassette II, Mappe 3, Bl. 245 (die ebd. zu findende Datumsangabe 3.9.1923 ist offensichtlich falsch und wohl auf ein Versehen 
dürfe, wurde hier schließlich mit $61 \mathrm{zu} 54$ Stimmen verneint, wobei unklar ist, inwieweit sich die restlichen Fraktionsmitglieder der Stimme enthielten oder abwesend waren ${ }^{225}$. Partei- und Fraktionsvorsitzender Müller sowie Reichstagspräsident Löbe traten gegen eine derart gefaßte Ermächtigung auf, der preußische Innenminister Severing warb dafür, diese Bedingung zu akzeptieren. Erstaunlich ist, daß die im Kabinett noch ernsthaft erörterte Kompromißlösung, nach der allein die Arbeitszeitthematik aus dem Ermächtigungsgesetz herausgenommen werden solle, in der SPD-Fraktion anscheinend überhaupt nicht mehr diskutiert wurde. Ausschlaggebend hierfür war nach der späteren Aussage Sollmanns die auf die „Erklärung des Kanzlers“ gestützte Auffassung, „daß die deutsche Volkspartei diesen Weg ablehne“226. Vermutlich war inzwischen zudem bekannt geworden, daß die DVP-Fraktion die Kompromißlösung bereits verworfen hatte 227 .

In der letzten Kabinettssitzung dieses 3. Oktober war das Scheitern des ersten Kabinetts einer Großen Koalition nicht mehr abzuwenden 228. Nachdem Hilferding über das Abstimmungsergebnis seiner Fraktion berichtet hatte, machten Brauns und Oeser, offenbar im Auftrag ihrer Fraktionen, einen Versuch, die Ausklammerung der Arbeitszeitfrage aus dem Ermächtigungsgesetz als Kompromiß doch noch zu retten. Brauns, der selbst eher skeptisch war und wohl eher auf einen Bruch mit der SPD zusteuerte, wies dabei ausdrücklich auf das Einverständnis der Zentrumsfraktion hin 229 . Da aber Stresemann nochmals bestätigte, daß die DVP einer derartigen Lösung nicht zustimme, war das Ende des Kabinetts besiegelt. Der erneut auftauchende Vorschlag, die Entscheidung in einem Votum des Reichstags zu suchen, wurde von Stresemann abermals zurückgewiesen. Zum Schluß stellte der Kanzler das „Einverständnis des Kabinetts“ über die Demission fest. Kurz vor Mitternacht begab sich Stresemann zum Reichspräsidenten, teilte seinen Rücktritt mit - und wurde sofort mit der Neubildung einer Regierung beauftragt ${ }^{230}$.

Über die Hintergründe dieser schnellen Vorentscheidung ist kaum etwas bekannt. Zweifellos gab es für Ebert gute Gründe, einen zweiten Versuch mit Stresemann zu wagen. Die Person des bisherigen Kanzlers war in der kurzen Koalitionskrise innerhalb des Regierungslagers nie offen zur Disposition gestanden, ein Alternativkandidat war nicht in Sicht, und der enorme Druck der Ruhrfrage for-

Giebels zurückzuführen). Hinzu kommen diverse Presseberichte, v.a. FZ, 4. 10. 1923 mo/2, S. 1, „Die Arbeitszeitfrage“. Demnach gab eine Rede des Reichstagspräsidenten Löbe den Ausschlag für die Ablehnung. Vgl. auch Winkler, Von der Revolution zur Stabilisierung, S. 631 f. Nicht crwähnt bei Arns, Regierungsbildung.

225 ASD Bonn, Nl. Giebel, Kassette II, Mappe 3, Bl. 245. Dasselbe Abstimmungsergebnis wurde auch durch die Presse verbreitet.

226 Protokoll der um 22 Uhr beginnenden Kabinettssitzung; AdR Stresemann, Nr. 106, S. 460. Zuvor hatte Brauns gefragt, „ob der Weg der gesetzlichen Regelung der Arbeitszeit in der Fraktion nicht erörtert sei“.

227 Vgl. auch Winkler, Von der Revolution zur Stabilisierung, S. 632.

228 AdR Stresemann, Nr. 106, S. 459-462.

229 Ebd., S. 460: „Er habe vorher ausgeführt, daß die Zentrumsfraktion hierzu grundsätzlich bereit sei." Worauf "sich „vorher" bezieht, bleibt hier unklar. Zur andauernden Skepsis von Brauns vgl. ebd., S. 461.

230 Vgl. Stresemann, Vermächtnis 1, S. 141, Tagesnotizen: „Demission des Kabinetts in der Nacht nach Scheitern Verhandlungen über Arbeitszeitgesetz/ Von Ebert mit Neubildung betraut/ Henrich - !“ - Zur Regierungsbildung vgl. allgemein v.a. Arns, Regierungsbildung, S. 166-169; AdR Stresemann, S. XXXVf.; Kastning, Sozialdemokratic, S. $118 \mathrm{f}$. 
derte Kontinuität in der politischen Führung. Andererseits darf nicht übersehen werden, daß die sofortige Festlegung Eberts die Spielräume der späteren Regierungsbildung verengte. Eine erneute Kanzlerschaft Stresemanns stand insbesondere der Möglichkeit im Wege, nun doch wieder eine Weimarer Koalition zu bilden, die im Reichstag über eine passable Mehrheit - 280 von 459 Mandaten verfügt hätte. Eine derartige Lösung blieb freilich trotz der vielfachen Kritik am Verhalten der DVP-Fraktion auch in der politischen Öffentlichkeit außerhalb jeder Diskussion. Ob ein entsprechender Impuls des Reichspräsidenten hier für Bewegung gesorgt hätte, mag dahingestellt bleiben.

In einer Situation höchster innenpolitischer Spannung, vor dem Hintergrund der weiterhin galoppierenden Hyperinflation, einer extrem unflexiblen französischen Haltung im Ruhrkonflikt, erstarkender separatistischer und extremistischer Bewegungen und einer neuen Welle der Parlamentarismuskritik herrschte nun zwei Tage lang Unklarheit über die Art und Weise der Regierungsbildung und vor allem über den Charakter des neuen Kabinetts. Die personell modifizierte Fortsetzung der Großen Koalition wurde erst nach einer für die zeitgenössische Öffentlichkeit und auch für den Historiker kaum noch nachzuvollziehenden Abfolge von Besprechungen und Lösungsvorschlägen erreicht. Ein Blick auf diese Vorgänge ist vor allem aus zwei Gründen instruktiv: Zum einen mußte sich jetzt erweisen, wie stark der im August revitalisierte Wille zur parlamentarischen Regierungsbildung angesichts der akuten Krise noch ausgeprägt war, zum anderen verband sich die Regierungsbildung mit der Weichenstellung für ein umfassendes Ermächtigungsgesetz.

Die Grundfrage war, ob es eine parteimäßig gebundene Regierungsbildung geben werde oder ob - analog zur Situation im November 1922 - erneut der Versuch zu einem „überparteilichen“ Kabinett der Persönlichkeiten unternommen werden sollte. Stresemann setzte zunächst klar auf den letztgenannten Weg, der auch von Rheinbaben, dem Leiter der Reichskanzlei, favorisiert wurde 231 , und kündigte dies vermutlich bereits am 3. Oktober gegenüber dem Reichspräsidenten an ${ }^{232}$. Entsprechende Verhandlungen beherrschten den 4. Oktober, wobei Stresemann demonstrativ auf Fühlungnahme mit den Fraktionen verzichtete ${ }^{233}$. Neben einigen „Wirtschaftlern“234 - Friedrich Minoux, Generaldirektor im Stinnes-Konzern ${ }^{235}$, Otto Wiedfeldt, der ehemalige Vorsitzende des Krupp-Direktoriums und aktuelle deutsche Botschafter in Washington, Hjalmar Schacht, zum damaligen

231 Vgl. Rheinbaben, Viermal Deutschland, S. 188-190. Vgl. hierzu auch AdR Stresemann, S. XXXV. Rheinbaben warb bei Stinnes und DNVP-Politikern um Unterstützung. Zur späteren Demission Rheinbabens vgl. unten S. 281.

${ }^{232}$ Erschließbar aus Stresemann, Vermächtnis 1, S. 141, Tagesnotizen.

${ }^{233}$ Vgl. z. B. VZ, 4. 10. 1923 ab, S. 1, „Stresemanns zweites Kabinett“.

${ }^{234}$ Vgl. Bericht Koch-Wesers vom 4. 10. 1923: „Anscheinend will er in erster Linie Wirtschaftler hincinnehmen, ohne einzusehen, dass gerade derjenige, der einem überpolitischen Kabinett angehört, in noch höherem Masse ein politischer Kopf sein muss, als der Minister eines parteipolitischen Kabinetts, der mit seiner Fraktion in Fühlung ist." BA Koblenz, Nl. Koch-Weser, Nr. 139, Bl. 180. Tagesnotiz in Stresemann, Vermächtnis 1, S. 145, nennt die ersten drei Namen. Tagesnotiz ebd., S. 141, nennt Henrich offenbar als Ministerkandidaten.

${ }_{235}$ Minoux war wohl Favorit von Stinnes für die Kanzlerschaft. Vgl. Meier-Welcker, Seeckt, S. 390 f.; zum baldigen politischen Zerwürnis zwischen Minoux und Stinnes vgl. Feldman, Stinnes, S. 890893. 
Zeitpunkt Direktor der Darmstädter und Nationalbank, der Industrielle Erich Rabbethge ${ }^{236}$ und erneut wohl Otto Henrich - waren auch mehrere "politische“ Kandidaten für ein verkleinertes Kabinett im Gespräch, so die bisherigen Minister Geßler, Brauns, Luther, Sollmann sowie der preußische Ministerpräsident Otto Braun $^{237}$. Die politische Bandbreite der angestrebten Regierungsbildung umfaßte damit auch die Sozialdemokratie.

Zum zweiten Male binnen eines Jahres wurde somit der Versuch gemacht, den Dissens innerhalb einer potentiellen Großen Koalition durch eine Entparlamentarisierung der Regierungsbildung zu überwinden. Das neue Kabinett sollte als Art Notregierung offenbar nur wenige Personen umfassen. Eine gewisse Nähe zur Vorstellung eines "Direktoriums“ ist unverkennbar. Daß gerade Stresemann, der immer wieder ein hohes $\mathrm{Maß}$ an pragmatischem Parlamentarismusverständnis bewies, zäh am Konzept einer überparteilichen Regierungsbildung und an der Hoffnung auf die staatspolitische Verantwortungsbereitschaft führender "Wirtschaftler" festhielt, mag erstaunen. Vermutlich spiegeln sich hier die auch bei Stresemann fortbestehenden Reserven gegen eine parteienstaatliche Organisation des parlamentarischen Systems. Ausschlaggebend aber war wohl das Verhalten seiner eigenen Fraktion, die sich klar gegen das Fortbestehen einer Großen Koalition in der bisherigen Form gewandt hatte. Möglicherweise versuchte Stresemann mit seinem Anlauf zur Kabinettsbildung die ursprüngliche Forderung der DVP-Fraktion nach einem Regierungseintritt der DNVP zu unterlaufen und gleichzeitig den „Putschversuch“ des schwerindustriellen Flügels seiner Fraktion aufzufangen, indem er sich um führende Wirtschaftsvertreter und insbesondere um Minoux bemühte.

Glaubt man einer Tagesnotiz Stresemanns, die von „tiefste[r] Depression“ spricht, war die Stimmung freilich von Anfang an ungünstig. Ähnlich wie bereits Cuno im November 1922 fand der DVP-Vorsitzende wenig Bereitschaft bei den ins Auge gefaßten Ministerkandidaten aus der Wirtschaft. Lediglich Schacht sagte schließlich zu und hätte auch den Platz des Finanzministers im Kabinett Stresemann II eingenommen, wenn dies nicht am 6. Oktober in letzter Minute durch eine Intrige aus dem betroffenen Ministerium verhindert worden wäre 238 . $\mathrm{Ob}$ für die Absagen lediglich die abschreckenden „Spuren Cunos" verantwortlich waren, wie die Germania am 4. Oktober meinte ${ }^{239}$, erscheint zweifelhaft. Vielmehr gibt es Hinweise darauf, daß Stresemann selbst die Ursache der Verweigerung gewesen sein könnte. Vermutlich spekulierten einige der Ministerkandidaten aus der Wirtschaft auf eine weiter nach rechts gerichtete Regierungsbildung unter einem anderen Kanzler. In diesem Zusammenhang spielte auch das Verhalten der DNVP eine Rolle, die am Morgen des 4. Oktober in einem markigen Aufruf ein Ende der „Kompromißpolitik“ mit dem „Marxismus“ forderte und nach einer Regierung

236 Nach NPZ, 5.10,1923 mo, S. 1, „Dr. Stresemanns Bemühungen um die Regierungsbildung“, war

Rabbethge - „Demokrat, Besitzer von Sämereien im Anhaltischen und Vertrauensmann des Herrn

Ebert“ - auch schon bei der Regierungsbildung Cuno im Gespräch gewesen. Nach Deutscher Wirtschaftsführer, S. 1754, stammte Rabbethge aus der Zuckerindustrie.

237 Vgl. diverse Pressemeldungen dieser Tage sowie den Bericht Koch-Wesers vom 4. 10. 1923; BA

Koblenz, Nl. Koch-Weser, Nr. 139, Bl. 180.

$238 \mathrm{Vgl}$. Anm. 273.

${ }^{239} \mathrm{Ge}, 4$. 10. 1923, S. 1, „Ein nichtparlamentarisches Kabinett?“ 
rief, „die sich bewußt auf die nationalen Kräfte in allen Volksschichten stützt“240. Am Abend erteilte die DNVP dann einer erneuten Kanzlerschaft Stresemanns durch einen Fraktionsbeschluß eine Absage ${ }^{241}$.

Die Problematik von Stresemanns Plan für ein „Kabinett der Köpfe“ lag darin, $\mathrm{da}$ es fließende Übergänge zu den kursierenden Spekulationen über eine notwendig werdende „Diktatur" gab. Allseits wurde erwartet, daß eine „überparteiliche“ Regierung bzw. ein „Direktorium“ mit einem Verordnungsregime gekoppelt werde. Dabei kam sicher auch eine gewisse Eigendynamik der in den letzten Tagen koalitionspolitisch instrumentalisierten Diskussion um eine Ermächtigung zur Geltung. Ein derartiges verfassungsdurchbrechendes Gesetz aber bedurfte, darüber war man sich in Politik und Staatsrecht weitgehend einig, einer parlamentarischen Zweidrittelmehrheit (306 von 459 Abgeordneten). Eine gemeinsame Stellungnahme des Innen- und Justizministeriums an den Reichskanzler bestätigte am 4. Oktober ausdrücklich diese Rechtsauffassung und hielt für den Fall einer parlamentarischen Verweigerung eine Reichstagsauflösung für statthaft ${ }^{242}$. Offenbar hatte es zuvor eine entsprechende Anfrage des Kanzlers gegeben; inwieweit dieser kurzzeitig - wie eine Bemerkung Koch-Wesers nahelegt - mit dem Gedanken der Auflösung und darüber hinaus auch mit einer verfassungswidrigen Verzögerung von Neuwahlen gespielt hatte ${ }^{243}$, läßt sich daraus freilich nicht erschließen.

Ein Kabinett der Persönlichkeiten war - sollte es eine realistische Überlebenschance besitzen - auf die Unterstützung der SPD angewiesen. Es überrascht daher nicht, daß Stresemann am 4. Oktober dem bisherigen Innenminister Sollmann anbot, sein Ressort fortzuführen, was dieser freilich nach Rücksprache mit der Fraktionsführung umgehend ablehnte ${ }^{244}$. Nach den Vorgängen der letzten Tage und der damit verbundenen Erbitterung innerhalb der Sozialdemokratie war eine andere Entscheidung auch kaum denkbar ${ }^{245}$.

240 Im Kontext: „Wie lange noch?/ Die Losung des Tages heißt: das Steuer muß nach rechts geworfen werden!/ Die Koalitionsparteien des Reichstages aber antworten: es soll weiter gewurstelt werden./ Der Marxismus hat Deutschland ruiniert. Er hat abgewirtschaftet. Die bürgerlichen Regierungsparteien halten ihn künstlich am Leben. Sie wagen nicht, den Trennungsstrich zu ziehen. Es sinkt Deutschland in Not und Verderben!/ Wie fordern Klarheit! Schluß mit der Kompromißpolitik! Fort mit den Sozialisten aus der Regierung! Wir verlangen endlich eine Regierung, die sich bewußt auf die nationalen Kräfte in allen Volksschichten stützt." Zitiert nach NPZ, 5. 10.1923 mo, S. 1, „Gegen den Marxismus“. Gekürzt auch in Stresemann, Vermächtnis 1, S. 145. Die Frage, was die DNVP nun wirklich wollte, bleibt ein Forschungsdesiderat. Sehr wenig hierzu in Hertzman, DNVP, S. $199 \mathrm{f}$.

241 So FZ, 5. 10. 1923 ab, S. 1, „Die Deutschnationalen gegen Stresemann“. Die DVP sei „bündig“ von dieser Entscheidung informiert worden. Vgl. auch Arns, Regierungsbildung, S. 166.

242 BA Berlin, R 1501, Nr. 17100, Bl. 2-4, Zitat Bl. 3.

${ }^{243}$ BA Koblenz, N1. Koch-Weser, Nr. 139, Bericht vom 20. 10. 1923, Bl. 187, rückblickend zur Frage, was geschehen wäre, wenn das Kabinett Stresemann II nicht zustande gekommen wäre: „Der Gedanke Stresemanns, in diesem Fall den Reichstag aufzulösen und die jetzt unmöglichen Neuwahlen verfassungswidrig hinauszuschieben, war undurchführbar. Wenn gegen die Verfassung regiert wird, so ist der Einfluss der Mittelparteien dahin. Viele werden sich fragen, ob wenn einmal eine Diktatur da sein soll, nicht besser Herr von Seeckt am Platze wäre“. Koch-Weser behauptet anschließend, „an allen Stellen, namentlich auch beim Reichspräsidenten und beim Reichskanzler auf das dringendste" vor einer derartigen Lösung gewarnt zu haben.

${ }^{244}$ So VZ, 5. 10. 1923 mo, S. 1, „Die Kabinettsbildung abgeschlossen“. Vgl. auch Arns, Regierungsbildung, S. 167.

245 BA Koblenz, Nl. Koch-Weser, Nr. 139, Bericht vom 4. 10. 1923, Bl. 180f. zu Stresemanns Regierungsbildung: „Für sein neues Kabinett kann er besten Falles auf ein schwaches Vertrauensvotum rechnen, wobei die Haltung selbst der Sozialdemokraten noch keineswegs geklärt ist. Niemals 
Ohne sozialdemokratische Unterstützung für ein Ermächtigungsgesetz blieb, wollte man ein zeitweises Verordnungsregime installieren, noch der Weg über Artikel 48, der ja bereits seit Herbst 1922 vereinzelt als Instrument allgemeiner Gesetzgebung genutzt worden war. Das Heranziehen des „Diktaturparagraphen “ als Ersatz für ein Ermächtigungsgesetz aber hätte alle bisherigen Dimensionen seiner Anwendung gesprengt und wurde - wie Koch-Weser berichtet - von Ebert auch explizit abgelehnt ${ }^{246}$. Daß eine derartige Option in parlamentarischen Kreisen bereits ernsthaft diskutiert wurde, legen die Ausführungen Wirths am 4. Oktober in der Zentrumsfraktion nahe. Der ehemalige Reichskanzler warnte eindringlich davor, daß die Ausschaltung der Verfassung die Möglichkeit zu „Abenteuer[n]“ gebe $^{247}$. In diesem Zusammenhang muß auch berücksichtigt werden, daß mit der Notverordnung vom 26. September 1923 der militärische Ausnahmezustand über das Reich verhängt worden war. Eventuelle Proteste aus der Arbeiterschaft gegen eine sozialpolitisch restriktive Verordnungspolitik auf der Grundlage des Artikels 48 hätten unter diesen Umständen möglicherweise zu einer Eskalation geführt. Des weiteren ist zu bedenken, daß mittelfristig auch ein auf Artikel 48 gestütztes Verordnungsregime zumindest die Tolerierung des Reichstags benötigte, der jederzeit die Aufhebung erlassener Verordnungen verlangen konnte. Geradezu zwangsläufig mußte hier wiederum der Gedanke einer Parlamentsauflösung zum Zwecke der legislativen „Handlungsfreiheit“248 ins Spiel kommen. Diese bereits auf das Präsidialregime der letzten Weimarer Jahre hindeutende Option wurde auch von Rheinbaben vertreten, der allerdings auf den Widerstand von Stresemann traf 249 .

Parallel zu Stresemanns Bemühungen um ein überparteiliches Kabinett erfolgte freilich auch ein erster Anlauf zu einer parlamentarischen Regierungsbildung. In einer durchaus kontroversen Diskussion am Morgen des 4. Oktober scheint in der Zentrumsfraktion die Tendenz für eine parlamentarisch gebundene Regierung die Oberhand gewonnen zu haben ${ }^{250}$. Diese Position wurde insbesondere von Wirth vorgetragen, der treffend bemerkte, daß eine „parteilose Regierung [...]

aber kann er erwarten, dass er etwa das Ermächtigungsgesetz mit der erforderlichen 2/3 Mehrheit durchsetzt. Ohne dieses kann er nicht regieren."

246 BA Koblenz, Nl. Koch-Weser, Nr. 139, Bl. 181: „Auf Grund des Artikels 48 ihm ausserordentliche Vollmachten gegen das Parlament zu geben, ist der Reichspräsident - wie er uns sagte - nicht bereit. Es wäre auch verfassungswidrig."

247 Im Kontext: „Man kann nicht sagen, der Reichspräsident nimmt die Diktatur. $\ 48$ der Verfassung bekäme die Bedeutung, die Verfassung auszuschalten. Solche Möglichkeiten geben Abenteuer." Protokolle Zentrumspartei, Nr. 260, S. 486.

${ }^{248}$ So Rheinbaben, Viermal Deutschland, S. 189, mit bezeichnender Anspielung auf den preußischen Verfassungskonflikt: „Mein Rat bedeutete, daß eine solche Regierung vom Reichspräsidenten die Auflösungsorder verlangen müßte, falls der Reichstag sie in dieser für das Vaterland so bedrohlichen Lage zu stürzen versuchte [...] In vier Monaten konnte Ordnung geschafft und die notwendige Gesetzgebung - selbstverständlich musste später der Reichstag vor die Frage der ,Indemnität gestellt werden - durchgeführt sein."

249 Ebd., S. 189; IfZ München, Nl. Seeckt, Stück 72, Brief von Rheinbaben an Seeckt vom 16. 10. 1923 :

Der Rücktritt sei „in Wahrheit [erfolgt], weil ich meinem bisherigen Chef gegenüber mit meinen Ratschlägen nicht durchgedrungen bin und er, als die große Koalition wieder zustandegekommen war, mit schon nicht mehr sanfter Hilfe gewisser Fraktionskollegen sich einen anderen an meinen Platz wünschte“. Vgl. auch Turner, Stresemann, S. 123.

250 Protokolle Zentrumspartei, Nr. 260, S. 486 f. Ebd. auch zum folgenden. 
Schwäche der Parteien" sei251. In diesem Zusammenhang sprach er auch die oben zitierte Warnung vor einem Gebrauch des Artikels 48 aus. Die Germania erklärte sich am selben Morgen im Namen der Zentrumspartei klar für eine parlamentarische Regierungsbildung252. Eine ähnliche Willensbildung erfolgte in der DDPFraktion. Zwar hatte sich - so wiederum Koch-Weser - Petersen in der morgendlichen Fraktionssitzung "mit der neuen Wendung der Dinge zunächst abgefunden“ und „unbefangen eine neue Ideologie vor[getragen], nach der es jetzt um den Kampf gegen den konservativen Dogmatismus der Sozialdemokratie gehe“. Auf Druck der Fraktion sei Petersen freilich "veranlasst“ worden, „sich noch um die Wiederherstellung der alten Koalition zu bemühen "253. Der Reichspräsident war offenbar rasch für diesen Versuch gewonnen, während gleichzeitig Gespräche mit der SPD aufgenommen wurden ${ }^{254}$. Reserviert reagierte nach Koch-Weser allerdings Stresemann, „der seine Bemühungen um Bildung eines neuen Kabinetts fortsetzen wollte". Dieser Versuch, wieder eine parlamentarisch verankerte Große Koalition herzustellen, scheiterte freilich vorerst daran, daß die DVP-Fraktion ihre Ablehnung signalisierte 25 .

Am Abend des 4. Oktober war, wie Müller in einer Fraktionssitzung der SPD feststellte, ,immer noch alles unklar"256. Der erste Anlauf für eine parlamentarische Regierungsbildung war gestoppt, und nach Informationen aus dem Reichstag standen Stresemanns Bemühungen um ein überparteiliches Kabinett trotz mehrerer Absagen kurz vor dem Abschluß257. Richtungsweisend für den folgenden Tag wurden nun allerdings das definitive Nein der DNVP-Fraktion zu einer Fortführung der Kanzlerschaft Stresemanns sowie die klaren Äußerungen Müllers gegenüber Stresemann, daß die SPD einer überparteilichen Regierung kein Vertrauensvotum geben werde 258 .

Inwieweit der DVP-Vorsitzende unter diesen Umständen vielleicht doch die "offene Feldschlacht“" vor dem Reichstag und eventuell eine anschließende Reichstagsauflösung ins Auge faßte 259 , mag hier dahingestellt bleiben. Entscheidende Bedeutung gewann nun vielmehr eine erneute Initiative der DDP für eine parlamentarische Regierungsbildung. Obgleich der Partei- und Fraktionsvorsitzende Petersen noch in der abendlichen Fraktionssitzung die Auffassung vertreten hatte, „man dürfe dem Reichspräsidenten und dem Reichskanzler nicht in die

251 Ebd., S. 486. Zur Rolle Wirths Anfang Oktober 1923 vgl. auch Hörster-Philipps, Wirth, S. $290 \mathrm{f}$. Küppers, Wirth, geht hierauf nicht ein.

$252 \mathrm{Ge}, 4$. 10. 1923 (Nr. 275), S. 1f., „Die frivole Krise“. Sehr scharf wird in diesem Artikel die DVP kritisiert.

253 BA Koblenz, Nl. Koch-Weser, Nr. 139, Bericht vom 5. 10. 1923, Bl. 182.

${ }^{254}$ Tag, 5. 10. 1923, S. 1, „Die neuen Pläne Stresemanns“. Als Begründung heißt es: „[...] da man sich offenbar noch nicht überall von dem Gedanken der Großen Koalition trennen kann". Zum Drängen bei Ebert am 4.10. vgl. auch NPZ, 5. 10. 1923 mo, S. 1.

255 Eine Aufzeichnung Koch-Wesers vom 5. 10.1923 erwähnt „Widerspruch Scholz's, der Stresemann nicht in seinen Bemühungen stören wollte". BA Koblenz, Nl. Koch-Weser, Nr. 139, Bl. 182.

256 ASD Bonn, Nl. Giebel, Kassette II, Mappe 3, Bl. 250.

${ }^{257}$ NPZ, 5. 10. 1923 mo, S. 1. In diesem Sinne auch Rheinbaben, Viermal Deutschland, S. 191.

258 Vgl. ASD Bonn, Nl. Giebel Kassette II, Mappe 3, Bl. 251-253, Notizen zur Fraktionssitzung am 5.10.: „Müller: gestern abend Rücksprache [?] Kanzler. Kein Zweifel gelassen, daß wir kein Vertrauensvotum. keine Ermächtigung, weil wir nicht vertreten sind." Vgl. auch Arns, Regierungsbildung, S. 167.

259 Darauf deutet der Bericht Koch-Wesers vom 20. 10. 1923; BA Koblenz, Nl. Koch-Weser, Nr. 139, Bl. 187. 
Kabinettsbildung hineinreden“, setzten sich jetzt jene Kräfte unter den Demokraten durch, die mit Nachdruck eine Wiederherstellung der Großen Koalition anstrebten $^{260}$. Am Morgen des 5. Oktober verabschiedete die DDP-Fraktion eine Erklärung, mit der sie jeglichen Vertrauensbeweis für ein überparteiliches Kabinett ablehnte, wenn nicht nochmals ein Versuch zur Großen Koalition unternommen werde ${ }^{261}$. Im Anschluß trugen Petersen und Koch-Weser diese Forderung Stresemann vor ${ }^{262}$.

Unklar ist, ob dieser von der Forschung bisher übersehene Vorstoß der DDP tatsächlich allein ausschlaggebend für den Abbruch einer überparteilichen Regierungsbildung war, wie Rheinbaben in seinen Erinnerungen behauptet ${ }^{263}$, oder ob er sich, wie Koch-Weser in seinen Notizen vermerkte, "mit Ueberlegungen Stresemanns" „begegnete“, „der sein neues Kabinett nicht zustande bringt, und wenn er es zustande bringt, weder darauf rechnen kann, dass er eine Mehrheit im Parlament bekommt, noch dass der Reichspräsident ihm die Auflösung des Reichstags konzediert" ${ }^{264}$. Fest entschlossen zur Wiederherstellung der Großen Koalition war am 5. Oktober auch die Zentrumsfraktion. Ein bemerkenswerter Beschluß zeigt sogar, daß die Fixierung auf ein Ermächtigungsgesetz hier keineswegs absolut war. Das Zentrum solle, so wurde festgelegt, auch dann in eine Regierung der Großen Koalition eintreten, wenn keine Einigung über ein Ermächtigungsgesetz zustande kommen sollte: „Die Regierung müsse dann im beschleunigten Verfahren die notwendigen Gesetze durchbringen, wozu sich dann mit einfacher Mehrheit die Möglichkeiten ergäben. "265 Im Gegensatz zum Vortag stieß der nun von Stresemann unterstützte neuerliche Anlauf für eine Große Koalition auch nicht mehr auf den kategorischen Widerspruch der DVP-Fraktion. Nach Presseberichten setzte sich hier am 5. Oktober "unter ziemlich lebhaften Auseinandersetzungen" eine neue Fraktionsmehrheit durch, wobei die Absage der DNVP vom Vorabend ${ }^{266}$ vermutlich eine ausschlaggebende Rolle spielte.

Im Laufe der interfraktionellen Verhandlungen einigte man sich nun im Prinzip relativ rasch auf jenen Vorschlag, der bereits am 3. Oktober im Raume gestanden

260 Ebd.

261 „Die Deutsche Demokratische Partei richtet an den Reichspräsidenten und an den Reichskanzler die dringende Aufforderung, die Versuche zur Wiederherstellung der Großen Koalition nochmals ernstlich vorzunehmen. Wird ein solcher Versuch nicht unternommen, so sieht die Fraktion sich nicht in der Lage, einem sogenannten unpolitischen Kabinett das Vertrauen auszusprechen." Zitiert nach VZ, 5. 10. 1923 ab, S. 1, „Ein Beschluß der Demokraten“. Nach dem Bericht KochWesers vom 5. 10. 1923 kam es "nach kurzer Beratung“ zum Fraktionsbeschluß. BA Koblenz, Nl. Koch-Weser, Nr. 139, Bl. 183.

${ }^{262}$ Vgl. Rheinbaben, Viermal Deutschland, S. 191: „Da, am nächsten Morgen, griff das Schicksal in Gestalt der beiden Vorsitzenden Koch (Weser) und Petersen der Demokratischen Partei ein. Sie betrachteten sich gewissermaßen als, Gralshüter der Demokratie', und mit Sorge dachten sie an die Möglichkeit, daß die in Aussicht genommene ,Regierung der Köpfé eine Minderheitsregierung sein könnte, die den Regeln der Demokratie nach ihrer Auffassung nicht entspräche. Sie würde im Reichstag kämpfen, ihn womöglich auflösen müssen und, o Schrecken über Schrecken, wahrscheinlich die Gegnerschaft der Sozialdemokratischen Partei auf sich ziehen. Als beide Herren nach dreiviertel Stunden Stresemann verließen - ich selbst wurde vorsorglich zu dieser Unterredung nicht zugezogen -, war Stresemann bereit, noch einmal den Versuch des Zusammenleimens der Großen Koalition mit den Sozialdemokraten zu versuchen“.

263 Ebd.

${ }_{264}$ BA Koblenz, Nl. Koch-Weser, Nr. 139, Bericht vom 5. 10. 1923, Bl. 183.

265 Protokolle Zentrumspartei, Nr. 262, S. 490.

266 Vgl. auch Arns, Regierungsbildung, S. 168. 
hatte: die Verabschiedung eines breit gefaßten finanz-, wirtschafts- und sozialpolitischen Ermächtigungsgesetzes unter Ausklammerung der Arbeitszeitfrage ${ }^{267}$. Gleichzeitig wurde auf Vorschlag der DDP eine Konferenz von Sachverständigen aus den betroffenen Fraktionen einberufen, die bis in die frühen Morgenstunden eine Kompromißformel für ein Arbeitszeitgesetz ausarbeitete ${ }^{268}$. Demnach sollte es zu einer "Neuregelung der Arbeitszeitfrage unter grundsätzlicher Festhaltung des Achtstundentages als normalen Arbeitstag" kommen"269. Eingeräumt wurde freilich „die Möglichkeit der tariflichen oder gesetzlichen Überschreitung der jetzigen Arbeitszeit im Interesse einer volkswirtschaftlich notwendigen Steigerung und Verbilligung der Produktion"270. Eine gewisse Ähnlichkeit zu dem im November 1922 in einem interfraktionellen Ausschuß gefundenen Ergebnis ${ }^{271}$ ist unverkennbar, die jetzigen Formulierungen waren allerdings konkreter.

Nach Billigung der Vereinbarung in den Fraktionen"272 war der Weg frei für das zweite Kabinett Stresemann. Die personellen Veränderungen betrafen vor allem das Wirtschafts- und das Finanzministerium. Nachdem Raumer bereits am 2. Oktober zurückgetreten war, wurde jetzt auch Hilferding abgelöst. Damit war eine der Hauptforderungen der DVP-Fraktion vom 2. Oktober erfüllt worden. Dies gilt umso mehr, als kein Sozialdemokrat die Nachfolge Hilferdings antrat, sondern der parteilose bisherige Ernährungsminister Hans Luther 273. Neuer Wirtschaftsminister wurde der ebenfalls parteilose Josef Koeth, ehemals Offizier im Dienste der Kriegswirtschaft und 1918/19 Staatssekretär des Demobilmachungsamtes ${ }^{274}$. So entsprach die Besetzung des Finanz- und Wirtschaftsministeriums doch noch dem Leitbild einer „überparteilichen" Regierungsbildung. Das Ernährungsministerium blieb vorerst vakant; am 23. Oktober wurde es dann mit dem bisherigen DNVP-Abgeordneten Graf von Kanitz besetzt, der das Amt gegen den Willen seiner Partei antrat und umgehend seinen Austritt erklärte ${ }^{275}$. Alle anderen

267 Nach ebd. fanden nachmittags und abends um 19 Uhr Besprechungen statt. Kurzes Protokoll vom 5. 10. 1923 über eine Besprechung mit Scholz, Petersen, Koch-Weser, Marx und Müller in PA AA Berlin, Nl. Stresemann, Nr. 2, H154170; Bericht von Marx in der Zentrumsfraktion am 5.10.; Protokolle Zentrumspartei, Nr. 262, S. 488-490.

268 Bericht von Marx in der Zentrumsfraktion am 5. 10. 1923; ebd., Nr. 263, S. 491 f. Vgl. auch Stresemann, Vermächtnis 1, S. 145, Tagesnotizen: „Verhandlungen mit Hermann Müller und Ebert. Nachts 3 Uhr Einigung betr. Arbeitszeit.“

269 So der Herausgeberkommentar ebd.

270 Bericht von Marx in der Zentrumsfraktion am 5.10. 1923; Protokolle Zentrumspartei, Nr. 263, S. 491.

271 Vgl. oben S. $155 \mathrm{f}$.

272 Zur SPD vgl. Aussage Müllers in der Fraktionssitzung: „Ermächtigung bedeutet zwar ein Stück Diktatur: aber statt dieser legalen Diktatur käme die der Gewalt!“” „Ermächtigungsgesetz: Grundrechte ausschalten, um in Eigentumsrechte u. wohlerworbene Rechte eingreifen [sic!] können.“ ASD Bonn, Nl. Giebel, Kassette II, Mappe 3, Bl. 254-255. Teilweise zitiert in AdR Stresemann, S. 485, Anm. 2; Winkler, Von der Revolution zur Stabilisierung, S. 638.

273 Die eigentlich vorgesehene Berufung Schachts war zuvor gleichsam in letzter Minute durch eine Intrige aus dem Finanzministerium zu Fall gebracht worden. Schacht war 1915 vorgeworfen worden, in seiner Position als Mitglied der Finanzverwaltung des Generalgouvernements die Interessen der Dresdner Bank wahrgenommen zu haben, und daraufhin aus dem Dienst in Belgien ausgeschieden. Stresemann und Ebert fürchteten jetzt eine Wiederholung des Falles Müller-Bonn. Vgl. Pentzlin, Hjalmar Schacht., S. 27f., 48-50; AdR Stresemann, S. XXXV und S. 500f. Anm. 1.

${ }^{274}$ Nach AdR Stresemann, S. XXXV, war Koeth „bekannt wegen guter Zusammenarbeit mit der SPD“ in seiner Zeit als Staatssekretär.

275 Vgl. die in der Presse veröffentlichte Erläuterung von Kanitz, z.B. in VZ, 23. 10. 1923 ab, S. 1, „Der Ernährungsminister an die Landwirte“. Zum Hintergrund vgl. auch eine Erklärung der 
Ministerien gingen an die bisherigen Ressortinhaber. Insgesamt wurde durch die Kabinettsneubildung vor allem die Stellung der SPD geschwächt, die nur noch über drei Ministerien (Inneres, Justiz und Wiederaufbau) verfügte und die hinsichtlich der Währungsstabilisierung einen erheblichen Einflußverlust erlitt. Auch wurde der bisher von Wiederaufbauminister Schmidt ausgefüllte Posten des Vizekanzlers nicht mehr besetzt. Die DVP war neben Stresemann nur noch mit dem Staatssekretär der Reichskanzlei im Kabinett vertreten. Allerdings war die Ablösung Raumers im Sinne der Fraktionsmehrheit der DVP gewesen, und Nachfolger Koeth stand der DVP durchaus nahe. Die Führung der Reichskanzlei besetzte Stresemann zunächst erneut mit Rheinbaben. Kurz darauf zog der Kanzler jedoch die Konsequenz aus den Vorgängen Anfang Oktober, bei denen Rheinbaben eine etwas zwielichtige Rolle gespielt hatte276, und berief am 17. Oktober mit Adolf Kempkes einen seiner treuesten Anhänger innerhalb der Fraktion zum neuen Staatssekretär.

Noch am 6. Oktober präsentierte Stresemann sein neues Kabinett im Reichstagsplenum und holte dabei auch jene Regierungserklärung zur Aufgabe des passiven Widerstands und zur Verhängung des militärischen Ausnahmezustands nach, die am 2. Oktober hatte verschoben werden müssen277. Auch wenn dem Kanzler vielfach erneut eine starke Rede bescheinigt wurde ${ }^{278}$, läßt bereits der insgesamt defensive Duktus eine gewisse politische Schwächung erkennen. Der Koalitionskonflikt wurde sehr allgemein mit „Differenzen“ in der Frage erklärt, nach welchen "Grundlinien“ „in bezug auf die Wirtschaft, in bezug auf die Finanzen und auf dem Gebiet der Sozialpolitik" auf der Grundlage des angestrebten Ermächtigungsgesetzes gehandelt werden solle 279 . Vehement wies Stresemann die Parlamentarismuskritik aus Teilen der Wirtschaft zurück und bezog sich dabei auf eine Stellungnahme des Verbands der Eisen- und Stahlindustrie, die am 5. Oktober von einem „Versagen“ des Parlamentarismus gesprochen hatte 280 . Dem hielt er ein Versagen der Wirtschaft entgegen, „indem sie sich in ihren führenden Persönlichkeiten nicht dem Staat zur Verfügung gestellt hat" 281 . Dennoch räumte auch der Kanzler eine „berechtigte Kritik“ am Parlamentarismus ein, wobei er wiederum auf den vermeintlich zu großen Einfluß der Fraktionen abstellte282. Die Ausführungen zur künftigen Politik der Reichsregierung blieben erneut vage und liefen - hiervon wird zu Beginn des nächsten Kapitels zu sprechen sein - auf die Begründung eines Ermächtigungsgesetzes zu²83.

„Deutschnationalen Pressestelle“, z.B. in NPZ, 23. 10. 1923 mo, S. 2, „Der Austritt des Grafen Kanitz aus der Deutschnationalen Volkspartei“.

276 Vgl. oben S. 177.

277 Verh. RT 361, S. 11933-11943.

278 Vgl. z. B. Bericht Koch-Wesers vom 20.10. 1923: „[...] mit einer glänzenden Rede einen starken Erfolg erzielt“. BA Koblenz, Nl. Koch-Weser, Nr. 139, Bl. 185.

279 Verh. RT 361, S. 11934.

280 Ebd., S. 11933 . Vgl. zur schwerindustriellen Stellungnahme Weisbrod, Schwerindustrie, S. $151 \mathrm{f}$., ebd. Zitat der Schlüsselstelle: „Der Parlamentarismus hat versagt. Über die jetzige Not helfen uns nur willensstarke und zielbewußte Männer hinweg, die vom Vertrauen des Volkes getragen werden."

281 Verh. RT 361, S. 11933.

282 Ebd., S. 11934.

${ }^{283}$ Ebd., S. 11934 f. 
Der Rückblick auf die Koalitionskrise spielte zwei Tage später auch in den Ausführungen der Fraktionsredner eine bedeutsame Rolle. Graf Westarp von der DNVP nutzte die Gelegenheit zu einer scharfen und teilweise geradezu triumphierenden Attacke und setzte sich in seinem vielbeachteten Auftritt als Gegenspieler Stresemanns in Szene. Dieser Eindruck wurde durch eine heftige Replik des Kanzlers noch verstärkt ${ }^{284}$. Der Sozialdemokrat Breitscheid kritisierte, ohne die DVP explizit zu nennen, vor allem die Herbeiführung der Krise und ging dabei auch ausführlich auf die Gefahr eines "trockenen" Rechtsputsches ein. Die anschwellende Parlamentarismuskritik bewertete er als Instrument in diesem Angriff auf die bestehenden Regierungsverhältnisse285. Die Vertreter der bürgerlichen Koalitionsparteien vermieden es in noch stärkerem Maße als Breitscheid, auf Einzelheiten der Krise einzugehen und zeigten sich, bei allen Unterschieden in den Akzenten, einig in einer pauschalen Kritik an der aktuellen Leistungsfähigkeit des parlamentarischen Systems in Deutschland 286 . Auch hier richtete sich die Schelte in erster Linie gegen die Bedeutung von Fraktionen und Parteiführungen. Stresemanns Verhalten als Reichskanzler mußte in diesem Zusammenhang als Ausdruck von Führungsschwäche erscheinen. Koch-Weser, der ja bereits in diversen Parteiführerbesprechungen derart argumentiert hatte, hielt dem Kanzler dann auch offen vor, daß es „seine Aufgabe gewesen [wäre], in einer öffentlichen Sitzung des Reichstags seine Politik zu vertreten, unbekümmert darum, ob sie in allen Nuancen den in der Koalition vertretenen Parteien gefällt" ${ }^{\text {"287. }}$. Hier wird sehr deutlich, daß die Anfang Oktober intensivierte Parlamentarismuskritik mindestens ebensoviel mit einem den deutschen Verhältnissen unangemessenen Parlamentarismusverständnis zu tun hatte wie mit den tatsächlichen Funktionsproblemen.

In der Plenaraussprache offenbarte sich auch die Fragilität der mühsam erneuerten Großen Koalition. Sieht man von verschiedenen Anspielungen Breitscheids und Scholz $\mathrm{ab}$, so wurden zwar koalitionsinterne Vorwürfe vermieden, es fällt aber auf, wie bescheiden die Unterstützung für die neue Regierung seitens der beiden Flügelparteien SPD und DVP ausfiel. Am deutlichsten wird dies bei Breitscheid, der auf jegliche Loyalitätsbekundung verzichtete und sich darauf beschränkte, die sozialdemokratische Regierungsbeteiligung mit der akuten Gefahr für die Republik zu rechtfertigen. Unmißverständlich wies der Sozialdemokrat auf die zerrüttete Vertrauensgrundlage innerhalb der Koalition hin, indem er die „alte parteipolitische Zusammensetzung“ mit dem Satz kommentierte: „Derartige Tage wie die letzten erlebt man nicht, ohne daß sie eine tiefe Spur hinterlassen. “288 Scholz fügte am Ende seiner Rede allenfalls die Andeutung einer Vertrauensfor-

284 Westarp ebd., S. 11968-11979, v.a. S. 11968; Stresemann ebd., S. 11979-11986.

285 Ebd., S. 11949-11958, v.a. S. 11952, 11954.

286 So meinte Bell für das Zentrum mit Bezug auf die Regierungskrise, „das deutsche Parlament [habe] wahrlich den großen Befähigungsnachweis nicht erbracht“. Ebd., S. 11958-11968, hier S. 11958.

287 Ebd., S. 11991. Vgl. auch den rückblickenden kritischen Bericht Koch-Wesers vom 20. 10. 1923;

BA Koblenz, Nl. Koch-Weser, Nr. 139, Bl. 187: „So hat Stresemann sein Kabinett wieder zusammen. An Ansehen hat er nicht gewonnen. Innerhalb des Kabinetts sind starke Meinungsverschiedenheiten. Namentlich scheint es, dass Geßler und Brauns Stresemann für nicht geeignet ansehen, das Reich zu führen."

288 Verh. RT 361, S. 11949. 
mel ein, indem er angesichts der "Not unseres Vaterlandes" von "gemeinsamer Arbeit mit der Regierung“ sprach, um zu „versuchen, unser Volk wieder zu denjenigen Tugenden zurückzuführen, die es einst groß gemacht haben, zur Arbeit, zur Ordnung und zur Sparsamkeit“289. Deutliche Vertrauenserklärungen gaben hingegen Koch-Weser und Bell für DDP und Zentrum ab, - letzterer in einem geradezu kuriosen Treueschwur, der ein hohes Maß an Bereitschaft verriet, sich der Führung der Exekutive zu unterwerfen ${ }^{290}$.

Am Ende der Plenarsitzung erfolgte das obligatorische Vertrauensvotum. Ähnlich wie bereits im Falle des ersten Kabinetts Stresemann wählte der von den Koalitionsparteien eingebrachte Antrag erneut eine explizite Bekundung: „Der Reichstag billigt die Erklärungen der Reichsregierung und spricht ihr das Vertrauen aus." 291 Nachdem ein kommunistischer Antrag auf namentliche Abstimmung gescheitert war, erfolgte die Vertrauenserklärung durch bloßes Erheben ${ }^{292}$. Wie groß der Anteil der Dissidenten innerhalb der Flügelparteien SPD und DVP genau war, läßt sich daher nicht sagen.

Mit dem Vertrauensvotum war eine Regierungskrise zu einem formalen Abschluß gelangt, die gut eine Woche zuvor völlig überraschend ausgebrochen war, deren Verlauf und Hintergründe kaum noch vollständig zu klären sind und die eine nachhaltige Erschütterung und einen weiteren schweren Ansehensverlust für das parlamentarische Regierungssystem bedeutete ${ }^{293}$. Eine zusammenfassende Bewertung dieser komplexen Vorgänge fällt nicht leicht. Drei Fragen sollen im folgenden in den Mittelpunkt gestellt werden. 1. Worin lagen die tieferen Ursachen für den Bruch der Koalition? 2. Wie ist die anschließende Regierungsbildung zu beurteilen? und 3. Inwieweit verband sich die Regierungskrise mit dem Prozeß des legislativen Funktionsverzichts?

1. Daß der Rücktritt der Regierung Stresemann I vor allem die Folge einer Attacke der DVP-Fraktion gegen die sozialdemokratische Regierungsbeteiligung war und daß es um eine Verlagerung des Regierungsspektrums nach rechts ging, ist in der Forschung inzwischen weithin anerkannt ${ }^{294}$. Innerhalb kürzester Zeit wurde seitens der Koalitionsgegner das in den Vordergrund gerückte Thema „Verlängerung der Arbeitszeit“ symbolträchtig mit dem Projekt eines Ermächti-

289 Ebd., S. 11990.

290 Ebd., S. 11967 f.: „Herr Reichskanzler, bleiben Sie stark, bleiben Sie hart allen Anfeindungen zum Trotz. Nehmen Sie auch die schweren Opfer und diese bitteren Demütigungen im Dienste unseres Volkes und unseres Vaterlandes auf sich. Seien Sie überzeugt davon, Herr Reichskanzler, daß wir Ihnen auf Ihrem Kreuzzug durch Dickicht und Dornen vertrauensvoll folgen (hört! hört! rechts) und getreulich im gleichen Schritt und Tritt mit Ihnen marschieren zur Rettung unseres hartgeprüften deutschen Volkes." Vertrauensbekundung Koch-Wesers ebd., S. 11996.

291 Verh. RT 380, S. 7533, Drucks. Nr. 6243.

292 Verh. RT 361, S. 12029.

293 Eine sehr interessante Deutung gibt in diescm Zusammenhang Carl von Ossietzky in der Berliner Volkszeitung, 5. 10. 1923, „Der Weg ins Freie“: Die Große Koalition sei „nicht einem politischen Elementarereignis zum Opfer gefallen [...], sondern einem Stürmchen in den fraktionellen Wassergläsern“. „Es ist schlimm, daß die Demokratic an ihrem Siege zweifelt. Von allen Seiten schreit man es ihr zu, daß sie ja eigentlich gar nicht mehr lebe, daß sie längst tot sei. Und so wird sie an ihrer eigenen Existenz irre. Wie jemand, der in einer Jahrmarktsbude sein verzerrtes Bild in Hohlspiegeln erblickt und zwischen Lachen und Erschrecken schließlich nicht mehr weiß, wie die Linien seines Körpers verlaufen.“ (BA Berlin, R 8034 II, Nr. 9106, Bl. 199.)

${ }_{294}$ Vgl. v.a. Arns, Krise, S. 165f; Winkler, Von der Revolution zur Stabilisierung, S. 632, 634; dagegen Belastung der SPD bei Huber, Verfassungsgeschichte 7, S. 358. 
gungsgesetzes verbunden und als Hebel gegen die Sozialdemokratie instrumentalisiert, die zu einer pragmatischen Suspendierung des Achtstundentages durchaus bereit gewesen wäre.

Trotz dieses machtstrategischen Aspekts darf nicht übersehen werden, daß sich in der Arbeitszeitfrage der zentrale Konflikt um die Bewältigung der Hyperinflation zuspitzte. Dahinter standen konkrete sozioökonomische Interessenkonflikte, die sich schon 1922 formiert hatten und die dann während des Ruhrkampfes vorübergehend in den Hintergrund getreten waren. Die Aufhebung des Achtstundentages war gleichsam der Preis, den die bislang einer Beendigung der $\mathrm{Hy}-$ perinflation wenig zugeneigten Wirtschaftskreise für ihre Kooperation in der Stabilisierungsfrage forderten. Es überrascht daher nicht, daß Stinnes nun wieder in das Lager der Gegner der Großen Koalition übergegangen war und eine wichtige Rolle im „Putschversuch“ der DVP-Fraktion spielte. Mit der erzwungenen Ablösung Hilferdings als Finanzminister wurde dann auch das Ende einer stärker sozialdemokratisch bestimmten Stabilisierungsstrategie markiert.

Zeitweise erfolgreich war die vom DVP-Fraktionsvorsitzenden Scholz angeführte Attacke nur deshalb, weil Teile der Zentrums- und auch der DDP-Fraktion ihr durchaus sympathisch gegenüberstanden und so den von der DVP ultimativ vorgebrachten Forderungen Nachdruck verliehen. Die Frage, ob man die Sozialdemokratie in eine möglichst breite Koalition einbinden oder sie aber von allen Positionen der Regierungsmacht verdrängen sollte, wurde zu diesem Zeitpunkt in allen drei bürgerlichen Mittelparteien kontrovers beantwortet. Am schärfsten waren die Antipathien gegen eine Große Koalition aber in der DVP. Jener Riß, der sich Mitte August bereits in der Verweigerung des Vertrauensvotums durch eine Fraktionsminderheit gezeigt hatte ${ }^{295}$, brach nun offen auf. Dabei kehrten sich zeitweise die Stärkeverhältnisse innerhalb der DVP-Fraktion um, und Stresemann befand sich vorübergehend in einer Minderheitenposition, was seine Position als Reichskanzler nachhaltig schwächte.

Inwieweit der Vorstoß der DVP-Fraktion noch von weiterreichenden Zielen getragen war, ob dahinter auch eine Art Verschwörung einzelner Akteure des rechten DVP-Flügels und der DNVP stand, welche die Funktionsunfähigkeit der parlamentarischen Demokratie demonstrieren und über ein wie auch immer geartetes Ausnahmeregime zu einem autoritären Regierungssystem führen sollte, muß freilich offen bleiben. Zweifellos gibt es Indizien für eine derartige These; die Beweislage dafür, daß mehr als ein von Artikel 48 und damit auch vom Reichspräsidenten gedecktes Notverordnungsregime angestrebt wurde, bleibt insgesamt aber recht dünn.

Der SPD-Fraktion wird in der Forschung meist eine gewisse Mitschuld am Zerbrechen der Regierung gegeben, da sie - wie anknüpfend an die ältere Literatur vor allem Winkler betont ${ }^{296}$ - die weitergehende Kompromißbereitschaft der SPD-Minister nicht mitgetragen habe. Dem ist zunächst entgegenzuhalten, daß es angesichts der unnachgiebigen Forderungen der DVP weniger um einen Kompro-

295 Vgl. oben S. 243-245.

296 Vgl. Winkler, Von der Revolution zur Stabilisierung, S. 635 f., vgl. auch Zitat in Anm. 298. Ohne Schuldzuschreibung an die SPD Arns, Regierungsbildung, S. $165 \mathrm{f}$. 
miß als um ein einseitiges Nachgeben der SPD ging. Die weitaus stärkste Fraktion des Regierungslagers und des Reichstags hätte sich so dem Willen eines kleineren Koalitionspartners unterworfen. Darüber hinaus zeigt die genaue Betrachtung des Krisenprozesses, daß sich mit dem DDP-Vorschlag einer separaten legislativen Regelung der Arbeitszeitfrage bereits am 2. Oktober, d.h. unmittelbar vor dem Bruch der Regierung, eine Lösung abgezeichnet hatte. Diese Option, die wenige Tage später tatsächlich gewählt wurde, scheiterte zunächst an der negativen Resonanz innerhalb der DVP. Öffentlichkeitswirksam wurde das Koalitionsende freilich mit dem SPD-Fraktionsbeschluß vom Abend des 3. Oktober eingeleitet.

Aus Sicht einer breiten funktionalen Analyse muß zudem festgestellt werden, daß hinter der Forderung nach einem weitergehenden sozialdemokratischen Nachgeben eine Verabsolutierung der regierungsstützenden parlamentarischen Funktion steht. Angesichts einer erstarkenden systemfeindlichen Opposition der KPD und angesichts des wachsenden Unmuts innerhalb der SPD kann man auch zu dem Urteil gelangen, daß es „staatspolitisch“ 297 durchaus vernünftig war, wenn die SPD-Fraktion vor einer Kapitulation gegenüber dem Erpressungsversuch der DVP zurückschreckte, sich einer Einbeziehung der hoch symbolischen und von der DVP bewußt ins Grundsätzliche erhobenen Arbeitszeitfrage in das geplante Ermächtigungsgesetz widersetzte und damit ansatzweise eine systemloyale Alternativposition markierte.

Daß das erste Experiment einer Großen Koalition mit einem Bruch zwischen zwei Fraktionen endete und daß es zum Schluß keinen Rettungsversuch in einer „offenen Feldschlacht" im Reichstag gab, wie vor allem linksliberale Stimmen gefordert hatten, entsprach der Krisenlogik einer parteiengestützten parlamentarischen Demokratie. Ob Stresemann für einen kurzen Augenblick tatsächlich mit dem Gedanken einer freien parlamentarischen Entscheidung gespielt hat, wie einzelne Indizien nahelegen, bleibt unklar. Wenn sich der Kanzler damit eine parlamentarische Mehrheit gesichert hätte, wäre der Preis für ihn vermutlich hoch gewesen: der offene Dissens innerhalb der DVP und damit möglicherweise das politische Aus für die unter seinem Vorsitz stehende Partei. Bezogen auf das bürgerliche Parteienspektrum wäre hier aber vielleicht die Chance zu einer produktiven Klärung gelegen.

2. Mit dem Zerbrechen der Großen Koalition war das parlamentarische System noch lange nicht funktionsunfähig, wie eine bereits zeitgenössisch zu findende und in der Literatur teilweise wiederholte Bewertung nahelegt ${ }^{298}$. Die nun von den Fraktionen der DDP und des Zentrums demonstrierte Aktivität für eine strikt parlamentarische Kabinettsbildung ist bislang kaum angemessen gewürdigt worden. Dieser Einsatz, der wohl auch eine Konsequenz aus den Erfahrungen mit der

297 Dies sei hier gegen Winkler, Von der Revolution zur Stabilisierung, S. 635, gewendet, der die Entscheidung der SPD-Fraktion gegen den Regierungseintritt der DVP als "staatspolitisch" für „kaum vertretbar" bewertet.

298 Vgl. ebd., S. 636: „Die Sozialdemokraten waren mehrheitlich für das bestehende Regierungsbündnis; zu den Kompromissen aber, die seinen Fortbestand - vielleicht - ermöglicht hätten, waren sie bis zum 3. Oktober nicht bereit. Ein funktionsfähiges parlamentarisches Regierungssystem existierte mithin nicht mehr. Deutschland schien reif für irgendeine Art der Diktatur." Winkler übernimmt damit ein Bewertungsmuster, das zeitgenössisch auf dem rechten Flügel der SPD als Argument für eine unbedingte Koalitionspolitik verwendet wurde. 
Regierung Cuno darstellte, ist umso höher zu bewerten, als Stresemann zunächst ganz auf ein „überparteiliches“ Kabinett unter Zuziehung führender „Wirtschaftler" gesetzt hatte. Die Erneuerung der Großen Koalition war aber auch Ausdruck der fortbestehenden Regierungsbereitschaft der SPD und der unter dem Eindruck der deutschnationalen Verweigerung plötzlich wiederbelebten Kompromißbereitschaft der DVP. Die Neubildung der Regierung gelang so nach den Spielregeln eines parteiengestützten Parlamentarismus.

Die Große Koalition wurde nicht zuletzt auch wegen des Postulats eines möglichst bald zu verabschiedenden Ermächtigungsgesetzes angestrebt, das eine parlamentarische Zweidrittelmehrheit erforderte. Damit aber wurden andere mehrheitsfähige Kombinationen vorab ausgeschlossen. Die von Teilen der DVP angestrebte und zumindest von einzelnen Persönlichkeiten in DDP und Zentrum unterstützte Option einer bürgerlichen Rechtsregierung wurde - unabhängig von sonstigen Hindernissen - dadurch ebenso erschwert wie eine nur vereinzelt diskutierte Option einer Weimarer Koalition. Eine Vorentscheidung gegen beide Koalitionsmodelle war freilich schon gefallen, als Ebert noch am Abend des 6. Oktober Stresemann wieder mit einer Regierungsneubildung beauftragt hatte. Hinzu kam, daß eine bürgerliche Rechtsregierung bei der Fraktionsmehrheit von Zentrum und DDP kaum eine Chance hatte, wobei neben grundsätzlichen verfassungspolitischen Vorbehalten sicher auch die zur Schau getragene außen- und reparationspolitische Intransigenz der DNVP eine Rolle spielte. Offen ist schließlich, ob ein ernsthafter Versuch zu einem „Bürgerblock“ die in der DNVP vorhandenen Widerstände gegen eine Regierungsbeteiligung hätte brechen können.

Lief unter den gegebenen Umständen alles auf eine Wiederherstellung der Großen Koalition zu, so sollte doch die grundsätzliche Problematik dieser Lösung nicht übersehen werden. Die Krise hatte - wie Radbruch in seinen Erinnerungen bemerkte - „ein von Mißtrauen zerklüftetes Kabinett“ hinterlassen ${ }^{299}$, in der Sozialdemokratie waren die Vorbehalte gegen eine breit angelegte Koalitionspolitik gewachsen, und die Autorität des Kanzlers hatte gelitten. Darüber hinaus ist festzustellen, daß der Ausfall einer systemloyalen parlamentarischen Alternative nun auf unbestimmte Zeit fortgeschrieben wurde, während sich DNVP und KPD in einer radikalen Oppositionsrolle gebärden konnten. Bedrohlich war die Lage vor allem im Hinblick auf das potentielle Wählerreservoir der Sozialdemokratie, denn die SPD ging stark geschwächt in die neue Regierung und hatte somit - trotz ihrer nominellen Stärke im Reichstag - noch weniger Chancen, nachhaltigen Einfluß auf die politische Gestaltung zu nehmen. Insbesondere war nun eine weitestgehend von Wirtschaftsinteressen bestimmte Währungsstabilisierung zu erwarten. Unter den gegebenen Verhältnissen war dies vermutlich die einzige realistische Möglichkeit, um die deutsche Wirtschaft in den dringend notwendigen Stabilisierungsprozeß einzubinden. Allerdings wären in dieser Situation eine bürgerliche Rechtsregierung und die Opposition der SPD die konsequenteste parlamentarische Lösung gewesen. Fatalerweise stand dem die immer noch bedeutsame Kluft zwischen DNVP und bürgerlicher Mitte entgegen. 
3. Kaum beachtet wurde bislang die enge Verbindung zwischen Koalitionspolitik und Durchsetzung des großen Ermächtigungsgesetzes, das die Grundlage für das weitere sozioökonomische Krisenmanagement bilden sollte. Diese Verbindung läßt sich in dreierlei Hinsicht erkennen:

a) Das Thema eines mit der Arbeitszeitfrage aufgeladenen Ermächtigungsgesetzes war von der DVP-Fraktion als Hebel gegen die Große Koalition instrumentalisiert worden. Die rasche Fixierung der Regierungsparteien auf diesen Weg der legislativen Krisenbewältigung scheint damit noch gefördert worden zu sein, während die Chancen auf ein Festhalten an der regulären Gesetzgebung sanken. Bei allem Streit um die inhaltliche Reichweite des Ermächtigungsgesetzes darf daher nicht übersehen werden, daß das Mittel einer legislativen Kompetenzabgabe an sich nicht zur Diskussion stand, sondern an Selbstverständlichkeit hinzugewann.

b) Im Falle des Scheiterns einer parlamentarischen Ermächtigung gab es zwei Möglichkeiten. Nur vereinzelt wurde offenbar daran gedacht, dann doch in den Bahnen der regulären Gesetzgebung zu bleiben. Bedeutsamer waren entgegengesetzte Überlegungen, ein tendenziell antiparlamentarisches Verordnungsregime zu errichten. Dies betraf die Vorstellung, den Artikel 48 als Ersatz für eine nicht durchsetzbare Ermächtigung heranzuziehen, ebenso wie Gedanken an eine Reichstagsauflösung, ein verfassungswidriges Hinausschieben von Neuwahlen oder eine Verlängerung des militärischen Ausnahmezustands als Begleitmaßnahmen. Wie weit die Akzeptanz derartiger Optionen innerhalb der Regierungsparteien bereits reichte, ist schwer $\mathrm{zu}$ bestimmen. Immerhin scheinen sie hier diskutiert worden zu sein, und es gibt Indizien, daß auch Stresemann kurzzeitig mit derartigen Vorstellungen gespielt hat.

c) Wie bereits erwähnt, komplizierte die Festlegung auf ein Ermächtigungsgesetz sowie die damit verbundene Notwendigkeit einer Zweidrittelmehrheit im Reichstag die Regierungsbildung erheblich. Das Postulat der legislativen Funktionsabgabe erzwang geradezu eine extrem breite Regierungsbildung und war so indirekt auch für die eklatanten Defizite in der Ausübung der parlamentarischen Alternativfunktion verantwortlich. Die Festlegung auf ein Ermächtigungsgesetz wurde damit zu einem funktional weit über den legislativen Bereich hinausgreifenden Faktor.

\section{Ermächtigungsgesetz und Zerbrechen der Koalition}

Bereits mit der Neukonstituierung der Regierung Stresemann waren die Weichen für ein breit angelegtes Ermächtigungsgesetz gestellt ${ }^{300}$. Nachdem am 5 . Oktober in den wesentlichen Punkten Einigung über die inhaltliche Gestaltung erzielt worden war, brachten die ersten Kabinettssitzungen der neuen Regierung dieses Ergebnis einen Tag später in die Form einer Gesetzesvorlage. Letzte Meinungsverschiedenheiten gab es darüber, ob - wie von der SPD gefordert - neben Arbeitszeit und Versicherungsfragen auch das Thema Erwerbslosenfürsorge aus der sozialpolitischen Ermächtigung auszuschließen sei ${ }^{301}$. Tagsüber fanden hierzu

300 Allgemein zum Durchsctzungsprozeß vgl. v.a. Frehse, Ermächtigungsgesetzgebung, S. 91-103.

301 Protokoll der um 13 Uhr beginnenden Sitzung in AdR Stresemann, Nr. 115, S. 489-492. Im ersten 
noch interfraktionelle Verhandlungen statt, in der abendlichen Kabinettsrunde wurde dann ein Entwurf verabschiedet, der auf eine diesbezügliche Einschränkung der Ermächtigung verzichtete ${ }^{302}$. Da die Fraktionen in diesem Nachhutgefecht um die Reichweite der Ermächtigung offenbar keine Einigung erzielen konnten, wurde der Konflikt bis zur parlamentarischen Behandlung der Gesetzesvorlage verschoben.

Ansonsten waren alle zentralen Elemente des späteren Gesetzes bereits vorhanden: die pauschale finanz-, wirtschafts- und sozialpolitische Ermächtigung mit den erwähnten Ausschlußklauseln, die Möglichkeit, von der Reichsverfassung abzuweichen, das analog zur Bestimmung des Artikels 48 und auch zu früheren Ermächtigungsgesetzen gestaltete Recht des Reichstags, Verordnungen aufheben zu lassen, sowie die Befristung bis zum „Wechsel der derzeitigen Reichsregierung oder ihrer parteipolitischen Zusammensetzung". Die ursprünglich vorgesehene Terminierung bis zum 31. März 1924 war auf Bedenken bei der SPD gestoßen, wo man die Lebensdauer des Kabinetts skeptisch beurteilte ${ }^{303}$. Die Bindung der legislativen Vollmacht an die aktuelle Koalitionsregierung stellte zweifellos einen geschickten Schachzug dar, um formal einen parlamentarischen Grundcharakter zu wahren.

Die Verabschiedung des Ermächtigungsgesetzes, das gleichsam zum Gründungspakt der neuen Regierung gehörte, war angesichts der parlamentarischen Mehrheitsverhältnisse an sich eine Formsache. Daß daraus dennoch eine bis zuletzt spannende parlamentarische Entscheidung wurde und daß dabei der Bestand der gerade erst erneuerten Großen Koalition bereits wieder akut bedroht wurde, lag im wesentlichen an den nun auftretenden Turbulenzen innerhalb der SPD. Der Verlauf der Regierungskrise und die Wiederherstellung der Großen Koalition unter verschlechterten Bedingungen für die Sozialdemokratie hatten hier in Verbindung mit dem symbolgeladenen Arbeitszeitkonflikt erheblichen Unmut erregt und den Gegnern einer Großen Koalition Auftrieb gegeben ${ }^{304}$. Ein Forum für die erstarkende innerparteiliche Opposition bot der auf nationaler Ebene vielbeachtete Berliner Bezirksparteitag vom 7. Oktober ${ }^{305}$. Der Dissens der Reichstagsfraktion in Sachen Koalitionspolitik und Ermächtigung wurde hier offenkundig. Mit Hertz und Hilferding kamen prominente Vertreter der Mehrheit zu Wort und mit Aufhäuser auch ein Repräsentant der Minderheit. Letzterer kündigte an, daß sich die Gegner des Ermächtigungsgesetzes im Reichstag der Stimme enthalten woll-

Entwurf von Justizminister Radbruch fehlte jeder Hinweis auf eine sozialpolitische Ermächtigung, was den sofortigen Widerspruch von Arbeitsminister Brauns hervorrief, der auf die Vereinbarung der Parteiführer vom Vortag verwies und gleichzeitig auch eine Ermächtigung in Sachen Erwerbslosenfürsorge forderte. Letzteres traf auf den Widerspruch von Sollmann und Schmidt, die nicht glaubten, „zu einer solchen Erstreckung des Ermächtigungsgesetzes die Zustimmung ihrer Fraktion in Aussicht stellen zu können“. Ebd., S. 491.

302 Protokoll der um 18 Uhr beginnenden Sitzung in AdR Stresemann, Nr. 117, S. 494-500, hier S. 495, 499 f., mit Text des Gesetzesentwurfs. Der Tagesordnungspunkt wurde nach hinten gezogen, weil zunächst noch das Einverständnis der SPD ausstand.

303 Vgl. etwa Breitscheid am 8. 10. 1923 in seiner Plenarrede. Verh. RT 361, S. 11957.

${ }^{304}$ So spricht Dittmann, Erinnerungen 2, S. 861, von „starke[m] Widerstand“ innerhalb der SPD; , in den Parteiversammlungen und in Volksversammlungen“ habe es „stürmische Auseinandersetzungen" gegeben.

305 Vgl. ausführlicher Bericht in Vo, 8. 10. 1923 ab, S. 2f., „Berliner Bezirksparteitag“. 
ten. Die Meinungsunterschiede wurden freilich durch einen demonstrativen Willen zum Erhalt der Parteieinheit überlagert, der die scharfen Konflikte innerhalb der Fraktion zumindest teilweise gegen die Öffentlichkeit abschirmte ${ }^{306}$.

Im Reichstag sollte das Ermächtigungsgesetz unter Verzicht auf jede Ausschußberatung innerhalb kürzester Zeit durch die obligatorischen drei Lesungen gebracht und als verfassungsänderndes Gesetz analog Artikel 76 der Weimarer Verfassung mit qualifizierter Mehrheit verabschiedet werden ${ }^{307}$. Die Plenardiskussion hierüber begann de facto bereits in der Debatte, die am 6. und 8. Oktober über die Regierungserklärung stattfand. Am 9. Oktober wurde dann der inzwischen im Reichsrat gebilligte Gesetzesentwurf des Innenministeriums, der die Kabinettsfassung vom 6. Oktober nur leicht modifizierte, in erster und zweiter Lesung behandelt ${ }^{308}$. Unter dem Druck der auf den politischen Extremen verkündeten Schlagworte vom "Versagen" und vom "Bankrott" des Parlamentarismus und was die SPD betrifft - auch unter dem Druck der parteiinternen Opposition - kam es im Laufe dieser drei Sitzungstage zumindest ansatzweise zu einer grundsätzlichen Auseinandersetzung mit dem Instrument einer legislativen Ermächtigung. Diese Diskussion spiegelt das im systemloyalen Spektrum verbreitete parlamentarische Selbstverständnis und läßt bei einzelnen Rednern über die bloße Begründung der Ermächtigung hinaus auch eine parlamentarismustheoretische Rechtfertigung erkennen.

Das maßgebliche Argument der Befürworter einer Ermächtigung lag in der Aussage, daß der parlamentarische Betrieb den anstehenden legislativen Aufgaben nicht gewachsen sei. So meinte der Kanzler in seiner Regierungserklärung: „Wir haben eine große Anzahl von Maßnahmen in Aussicht genommen. Das geht nicht mit dem parlamentarischen Apparat, so wie er aufgezogen ist. Deshalb wenden wir uns an Sie um entsprechende Ermächtigung für die Lösung der finanziellen und wirtschaftlichen Fragen." ${ }^{09}$ Kaum anders klang die Begründung bei dem Sozialdemokraten Breitscheid: Der gegenwärtige parlamentarische Apparat sei „etwas schwerfällig“; die Situation könne daher verlangen, „daß auf dem einen oder anderen Gebiete dem Ausschuß des Parlaments, den doch das Kabinett in einem verfassungsmäßigen Staate darstellen soll, vorübergehend außerordentliche Vollmachten gegeben werden“310. Der DDP-Abgeordnete Schiffer meinte, „die Lage unseres Vaterlandes [sei] so, daß der Mechanismus des Parlaments zu kompliziert ist, als daß die Aufgaben, die jetzt dem Parlament gestellt sind, erfolgver-

${ }^{306}$ Zur Schärfe des innerfraktionellen Konflikts vgl. Protokoll Giebels zur Fraktionssitzung vom 10. 10. 1923: „Dißmann: etwas [?] ihnen zugemutet ist, sei nicht tragbar! Hätten hierauf Rücksicht nehmen können." ASD Bonn, NI. Giebel, Kassette II, Mappe 3, Bl. 256.

307 Ein Gutachten des Innen- und Justizministeriums, mit Anschreiben vom 4. 10. 1923 der Reichskanzlei übersandt, bekräftigte den verfassungsändernden Charakter. BA Berlin, R 1501, Nr. 17100 , Bl. 2-4.

308 Verh. RT 361, S. 12033-12093; Gesetzesentwurf als Drucks. Nr. 6239 mit Datum vom 8. 10. 1923 in Verh. RT 380, S. 7530. Der Wortlaut ist nahezu identisch mit der verabschiedeten Fassung vom 13.10. Zum Reichsrat vgl. Frehse, Ermächtigungsgesetzgebung, S. $97 \mathrm{f}$. Mit Nein stimmten hier Bayern, Mecklenburg-Strelitz und mehrere preußische Provinzen. Zum parlamentarischen Verfahren vgl. auch ebd., S. 98-103.

${ }^{309}$ Verh. RT 361, S. $11942 \mathrm{f}$.

310 Ebd., S. 11954 (8.10.). 
sprechend gelöst werden können“311. Noch stärker von der aktuellen „drückenden Notlage“ her argumentierte der Zentrumssprecher Bell. Diese Notlage erfordere, daß der Reichstag "von seinen Befugnissen soviel an die Reichsleitung abgibt, wie zur Bewältigung der notwendigsten Aufgaben auf finanziellem, steuerlichem, wirtschaftlichem und sozialem Gebiete unvermeidlich ist" 312 .

Waren die Akzente im Detail auch unterschiedlich gesetzt, gemeinsam sind diesen Äußerungen der Verzicht auf eine Konkretisierung der legislativen Herausforderungen sowie die pauschale Annahme parlamentarischer Unzulänglichkeit. Eine erfolgreiche Krisenbewältigung wurde dem Reichstag offenbar grundsätzlich nicht zugetraut ${ }^{313}$. Die Tatsache, daß eine reguläre legislative Bewältigung der Währungsstabilisierung vor allem durch die großen Interessengegensätze innerhalb der Koalition gefährdet wurde, blieb so außerhalb der Diskussion.

In den zitierten Aussagen Breitscheids und Bells klingt auch das Bemühen um eine verfassungsrechtliche Legitimation und Begrenzung der Ermächtigungsgesetzgebung an. Beide erweckten den keineswegs mit der Realität übereinstimmenden Eindruck einer materiell eng gefaßten Ermächtigung. Ähnlich wie Breitscheid in der zitierten Passage wies auch Bell in seiner Rede auf den vorübergehenden Charakter der Vollmachten hin ${ }^{314}$. Beide Parlamentarier betonten auch ausdrücklich die parlamentarische Kontrolle über die Ausübung sowie die Möglichkeit der parlamentarischen Außerkraftsetzung von Verordnungen ${ }^{315}$. Beide führten zudem ein Argument an, das in der Tat zentral für die Legitimation von Ermächtigungsgesetzen im modernen Parlamentarismus ist. Breitscheid erwähnte - wie oben zitiert - den bekannten Topos von der Regierung als „Ausschuß des Parlaments" und wies besonders auf die sozialdemokratische Präsenz innerhalb der Regierung hin ${ }^{316}$. Bell erläuterte, „daß sich Reichsregierung und Reichstag nicht etwa als selbständige und von einander unabhängige Faktoren gegensätzlich gegenüberstehen, sondern daß nach der Reichsverfassung Reichsregierung und Reichstag in engstem Zusammenhang stehen "317. Genau dieser Zusammenhang bestand auch in dem ausgehandelten Gesetzentwurf, der die Dauer der Ermächtigung an die Amtszeit der aktuellen Regierung band. Unabhängig davon, daß eine pauschale Ermächtigung auch im Fall einer parlamentarisch fest verankerten Regierung bedenklich ist, litt die Argumentation Breitscheids und Bells vor allem unter einer gewissen Ausblendung des zeitgenössischen Vorstellungshorizonts. Denn im Parlamentarismusverständnis weiter Kreise war der Konnex von Regie-

311 Ebd., S. 12034 (9.10.). Schiffer sprach für die Reichsregierung. Zusammenfassung der Rede in Frehse, Ermächtigungsgesetzgebung, S. $98 \mathrm{f}$.

312 Verh. RT 361, S. 11960 (8.10.).

313 Vgl. auch Marx in Parteiführerbesprechung am 2. 10. 1923. Zurückzuweisen ist freilich die hierzu von Hehl, Marx, S. 241, gegebene Erklärung, dieses „vernichtende Urteil [entspränge] nicht grundsätzlicher Ablehnung des parlamentarischen Systems, sondern umschrieb lediglich zutreffend die destruktive Rolle der radikalen Oppositionsparteien unter Einschluß der DNVP“.

314 Verh. RT 361, S. 11960: „Und noch ein Zweites, meine Damen und Herren, kommt hinzu, daß nicht auf unabsehbare Zeit hinaus der Reichstag diese seine Vollmachten an die Reichsregierung abgegeben hat, sondern nur auf eine beschränkte Zeit und für ein genau abgegrenztes Anwendungsgebiet."

315 Breitscheid ebd., S. 11954; Bell ebd., S. 11960.

316 Ebd., S. 11954 f.

317 Ebd., S. 11960. 
rung und parlamentarischem Regierungslager keineswegs selbstverständlich; eine umfassende Ermächtigung schuf unter diesen Umständen einen höchst problematischen Präzedenzfall für eine entparlamentarisierte Gesetzgebung.

Die beiden sozialdemokratischen Plenarredner dieser Tage, Breitscheid und Müller, gingen noch über die übliche Rechtfertigung des Ermächtigungsgesetzes hinaus, indem sie dieses, ähnlich wie bereits Hilferding auf dem Berliner Bezirksparteitag 318 , in dramatisierender Weise als einzige Alternative gegen eine drohende Militärdiktatur und den Untergang der Republik deuteten. „Wenn zwischen der Diktatur des Säbels und der eines parlamentarischen Kabinetts zu wählen ist“, erklärte Breitscheid, „so ziehen wir die des parlamentarischen Kabinetts allerdings vor" ${ }^{319}$. Und Müller meinte am Ende seiner Rede, die sozialdemokratische $\mathrm{Zu}$ stimmung sei davon bestimmt, eine „Mussolini-Politik in Deutschland unmöglich zu machen" ${ }^{320}$. In diesem apodiktischen Entweder-Oder kam neben den reellen und nicht unbegründeten Sorgen um die parlamentarische Demokratie auch das Bemühen zur Geltung, den widerspenstigen Kräften in der eigenen Partei ein unüberwindliches Argument entgegenzuhalten. Zudem wurde damit ein scharfer Kontrapunkt gegenüber den kommunistischen Vorhaltungen gesetzt, das Ermächtigungsgesetz bedeute das Ende der Demokratie und die Einführung der „Diktatur von rechts“321.

Auffallend ist, wie wenig sich die liberalen Redner dieser Tage um eine Legitimierung der Ermächtigung bemühten. Dies gilt für Scholz und Hugo von der DVP, aber auch für Koch-Weser und Schiffer von der DDP. Abgesehen von der zitierten Begründung Schiffers wurde in beiden Parteien die Notwendigkeit einer Ermächtigung und der damit verbundenen „Diktatur“ als selbstverständlich vorausgesetzt. Das hier massiv vertretene Postulat des „Handelns“ und der „Entschlußkraft" und der nachdrücklich vorgebrachte Verweis auf eine Ausnahmesituation ließen für grundsätzliche Betrachtungen offenbar keinen Raum ${ }^{322}$. Und es ist bezeichnend für das gerade auch in der DDP herrschende Parlamentarismusverständnis, wie Schiffer dem Vorwurf, daß „der Reichstag seine Verantwortlichkeit auf andere Schultern überwälzt“, entgegentrat: Es sei „im Gegenteil [...] ein Akt der Selbstentäußerung des Reichstags, wenn er die Verantwortung nunmehr für Handlungen und Unterlassungen der Regierung mit übernimmt, an denen mitzuwirken er selbst nicht in der Lage ist“"323.

Daß ein Ermächtigungsgesetz auf der politischen Rechten keineswegs als Korrelat einer engen Verbindung von Regierung und parlamentarischer Regierungsmehrheit aufgefaßt wurde, sondern primär als Instrument einer starken und vom Parlament unabhängigen Exekutive, zeigt das Verhalten der DNVP und der BVP.

318 Vgl. Vo, 8. 10. 1923 ab, S. 2f., „Berliner Bezirksparteitag“.

319 Verh. RT 361, S. 11954 f.

320 Ebd., S. 12047.

321 Vgl. v.a. Frölich, ebd., S. 12038, 12043.

322 Vgl. v.a. die Rede Schiffers am 9.10., ebd., S. 12034 f.: „Wir haben die Regierung von der Notwendigkeit freigestellt, viel zu sprechen und lange Reden zu halten; dann soll sie aber auch handeln. [...] Alle die Rufe nach dem Diktator und der Diktatur sind ja nichts weiter als der Ruf nach einem befreienden Handeln, als der Ruf herauszukommen aus dem ewigen Überlegen und Erwägen und endlich einmal Taten vor sich zu sehen, die dem rasenden Absturz aller Verhältnisse sich entgegenstellen."

323 Ebd., S. 12034. 
Westarp und Leicht, die Hauptredner beider Parteien, kritisierten mit äußerster Schärfe nicht die Ermächtigung an sich, sondern ihre Bindung an die aktuelle Reichsregierung. Damit, so ereiferte sich Westarp, werde durch „die ungeheuerlichste Übertreibung " der "ganze Gedanke des Parlamentarismus und der Parlamentsherrschaft ins Lächerliche gekehrt“. „Diktatorische Vollmachten einer Parteikonstellation zu geben“, sei "die höchste Höhe des parteipolitischen Egoismus", sei „Wahnsinn" 324 .

Obgleich die Empörung der radikalen Opposition gegen das Ermächtigungsgesetz alles andere als glaubwürdig ist, sprachen die Redner dieser Parteien und Gruppen doch manche Kritik aus, die für sich durchaus berechtigt erscheint. So bemängelte Helfferich, als er zu Beginn der ersten Lesung die Verweisung in eine Ausschußberatung forderte, die fehlende „Aufklärung durch die Regierung über die Absichten, die sie mit dem Ermächtigungsgesetz verfolgt, und die Richtungen, in denen sie das Ermächtigungsgesetz zu handhaben beabsichtigt" ${ }^{325}$. Und paradox erscheint, daß ausgerechnet der Abgeordnete Graefe von der Deutschvölkischen Freiheitspartei, der im Reichstag offen eine "große nationale Erhebung" mit dem Ziel einer Rechtsdiktatur propagierte und der das geplante Ermächtigungsgesetz nur mit Hohn und Spott bedachte, kritisch anmerkte, daß die Verabschiedung von einer latenten Drohung mit dem legislativen Einsatz von Artikel 48 begleitet war. Ebenso wandte sich Graefe gegen die „hier im Reichstag eingebürgert[e]“ „Art und Weise“, verfassungsändernde Gesetze mit Zweidrittelmehrheit zu verabschieden ${ }^{326}$.

Im Laufe der zweiten Lesung wurde über eine Fülle von Änderungsanträgen abgestimmt, die in ihrer großen Mehrheit von den radikalen Fraktionen und Gruppen ausgingen und die im Plenum chancenlos waren. Zur Entscheidung stand aber auch noch die bislang in den Parteiführergesprächen der Regierungsparteien noch nicht definitiv geklärte Frage, in welcher Weise auch die Erwerbslosenfürsorge von der Pauschalermächtigung ausgenommen werden sollte. Gegen den Versuch der SPD, die gesamte Thematik auszuklammern ${ }^{327}$, setzte sich ein Antrag des Zentrums durch, der dies lediglich für die „Leistungen aus der Erwerbslosenversicherung" vorsah ${ }^{328}$. Die von Arbeitsminister Brauns seit langem geplante und wenige Tage später mit ersten Verordnungen umgehend in Angriff genommene Reform ${ }^{329}$ fiel so, wie vom Minister nachdrücklich gefordert, in den

${ }^{324}$ Ebd., S. 11997 . Vgl. zu Westarp auch Liebe, Deutschnationale Volkspartei, S. 74. Vgl. auch Änderungsanträge der DNVP; Drucks. Nr. 6255, 6265 in Verh. RT 380, S. 7536, 7539.

325 Verh. RT 361, S. 12033.

326 Ebd., S. 12011: „Ich bin der Überzeugung, daß die Art und Weise, wie diese diktatorische Macht unter Hinweis auf den Art. 48 der Verfassung gewissermaßen auf gesetzlichem Wege herbeigeführt werden soll, verfassungswidrig ist." Vgl. ebd. auch zur Nutzung des Art. 48 für wirtschaftliche Maßnahmen: „Wenn so der Art. 48 bei jeder Gelegenheit, wo die Reichsregierung wirtschaftliche Maßnahmen vornehmen will wie mit ihrer neuesten Steuergesetzgebung usw., die Einzelrechte des Staatsbürgers einfach außer Kraft setzen soll, dann ist die ganze Verfassung nur noch eine Kulisse, dann ist überhaupt gar nichts mehr übrig von den Grundrechten, dann hätten wir von vornherein einen absoluten Präsidenten einsetzen können.“

327 Vgl. Antrag in Drucks. Nr. 6245b; Verh. RT 380, S. 7534.

328 Ebd., S. 7535, Drucks. Nr. 6249.

329 Verordnungen vom 13. und 15. 10. 1923 auf der Grundlage des Ermächtigungsgesetzes; RGBl. 1923 I, S. $946 \mathrm{f}$. und $984 \mathrm{f}$. Vgl. hierzu Lewek, Arbeitslosigkeit und Arbeitslosenversicherung, S. $142-146$. 
Zuständigkeitsbereich des Ermächtigungsgesetzes. Ebenso scheiterte die SPD mit ihrem überraschenden und vermutlich mit den innerparteilichen Problemen in Verbindung stehenden Vorstoß, die Gültigkeit der auf Grundlage des Ermächtigungsgesetzes erlassenen Maßnahmen, „soweit nicht durch Gesetz anders bestimmt wird“, bis zum 1. Januar 1925 zu befristen ${ }^{330}$. Bereits im Vorfeld blieb ein Versuch der DVP-Fraktion stecken, ein Junktim zwischen der Verabschiedung des Ermächtigungsgesetzes und dem vorgesehenen Arbeitszeitgesetz herzustellen. Nachdem der DVP-Parlamentarier Fritz Mittelmann den Kanzler telefonisch in Kenntnis gesetzt und dabei auch vor einer neuen Regierungskrise gewarnt hatte, genügte offenbar ein ablehnender Wink Stresemanns gegenüber seiner Fraktion ${ }^{331}$.

Am 11. Oktober fand die dritte Lesung des Ermächtigungsgesetzes statt ${ }^{332} . \mathrm{Da}$ sich die Regierungsparteien nicht mehr zu Wort meldeten, dominierten die Attakken der Opposition. Gegen Ende wurde über den zentralen $\ 1$ in namentlicher Abstimmung votiert. Das Ergebnis von $252 \mathrm{Ja}$ - gegen 97 Nein-Stimmen bei einer Enthaltung und einer ungültigen Stimme (vgl. auch Tab. 8) entsprach der analog Artikel 76 der Reichsverfassung geforderten Zweidrittelmehrheit bei Anwesenheit von zwei Dritteln (306) aller Abgeordneten. \$2, der die sofortige Gültigkeit des Ermächtigungsgesetzes und seine Bindung an die aktuelle Reichsregierung bestimmte, wurde anschließend in einfacher Abstimmung gebilligt ${ }^{333}$.

Tab. 8: Votum des Reichstags am 11. 10. 1923: \1 Ermächtigungsgesetz ${ }^{334}$

\begin{tabular}{lrrrllll}
\hline $\begin{array}{l}\text { Fraktion oder } \\
\text { Gruppe } 335\end{array}$ & Abg. & ja & nein & $\begin{array}{l}\text { ent- } \\
\text { halten }\end{array}$ & fehlend & $\begin{array}{l}\text { beurl. } \\
\text { krank } \\
\text { entsch. }\end{array}$ & $\begin{array}{l}\text { Kohä- } \\
\text { renz }\end{array}$ \\
\hline KPD & 16 & - & 12 & - & 2 & 2 & $86 \%$ \\
USPD & 2 & - & 2 & - & - & - & - \\
SPD & 171 & 108 & - & - & 58 & 5 & $65 \%$ \\
DDP & 39 & 37 & - & - & - & 2 & $100 \%$ \\
Zentrum & 66 & 53 & - & - & 10 & 3 & $84 \%$ \\
DVP & 66 & 54 & - & - & 6 & 6 & $90 \%$ \\
BBMB & 4 & - & 4 & - & - & - & - \\
BVP & 20 & - & 15 & 1 & 1 & 3 & $88 \%$ \\
DHP & 4 & - & 3 & - & 1 & - & - \\
DNVP336 & 65 & - & 56 & - & 4 & 5 & $93 \%$ \\
DVFP & 3 & - & 3 & - & - & - & - \\
fraktionslos & 2 & - & 2 & - & - & - & - \\
\hline Gesamt & 458 & 252 & 97 & 1 & 82 & 26 & - \\
\hline
\end{tabular}

330 Verh. RT 380, S. 7533, Drucks. Nr. 6245a.

331 Vgl. Protokoll über die Mitteilung Mittelmanns in PA AA Berlin, Nl. Stresemann, Nr. 261, H146015. Vgl. auch AdR Stresemann, Nr. 118, S. 500, Anm. 22.

332 Verh. RT 361, S. 122115-12141.

333 Ebd., S. 12139.

334 Nach Verh. RT 361, S. 12142-12146. Nach dem ebd., S. 12146 angebenen Gesamtergebnis waren es 353 Ja-Stimmen. Die Unstimmigkeit zur fraktionellen Auszählung konnte nicht geklärt werden.

335 Einschließlich Hospitanten.

336 Einschließlich der Bayerischen Mittelpartei. 
Trotz der klaren Mehrheit erbrachte die Abstimmung über $\$ 1$ für die Regierungskoalition ein alarmierendes Ergebnis: Die Zahl der Ja-Stimmen blieb weit unter der nominellen Regierungsmehrheit von 346 Abgeordneten. Dies lag in erster Linie daran, daß sich 58 SPD-Abgeordnete, das ist ein Drittel der Fraktion, der Entscheidung bewußt entzogen und bei der Abstimmung gefehlt hatten ${ }^{337}$. Die überwiegend aus den Reihen der ehemaligen USPD stammenden Dissidenten vermieden damit gemäß alter sozialdemokratischer Parlamentspraxis ein abweichendes Votum. Auffällig ist auch das Fehlen einer kleinen Gruppe von DVP-Abgeordneten um Stinnes ${ }^{338}$. Unter diesen Umständen konnte die für die Billigung des Gesamtgesetzes notwendige Anwesenheit von zwei Dritteln aller Abgeordneten nicht erreicht werden, denn die Gegner des Ermächtigungsgesetzes aus KPD, DNVP und kleineren Gruppen, die beim Votum über $\ 1$ weitgehend präsent gewesen waren und mit Nein votiert hatten, kündigten nun triumphierend an, bei der Schlußabstimmung das Plenum zu verlassen. In dieser dramatischen Situation setzte der Kanzler sein schärfstes Disziplinierungsmittel ein und drohte mit einer von Ebert bereits gebilligten Reichstagsauflösung 339 . Der Regierungskoalition blieb in dieser Lage gar nichts anderes übrig, als umgehend die Vertagung zu beantragen $^{340}$. Die Entscheidung wurde so um zwei Tage auf den 13. Oktober verschoben.

Vermutlich noch am Abend des 11. Oktober gelang es innerhalb der SPD-Fraktion, eine strikte Bindung an die Fraktionsdisziplin durchzusetzen. Das traditionelle sozialdemokratische Recht des Fehlens wurde aufgehoben, was auf eine einheitliche Billigung des Ermächtigungsgesetzes hinauslief ${ }^{341}$. Hinzu kam, daß seitens der Reichsregierung nochmals die Entschlossenheit zur Reichstagsauflösung und zum nachfolgenden Gebrauch des Artikels 48 bekräftigt wurde ${ }^{342}$. Wie zur Bestätigung unterzeichnete der Reichspräsident am 11. Oktober eine umfangreiche steuerpolitische Notverordnung, die eine Anpassung an den Inflationsprozeß und diverse Vereinfachungen der Steuererhebung vorsah ${ }^{343}$.

337 Vgl. Liste der namentlichen Abstimmung; Verh. RT 361, S. 12142-12146.

338 Becker(-Hessen), Quaatz, Vögler und Stinnes fehlten offensichtlich bewußt, da sie auch am 13.10. nicht mit Ja stimmten. Ebd., S. 12142-12146.

$339 \mathrm{Vgl}$. Mitteilungen Stresemanns in der nach der Reichstagssitzung stattfindenden Kabinettssitzung; AdR Stresemann, Nr. 128, S. 543; demnach habe Ebert „auf die Nachricht von der Obstruktionsabsicht der Deutschnationalen Partei“ bereits am 10.10. seine Entscheidung getroffen. Deutlich wurde die Auflösungsabsicht auch, als Graefe (DVFP) Stresemann im Reichstag vorhielt, „mit der Androhung der Auflösung bluffen zu wollen, wenn die Sache nicht zustande kommt". Stresemann erwiderte darauf u.a.: „Die Entschlüsse darüber, was die Regierung tut, wenn das Ermächtigungsgesetz abgelehnt wird, stehen fest, stehen wenigstens für mich und für diejenige Stelle fest, die darüber zu entscheiden hat." Verh. RT 361, S. $12140 \mathrm{f}$.

340 Verh. RT 361, S. 12140 f. Vgl. auch Nachlaß des Reichskanzlers Wilhelm Marx, S. 294; HA Köln, Nl. Marx, Nr. 55, Bl. 26: „Im Einverständnis mit dem Kanzler und mit mehreren Parteien bringe ich den Antrag auf Vertagung auf Samstag ein. [...] Die S.P.D. fürchten selbst, daß eine größere Anzahl ihrer Leute nicht für das Ermächtigungsgesetz stimmen wird. Sie bekommen aber am folgenden Tag mehr Mut."

${ }^{341} \mathrm{FZ}, 12.10 .1923 \mathrm{mo} / 2$, S. 1, „Klärung innerhalb der sozialdemokratischen Fraktion“, berichtete z.B. über eine abendliche Krisensitzung und glaubte „annehmen zu dürfen, daß sich nach diesen Beratungen der sozialdemokratischen Reichstagsfraktion [...] weitere Schwierigkeiten für die Verabschiedung des Ermächtigungsgesetzes am kommenden Samstag wohl kaum ergeben werden."

342 Vgl. nach Kabinettssitzung vom 11. 10. 1923 z.B. FZ, 12. 10. $1923 \mathrm{mo} / /, \mathrm{S} .1$ „Entscheidungen der Reichsregierung".

${ }^{343}$ RGBl. 1923 I, S. 939-941. Vgl. auch FZ, 12. 10. 1923 mo2/, S. 1 „Entscheidungen der Reichsregie- 
In der entscheidenden Schlußabstimmung am 13. Oktober entzogen sich dann nur 13 SPD-Parlamentarier, das sind etwa 8\% der Fraktion, der Parteilinie ${ }^{344} .11$ der Dissidenten - darunter insbesondere Aufhäuser und Levi ${ }^{345}$ - hatten bis 1922 der USPD angehört. Noch am selben Tag publizierte eine Gruppe von 31 SPDAbgeordneten eine Erklärung, in der sie ihre Billigung des Ermächtigungsgesetzes allein mit der vorgegebenen Fraktionsdisziplin sowie mit der Sorge um die Einheit der Partei rechtfertigten ${ }^{346}$. Auch die anderen drei Fraktionen des Regierungslagers stimmten fast vollständig für das Ermächtigungsgesetz; lediglich eine kleine Gruppe von DVP-Parlamentariern um Stinnes gab demonstrativ blaue Enthaltungszettel $a b^{347}$. Von einzelnen Abgeordneten abgesehen verließen KPD, DNVP und einige Splittergruppen wie angekündigt vor der Abstimmung den Saal. Geschlossen mit Nein stimmten daher nur die BVP und die Deutsch-Hannoveraner. Alles in allem ergab sich ein Endergebnis von 316-Ja- zu 24-Nein-Stimmen bei 7 Enthaltungen und einer ungültigen Stimme. Diese nach den Vorgängen vom 11. Oktober „unerwartet große Mehrheit“" ${ }^{348}$ lag weit über den verfassungsrechtlichen Anforderungen einer qualifizierten Mehrheit und bot ein eindrucksvolles Beispiel fraktioneller Disziplinierung.

Mit dem Ermächtigungsgesetz ${ }^{349}$ wurden der Reichsregierung extrem weitgehende Vollmachten übertragen, die das bisher in der Weimarer Republik Übliche deutlich sprengten ${ }^{350}$. Abgesehen von den ausgehandelten Einschränkungen im Bereich von Arbeitszeit, Rentenleistungen und Versicherungsfragen gab es keine eindeutige Begrenzung. Die Ermächtigung der Reichsregierung, „die Maßnahmen zu treffen, welche sie auf finanziellem, wirtschaftlichem und sozialem Gebiete für erforderlich und dringend erachtet“, war, wie Frehse zu Recht feststellt, „beinahe schrankenlos" 351 , und ähnelte damit inhaltlich der Kriegsermächtigung für den Bundesrat vom 4. August 1914352. Erstmals in der Weimarer Ermächtigungsgesetzgebung durfte mit den Verordnungen zudem pauschal von den Grundrechten abgewichen werden, eine Freiheit, die weit über die erwarteten eigentumsrechtlichen Regelungen der Währungsstabilisierung hinausging. Berücksichtigt man zudem, daß auch der seit dem 26. September geltende reichsweite militärische Ausnahmezustand eine Suspendierung der zentralen Grundrechte umfaßte, so muß von einer breit angelegten Demontage der Weimarer Grundrechte gespro-

rung", wo die Verordnung vom 11.10. als "Anfang der dringendsten finanzpolitischen Aufgaben“ bezeichnet wird.

${ }^{344}$ Ein Abgeordneter fehlte wegen Krankheit.

345 Von 1919-1921 hatte Paul Levi bekanntlich eine führende Rolle in der KPD gespielt.

346 Abdruck in Vo, 14. 10. 1923, S. 2, "Erklärung“; auch in Arns, Die Linke in der SPD-Reichstagsfraktion, S. 196.

${ }^{347}$ Laut Protokoll fehlten Quaatz, Döbrich, Hepp, Vögler, Stinnes, Zeschke und Becker-(Hessen). Liste der namentlichen Abstimmung in Verh. RT 361, S. 12142-12146. Nach Handbuch für sozialdemokratische Wähler, S. 19, gab ,der schwerindustrielle Flügel der Deutschen Volkspartei unter Führung von Stinnes und Vögler blaue Enthaltungszettel“ ab.

348 So Marx in seinem Erinnerungsbericht „Miscellen aus dem Jahre 1923“, S. 25 f.: „Am Samstag, dem 13.10. wird dann auch das Gesetz mit einer unerwartet großen Mehrheit angenommen. [...] An eine solche Mehrheit hatte niemand gedacht!" HA Köln, Nl. Marx, Nr. 55.

349 RGBl. 1923 I, S. 943; Text auch in Frehse, Ermächtigungsgesetzgebung, Anhang, Teil II, S. 6.

$350 \mathrm{Vgl}$. zum folgenden ebd., S. 103-107.

351 Ebd., S. 104.

352 Vgl. oben S. 37. 
chen werden. Da das Zustandekommen von Verordnungen nicht wie in einigen der früheren, eng begrenzten Ermächtigungsgesetze an die Mitwirkung eines Reichstagsausschusses gebunden wurde, blieben als parlamentarische Mitwirkungs- und Kontrollbefugnisse nur die notwendige - in der Praxis dann aber keineswegs immer rechtzeitig gewährleistete ${ }^{353}$ - parlamentarische Kenntnisnahme sowie die Möglichkeit eines Aufhebungsverlangens. Auch wenn mit der Bindung der Vollmacht an die aktuelle Reichsregierung eine gewisse Sicherung eingebaut war, wurde so eine neue Stufe des legislativen Funktionsverzichts erreicht. Denn zum einen gab es nun eine materiell extrem weitgehende Ermächtigung, und zum anderen wurde das Verordnungsregime von jeglicher aktiven Mitwirkung des Reichstags abgekoppelt. Neuartig war schließlich auch der Verzicht auf eine Beteiligung des Reichsrats, dem die erlassenen Verordnungen lediglich zur Kenntnis zu bringen waren ${ }^{354}$. Die Stärkung der Reichsexekutive gewann damit auch einen tendenziell antiföderalen Charakter.

Während in der Sozialdemokratie nach Verabschiedung des Ermächtigungsgesetzes weithin ein rechtfertigender Tenor dominierte ${ }^{355}$, bewerteten die bürgerlichen Kräfte des Regierungslagers das Ergebnis mit deutlicher Genugtuung. Nicht ohne Stolz behauptete etwa eine Entschließung der Zentrumsfraktion vom 13. Oktober, der Reichsregierung seien „Vollmachten übertragen worden [...], wie sie wohl noch nie von einem Parlament einer Regierung anvertraut wurden“"356. Verfassungsrechtliche Bedenken, die vor Verabschiedung hie und da diskutiert worden waren, hatten in der öffentlichen Debatte der bürgerlichen Mitte keinerlei Raum mehr. Daß die anstehende Währungsstabilisierung ursprünglich auf regulärem legislativem Weg hatte angegangen werden sollen und daß die nun erteilte pauschale Ermächtigung auch etwas mit der Regierungskrise von Anfang Oktober zu tun hatte, war - abgesehen von einer scharfsinnigen Analyse in der Frankfurter Zeitung 357 - offenbar bereits weithin in Vergessenheit geraten.

Mit der Verabschiedung des ersten großen Ermächtigungsgesetzes der Weimarer Republik begann eine Phase politischer Krisenbewältigung, die weitgehend ohne Beteiligung des Reichstags erfolgte. Zum Zusammenbruch der legislativen Funktion kam so de facto auch eine Suspendierung der Kontrollfunktion. Äußerlich wird dies bereits durch die bis Ende Februar 1924 andauernde starke Reduzierung des parlamentarischen Betriebes augenfällig. Die wenigen Plenarsitzungen (20.-23. November und 4.-8. Dezember) beschränkten sich weitgehend auf die Beratung einzelner Gesetzentwürfe, die nach dem Ausscheiden der SPD aus

${ }^{353}$ Vgl. Telegramm des Innenministeriums an die Reichsminister vom 16.11. 1923: Es bestehe "Grund zu der Annahme“, daß „vereinzelt" Verordnungen dem Reichstag und Reichsrat nicht zur Kenntnis gebracht würden. Dies sei „baldmöglichst nachzuholen“. BA Berlin, R 1501, Nr. 17100, Bl. 123.

354 Vgl. Frehse, Ermächtigungsgesetzgebung, S. 105.

355 Vgl. z. B. Vo, 14. 10. 1923, S. 1, „Nach der Entscheidung des Reichstags“.

356 BA Koblenz, Nl. ten Hompel, Nr. 17.

357 FZ, 14. 10. $1923 \mathrm{mo} / 2$, „Die Vollmacht für die Regierung“. Bemerkenswert ist hier v.a. die Polemik gegen die "mächtigen Männer der Schwerindustrie“ um Stinnes, denen die Schuld an der zurückliegenden Krise zugeschrieben wird. „Ohne sie“, so der Artikel, „hätte der Reichstag die Währungsprojekte längst sachlich beraten, hätte er dringende finanz- und wirtschaftspolitische Gesetze längst auf dem ordentlichen Wege erledigen können, wäre die Regierung frei gewesen für außenpolitische Aktivität.“ 
der Regierung nicht mehr durch ein Ermächtigungsgesetz gedeckt waren, auf die Installierung der Regierung Marx und vor allem auf die Verabschiedung eines zweiten großen Ermächtigungsgesetzes Anfang Dezember. Ebenso deutlich ist der extreme Rückgang der Ausschußsitzungen. Der zentrale Haushaltsausschuß legte gar eine vom 12. Oktober 1923 (291. Sitzung) bis zum 28. Februar 1924 (292. Sitzung) währende viereinhalbmonatige Pause ein ${ }^{358}$. Und bei der legislativen Umsetzung der Ermächtigung durch die Verordnungsentwürfe der verschiedenen Ministerien scheint - wie eine Mahnaktion des Innenministers und des Reichswirtschaftsministers Ende Oktober/Anfang November 1923 zeigt - selbst die bescheidene Informationspflicht gegenüber dem Reichstag zunächst nur unzureichend wahrgenommen worden zu sein ${ }^{359}$, bis es schließlich zu einer Formalisierung der Mitteilungen an den Reichstag kam ${ }^{360}$.

Auf der Grundlage des Ermächtigungsgesetzes erließ die Reichsregierung bis zum 2. November insgesamt 45 Rechtsverordnungen ${ }^{361}$. Dank der bürokratischen Effizienz der beteiligten Ministerien konnte die Maschinerie des Verordnungswesens rasch anlaufen ${ }^{362}$. Auf diesem Wege wurde nun auch die Währungsstabilisierung vorangetrieben. Der entscheidende Schritt hierzu war bekanntlich am 15. Oktober die „Verordnung über die Errichtung der Deutschen Rentenbank" 363 . Das vorübergehend gültige, auf eine Hypothekenbelastung der deutschen Wirtschaft gestützte und an den Goldpreis gebundene Zahlungsmittel der Rentenmark zum Wert von einer Billion Papiermark wurde am 15. November ausgegeben ${ }^{364}$. 4,2 Rentenmark entsprachen nun einem US-Dollar. Von einer lange Zeit mit Vehemenz von der SPD geforderten - Belastung der Sachwerte konnte bei einer bis zu 6\%igen Gewinnbeteiligung der Anteilseigner an der Rentenbank kaum mehr die Rede $\operatorname{sein}^{365}$. Statt eines staatlichen erhielt die neuzuschaf-

358 BA Berlin, R 101, Nr. 1363 („Haushaltsausschuß, August 1923 - März 1924“); BA Berlin, R 101, Nr. 1476 („Die gedruckten Protokolle des Ausschusses für den Reichshaushalt, März 1923 - März 1924).

359 Vgl. Mahnaktion des Innenministers und des Reichswirtschaftsministers Ende Oktober/ Anfang November 1923. BA Berlin, R 3101, Nr. 5738/1, B1. 20, Brieftelegramm an Reichsminister vom 16. 11. 1923; BA Berlin, R 1501, Nr. 17100, Rundschreiben des Reichsinnenministers, Bl. 25.

360 Rundschreiben des Reichsministeriums des Innern vom 29. 10. 1923 zur Form der Mitteilungen an den Reichstag. Ebd., Bl. 123.

361 Nach Frehse, Ermächtigungsgesetzgebung, Anhang III, S. 1-4. In Poetzsch, Staatsleben 1, S. $213 \mathrm{f}$., sind lediglich 36 Verordnungen aufgeführt. - Weitere wichtige und dauerhafte Verordnungen waren neben der Verordnung vom 15. 10. 1923 v.a. die Verordnung über das Schlichtungswesen vom 30.10. 1923 und die Verordnung gegen den Mißbrauch wirtschaftlicher Machtstellungen (Kartellverordnung) vom 2.11. 1923; RGBI. 1923 I, S. 1043-1045 und 1067-1070.

362 Zum Vorgehen vgl. z. B. Anweisungen an die Abteilungsleiter vom 23. Oktober. BA Berlin, R 3901, Nr. 1730 (ohne Paginierung); zu internen Differenzen vgl. ebd. zusammenfassendes Schreiben vom 7. 12. 1923.

363 RGBl. 1923 I, S. 963-966. Zur währungspolitischen Seite vgl. v.a. Holtfrerich, Die deutsche Inflation, S. $313 \mathrm{f}$.

364 Im August 1924 wurde dann die Rentenmark durch die (neue) Reichsmark ersetzt. Maßgeblich für die technische Umsetzung des Stabilisierungsprozesses war bekanntlich der im Dezember 1923 neu ernannte Reichsbankpräsident Hjalmar Schacht.

365 Zunächst waren nur 3\% geplant gewesen. Vgl. zusammenfassend AdR Stresemann, S. LXXXf.; Winkler, Von der Revolution zur Stabilisierung, S. 673. Zur Bewertung vgl. ebd.: „Da die Zinsschuld, die der pfandbelastete Besitz gegenüber der Bank trug, sich ebenfalls auf $6 \%$ der eingebrachten Grundschulden etc. belief, konnte von einer realen Sachwertbelastung also nicht mehr die Rede sein.“ 
fende Rentenbank einen berufsständischen ${ }^{366}$ und „ausgesprochen besitzfreundlichen "Charakter ${ }^{367}$. Der langwierige und seit zwei Monaten heftig umstrittene Gesetzgebungsprozeß hatte damit zu einem Ergebnis geführt, das im Prinzip auf der Linie Helfferichs lag und das sich bereits vor der Ablösung Hilferdings als Finanzminister abgezeichnet hatte.

Obwohl die Verordnung vom 15. Oktober in einzelnen Punkten auch von der Mitwirkung Hilferdings am Stabilisierungskonzept geprägt war, bedeutete sie eine Niederlage der stärksten Koalitionspartei. Die Verordnung gründete in einer bürgerlich-konservativen Stabilisierungskonzeption, die unter maßgeblicher Beteiligung eines führenden Politikers der DNVP-Opposition entstanden und die vom Lobbyismus wirtschaftlicher Interessengruppen stark beeinflußt war. Bezeichnend ist, daß bei den letzten Beratungen die Gewerkschaften überhaupt nicht mehr zugezogen wurden und daß der sozialdemokratische Wiederaufbauminister Schmidt dies in der Kabinettssitzung vom 15. Oktober nur sehr verhalten kritisierte ${ }^{368}$.

Ob eine analoge Lösung im Rahmen der bestehenden Koalition auch unter formeller Wahrung des regulären legislativen Weges hätte erreicht werden können, erscheint trotz des inhaltlichen Zurücksteckens der SPD äußerst fraglich. Widerstände an der sozialdemokratischen Basis waren hier geradezu vorprogrammiert ${ }^{369}$. Dies darf freilich nicht als grundsätzliches Argument für die Praxis des legislativen Ausnahmezustands mißverstanden werden. Vielmehr offenbarte sich hier die paradoxe Situation, daß eine Regierung der Großen Koalition unter Einbeziehung der Sozialdemokratie schließlich jene Form der Währungsstabilisierung durchsetzte, die auch von den bislang widerspenstigen Kreisen der deutschen Wirtschaft, die jeden sozialdemokratischen Akzent der Regierungspolitik vehement bekämpften, akzeptiert wurde. Die Entwicklung und Durchsetzung einer konkreten Stabilisierungskonzeption wurde in dieser Situation zu einem technokratischen Prozeß, der von Anfang an parlamentarische Instanzen mied und schließlich mit einer gewissen Konsequenz auf dem Verordnungsweg endete. Um eine stärker sozialdemokratisch geprägte Form der Stabilisierung auf den Weg zu bringen, hätte die SPD vermutlich ihrem umstrittenen Finanzminister Hilferding mehr Rückhalt gewähren müssen, - was bereits Anfang Oktober zum Bruch der Koalition geführt hätte ${ }^{370}$.

Eine im Einklang mit den führenden Wirtschaftskreisen vollzogene Einleitung der Währungsstabilisierung hätte auf dem Wege regulärer parlamentarischer $\mathrm{Ge}$ setzgebung wohl nur im Rahmen einer Mitte-rechts-Mehrheit unter Einschluß der DNVP eine Chance gehabt. Wie später zu sehen sein wird, drängt sich hier eine Parallele zur französischen Situation im Jahre 1926 auf, als eine dauerhafte Stabilisierung des Franc erst nach dem Wechsel zu einer das Vertrauen der Wirt-

\footnotetext{
366 Vgl. $\$ 1$ der Verordnung (s. Anm. 363): „Von Vertretern der Landwirtschaft, der Industric, des Gewerbes und des Handels einschließlich der Banken wird die Deutsche Rentenbank errichtet.".

${ }^{367}$ So Winkler, Von der Revolution zur Stabilisierung, S. 673, im Vergleich zum Plan Hilferdings.

368 Vgl. Protokoll in AdR Stresemann, Nr. 136, hier S. 579.

369 Vgl. z. B. Schmidt zur Enttäuschung der Gewerkschaften in der Kabinettssitzung vom 15.10. 1923. AdR Stresemann, Nr. 136, S. 579.

$370 \mathrm{Ob}$ eine andere als die schließlich erreichte Lösung gegen Widerstände aus der Wirtschaft hätte umgesetzt werden können, sei hier dahingestellt.
} 
schaft besitzenden Regierung der Union nationale erreicht werden konnte. Die starre Haltung der DNVP in der Reparationsfrage schien freilich die SPD fast dazu zu zwingen, sich in eine Regierung zu fügen, die ihr in der zentralen währungspolitischen Thematik kaum mehr Einfluß einräumte. Damit beraubte sich die SPD aber auch der Chance, gegenüber der politischen Öffentlichkeit eine inhaltliche Alternative in Sachen Währungsstabilisierung zu markieren.

Trotz des Zurücksteckens der SPD in der Stabilisierungsfrage war der Anfang Oktober eingeleitete Zerfall der Großen Koalition nicht mehr zu stoppen, zumal jetzt der eigentliche Anlaß zur Erneuerung des Regierungsbündnisses - die Verabschiedung eines Ermächtigungsgesetzes - in die Realität umgesetzt worden war ${ }^{371}$. Vorangetrieben wurde die Auflösung des Regierungslagers vor allem durch zwei Entwicklungen. Zum einen blieben die auf einen Koalitionswechsel zielenden Verbindungen zwischen DNVP und DVP weiterhin aktiv. Wie aus einem Bericht von Scholz in der Sitzung des Fraktionsvorstands vom 27. Oktober hervorgeht, wurden die quasi-offiziellen Verhandlungen mit der DNVP offenbar fortgeführt ${ }^{372}$. Gleichzeitig erhielt die deutschnationale Presse in ihren Angriffen auf die Regierung Stresemann weiterhin Unterstützung von einzelnen DVP-Parlamentariern $^{373}$. Auf Stresemann lastete so ein permanenter Druck der eigenen Fraktion, die von einer loyalen Stützung ihres Kanzlers weit entfernt blieb. Daß dies Folgen für die Politik des Regierungschefs hatte, zeigte sich auch im zweiten akuten Belastungsfaktor für die Koalition, den Problemen mit Bayern, Sachsen und Thüringen im allgemeinen und der Reichsexekution gegen die seit dem 10. Oktober in Sachsen bestehende SPD-KPD-Koalition im besonderen.

Auf die inhaltliche Seite dieser Konflikte braucht hier nicht im einzelnen eingegangen zu werden ${ }^{374}$. Für den Reichsparlamentarismus relevant waren vor allem drei Aspekte:

1. Auf einer allgemeinen koalitionspolitischen Ebene ging es seitens der bürgerlichen Parteien wohl auch um eine nachhaltige Diskreditierung jedes Ansatzes zu einer sozialdemokratisch-kommunistischen Kooperation, mit der in Sachsen und auch in Thüringen experimentiert wurde ${ }^{375}$.

2. Auf der politischen Rechten wurde in dieser Frage - wie etwa ein taktisches Exposé des Reichs-Landbundes zeigt ${ }^{376}$ - bewußt öffentlicher Druck auf Stresemann aufgebaut, damit dieser entweder mit einer harten Haltung die Große Koalition gefährdet oder sich durch ein Nachgeben politisch kompromittiert.

3. Ebenso wie in der Stabilisierungsfrage gab es auch in der Reich-Länder-Thematik so gut wie keine parlamentarische Diskussion, weder im Reichstagsplenum noch in einem Ausschuß. Dies ist insofern verständlich, als es sich hier um ein

371 Vgl. zum folgenden allgemein Arns, Regierungsbildung, S. 171-174; Winkler, Von der Revolution zur Stabilisicrung, S. 648-669; Turner, Stresemann, S. 123-148.

372 Im Kurzprotokoll wird erwähnt: „Bericht des Vorsitzenden über die Gesamtlage und Verhandlungen mit Hergt.“ BA Koblenz, R 45 II, Nr. 66, Bl. 9.

373 Vgl. die Diskussion in der Sitzung des Vorstands der DVP-Reichstagsfraktion am 27.10.1923 zu einem Artikel von Quaatz im Tag vom 20. 10. 1923. Ebd.

${ }^{374}$ Vgl. hierzu v.a. Weiler, Die Reichsexekution gegen den Freistaat Sachsen; Rudolph, Die sächsische Sozialdemokratie, S. 402-414.

375 Wie Rudolph, ebd., von einer „linken Alternative“ für die Weimarer Republik zu sprechen, erscheint angesichts des Zustands der KPD allerdings mehr als gewagt.

376 BA Berlin, R 8005, Nr. 2, Bl. 33-35 ("Geheimakten Hergt“). 
Problemfeld der Reichsexekutive handelte, kein Gesetzgebungsbedarf bestand und die Koalition auch kein Interesse haben konnte, ihre internen Konflikte in die Öffentlichkeit zu tragen. Zeitgenössisch dürfte sich allerdings der Eindruck verstärkt haben, daß die wesentlichen politischen Fragen ohne Beteiligung des Reichstags gelöst wurden.

Zur Zuspitzung in der bayerisch-sächsischen Frage kam es, als sich Reichswehrminister Geßler am 27. Oktober im Kabinett mit seinem Verlangen nach einer Reichsexekution gegen Sachsen durchsetzte. Unmittelbarer Anlaß waren die Umtriebe der von der KPD beherrschten proletarischen Hundertschaften und die vermeintliche Unfähigkeit der sächsischen Landesregierung unter dem Sozialdemokraten Erich Zeigner, damit fertigzuwerden. Den SPD-Ministern gelang es zwar noch, mit einer ultimativen Rücktrittsforderung an Zeigner eine kurze Frist zu gewinnen. Als dieser aber ablehnte, fügten sich die sozialdemokratischen $\mathrm{Ka}$ binettsvertreter, und die Regierung Stresemann erwirkte bei Ebert nach Artikel 48 Abs. 1 eine Verordnung zur Reichsexekution. Unter der Leitung des als Reichskommissar eingesetzten ehemaligen DVP-Justizministers Heinze wurde schließlich die sächsische Regierung am 30. Oktober von der martialisch vorgehenden Reichswehr zum Rücktritt gezwungen und durch ein sozialdemokratisches Übergangskabinett ohne kommunistische Beteiligung ersetzt.

Die SPD-Spitze geriet durch ihre Rückendeckung für das harte Vorgehen in Sachsen unter massiven Druck aus der eigenen Partei, der noch dadurch gesteigert wurde, daß sich die Reichsregierung gegenüber dem eigenmächtigen Bayern weiterhin passiv verhielt. Dort blieb bekanntlich der gesonderte Ausnahmezustand weiterhin in Kraft und diente in erster Linie als Grundlage zu Maßnahmen gegen die politische Linke einschließlich der SPD. Die auf der extremen Rechten agierenden Kräfte hatten hingegen Narrenfreiheit, und der bayerische Landeskommandant der Reichswehr, Otto von Lossow, widersetzte sich mit Rückendeckung des bayerischen "Generalstaatskommissars" von Kahr offen seiner Absetzung durch Reichswehrminister Geßler.

All dies bildete für die seit Monaten in die Defensive gedrängte stärkste Regierungsfraktion einen unhaltbaren Zustand ${ }^{377}$. Die SPD mußte daher eine Aktion des Reiches gegen Bayern durchsetzen, wollte sie ihre Glaubwürdigkeit an der Basis nicht noch mehr beschädigen, als dies ohnehin schon der Fall war. Wenn Stresemann in der bayerischen Frage dennoch weiterhin dilatorisch vorging und so - wie Koch-Weser rückblickend formulierte - eine „unerklärliche Reizung der Sozialdemokratie“ bewirkte ${ }^{378}$, dann provozierte er geradezu einen Regierungsaustritt der SPD. Allerdings hatte der Kanzler für seinen "unverständlichen“"379 Kurs gegenüber Bayern schwerwiegende Motive. Neben der explosiven Lage im Reich $^{380}$ und der drohenden Konfrontation innerhalb der Reichswehr spielten da-

377 Vgl. auch Resümee in Vo, 1. 11. 1923 mo, S. 1, „Der Beschluß der Reichstagsfraktion“.

378 „Notizen: 17. November 1923“ (Die möglicherweise nachträglich angebrachte Datierung ist vermutlich falsch. Sie kann sich jedenfalls nicht auf das gesamte Notizenblatt beziehen, da hier gegen Ende auch vom Sturz Stresemanns am 23.11. die Rede ist.); BA Koblenz, Nl. Koch-Weser, Nr. 139, Bl. 217.

${ }^{379}$ Nach Severing, Lebensweg 1, S. 455, herrschte v.a. wegen der „unverständlichen Bayernpolitik Stresemanns" sozialdemokratische Mißstimmung.

380 Einen Eindruck der Problemfülle - Zuspitzung der sozialen Lage, beschleunigte Preissteigerun- 
bei wohl auch die Loyalitätsprobleme innerhalb der eigenen Fraktion und Partei eine Rolle. Eine Reichsexekution gegen Bayern hätte vermutlich den offenen Bruch zwischen Stresemann und jenen Teilen der DVP bedeutet, die mit der Politik Bayerns sympathisierten und zudem in dieser Frage eine Chance sahen, die SPD nun doch noch aus der Reichsregierung „herauszudrängen“381.

Das Ende der formellen Koalition war unter diesen Umständen schwer zu vermeiden ${ }^{382}$. Freilich wurde der Bruch jetzt wesentlich durch das schroffe und "plumpe“383 Verhalten der Sozialdemokraten geprägt. Am 31. Oktober verabschiedete die Reichstagsfraktion gleich drei ultimative Forderungen zum Verbleib in der Koalition, die umgehend der Reichskanzlei übermittelt und der Öffentlichkeit zugänglich gemacht wurden: 1. Aufhebung des militärischen Ausnahmezustandes, 2. Vorgehen gegen Bayern, 3. Sicherung von Ruhe und Ordnung in Sachsen durch die Schutzpolizei und nicht durch die Reichswehr ${ }^{384}$. Als Stresemann diese für ihn inakzeptablen Forderungen nach Rücksprache mit den bürgerlichen Kabinettsmitgliedern am 2. November im Kabinett entschieden zurückwies, erklärten die drei SPD-Minister noch am selben Tag ihren Austritt aus der Regierung ${ }^{385}$. Das somit in die parlamentarische Minderheit geratene Kabinett blieb jedoch im Amt, wobei von den freigewordenen Ressorts lediglich das besonders wichtige Innenministerium neu besetzt wurde. Nachfolger von Sollmann wurde der politisch weit rechts stehende und wegen seiner Nähe zum Konzept der „Versackungspolitik“ im Rheinland umstrittene Duisburger Oberbürgermeister Karl Jarres (DVP) ${ }^{386}$.

Der Koalitionsaustritt der SPD hatte zwei wesentliche legislative Konsequenzen. Zum einen war sehr fraglich geworden, ob das Arbeitszeitgesetz, das gemäß Koalitionsvereinbarung aus dem Geltungsbereich der Ermächtigung ausgenommen worden war und das der Reichstag bei Wiederzusammentritt hätte verab-

gen, Ernährungsprobleme, extremistische und separatistische Aktivitäten - vermittelt die Entschließung der Zentrumsfraktion vom 13.10.23 in BA Koblenz, Nl. ten Hompel, Nr. 17.

381 Vgl. Koch-Weser in der DDP-Vorstandssitzung vom 11.11. 1923: „Die Sozialdemokratie ist aus der Regierung hinausgedrängt worden. Ein Verbleiben für uns in der Regierung ist davon abhängig, daß der Einfluß der Sozialdemokraten sehr viel mehr gestärkt wird. "Zitiert nach AdR Stresemann, Nr. 214, S. 945, Anm. 8. Paraphrasierung des Protokolls in Linksliberalismus, Nr. 110, S. $302 \mathrm{f}$.

382 Dies sei gegen die erneut festzustellenden Klagen in der Literatur über mangelnde Kompromißfähigkeit der SPD festgestellt. Vgl. etwa Winkler, Von der Revolution zur Stabilisierung, S. 669: „Wie schon im November 1922 obsiegte damit wiederum die Parteiräson über das Interesse, das parlamentarische Regierungssystem funktionsfähig zu erhalten. Der Unterschied zum Herbst 1922 lag darin, daß die innere Krise inzwischen viel radikalere Dimensionen angenommen hatte und die Alternativen zur Großen Koalition noch erschreckender waren als ein Jahr zuvor." Hehl, Marx, S. 234, resümierend: „Indessen scheiterte die Große Koalition nicht eigentlich an diesen Herausforderungen, sondern an der Unfähigkeit bzw. Unwilligkeit der Parteien zum Kompromiß.“

${ }^{383}$ Vgl. Bericht Koch-Wesers vom 6. 11.1923: „Plump wie immer, wenn Verhandlungen im Gremium dieser grossen Fraktion stattgefunden haben“. BA Koblenz, Nl. Koch-Weser, Nr. 139, Bl. 206. Teilweise zitiert bei Arns, Regierungsbildung, S. 173.

${ }^{384}$ Text in Vo, 1. 11. 1923 mo, S. 1, „Der Beschluß der Reichstagsfraktion“. Arns, Regierungsbildung, S. 173, spricht fälschlicherweise von vier Bedingungen.

385 Protokolle der Besprechung der bürgerlichen Kabinettsmitglieder und der anschließenden Kabinettssitzung unter Einschluß der SPD in AdR Stresemann, Nr. 214f., S. 944-953; Demissionsschreiben der sozialdemokratischen Minister ebd., Nr. 216, S. 954.

${ }^{386} \mathrm{Zu}$ Jarres vgl. Dünnebacke, Karl Jarres; zum Kabinettseintritt ebd., S. 304 f.; zur „Versackungspolitik" - einer Strategie, dem besetzten Rheinland die Reichsmittel zu entziehen und es demonstrativ sich selbst zu überlassen - ebd., S. 306-313. 
schieden sollen, noch auf regulärem Wege zu realisieren war. Die Gesetzesvorlage von Ende Oktober wurde dann dem Parlament gar nicht mehr zur Beratung vorgelegt. Sie fand sich schließlich in einer nahezu analogen Verordnung vom 21. Dezember 1923 wieder ${ }^{387}$. Zum anderen war das Ermächtigungsgesetz mit dem Ausscheiden der SPD-Minister aus der Regierung Stresemann, wie in $\$ 2$ vorgesehen, unwirksam geworden. Zeitweise wurden daher wichtige finanzpolitische Verordnungen wieder auf Grundlage von Artikel 48 erlassen, darunter etwa am 6. November eine tief in das Budgetrecht des Reichstags eingreifende Ausweitung älterer Kreditermächtigungen ${ }^{388}$ sowie am 7. Dezember die erste „Steuernotverordnung "389. Insgesamt 25 legislative Verordnungen wurden im Laufe des Jahres 1923 auf der Grundlage von Artikel 48 Abs. 2 erlassen ${ }^{390}$. Während der Reichstag in Aussetzung seiner Kontrollfunktion diese Praxis nahezu widerstandslos akzeptierte, äußerten sich nun in der Öffentlichkeit zumindest einzelne Proteste. So warnte die Frankfurter Zeitung am 19. November: „Es muß endlich einmal gegen eine schrankenlose Auslegung des Artikels 48 Einspruch erhoben werden, die nach dem Grundsatze beliebt wird: , Was nicht verboten ist, das ist erlaubt.' [...] es geht nicht an, fortwährend neues Ausnahmerecht zu schaffen, dem tatsächlich die Rechtsgültigkeit fehlt. Hier heißt es: principiis obsta. “391

Die komplizierte parlamentarische Lage nach dem Scheitern der Großen Koalition, mit ihren vielfältigen informellen Verhandlungen, kann hier nur in groben Linien umrissen werden ${ }^{392}$. Vorab sei daran erinnert, daß die allgemeine politische Situation extrem gespannt blieb. Weiterhin wurden auf der extremen Rechten Diktaturpläne gesponnen. Am 8. und 9. November unternahm Hitler seinen Münchner Putschversuch. Die vollziehende Gewalt wurde darauf von Reichspräsident Ebert im Rahmen des seit Ende September geltenden reichsweiten Ausnahmezustands auch formell an General von Seeckt übertragen. Am 15. November trat die neue Währungsordnung in Kraft, und das Schicksal der Rentenmark erschien zunächst äußerst ungewiß. Daß die gespannte Stimmungslage im Lande auch erhebliche Folgen für das Wahlverhalten hatte, zeigten die Bürgerschaftswahlen in Bremen am 18. November: Einem Erfolg der radikalen Parteien, die gegenüber dem letzten Wahltermin im Februar 1921 etwa 16\% hinzugewannen, standen deutliche Verluste der regierenden Großen Koalition und insbesondere der SPD entgegen ${ }^{393}$.

${ }^{387}$ RGBl. 1923 I, S. 1249-1251. Die Verordnung wurde auf der Grundlage des Ermächtigungsgesetzes vom 8. 12. 1923 erlassen.

$388 \mathrm{Vgl}$. Bericht und kritischen Kommentar in FZ, 7. 11. $1923 \mathrm{mo} / 2$, S. 3, „Kreditermächtigung ohne Befragen des Parlaments".

${ }^{389}$ RGBL. 1923 I, S. 1177. Die Verordnung diente v.a. der Vorverlegung von Steuerterminen. - Weitere Beispiele in Huber, Verfassungsgeschichte 6, S. 446, Anm. 64; Liste aller Verordnungen in Poetzsch, Staatsleben 1, S. 213.

390 Zwei Aufhebungsverordnungen sind hier nicht mitgerechnet. Vgl. Überblick im Anhang, Tab. 8, sowie Liste in Poetzsch, Staatsleben 1, S. 141-147; ebd. auch die Nachweise aus dem RGBl. Die bei Mergel, Parlamentarische Kultur, S. 223, für 1923 angegebene $Z$ ahl von insgesamt nur fünf Verordnungen auf der Grundlage von Art. 48 liegt viel zu niedrig. Zuzüglich „klassischer" Ausnahmeverordnungen und Aufhebungsverordnungen waren es sogar 41 Verordnungen auf der Grundlage von Art. 48 Abs. 2.

391 FZ, 19. 11. 1923 mo, S. 1, „Bemerkungen“.

392 Vgl. Arns, Regierungsbildung, S. 174-177; Huber, Verfassungsgeschichte 7, S. 390-428.

393 Kommunisten und extreme Rechte (DNVP, NSDAP und Deutschvölkische Freiheitspartei) ge- 
Wie konnte es nun parlamentarisch und auf Regierungsebene weitergehen? Aus funktionaler Sicht muß zunächst nochmals betont werden, daß sich die Spannweite innerhalb einer extrem breiten Koalition vom linken Flügel der SPD bis zum rechten der DVP für eine Erfüllung der regierungstragenden Funktion als zu groß erwiesen hat - wie immer man auch die Frage nach der Verantwortlichkeit für den Bruch beantwortet. Eine Erneuerung der Großen Koalition, wie sie von Stresemann und Reichspräsident Ebert erhofft wurde ${ }^{394}$, wäre daher wohl kaum ein sinnvoller Weg gewesen. Erschwert wurde ein derartiger Versuch zudem durch die engen Verhandlungsspielräume, da die SPD kaum hinter ihre apodiktischen Forderungen vom 31. Oktober zurück konnte und da Seeckt kaum bereit war, in der Frage des Ausnahmezustandes zumindest in Sachsen und Thüringen etwas einzulenken ${ }^{395}$.

Die zweite Möglichkeit, zu einer parlamentarischen Mehrheit zu kommen, wäre in einem „Bürgerblock“ unter Einschluß der DNVP gelegen ${ }^{396}$, jene Lösung, die von einem Teil der bürgerlichen Koalitionsfraktionen schon seit Wochen angestrebt wurde. Diesbezügliche Verhandlungen zwischen DVP und DNVP waren auch jetzt wieder im Gange ${ }^{397}$. Sie scheiterten letztlich wohl vor allem an Widerständen in der DDP, wo die Stimmungslage offensichtlich eher zur SPD hin tendierte ${ }^{398}$, an der Uneinigkeit innerhalb der DVP399, an weitreichenden Forderungen der DNVP, die insbesondere auch auf eine Auswechslung des Kanzlers zielten, und vermutlich auch an grundsätzlichen Vorbehalten Stresemanns. Ein ernsthafter Verhandlungsversuch wurde vom Kanzler offenbar nicht unternommen. Vielleicht wäre auch ein von der DNVP gefordertes „überparteiliches Kabinett mit starkem Rechtseinschlag“ mehrheitsfähig gewesen, wenn sich ein geeigneter Kanzlerkandidat gefunden hätte. Der von Reichspräsident Ebert favorisierte deutsche Botschafter in Washington, Otto Wiedfeldt, lehnte ein entsprechendes Angebot aber mit guten Gründen $a b^{400}$. Wie er in einem Brief an Seeckt betonte,

wannen jeweils rund $10 \%$ hinzu. Die vereinigte SPD kam lediglich auf $29,1 \%$ und blieb damit um $12,8 \%$ unter der Summierung des SPD- und USPD-Ergebnisses vom Februar 1921. Zahlen nach Falter, Wahlen, S. 93.

${ }^{394}$ Nach Meissner, Staatssekretär, S. 133, suchte Ebert die SPD-Führung zum Wiedereintritt zu bewegen. Zu Stresemann vgl. ausführlich Turner, Stresemann, S. $145 \mathrm{f}$.

395 Stresemann hoffte, über eine Aufhebung des speziellen Ausnahmezustands in Sachsen und Thüringen, die SPD etwas zu „besänftigen“. So ebd., S. $146 \mathrm{f}$.

396 Stand Ende 1923: SPD 173, DDP 39, Zentrum 68. Nach Arns, Regierungsbildung, Anlage II.

${ }^{397}$ Scholz verhandelte am 4. 11. 1923 unter Anwesenheit von Kempkes und unter Zustimmung von Stresemann mit Hergt und Westarp. Vgl. Fraktionsprotokoll vom 5.11. in Stresemann, Vermächtnis 1, S. 195 f. Ebd., S. 195 heißt es zur Kanzlerschaft: „Stresemann käme höchstens für eine gewisse Übergangszeit als Leiter eines neuen bürgerlichen Kabinetts in Frage. Kabinett müsse überparlamentarisch mit starkem Rechtseinschlag sein. Stresemanns Nachfolger Wiedfeldt, Stresemann vielleicht Botschafter in Washington." Zum Unterstützungsangebot des Stahlhelms vgl. Berghahn, Stahlhelm, S. $43 \mathrm{f}$.

398 Vgl. Koch-Weser in der DDP-Vorstandssitzung vom 11.11. 1923 (s. Anm. 381).

399 Erkelenz berichtete am 2. 11. 1923 in einem Brief an den bayerischen DDP-Landtagsabgeordneten Karl Hammerschmidt aufgrund „allerlei vertrauliche[r] Mitteilungen“, daß in der DVP „ein $\mathrm{Zu}$ stand völliger Verfahrenheit“ herrsche. BA Koblenz, Nl. Erkelenz, Nr. 29, Bl. 7. Vgl. auch Meissner, Staatssekretär, S. 133.

${ }_{400}$ Am 10. 11. 1923 erfolgte eine Anfrage im Auftrag von Seeckt und Ebert, ob Wredfeldt Kanzler und Außenminister werden wolle. Vgl. Abschrift eines Telegramms Holtzendorffs an J.P. Meyer; IfZ München, Nl. Seeckt, Stück 72, fasc. 14. Ablehnungsschreiben ebd. $-\mathrm{Zu}$ dem ganzen Vorgang aus der Perspektive Wiedfeldts vgl. Schröder, Otto Wiedfeldt, S. 142-145. Ebd., S. 170f., Brief Wied- 
besaß er keinerlei parteipolitische Verankerung und stand den Vorgängen in Berlin doch recht fremd gegenüber. Das Schicksal Cunos mag hier durchaus lehrreich gewirkt haben - umso unverständlicher erscheint es, daß Ebert erneut auf einen parlamentsfernen Kandidaten setzte. Wiedfeldt tauchte auch in den von Rechtskreisen in Verwaltung, Wehrmacht und Wirtschaft propagierten und von Ebert ernsthaft erwogenen Plänen auf, ein parlamentarisch nicht verantwortliches befristetes Reichsdirektorium zu installieren. Eine derartige Lösung wäre eine klar systemsprengende und verfassungswidrige Entparlamentarisierung der Regierungsbildung gewesen, die von Seeckt und Ebert dann doch nicht gewagt wurde ${ }^{401}$. Allerdings, dies erklärt Eberts Verhalten teilweise, war ein geeigneter parlamentarischer Kandidat, der kraft seiner persönlichen Autorität geeignet gewesen wäre, eine mehrheitsfähige Mitte-rechts-Regierung zusammenzubringen, nicht in Sicht, und Stresemann, der dies ein Jahr zuvor vielleicht noch hätte erreichen können, war inzwischen auf der parlamentarischen Rechten in Ungnade gefallen.

Eine dritte Möglichkeit zur parlamentarischen Mehrheits- und Regierungsbildung spielte zeitgenössisch fast überhaupt keine Rolle und wird auch in der Literatur übersehen: Eine Rückkehr zur Weimarer Koalition hätte über eine komfortable Reichstagsmehrheit von immerhin 280 von 459 Mandaten verfügt ${ }^{402}$. Blokkiert wurde eine derartige Option offenbar von einer ganzen Reihe von Hindernissen. So wäre eine Beendigung der Koalition mit der DVP im Zentrum wohl kaum durchzusetzen gewesen ${ }^{403}$. Die in Rechtskreisen im ganzen Land aufgeheizte Stimmung aber wäre durch eine "marxistisch“ dominierte Regierungsbildung zweifellos weiter angefacht worden. Unsicher waren auch die Reaktionen der Finanzmärkte und damit die währungspolitischen Konsequenzen.

Eine vierte Option lag in einem Weiterregieren des bürgerlichen „Rumpfkabinetts" Stresemann, verbunden mit der Hoffnung auf Tolerierung und partielle Unterstützung durch die SPD. Ein Hauptproblem war, daß Stresemann infolge seiner Sachsen- und Bayernpolitik viel an persönlicher Glaubwürdigkeit verloren hatte. Das Vorhaben des Kanzlers, die SPD mit der Drohung einer Reichstagsauflösung gefügig zu machen, scheiterte an der Weigerung Eberts, erneut - wie bereits Anfang Oktober - eine präsidentielle Auflösungsorder zuzugestehen ${ }^{404}$.

$\mathrm{Da}$ Stresemann, der weiterhin auch unter erheblichem innerparteilichem Druck stand ${ }^{405}$, um eine Fortsetzung seiner Kanzlerschaft bemüht war und nicht - wie alle seine Vorgänger - von selbst zurücktrat, entschied sich das Schicksal seiner

feldts an Seeckt vom 24.11. 1923 mit Begründung der Ablehnung. Wiedfeldt gibt hier eine sehr triftige Begründung: „Aber hinter mir steht keine der politischen Parteien, mit denen ich kaum Fühlung habe."

401 Vgl. v.a. Huber, Verfassungsgeschichte 7, S. 391-394.

402 Stand Ende 1923: SPD 173, DDP 39, Zentrum 68. Vgl. Anhang, Tab. 4.3.

${ }^{403}$ Vgl. v.a. Marx in der Fraktionssitzung vom 19. 11. 1923: „Geht Kabinett Stresemann, werden Neuwahlen kommen. Kleine Koalition? Nein! Herr Oberbürgermeister Adenauer [?] wollte an Beratung teilnehmen; ich habe abgelehnt." Protokolle Zentrumspartei, Nr. 266, S. 502. Ob es einen Zusammenhang zwischen der Option „Kleine Koalition“ und Adenauer gibt, bedürfte der Klärung. Giesberts fürchtete beim Sturz Stresemanns eine Spaltung des Zentrums. Ebd., S. 503.

404 Vgl. Turner, Stresemann, S. 146, hier auch Diskussion der Motive Eberts; Hertzman, DNVP, S. $201 \mathrm{f}$.

405 Einen gewissen Erfolg erzielte Stresemann freilich am 18.11. 1923 in der Tagung des Zentralvorstandes, wo er eine klare, mit $206 \mathrm{zu} 11$ Stimmen verabschiedete Vertrauenserklärung erlangte. Abgedruckt in Nationalliberalismus, Nr. 53, S. 487. 
Regierung im Parlament. Zunächst mußte der Reichstag allerdings erst einmal zusammentreten. Stresemann und die verbliebene bürgerliche Minderheitskoalition hatten dies nach der Demission der drei sozialdemokratischen Minister bewußt vermieden. Auch der verfassungsgemäß vorgesehene Termin für den automatischen Zusammentritt des Reichstags am ersten Mittwoch im November war verstrichen ${ }^{406}$. Die SPD-Fraktion, in der man inzwischen zu einem Mißtrauensantrag neigte, vermochte es jedoch dank ihrer Fraktionsstärke, die über einem Drittel der Abgeordnetenzahl lag407, eine Einberufung des Reichstags für den 20. November durchzusetzen.

Die wesentlichen Vorgänge und Ergebnisse der bis zum 23. November dauernden Aussprache sind bekannt und können hier knapp behandelt werden ${ }^{408}$. Herausgehoben sei Stresemanns große Rede vom 22., in der er im Zeichen der „Volksgemeinschaft" um parlamentarisches Vertrauen warb ${ }^{409}$. Deutlich wies der Kanzler dabei auf die bestehende Gefährdung des parlamentarischen Systems hin, das in Deutschland gegenwärtig "alle Kinderkrankheiten" durchmache. Auffallend ist der defensive, an die konservative Akzeptanz der frühen Dritten Republik in Frankreich ${ }^{410}$ erinnernde Ansatz in der grundsätzlichen Verteidigung dieses Systems: „Jedenfalls soll man etwas - ich sage nicht das Gute, das Bestehende - solange nicht aufgeben, ehe man nicht sagt, was man Besseres an die Stelle zu setzen hat. Ich glaube, daß der Bolschewismus nach russischem Muster oder der unter einer ganz anderen Sonne unter der Führung eines genialen Staatsmannes geschaffene Faszismus in Italien nicht die Vorbilder sind, die plötzlich an die Stelle dieses Systems in Deutschland treten könnten, ohne Deutschland zu zerreißen. Unser deutscher Volkskörper ist fieberkrank und verträgt nicht die Eisenbartkur eines neuen Bürgerkrieges." 411

Möglicherweise unternahm hier Stresemann tatsächlich den heroischen Versuch, durch eine wirkungsvolle Reichstagsrede die Verhärtung der politischen Fronten aufzubrechen, vielleicht sogar die Logik des parteiengestützten Systems zu durchbrechen und ganz im Sinne des deliberativen Parlamentarismus eine Individualisierung des Abgeordnetenverhaltens zu erreichen ${ }^{412}$. „Obwohl er vielleicht der beste Kenner des Parlaments war", so erinnert sich Geßler, "glaubte er (oder tat wenigstens so), als könne er durch die Macht seiner Rede und das Ge-

406 Art. 24, Satz 1: „Der Reichstag tritt in jedem Jahre am ersten Mittwoch des November am Sitze der Reichsregierung zusammen." Vgl. auch Hinweis in Arns, Regierungsbildung, S. 176.

407 Vgl. Art. 24, Satz 2, WRV: Der Präsident des Reichstags muß ihn früher berufen, wenn es der Reichspräsident oder mindestens ein Drittel der Reichstagsmitglieder verlangt.

408 Vgl. v.a. Arns, Regierungsbildung, S. $176 \mathrm{f}$., der allerdings nicht auf Stresemanns Rede vom 22. eingeht. Hierzu Turner, Stresemann, S. $147 \mathrm{f}$.

409 Verh. RT 361, S. 12180-12196. Zum Eindruck, den diese Rede gemacht hat, vgl. z. B. Koch-Weser in dem auf den 16.5.1924 datierten Nachtrag zu seinen tagebuchartigen Notizen: „Stresemanns Sturz als Kanzler erfolgt in offener Feldschlacht. Er benahm sich würdiger im Sterben als im Leben. Glänzende Schlussrede und Markierung äusserster Festigkeit“. BA Koblenz, Nl. KochWeser, Nr. 30, Bl. 19.

410 Vgl. das bekannte Diktum von Adolphe Thiers zur Staatsform der Republik: „ce régime qui divise le moins".

4 11 Verh. RT 361, S. 12195; auch zitiert bei Turner, Stresemann, S. 147.

412 Dies ist in der Literatur bislang nicht wahrgenommen worden. Turner, Stresemann, S. 148, stellt lediglich trocken fest: „Seine Beredsamkeit übte indes auf die Sozialdemokraten keine Wirkung aus." 
wicht seiner Gründe bei der ungeheuren Verwirrung den Fraktionsgeist besiegen“413. Ein derartiges Vorhaben entspräche Stresemanns Glauben an die „Courage" des individuellen politischen Führers ${ }^{414}$. Möglicherweise ging es dem erfahrenen Parlamentarier aber auch nur darum, einen wirkungsvollen Abgang zu vollziehen. Hierfür spricht, daß es der Kanzler in seiner Rede versäumte, der SPD ein inhaltliches Signal des Entgegenkommens zu geben. Von einer Abmilderung des militärischen Ausnahmezustands war ebensowenig die Rede wie von einem schärferen Vorgehen gegen Bayern ${ }^{415}$.

Am 23. November lagen schließlich drei Mißtrauensanträge vor: ein kommunistischer, ein deutschnationaler und ein sozialdemokratischer, zu dem sich die SPD-Fraktion nach langen Beratungen am Abend des 22. entschlossen hatte ${ }^{416}$. $\mathrm{Da}$ es bisher parlamentarische Praxis war, „daß die einzelnen Parteien nur für ihren eigenen Mißtrauensantrag stimmten und damit bewußt und gewollt in der Minderheit blieben" ${ }^{417}$, war damit eine reelle Überlebenschance des Kabinetts Stresemann gegeben. Diese wurde noch dadurch vergrößert, daß die SPD ihren Antrag inhaltlich mit der Diskrepanz zwischen der Handhabung des Ausnahmezustands in Sachsen und Thüringen und der Passivität gegenüber Bayern begründete, was eine Zustimmung der DNVP so gut wie ausschloß. Vermutlich hat Arns recht, wenn er annimmt, daß die SPD-Fraktion eine Ablehnung ihres Mißtrauensantrags „insgeheim erhoffte" ${ }^{418}$. Daß die SPD diesen Antrag trotzdem stellte, wurde zeitgenössisch wie auch in der Literatur häufig und hart kritisiert. Am bekanntesten ist das immer wieder zitierte Diktum des verärgerten Reichspräsidenten gegenüber seinen Parteifreunden: „Was Euch veranlaßt, den Kanzler zu stürzen, ist in sechs Wochen vergessen, aber die Folgen Eurer Dummheit werdet Ihr noch zehn Jahre lang spüren." ${ }^{419}$

Zweifellos handelte es sich bei dem Mißtrauensantrag der SPD-Fraktion um einen fragwürdigen Akt rein demonstrativer Politik, der wenig Rücksicht auf die akute Krisensituation nahm. Allerdings sind auch die längerfristigen Hintergründe zu beachten. Seit Regierungsantritt hatte sich die SPD als die weitaus stärkste Fraktion des Kabinetts mit einer eher zurückgezogenen Rolle begnügt, sie hatte Kompromißfähigkeit und Nachgiebigkeit gezeigt, und sie war dabei vom rechten Flügel der DVP zunehmend in die Enge getrieben worden. Der Kanzler hatte es in dieser Zeit nicht gewagt, mit seinen innerparteilichen Gegnern zu brechen und seinen Kurs stärker nach den Kräfteverhältnissen innerhalb des Regie-

${ }^{413}$ Geßler, Reichswehrpolitik, S. 280.

414 Vgl. z. B. Stresemann am 10.8. 1923 in der DVP-Fraktionssitzung: „Ein Führer muß selbst wissen, ob er sich die Courage zutrauen darf; sie kann ihm nicht von außen zugeführt werden.“ Stresemann, Vermächtnis 1, S. 78.

$415 \mathrm{Vgl}$. in diesem Sinne auch den Bericht in FZ, 23.11. $1923 \mathrm{mo} / 2$, S. 1, „Noch keine entscheidende Abstimmung".

${ }_{416}$ Vgl. FZ, 23. 11. 1923 mo/2, S. 1, „Die Kabinettsfrage“; Arns, Regierungsbildung, S. 176.

417 Geßler, Reichswehrpolitik, S. 279.

418 Arns, Regierungsbildung, S. 176.

${ }_{419}$ Stresemann, Vermächtnis 1, S. 245. Vgl. auch Meissner, Staatssekretär, S. 134: „[...] an den Folgen dieser übereilten und unüberlegten Entschließung würden Parlament und Regierung noch lange zu tragen haben". Ebert kritisierte in einer Parteiführerbesprechung - wie Meissner überliefert „den Fraktionsbeschluß mit einer bei ihm sonst ungewohnten Schärfe als eine politische Dummheit und als Mangel an Verantwortungsgefühl“. 
rungslagers auszurichten. Stresemanns Sachsen- und Bayernpolitik hatte daher zum sozialdemokratischen Regierungsaustritt geführt, und eine Mißtrauensbekundung der SPD-Fraktion im Reichstag bedeutete letztlich nur die parlamentarische Ratifizierung dieses Schrittes. Aus Sicht einer funktionalen Parlamentarismusanalyse muß zudem festgestellt werden, daß die Kritik an der SPD wiederum einseitig auf die parlamentarische Stützung der Regierung fixiert ist. Der Mißtrauensantrag bot, dies war gleichsam seine positive Kehrseite, eine gewisse Chance zur Belebung der parlamentarischen Alternativfunktion. Die SPD konnte so versuchen, ihr in den letzten Monaten stark verschwommenes Profil wieder zu schärfen und zumindest eine symbolische Besetzung der neuen Oppositionsrolle vorzunehmen. Angesichts des offensichtlichen kommunistischen Terraingewinns in der Arbeiterschaft ${ }^{420}$ war das Verhalten der SPD daher keineswegs so irrational, wie es meist dargestellt wird, zumal - wie bereits erläutert - mit der spezifischen Begründung des Antrags offenbar versucht wurde, das bürgerliche Rumpfkabinett vor einem Sturz zu verschonen.

Stresemann machte jedoch allen Spekulationen über eine gegenseitige Neutralisierung der drei Mißtrauensanträge ein Ende, indem er, vermutlich unter dem anhaltenden Druck des rechten DVP-Flügels und auch beeinflußt von der Stimmungslage in seinem Kabinett ${ }^{421}$, mittels eines gemeinsamen Antrags der drei verbliebenen Koalitionsfraktionen die Vertrauensfrage stellen ließ ${ }^{422}$. Dabei berief er sich ausdrücklich darauf, daß die „Motivierung“ des sozialdemokratischen Mißtrauensantrags möglicherweise dessen parlamentarische Ablehnung zur Folge habe ${ }^{423}$. Die Reichsregierung, so führte der Kanzler unter „lebhafte[m] Bravo bei der Deutschen Volkspartei und in der Mitte“ aus, habe "nicht die Absicht, ihre Geschäfte fortzuführen auf Grund einer durch solche parlamentarische Arithmetik herbeigeführten Entscheidung "424. Der primär als Demonstration gedachte Mißtrauensantrag der SPD wurde somit von Stresemann mit einem ebenso demonstrativen Akt beantwortet, für den eine zwingende Notwendigkeit eigentlich nicht vorlag.

Das Ergebnis des Vertrauensvotums, das im Reichstag gegenüber den Mißtrauensanträgen den Vorrang hatte, brachte dann auch die vom Kanzler erstrebte Eindeutigkeit: 156 Parlamentarier stimmten für die Regierung, 230 dagegen, 7 enthielten sich und 52 Abgeordnete fehlten unentschuldigt ${ }^{425}$. Die drei bürgerlichen Regierungsfraktionen traten weitgehend geschlossen für den Vertrauensantrag

${ }^{420}$ Erinnert sei hier auch an das Wahlergebnis vom 18.11. 1923 in Bremen. Vgl. oben S. 302. Ein direkter Zusammenhang zwischen diesem Ergebnis und der SPD-Fraktionsentscheidung vom 22. 11. 1923 ließ sich bislang freilich (noch) nicht feststellen.

421 Zum Kabinett vgl. Turner, Stresemann, S. 146f. Vgl. auch Protokoll der Kabinettssitzung vom 19. 11. 1923; AdR Stresemann, Nr. 268, hier v.a. S. 1130-1136.

422 Antrag Nr. 6352, eingebracht von „Dr. Scholz, Marx, Erkelenz und Genossen“. „Der Reichstag wolle beschließen: Der Reichstag spricht der Reichsregierung das Vertrauen aus." Verh. RT 380, S. 7628.

${ }^{423}$ Verh. RT 361, S. 12240-12241, hier S. 12240: „Diese Motivierung des Mißtrauensvotums ergäbe parlamentarisch-taktisch die Möglichkeit, daß die eingegangenen Mißtrauensvoten aus ganz verschiednen Beweggründen etwa abgelehnt würden.“

+24 Ebd., S. 12240.

425 Eine Reihe von Abgeordneten war zudem krank gemeldet und entschuldigt. Liste der namentlichen Abstimmung ebd., S. 12292-12294. 
ein. Allerdings gelang es Stresemann erneut nicht, seine eigene Fraktion vollständig hinter sich zu bekommen. Sechs Abgeordnete - darunter Stinnes und seine engsten Freunde 426 - fehlten bei der Abstimmung. Bei der SPD entzogen sich 32 Parlamentarier (knapp $20 \%$ ) $^{427}$ durch ihre Abwesenheit der fraktionell geforderten Ablehnung und gaben damit eine Mißbilligung der eigenen Parteilinie zu erkennen. Noch am selben Abend reichte das Kabinett seine Demission ein.

Tab. 9: Votum des Reichstags am 23. 11. 1923:

Vertrauensabstimmung Regierung Stresemann II ${ }^{428}$

\begin{tabular}{lrrrrrrc}
\hline $\begin{array}{l}\text { Fraktion/ } \\
\text { Gruppe }\end{array}$ & Abg. & ja & nein & $\begin{array}{l}\text { ent- } \\
\text { halten }\end{array}$ & fehlend & $\begin{array}{l}\text { beurl. } \\
\text { krank } \\
\text { entsch. }\end{array}$ & $\begin{array}{l}\text { Kohä- } \\
\text { renz }\end{array}$ \\
\hline KPD & 16 & - & 13 & - & 3 & - & $(81 \%)$ \\
USPD & 2 & - & 2 & - & - & - & - \\
SPD & 171 & - & 134 & - & 32 & 5 & $81 \%$ \\
DDP & 39 & 37 & - & - & - & 2 & $100 \%$ \\
Zentrum & 66 & 60 & 1 & - & 4 & 1 & $92 \%$ \\
DVP & 66 & 58 & - & - & 6 & 2 & $91 \%$ \\
BBMB & 4 & - & - & 4 & - & - & - \\
BVP & 20 & - & 14 & 3 & 2 & 1 & $74 \%$ \\
DHP & 4 & - & 4 & - & - & - & - \\
DNVP430 & 65 & - & 60 & - & 3 & 2 & $95 \%$ \\
DVFP & 3 & - & 1 & - & 2 & - & - \\
fraktionslos & 2 & 1 & 1 & - & - & - & - \\
\hline Gesamt & 458 & 156 & 230 & 7 & 52 & 13 & - \\
\hline
\end{tabular}

Gut drei Monate nach Amtsantritt war damit die Kanzlerschaft Stresemanns endgültig gescheitert. Daß in dieser kurzen Phase der Ruhrkampf beendet, die entscheidenden Schritte zur Währungsstabilisierung eingeleitet und die Staatskrise vom Oktober überwunden wurde, ergibt im historischen Rückblick - weniger freilich für die Zeitgenossen - durchaus eine positive Gesamtbilanz. Ganz anders fällt das Urteil über die funktionale Entwicklung des Reichstags aus. Die Anfang Oktober nur mit größter Mühe erneuerte Große Koalition war als parlamentarisches Regierungslager in ihrer regierungsstützenden Funktion gerade stark genug gewesen, ein weitreichendes Ermächtigungsgesetz zu verabschieden. Damit freilich war die raison d'être der Koalition sofort wieder hinfällig geworden. Der Regierungsaustritt der SPD Anfang November leitete dann eine neue Phase im legislativen Funktionsverzicht des Reichstags ein, indem zeitweise ein auf Artikel 48 gestütztes Verordnungsregime etabliert wurde. In den Wochen des bürgerlichen

426 Es fehlten die Abgeordneten Moldenhauer, Dannemann, Hepp, Vögler, Oertel und Stinnes. Ebd.

${ }^{427}$ Die meisten (25) der Fehlenden entstammten der MSPD.

${ }^{428}$ Nach Liste der namentlichen Abstimmung in Verh. RT 361, S. 12292-12294. Nach dem ebd., S. 12294 angebenen Gesamtergebnis waren es 231 Nein-Stimmen. Die Unstimmigkeit zur fraktionellen Auszählung konnte nicht geklärt werden.

${ }^{429}$ Einschließlich Hospitanten.

430 Einschließlich der Bayerischen Mittelpartei. 
Rumpfkabinetts, in denen das Parlament nicht zusammentrat, übten sich Seeckt und Ebert zudem in Planungen für eine erneute Entparlamentarisierung der Regierungsbildung. Daß schließlich mit dem gescheiterten Vertrauensvotum für Stresemann zum ersten Mal in der Weimarer Geschichte eine Regierung ,in offenem parlamentarischem Kampfe" stürzte, erscheint vor diesem Hintergrund schon fast wie ein Lebenszeichen des Reichstags ${ }^{431}$.

\section{Bildung der Regierung Marx}

Nachdem der Sturz der Regierung Stresemann, wie die Frankfurter Zeitung feststellte, einen „Haufen von Scherben“ hinterlassen hatte ${ }^{432}$, war es extrem schwierig, ein neues Kabinett zustande zu bekommen. Die dabei auftretenden Probleme übertrafen alles bisher bei Weimarer Kabinettsbildungen Erlebte. Mindestens vier Kanzlerkandidaten ${ }^{433}$ - Siegfried von Kardorff (DVP), Karl Jarres (DVP), Heinrich Albert (parteilos) und Adam Stegerwald (Zentrum) - mühten sich vergeblich, bis endlich dem Zentrumsvorsitzenden Marx am 30. November die Bildung eines Minderheitskabinetts von Zentrum, BVP, DVP und DDP gelang.

Auf die kaum mehr definitiv zu klärenden Verhandlungsprozesse kann hiẹr nicht detailliert eingegangen werden ${ }^{434}$. Um die funktionale Leistungsfähigkeit des Reichstags bei dieser Regierungsbildung zu bewerten, sollen vielmehr drei grundsätzliche Fragen in den Mittelpunkt der Analyse gestellt werden: 1. Unter welchen Umständen kam mit Albert erneut ein präsidentieller Kandidat ohne Parteienbindung ins Spiel, und wie reagierten die parlamentarischen Kräfte darauf? 2. Warum scheiterte die Einbeziehung der DNVP in einen „Bürgerblock“? 3. Warum hatte auch die zweite realistische Option für eine Mehrheitsregierung, eine Wiederbelebung der Weimarer bzw. - wie es zeitgenössisch meist hieß - der "Kleinen" oder „Wirthschen" Koalition, keine Chance?

1. Nach dem Rücktritt der Regierung Stresemann tendierte Ebert zunächst dazu, den neuen Kanzler in den Reihen des Zentrums zu suchen, was angesichts der Mittelposition dieser Partei innerhalb einer möglichen bürgerlichen Regierungsbildung sicher ein sinnvoller Ansatz war. Stegerwald 435 und Marx, den Ebert am Morgen des 24. November sogar durch einen Wagen von zu Hause abholen

431 Vgl. - in etwas anderem Kontext - zu einer generell positiven Bewertung FZ, 24. 11. 1923 ab, S. 1, „Frankfurt, 24. November": „Zum ersten Male in all den Kabinettskrisen dieser Jahre ist eine Regierung in offenem parlamentarischem Kampfe gestürzt, nicht in halbgeheimen KonventikelBesprechungen beseitigt worden. Das ist zu loben."

${ }^{432}$ Ebd.

${ }^{433}$ Erinnerungsbericht von Marx „Berufung zum Reichskanzler“, nach Nachlaß des Reichskanzlers Wilhelm Marx 2, S. 317, nennt zudem für den 23.11. Julius Curtius (DVP). Bei Arns, Regierungsbildung, S. 178, und auch in der sonstigen Literatur fehlt dieser Name. Stresemann, Vermächtnis 1 , S. 255, nennt zudem Adenauer. Arns, Regierungsbildung, Anmerkungsteil S. 83, Anm. 6, nimmt wohl zu Recht an, daß Adenauers Name "nur als Möglichkeit im Gespräch“ war.

434 Vgl. hierzu einander ergänzend, in manchen Punkten aber auch widersprüchlich v.a. Arns, Regierungsbildung, S. 178-182, sowie - speziell zu den Versuchen Kardorffs - S. 207-209; AdR Marx, S. VII-XI; Hehl, Marx, S. 249-253; Eilers, Ermächtigungsgesetz und militärischer Ausnahmezustand, S. 24-43; Winkler, Von der Revolution zur Stabilisierung, S. 677-679. Insgesamt besteht in Einzelfragen noch erheblicher Klärungsbedarf, der den Rahmen dieser Untersuchung sprengen würde.

${ }_{435}$ Diese von Arns, Regierungsbildung, übersehene Anfrage wird deutlich aus einer Erklärung Stegerwalds in Ge, 30. 11. 1923, S. 2, „Warum Stegerwald ablehnte“. 
ließ336, lehnten jedoch umgehend ab. Der ehemalige Reichskanzler Fehrenbach bekräftigte am 24. November gegen Mittag die grundsätzliche Weigerung der Fraktion, den künftigen Kanzler zu stellen. Begründet wurde diese Haltung damit, daß das Zentrum „schon wiederholt die Last der Verantwortung übernommen habe“437. Möglicherweise waren für die anfängliche Zurückweisung der Kanzlerschaft aber auch konkrete Bedenken wegen der aktuellen Situation im Rheinland maßgebend ${ }^{438}$. Fehrenbach schob die Frage der Kanzlerschaft an die DVP zurück, indem er den Namen Kardorffs ins Spiel brachte ${ }^{439}$. Nachdem dessen Regierungsbildungsversuche und kurz darauf auch die von Jarres rasch gescheitert waren ${ }^{440}$ und der Reichspräsident am Nachmittag des 25 . November mit den bisherigen Ministern Jarres, Geßler und Brauns über das weitere Vorgehen konferiert hatte, wandte sich Ebert brieflich an Albert, den ehemaligen Staatssekretär der Reichskanzlei ${ }^{441}$ sowie Schatz- und Wiederaufbauminister Cunos ${ }^{442}$. Seine „bisherigen Besprechungen über die Kabinettsbildung “ hätten ihn, so Ebert in seinem Schreiben, „überzeugt, daß es zurzeit nicht möglich ist, eine Koalitionsregierung auf ausreichender parlamentarischer Grundlage zu bilden“. Er strebe daher eine „Regierung bewährter Männer“ an ${ }^{443}$. Auf den dringenden Appell hin, seine bereits geäußerten Bedenken aus „vaterländischem Pflichtgefühl“ zurückzustellen, erklärte sich Albert in einem anschließenden Gespräch mit Ebert bereit, den Auftrag zur Regierungsbildung anzunehmen.

Albert, wie Cuno der kaiserlichen Ministerialbürokratie entstammend und dem als Reichskanzler gescheiterten HAPAG-Chef auch in anderen Aspekten ähnlich $^{444}$, war in seiner Ministerzeit vor allem durch eine zusammen mit dem Industriellen Otto Henrich verfaßte Denkschrift zur wirtschaftlichen Lage aufgefallen, in der neben wirtschaftlichen Reformen eine weitreichende parlamentarische Ermächtigung und eine Art von Notstandsdirektorium vorgesehen waren ${ }^{45}$. Eberts

${ }^{436}$ HA Köln, Nl. Marx, Nr. 57, Erinnerungsbericht „Berufung zum Reichskanzler, die beiden Kabinette, Londoner Konferenz", S. 3. Vgl. auch Morsey, Zentrumspartei, S. 551.

${ }^{437}$ So HA Köln, Nl. Marx, Nr. 57, S. 3.

${ }^{438}$ Möglicherweise fürchtete man, mit der „Versackungstheorie“ (s. Anm. 386) identifiziert zu werden. Die Hintergründe bedürften der genaueren Aufklärung. Morsey, Zentrumspartei, S. $551 \mathrm{f}$., und Hehl, Marx, S. 250f., gehen hierauf nur sehr knapp ein.

${ }^{439}$ Vgl. VZ, 24. 11. 1923 ab, S. 1, „Ein Kabinett der Mitte“. Nach einem Bericht von Curtius auf der Sitzung des Geschäftsführenden Ausschusses der DVP kam der Vorschlag von Zentrum und DDP. BA Koblenz, R 45 II, Nr. 57, Bl. 17f. Vgl. auch Einleitung zu AdR Marx, S. VIIf.

${ }^{440}$ Kardorff wurde durch die DNVP strikt abgelehnt (vgl. unten S. 313). Gegen Jarres sprach sich wohl die Zentrumsfraktion „wegen dessen Rheinpolitik“ aus. Vgl. VZ, 27.11.1923 ab, S. 1, „Jarres vom Zentrum abgelehnt“. Ohne Angaben hierzu Morsey, Zentrumspartei, S. 551 f.

441 Unter den Regierungen Bauer bis Wirth I 1919-1921.

${ }^{442}$ Vgl. zum ganzen Vorgang v.a. FZ, 26.11. 1923 mo, S. 1, „Die Bemühungen um die Lösung der Regierungskrise“. In der Literatur wird der Regierungsbildungsversuch Alberts nur beiläufig vermerkt. Die Parallele zur Berufung Cuno wird nur bei Arns, Regierungsbildung, S. 178f., knapp vermerkt.

${ }_{443}$ Abdruck in FZ, 26. 11. 1923 mo, S. 1, „Die Bemühungen um die Lösung der Regierungskrise“.

${ }^{44}$ Zum Lebenslauf und zur Person Alberts (geb. 1874) kurze Biographie in: Deutscher Wirtschaftsführer, S. 15; ausführlich Ge, 26. 11. 1923, S. 1, „Heinrich Friedrich Albert“. Ähnlich wie Cuno besaß Albert gute Beziehungen in die USA, wo er als Handelsattaché der Botschaft gewirkt hatte; ähnlich wie Cuno war Albert inzwischen in der freien Wirtschaft tätig (Aufsichtsrat der Deutschen Werke). Eine weitere Parallele im Persönlichkeitsprofil zeigt sich im "gewandten Auftreten“ (ebd.). Alles deutet demnach darauf hin, daß Ebert sein Vertrauen erneut in einen bestimmten Typus des weltläufigen Fachmanns setzte.

${ }^{445}$ Vgl. oben S. 224. 
intensive Bemühungen um diesen Exponenten einer autoritären, entparlamentarisierten Krisenlösung waren eine Konsequenz aus dem Scheitern der bisherigen, in Kooperation mit den Fraktionen durchgeführten Versuche zur Kabinettsbildung. Allerdings, eine Wendung in dem zitierten Brief weist darauf hin, hatte Albert, der als „Protegé Eberts“ galt ${ }^{466}$, bereits zuvor eine erste Bitte des Reichspräsidenten abgelehnt ${ }^{447}$. Wann genau diese erfolgt war, ließ sich nicht klären. Bemerkenswert ist aber, daß der Name Alberts in der Presse bereits unmittelbar vor dem Sturz Stresemanns gehandelt wurde ${ }^{448}$. Möglicherweise hatte Ebert daher schon vor den ersten Anläufen zu einer parlamentarischen Regierungsbildung auch die Option eines „neutralen Fachkabinetts“ 449 verfolgt.

War die Wahl Alberts die alleinige Entscheidung Eberts ${ }^{450}$, so scheint der Reichspräsident in seiner Wendung gegen eine parlamentarische Kabinettsbildung durch Jarres, Geßler und Brauns bestärkt worden zu sein. Offensichtlich sprachen die drei Stresemannschen Minister aber ohne jede Rückbindung an ihre Fraktionen, denn dort fand der Kandidat des Reichspräsidenten eine überraschte und durchweg negative Aufnahme ${ }^{451}$. Albert gab darauf am 27. den Regierungsbildungsauftrag wieder an Ebert zurück. Die bürgerlichen Fraktionen einschließlich der DNVP ernannten nun Stegerwald zu ihrem „Vertrauensmann“ für die weiteren Beratungen mit dem Reichspräsidenten ${ }^{452}$ - ein Indiz dafür, daß das Bewußtsein von der parlamentarischen Verantwortlichkeit hier keineswegs so schwach entwickelt war, wie es die anfängliche Verweigerung der Zentrumsfraktion nahelegt. Gleichzeitig erfolgte mit dem gemeinsamen Vorgehen der bürgerlichen Parteien ein Signal für eine eventuelle Mitte-rechts-Koalition. Ebert akzeptierte diese parlamentarische Initiative und bot Stegerwald formell die Regierungsbildung an.

2. Seit dem Sturz Stresemanns waren Ebert und die von ihm mit der Regierungsbildung beauftragten Politiker bemüht, durch Einbeziehung der DNVP eine

${ }_{446}$ D'Abernon, Ein Botschafter der Zeitwende 2, S. 327. Nach Luther, Politiker, S. 94, besaß Albert "das besondere Vertrauen“ Eberts. Vgl. auch Arns, Regierungsbildung, Anmerkungsteil, S. 83, Anm. 10.

447 Dies wird deutlich aus dem erwähnten Brief Eberts an Albert: „In dieser schweren Stunde appelliere ich nochmals dringend an Ihr vaterländisches Pflichtgefühl, Ihre mir geäußerten und auch von mir gewürdigten Bedenken zurückzusetzen und die Bildung einer solchen Regierung zu übernehmen.“ Abdruck in FZ, 26.11. 1923 mo, S. 1, „Die Bemühungen um die Lösung der Regierungskrise".

${ }^{448}$ So in DT, 23. 11. 1923, S. 1, „Die Kabinettskrise“. Bezeichnend für die Überraschung, die dieser Name auslöste, heißt es hier: "Was die Person des Ministers Albert anbelangt, so wird dieser Gedanke in weiten Kreisen sicherlich große Verwunderung erregen."

449 Ebd.

450 Dies wird auch betont von Arns, Regierungsbildung, S. 179, und Arns, Friedrich Ebert, S. 22. Es handelte sich freilich - wenn man die Wiedfeldt-Episode mit einbezieht - nicht um den „zweiten Versuch eigenmächtiger Kabinettsbildung", sondern bereits um den dritten.

451 Vgl. v.a. zusammenfassend FZ, 27. 11. 1923 ab, S. 1, „Frankfurt, 27. November“: „Die Betrauung Dr. Alberts mit der Neubildung des Kabinetts findet überall die skeptisch-unfreundliche und stellenweise bis zu schroffer Ablehnung gesteigerte Aufnahme, die zu erwarten war."

452 FZ, 29. 11. 1923 mo/1, S. 1, „Die Regierungskrise“. Stegerwald selbst sprach später in einer Presseerklärung davon, daß „, der Antrag, das neue Reichskabinett zu bilden, von den Demokraten, der Bayerischen Volkspartei, dem Zentrum, der Deutschen Volkspartei und den Deutschnationalen an mich gerichtet worden ist“. Vgl. Ge, 30.11. 1923, S. 2, „Warum Stegerwald ablehnte“. Ähnlich Ullmann, In der großen Kurve, S. 43. - In der Literatur scheint diese Entwicklung bislang übersehen worden zu sein. Bei Arns, Regierungsbildung, S. 179, und Eilers, Ermächtigungsgesetz und militärischer Ausnahmezustand, S. 28, bleibt die parlamentarische Initiative unklar. 
neue parlamentarische Mehrheit zu erreichen. Allerdings scheute der Reichspräsident davor zurück, einem Deutschnationalen die Kanzlerschaft anzubieten, obgleich dies infolge der maßgeblichen Beteiligung der Partei am Sturz Stresemanns durchaus nahegelegen hätte und obwohl der Partei- und Fraktionsvorsitzende Hergt - im Gegensatz zu allen anderen Parteien - Interesse signalisierte ${ }^{453}$. In der DNVP sorgte dieses Verhalten Eberts für offene Kritik am Reichspräsidenten, und in der gesamten Presse für einigen Diskussionsstoff. „Vieles hätte dafür gesprochen“, so urteilte etwa ein Leitartikel der Frankfurter Zeitung am 27. November über die mögliche Berufung eines DNVP-Politikers, und verwies darauf, daß die ,agitatorische Kraft der Rechten“ vor allem auf ihrer bisherigen Oppositionsstellung beruhte und daß die „Lage viel klarer wäre, wenn sich praktisch erwiesen hätte, ob die Deutschnationalen überhaupt eine Regierung bilden können" ${ }^{454}$. Über die genauen Motive, aus denen heraus Ebert es ablehnte, der DNVP die Regierungsbildung anzubieten, ist nichts bekannt. Sicher gab es angesichts der akuten Reparationsfrage ${ }^{455}$ außenpolitisch motivierte Bedenken. Vermutlich spielten Eberts grundsätzliches Bemühen um eine möglichst in der Mitte verankerte Regierung ebenso eine Rolle wie die Befürchtung des Reichspräsidenten, Unwillen innerhalb der SPD zu erwecken. Möglicherweise teilte der Reichspräsident auch die im eben genannten Artikel der Frankfurter Zeitung formulierte Befürchtung, „daß nämlich die extreme Rechte, einmal zur Macht gelassen und nur den Reichstag als Hindernis für ihre Ziele vorfindend, die Macht auch gegen das Parlament und gegen die Verfassung gebrauchen könnte" 456 .

Warum aber scheiterte eine Einbeziehung der DNVP in eine nicht von ihr selbst geführte Regierung? Von Teilen der DVP wurde eine derartige Lösung seit längerem gefordert, Zentrum und DDP standen dem Vorhaben aufgeschlossen gegenüber, machten es aber von einer unzweideutigen Anerkennung der Reichsverfassung und der republikanischen Staatsform sowie von weiteren inhaltlichen

${ }^{453}$ Vgl. v.a. das Interview Hergts mit einem Redakteur des Berliner Lokalanzeigers am 25.11. 1923, wiedergegeben z.B. in FZ, 26. 11. 1923 mo, S. 1, „Die Haltung der Deutschnationalen“. Hergt sagte u. a.: „Im übrigen ist die Deutschnationale Volkspartei entschlossen, jeden derartigen Auftrag anzunehmen." Vgl. knapp und ohne Beleg auch Hertzman, DNVP, S. 201. Nach AdR Marx, S. VIII, kam die Anregung, die DNVP mit der Regierungsbildung zu betrauen, von Stresemann. Allerdings wird dieser Hinweis ebd. nicht belegt. Dies gilt auch für die Behauptung, Ebert habe darauf "wegen unerfüllbarer Bedingungen der DNVP nicht eingehen wollen“.

${ }^{45+} \mathrm{FZ}, 27.11 .1923 \mathrm{ab}, \mathrm{S} .1$, „Frankfurt, 27. November".

455 Am 30. 11. 1923 setzte die Reparationskommission bekanntlich zwei Expertengremien ein. Der von dem amerikanischen Bankier Charles G. Dawes geleitete Ausschuß arbeitete bis Anfang April 1924 die Grundzüge des Dawes-Plans aus. Vgl. zusammenfassend Krüger, Außenpolitik, S. 218-247.

456 Ebd. Arns, Regierungsbildung, geht auf die Frage, warum kein DNVP-Politiker mit der Regierungsbildung betraut wurde, nicht ein. Die ebd., S. 178, zu findende Bemerkung, die Deutschnationalen "drängten ebenfalls nicht auf die Besetzung des Kanzlerpostens“, ist zwar im Wortsinne nicht ganz falsch, vermittelt aber doch einen irrigen Eindruck. Arns stützt sich hier auf einen Brief Eberts an Hergt vom 28.11. 1923, in dem der Reichspräsident bezugnehmend auf das Gespräch am Abend des 23.11. meinte, "den Eindruck gewonnen [zu haben], daß die Fraktion der Deutschnationalen keinen entscheidenden Wert auf die Führung bei der Regierungsbildung legte". Daß es sich bei dieser Äußerung auch um ein gewisses Abblocken Eberts handeln könnte, wird von Arns nicht berücksichtigt. Vor allem aber übersieht er spätere öffentliche Äußerungen von Hergt. Abdruck des Briefes in Ursachen und Folgen 5, S. 274. Ebd., S. 273 f., eine Art „Beschwerdebrief“ Hergts über mangelnde Berücksichtigung bei der Regierungsbildung. 
Forderungen abhängig457. Die DDP wäre im Falle einer DNVP-Regierungsbeteiligung allerdings wohl nur zu einer Tolerierungszusage bereit gewesen ${ }^{458}$. Während die Regierungsbildungsversuche von Jarres und Albert bereits innerhalb der bürgerlichen Mitte auf Widerstände stießen, so daß sich die Frage nach einer Beteiligung der DNVP gar nicht mehr ernsthaft stellte, gab es bei Kardorff - einem ehemaligen Angehöriger der DNVP-Fraktion, der nach dem Kapp-Putsch mit den Deutschnationalen gebrochen hatte und inzwischen als einer der Exponenten des linken DVP-Flügels galt ${ }^{459}$ - unüberwindliche politische und personelle Vorbehalte bei den Deutschnationalen. Erfolgversprechender sah die Lage bei den Verhandlungen mit Stegerwald aus. Der christliche Gewerkschaftler vom rechten Flügel des Zentrums wurde von den Deutschnationalen nicht nur akzeptiert, sondern war - im Bunde mit den anderen bürgerlichen Fraktionen - zunächst sogar von ihnen vorgeschlagen worden. Allerdings verband die DNVP die Bereitschaft zum Regierungseintritt mit der Forderung nach der Vizekanzlerschaft und nach einer Ablösung der amtierenden Großen Koalition in Preußen durch einen Bürgerblock ${ }^{460}$. Erstmals wurde damit versucht, einen Konnex zwischen Regierungsbildung im Reich und in Preußen herzustellen. Die Fraktionen von DDP und Zentrum hielten darauf weitere Verhandlungen für sinnlos, und Stegerwald gab seinen Versuch einer Regierungsbildung am 29. November auf ${ }^{461}$. Ob in der DNVP aus einem aktuellen, durch die herrschende Systemkrise genährten Gefühl der Stärke heraus tatsächlich die Illusion herrschte, sie könne über den Hebel der Regierungsbeteiligung im Reich auch die Machtbeteiligung in Preußen erreichen, ob diese Bedingung eher taktisch motiviert war, um den Eindruck grundsätzlicher Obstruktion zu vermeiden, sich einem Kabinettsbeitritt und dem dazu erforderlichen Treuebekenntnis zur Republik aber dennoch zu entziehen ${ }^{462}$, oder ob die Partei vielleicht doch auf die Kanzlerschaft spekulierte, sei hier dahingestellt.

3. Eine „Kleine Koalition“ war weiterhin kein ernsthaftes Thema. Lediglich in DDP-Kreisen wurde hin und wieder auf diese über eine klare parlamentarische Mehrheit verfügende Option hingewiesen ${ }^{463}$. Wie bereits erwähnt, stieß eine der-

${ }^{457}$ Auf einem Treffen der Arbeitsgemeinschaft am 27.11. 1923 erfolgte offenbar eine Einigung auf einen Forderungskatalog. Vgl. v.a. VZ, 27. 11.1923 ab, S. 1, "Jarres vom Zentrum anerkannt". Ein zusammenfassender Bericht über die Verhandlungen findet sich in einem auf den 16.5. $1924 \mathrm{da}$ ticrten Nachtrag zu Koch-Wesers tagebuchartigen Notizen. Koch-Weser vermerkt hier auch, die Gespräche für die DDP „in der Hoffnung“ geführt zu haben, „daß sie scheitern würden“. BA Koblenz, Nl. Koch-Weser, Nr. 30, BI. 19-21.

458 So VZ, 27. 11. 1923 ab, S. 1, "Jarres vom Zentrum anerkannt“.

${ }^{459}$ Vgl. Turner, Stresemann, S. 98 und 126.

${ }^{460}$ So in einer formellen Fraktionserklärung, vgl. z. B. FZ, 29.11. 1923 mo/1, S. 1, „Dic Regierungskrise“. Auf den hohen Stellenwert dieser Frage deutet auch die vom Parteivorstand der DNVP verbrcitete offiziöse Darstellung über die Beteiligung an den Gesprächen über die Regierungsbildung. Vgl. BA Berlin, R 8005, Nr. 9, Bl. 59-63. - Zur Lage in Preußen, wo seit November 1921 eine Große Koalition erfolgreich regicrte, vgl. Möller, Parlamentarismus in Preußen, S. 355-357.

$461 \mathrm{Vgl}$. Fraktionserklärung der DDP vom 28. 11. 1923, abgedruckt z. B. in FZ, 29. 11. $1923 \mathrm{mo} / 2$, S. 1, „Der Versuch Stegerwalds gescheitert“; ebd. auch kurze Notiz über Haltung des Zentrums.

462 Dies wird von Arns, Regierungsbildung, S. 180f., diskutiert. Unklar ist, inwieweit die DNVP zu entsprechenden Erklärungen bereit war. Entsprechende Andeutungen hatte VZ, 28.11.1923 mo/1, „Bindungen für die Deutschnationalen“ gemacht. Vgl. Widerspruch „von deutschnationaler Seite“ in DT, 28. 11. $1923 \mathrm{ab}$, S. 1, „Irreführungsversuche“. Die Annahme einer „bemerkenswerte[n] Konzessionsbereitschaft “ der DNVP in AdR Marx, S. VIII, erscheint vor diesem Hintergrund fragwürdig. Insgesamt gibt es hier erheblichen Klärungsbedarf.

t63 Vgl. z. B. FZ, 27.11.1923 mo/2, S. 1, „Die Krise“. 
artige Kombination, die durch die Sozialdemokratie beherrscht worden wäre, offenbar auf grundsätzliche Ablehnung in Teilen des bürgerlichen Spektrums und insbesondere wohl auch im Zentrum. Stegerwald stellte denn auch am 30. November in einer rückblickenden Betrachtung über seine Bemühungen zur Regierungsbildung fest, daß die „alte Kleine Koalition“ „wie wohl allgemein anerkannt wird“, nicht in Frage gekommen sei, weil sie die derzeitigen außen- und innenpolitischen Aufgaben nicht allein meistern kann" 464 . Ebert hatte zumindest die Betrauung eines Sozialdemokraten mit der Regierungsbildung ähnlich wie im Falle der DNVP frühzeitig ausgeschlossen ${ }^{465}$. Bemerkenswert ist schließlich, daß es offenbar auch in der SPD keinerlei Bestrebungen zur Wiederbelebung der Weimarer Koalition im allgemeinen und zur eigenen Kanzlerschaft im besonderen gab. Die Fraktion verfiel nach dem intern umstrittenen Sturz der Regierung Stresemann offenbar in eine vollständige Lähmung. Die meisten Mitglieder reisten, nachdem am 23. November kein fester Termin für den Wiederzusammentritt des Reichstags festgesetzt worden war, wohl auch umgehend aus Berlin ab ${ }^{466}$. Gegenüber der Presse scheint ausdrücklich betont worden zu sein, daß eine Erneuerung der Koalition mit DDP und Zentrum nicht in Frage komme. Auch wenn die Realisierung einer derartigen Verbindung zweifellos auf erhebliche Widerstände im Zentrum gestoßen wäre, zumindest in taktischer Hinsicht bleibt dieses Verhalten der SPD schwer verständlich. Die Forderung nach einer „Kleinen Koalition“, die Ende 1922 gegen den Widerstand der SPD durch den Beitrittsversuch der DVP beendet worden war, hätte der Partei möglicherweise ein wenig aus ihrer öffentlichen Defensive geholfen und sie auch von dem in Teilen der bürgerlichen Öffentlichkeit gepflegten Vorwurf der parteiegoistischen Verantwortungslosigkeit entlastet. Im Hinblick auf die parlamentarischen Grundfunktionen war das sozialdemokratische Abtauchen in doppelter Hinsicht bedenklich: Die SPD vergab nicht nur eine - vermutlich nur bescheidene - Chance auf die Bildung einer Mehrheitsregierung, sie versäumte es vor allem auch, in der akuten Krisensituation eine mögliche parlamentarische Alternative aufzuzeigen.

Nach dem Scheitern der Stegerwaldschen Bemühungen um einen Bürgerblock war schnell klar, daß jetzt nur ein bürgerliches Minderheitskabinett gebildet werden konnte, das auf die fallweise Unterstützung von DNVP und/oder SPD angewiesen war. Stegerwald war für eine eventuelle Kooperation mit der SPD sicherlich kein geeigneter Kandidat ${ }^{467}$, so daß nun doch der Zentrumsvorsitzende Marx die Aufgabe der Regierungsbildung übernahm.

${ }^{464}$ Vgl. Erklärung Stegerwalds in Ge, 30. 11. 1923, S. 2, „Warum Stegerwald ablehnte“.

465 Er habe, so teilte der Reichspräsident dem deutschnationalen Partei- und Fraktionsvorsitzenden Hergt am 29. 11. 1923 brieflich mit, davon abgesehen, „eine der beiden Oppositionsparteien mit der Neubildung der Regierung zu betrauen [...], weil ich durch meine vertrauliche Aussprache mit den Führern der Reichstagsfraktionen am Abend des 23. November zu der Überzeugung kommen mußte, daß für keine der beiden Oppositionsparteien die Möglichkeit der Bildung einer Regierung auf verfassungsmäßiger Grundlage vorhanden war". Abdruck des - sofort veröffentlichten - Bricfes in Ursachen und Folgen 5, S. 274.

466 Hierzu Arns, Regierungsbildung, S. 178.

467 Vgl. auch Ullmann, In der großen Kurve, S. 43: „Er lehnte ab, weil er die Zweidrittelmehrheit für ein Ermächtigungsgesetz nicht bekommen haben würde und damals noch vor der Anwendung des $\$ 48$ zurückscheute." 
Die bisherigen bürgerlichen Koalitionspartner waren sich am 30. November rasch über ein Kabinett einig, das weitgehend eine Fortsetzung der Regierung Stresemann II in ihrer zuletzt bestehenden Form bedeutete. Neben der Auswechslung des Kanzlers kam es zur Neubesetzung des Wirtschaftsministeriums mit Eduard Hamm (DDP) ${ }^{468}$ und zur Wiederbesetzung des seit dem 3. November vakanten Justizministeriums, das von Erich Emminger (BVP) übernommen wurde. Die Aufnahme eines Mitglieds der BVP-Reichstagsfraktion - wenn auch als „Fachminister ohne parteipolitische Bindung" ${ }^{469}$ - war ebenso wie die $\mathrm{Be}$ rufung des liberal-konservativen Hamm ein deutliches Signal für eine beabsichtigte Verbesserung der Beziehungen zwischen dem Reich und Bayern. Neu besetzt wurden weiterhin die Posten des Staatssekretärs der Reichskanzlei und des Pressechefs ${ }^{470}$. Alle anderen Ministerien blieben unter der zuletzt bestehenden Leitung, darunter auch das von Stresemann geführte Außenministerium ${ }^{471}$. Der zunächst für das Ernährungsministerium vorgesehene DNVP-Parlamentarier Martin Schiele, der dem Kabinett ebenfalls ohne „parteipolitische Bindung“ hatte beitreten sollen, hatte sich unter dem Druck seiner Fraktion zum Verzicht entschlossen $^{472}$. Nach dem Scheitern des Bürgerblocks war damit nun auch ein erster kleiner Schritt zur deutschnationalen Regierungsbeteiligung fehlgeschlagen.

Insgesamt lag der politische Schwerpunkt des Kabinetts so weit rechts, wie dies bisher in der Weimarer Republik noch nie der Fall gewesen war. Dennoch erschien, der mißlungene Kabinettseintritt Schieles demonstriert dies, die Hoffnung auf eine Tolerierung durch die DNVP nur schwach. Von der SPD hingegen scheint sich Marx eine Schonung versprochen zu haben, ohne hierauf in der Regierungsbildung Rücksicht zu nehmen ${ }^{473}$. Koch-Weser faßte die Situation in seinen tagebuchartigen Notizen prägnant zusammen: „Marx bildete Kabinett ohne sich klar zu machen, ob er Unterstützung von Sozialdemokraten oder Deutschnationalen erhoffte und nahm mehr Rücksicht auf rechts als links." ${ }^{474}$

Die funktionale Bilanz der Regierungsbildung fällt ambivalent aus. Einerseits muß das Scheitern einer Mehrheitslösung konstatiert werden. Zwangsläufig war dieser Mißerfolg freilich nicht. Die Realisierung eines Bürgerblocks unter Einschluß der DNVP oder - alternativ hierzu - die Wiederbelebung der Weimarer Koalition hätten allerdings erheblich mehr Mut zu einer angesichts der akuten Staatskrise nicht ganz ungefährlichen Option erfordert. Andererseits, dies verdient als weiteres parlamentarisches Lebenszeichen hervorgehoben zu werden,

${ }^{468}$ Der bisherige Ressortchef Koeth (parteilos) sollte in das Verkehrsministerium wechseln, schied aber dann auf eigenen Wunsch aus dem Kabinett aus. Denselben Weg wählte Johannes Fuchs, der bisherige Minister für besetzte Gebiete, dessen Ressort nun provisorisch von Postminister Höfle übernommen wurde. Zu diesen Details vgl. v.a. Hehl, Marx, S. 253.

469 So eine Erklärung der BVP-Reichstagsfraktion; zitiert nach AdR Marx, Einleitung, S. VIII.

470 Franz Bracht (Zentrum), der spätere stellvertretende Regierungskommissar nach dem Preußenschlag von 1932, kam für Adolf Kempkes (DVP) und der Direktor der Germania, Karl Spiecker (Zentrum), für Arnold Kalle (DVP).

471 Stresemann hatte das Amt zuvor kommissarisch verwaltet.

472 Ernährungsminister blieb von Kanitz, der selbst bei Amtsantritt aus der DNVP ausgetreten war.

473 Auch das Verbleiben von Jarres im Amt des Innenministers war kein günstiges Signal an die SPD.

${ }^{47+}$ Auf den 16. 5. 1924 datierter Nachtrag zu seinen tagebuchartigen Notizen; BA Koblenz, Nl. Koch-Weser, Nr. 30, Bl. 21. 
konnte die offensichtlich vom Reichspräsidenten favorisierte Neuauflage eines „überparteilichen“ Kabinetts à la Cuno durch die Ablehnung und durch die Eigenaktivität der bürgerlichen Mittelparteien verhindert werden.

\section{Erfolgreiche Stabilisierungspolitik - fast obne Parlament:}

Neues Ermächtigungsgesetz, Verordnungsregime, Reichstagsauflösung

Bereits die Bildung der Regierung Marx hatte sich mit dem Thema eines neuen Ermächtigungsgesetzes verbunden ${ }^{475}$. Unbestreitbar gab es im Zuge der Währungsstabilisierung vor allem steuerpolitisch hohen legislativen Regelungsbedarf, und der seit vier Wochen praktizierte Einsatz von Artikel 48 stieß auf breite verfassungspolitische Bedenken. Daß es dem bürgerlichen Minderheitskabinett extrem schwer fallen würde, auf regulärem Wege die nötigen legislativen Vorhaben durch den Reichstag zu bringen, war offenkundig. Andererseits war eine nach Artikel 76 der Reichsverfassung definierte $Z$ weidrittelmehrheit für ein verfassungsdurchbrechendes Ermächtigungsgesetz infolge des sozialdemokratischen Ausscheidens aus dem Regierungslager sehr fragwürdig. Der Versuch, eine neue Ermächtigung durchzusetzen, schwankte daher zwischen dem Bemühen, mit gewissen Zugeständnissen die Zustimmung der SPD zu erlangen, und einer eher harten Linie, die über eine gescheiterte Ermächtigung letztlich doch den Artikel 48 anvisierte.

Die ersten Diskussionen um eine neue Ermächtigung zeigen, daß wohl zunächst erwogen wurde, die Delegation inhaltlich zu beschränken. So erörterte die SPD-Fraktion am 30. November eine Ermächtigung nur für Steuerfragen ${ }^{476}$. In der Presse war am selben Tag teilweise von einer „kleinen Ermächtigung“ die Rede, zu der lediglich eine einfache Mehrheit erforderlich sei ${ }^{477}$. Eine ähnliche Auffassung hatte, daran sei nur kurz erinnert, die Regierung Cuno im Falle des "Notgesetzes" vom Februar 1923 vertreten ${ }^{478}$.

Allerdings waren sofort auch Stimmen zu hören, die eine weite und mit möglichst breiter Mehrheit verabschiedete Ermächtigung forderten. Der Zentrumsabgeordnete und ehemalige Postminister Giesberts verlangte am 30. in der Germania vom Reichstag, „das zu tun, was seine politische Pflicht ist, nämlich der Regierung diejenigen Rechte und Ermächtigungen zu geben, die notwendig sind, die deutsche Wirtschaft und die deutschen Finanzen vor dem völligen Zusammenbruch zu retten. " 479 Schon einen Tag zuvor hatte nach Pressemeldungen die DVPFraktion in den ersten Gesprächen zur Regierungsbildung Marx verlangt, daß ein

475 Vgl. allgemein zum Entstehungsprozeß der neuen Ermächtigung v.a. Frehse, Ermächtigungsgesetzgebung, S. 114-124; Eilers, Ermächtigungsgesetz und militärischer Ausnahmezustand, S. 5695; Arns, Regierungsbildung, S. 183-187, Huber, Verfassungsgeschichte 7, S. 451-455; aus Zentrumsperspektive Hehl, Marx, S. 257-259.

${ }^{476}$ Aufzeichnung über SPD-Fraktionssitzung am 30.11. 1923; ASD Bonn, Nl. Giebel, Kassette II, Mappe 3, Bl. 274.

47 DT, 30. 11. 1923 mo, S. 1, „Abg. Marx als Kanzlerkandidat“. Auch an den folgenden Tagen war in der Presse noch davon die Rede, daß das Ermächtigungsgesetz mit einfacher Mehrheit verabschiedet werden könnte. Vgl. z.B. FZ, 2. 12. 1923 mo/1, S. 1, „Reichskabinett und Reichstag“.

${ }_{478} \mathrm{Vgl}$. oben S. $203 \mathrm{f}$.

${ }_{479}$ Ge, 30.11. 1923, S. 1, „Reichskanzler Marx“. 
neues Ermächtigungsgesetz unter Beteiligung der SPD zustande kommen müßte ${ }^{480}$.

Auch in den Kabinettsberatungen des 1. und 2. Dezember spielten Überlegungen, ob und wie man auf eine Zweidrittelmehrheit verzichten könne, noch eine gewisse Rolle. Freilich machten Justizminister Emminger sowie die Staatssekretäre Meissner und Zweigert aus der Präsidialkanzlei und dem Innenministerium deutlich, daß das geplante Gesetz einen „verfassungsändernden“ Charakter habe und eine Zweidrittelmehrheit nicht $\mathrm{zu}$ umgehen sein werde ${ }^{481}$. Ausschlaggebend hierfür war vermutlich auch, daß bereits die erste, nicht überlieferte Fassung ${ }^{482}$ des Ermächtigungsgesetzes eine umfassende Delegation enthielt. Vermutlich war sie bereits weitgehend mit der am 2. Dezember im Kabinett vorgestellten Fassung identisch ${ }^{483}$. Diese wiederum entsprach in ihrem Kern ${ }^{484}$ dem später verabschiedeten Gesetz. Chancenlos war die von Finanzminister Luther vorgebrachte Überlegung, der verfassungsändernde Charakter könne insofern bestritten werden, als es sich „um ein Notgesetz, um eine Ausnahmeregelung" handle ${ }^{485}$. Ebenso erging es der Anregung von Wirtschaftsminister Hamm, „ob man nicht die Verfassungsänderung dadurch vermeiden könne, daß der Reichstag die Regierung ermächtige, Notverordnungen mit kurzer Frist zu erlassen"486. Als tatsächliche Befristung wurde dann in der Kabinettssitzung vom 2. Dezember der 15. Februar 1924 beschlossen $^{487}$.

Von Anfang herrschte im Kabinett Konsens, daß das überwiegend für wahrscheinlich gehaltene Scheitern einer umfassenden Ermächtigung die sofortige Auflösung des Reichstags und den weiteren legislativen Einsatz des Artikels 48 zur Folge haben müsse. Staatssekretär Meissner gab in der Kabinettssitzung vom 2. Dezember eine entsprechende Zusicherung Eberts $a^{488}$. Schon allein aus diesem Grund waren bedeutende Einschränkungen der Ermächtigung - sei es, um die Notwendigkeit einer Zweidrittelmehrheit zu vermeiden, sei es, um die SPD zur Annahme zu bewegen - nicht zu erwarten.

Inhaltlich war die neue Ermächtigungsvorlage noch unverbindlicher gefaßt als das Ermächtigungsgesetz vom 13. Oktober. War damals noch von Maßnahmen die Rede gewesen, welche die Reichsregierung „auf finanziellem, wirtschaftlichem und sozialem Gebiete für erforderlich und dringend erachtet", so fehlte jetzt jede auch noch so vage materielle Begrenzung ${ }^{489}$. Bezeichnenderweise scheint dieser

$480 \mathrm{Ge}, 30.11 .1923, \mathrm{~S} .1$, „Die vorläufige Ministerliste“.

481 Emminger am 1. 12. 1923; AdR Marx, Nr. 1, S. 1-7, hier S. 2. Meissner am 2. 12. 1923; ebd., Nr. 2, S. 7-10, hier S. 8; Meissner wies ausdrücklich darauf hin: „Diese Ansicht werde wohl auch der Herr Reichspräsident teilen." Zweigert ebd.

482 Vgl. hierzu auch Hinweis ebd., Nr. 1, S. 2, Anm. 9.

${ }^{483}$ Der Text wurde nach der Kabinettsberatung von den Staatssekretären Kempkes (Reichskanzlei) und Zweigert (Reichsministerium des Innern) „festgestellt". AdR Marx, Nr. 2, S. 9f.

${ }^{484}$ „Die Reichsregierung wird ermächtigt, die Maßnahmen zu treffen, die sie im Hinblick auf die Not von Volk und Reich für erforderlich und dringend erachtet." Ebd., S. 9.

485 Luther am 1. 12. 1923; Protokoll in AdR Marx, Nr. 1, S. 2 f.

486 Ebd., Nr. 2, S. 8. Lediglich Staatssekretär Kempkes ging auf die Anregung ein und schlug eine „kurze Frist für etwa 2-3 Wochen vor. Ebd.

487 Ebd., S. 9f.

488 Ebd., S. 8. Zuvor heißt es: „Da eine Annahme des Ermächtigungsgesetzes nicht wahrscheinlich sei, bedeute die Einbringung die Auflösung des Reichstages.“

${ }^{489}$ Vgl. zur inhaltlichen Bewertung v.a. Frehse, Ermächtigungsgesetzgebung, S. $125 \mathrm{f}$. 
Umstand in der Anfang Dezember herrschenden politischen Diskussion überhaupt keine Rolle gespielt zu haben. Auch von der heiß umstrittenen Frage, ob die Regelung der Arbeitszeit in die Ermächtigung einzubeziehen sei, war nicht mehr die Rede, so daß eine dem vorigen Gesetz analoge Ausschlußklausel nicht mehr zur Debatte stand. Arbeitsminister Brauns hatte bereits in der Kabinettssitzung vom 1. Dezember die Chance genutzt und gefordert, "das Arbeitszeitgesetz nicht" - wie nach der Koalitionsvereinbarung vom 5. Oktober vorgesehen - „an den Reichstag zu bringen, weil seiner Meinung nach der Reichstag es selber nicht wünscht" ${ }^{490}$. Die einzige Einschränkung im Vergleich zum Stresemannschen Ermächtigungsgesetz bildete der auf Anregung von Justizminister Emminger aufgenommene Hinweis, daß keine Abweichung von der Reichsverfassung möglich sei. Möglicherweise handelte es sich dabei um eine Konzession, die eine Annahme des Gesetzes im Reichstag erleichtern sollte ${ }^{491}$.

Im Ergebnis bleibt festzustellen, daß - mit Ausnahme des Verbots der Verfassungsänderung - während des Entstehungsprozesses des neuen Ermächtigungsgesetzes alle Überlegungen zu einer inhaltlich spezialisierten oder zeitlich eng befristeten Ermächtigung chancenlos geblieben waren. Angemerkt sei auch, daß eine ernsthafte Diskussion um eine reguläre legislative Behandlung der anstehenden Vorhaben und insbesondere der geplanten Steuergesetze weder im Kabinett noch in der politischen Öffentlichkeit geführt wurde. Finanzminister Luther deutete eine derartige Möglichkeit in der Kabinettssitzung vom 1. Dezember zwar kurz an, entkräftete sie aber umgehend mit der Befürchtung, der Reichspräsident könnte nach einem eventuellen Scheitern des Gesetzgebungsverfahrens den dann notwendigen Einsatz des Artikels 48 verweigern ${ }^{492}$.

Vor allem Reichskanzler Marx scheint von Anfang an entschlossen gewesen zu sein, eine weite Ermächtigung durchzusetzen. Wie eine rückblickende Notiz in einem seiner „Erinnerungsberichte“ zeigt, ging es ihm um ein Höchstmaß an Unabhängigkeit vom Parlament: „Man war darin einig, dass die ungeheuren Schwierigkeiten der Lage nicht durch Beratungen im Gremium oder in den Ausschüssen des Reichstags beseitigt werden könnten. Man war entschlossen, ein Ermächtigungsgesetz zu erlangen, damit die Reichsregierung freie Hand erhielte, unabhängig von dem Meinungsstreit der Parteien das zu tun und zu beschließen, was ihr nach ihrem pflichtmäßigem Ermessen das Richtige und Nötige zu sein schien. “493 Vermutlich bezog sich das von Marx verwendete "man“ auf den engsten Kreis seiner Minister ${ }^{494}$, möglicherweise war aber auch der Konsens mit General von Seeckt gemeint, der seit dem 8. November die vollziehende Gewalt im gesamten Reichsgebiet innehatte.

490 AdR Marx, Nr. 1, S. 1.

491 Ohne Diskussion der Motive bleibt Frehse, Ermächtigungsgesetzgebung, S. 125.

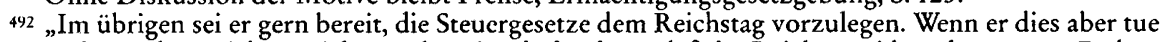
und Annahme nicht erreicht werde, sei zu befürchten, daß der Reichspräsident dann später Bedenken gegen einen Erlaß der Steuergesetze auf Grund von Art. 48 geltend machen werde." AdR Marx, Nr. 1, S. 2f.

493 Nachlaß des Reichskanzlers Wilhelm Marx 4, S. 317.

${ }^{94}$ Eilers, Ermächtigungsgesetz und militärischer Ausnahmezustand, S. 66-70, betont v.a. den Einfluß von Brauns und Luther. 
Ein bislang in diesem Zusammenhang nicht beachteter Bericht des Truppenamtes vom 7. Dezember läßt erkennen, daß Marx schon vor seiner Regierungsbildung Kontakt mit Seeckt aufgenommen und in Übereinstimmung mit dem General eine Reichstagsauflösung und ein Regieren mit Artikel 48 vielleicht sogar als die für ihn günstigere Lösung betrachtet hatte. „Der jetzige Kanzler hat sich“, so heißt es hier, "ehe er sein Amt übernahm, mit dem Chef der Heeresleitung in Verbindung gesetzt. Einigkeit herrschte darüber, daß man mit dem Parlament nicht regieren könne und wolle, daß das Parlament mit oder ohne Diäten nach Hause zu schicken sei. $\mathrm{Zu}$ diesem $\mathrm{Zweck}$ wurde das Ermächtigungsgesetz eingebracht." Die Regierung habe es „direkt auf Ablehnung abgesehen“495. Die weiteren Ausführungen dieses Berichts zeigen im übrigen, daß die Ausschaltung des Reichstags aus der Perspektive des Truppenamtes durchaus Teil einer systemverändernden Strategie war, die den legalen Weg wählte. Während ein „Putsch“ nur zu einem "Augenblickserfolg“ geführt hätte, sei man nun „auf dem besten Wege zu einer legalen Entwicklung“. Ziel sei eine "Gesundung" und die "Schaffung einer rein nationalen Entwicklung “496.

Es wäre sicherlich verfehlt, Marx oder auch die Mehrzahl der parlamentarischen Anhänger einer umfassenden Ermächtigung mit derartigen Motiven in Verbindung zu bringen. Allerdings ist im Rückblick offenkundig, daß das Mittel der Ermächtigung inzwischen eine höchst problematische Dimension erreicht hatte. Waren die Delegationen der gesetzgeberischen Gewalt nach dem Ersten Weltkrieg zunächst nur unspektakuläre Spezialregelungen gewesen, so hatten sie sich im Laufe des Jahres 1923 zu Demonstrationen nationaler Einigkeit und zu einem Notbehelf gegen Probleme der parlamentarischen Regierungsstützung gewandelt. Auch die jetzt geplante Ermächtigung ist im wesentlichen noch in diesem Sinne zu deuten. Freilich kam nun eine mehr oder minder offene antiparlamentarische Komponente hinzu: Die Beantragung eines Ermächtigungsgesetzes war auch ein Instrument zur Provozierung einer Reichstagsauflösung geworden und in führenden militärischen Kreisen auch ein Mittel zur langfristigen Überwindung des parlamentarischen Systems.

Verfassungsrechtlicher Widerspruch gegen die neue Ermächtigung scheint sich während dieser Tage in den bürgerlichen Reichstagsparteien nicht gerührt zu haben ${ }^{497}$. Daß sich hierin - wie Äußerungen einzelner Kabinettsmitglieder nahelegen ${ }^{498}$ - neben einem generell schwachen parlamentarischen Selbstbewußtsein

495 Zusammenfassung der vom Truppenamt vorgetragenen Beurteilung der inneren Lage, 7. 12. 1923; Krisenjahr 1923, Nr. 133, hier S. 196. Meier-Welcker, Seeckt, S. 415, geht nur sehr allgemein auf das hier auf den 30.11. 1923 datierte Gespräch ein. Bei Eilers, Ermächtigungsgesetz und militärischer Ausnahmezustand, wird die Absprache mit Seeckt nicht thematisiert.

496 Krisenjahr 1923, Nr. 133, hier S. 195.

497 Ähnlich wie bei der SPD scheint auch hier das fraktionelle Leben nach dem Sturz Stresemanns für einige Zeit zum Erliegen gekommen zu sein. So ist für die Zeit zwischen dem 22.11 und 8.12.1923 keine Sitzung der Zentrumsfraktion überlicfert. Vgl. Protokolle Zentrumspartei, S. $504 \mathrm{f}$.

498 So diagnostiziert Geßler, Reichswehrpolitik, S. 280, Verantwortungsscheu gegenüber unpopulären Stabilisierungsmaßnahmen: „Deshalb war denn auch der Reichstag dankbar, daß er einem neuen Kabinett ein neues Ermächtigungsgesetz bewilligen durfte." In eine ähnliche Richtung ging bereits eine Äußerung von Brauns in der Kabinettssitzung vom 4.12. 1923. Es sei, so forderte hier der Arbeitsminister, zu vereinbaren, daß in dem geplanten Kontrollausschuß keine Abstimmungen stattfänden: „Er glaube, daß dic Parteien auf diesen Vorschlag bereitwillig eingehen würden, da sie 
auch eine gewisse Bereitwilligkeit spiegelte, die direkte Verantwortung für unpopuläre finanzpolitische Maßnahmen abzuschieben, erscheint durchaus plausibel. Wenn unklar blieb, ob die DNVP dem Gesetz zustimmen werde, dann lag dies nicht an einer Ablehnung parlamentarischer Ermächtigungen, sondern an der grundsätzlichen Distanz, welche die Deutschnationalen zur neuen Regierung einnahmen ${ }^{499}$.

Von den Mehrheitsverhältnissen wichtiger war das Verhalten der SPD-Fraktion, und nur hier läßt sich - soweit dies bei einer schwierigen Quellenlage möglich ist - eine kritische Diskussion über die geplante Ermächtigung erkennen. Grundsätzlich, darüber kann kein Zweifel bestehen, herrschte in der Sozialdemokratie angesichts der nationalen Krisenlage eine weitgehende Bereitschaft, zur zeitweiligen Stabilisierung der neuen Regierung beizutragen und die anstehenden legislativen Maßnahmen zu ermöglichen ${ }^{500}$. Dabei kam es zunächst offenbar zu widersprüchlichen Signalen. Während ursprünglich im Kabinett eine Zustimmung der SPD kaum erwartet worden war, meinte Marx in der Kabinettssitzung vom Nachmittag des 3. Dezember, daß „bei den Sozialdemokraten mit der Möglichkeit der Annahme gerechnet werden" könne501. Am Abend des selben Tages legte dann der Reichskanzler in der Ministerrunde klar, daß eine Zweidrittelmehrheit aussichtslos erscheine: "Jedenfalls hätten die sozialdemokratischen Führer erklärt, daß es ihrer Partei nicht gut möglich sei, da sie an der Regierung nicht beteiligt seien, einem so umfangreichen Ermächtigungsgesetz zuzustimmen." 502

Parlamentarismustheoretisch traf dieser Einwand den entscheidenden Punkt. Eine breite Ermächtigung durch eine Regierungskoalition kann immer noch als spezielle Form der Kooperation von Regierung und parlamentarischem Regierungslager bewertet werden. Die Zustimmung einer eigentlich in der Opposition stehenden Partei aber bildet einen Blankoscheck ohne direkte Einflußmöglichkeit auf die legislative Umsetzung. Gleichzeitig verzichtet diese Partei dann auch weitgehend auf ihre Alternativfunktion.

Letztere wurde von der SPD, die sich seit ihrem vielgescholtenen Regierungsaustritt in einer extremen Position der Defensive befand, freilich kaum praktiziert. Dem Instrument einer Ermächtigung hatten die Sozialdemokraten außer ihrer möglichen Verweigerung nichts entgegenzusetzen. Vergleichend sei hier auf das Verhalten der französischen Sozialisten verwiesen, die 1926 als Alternative zu der geplanten finanzpolitischen Ermächtigung für die Regierung Briand ein beschleunigtes reguläres Gesetzgebungsverfahren anregten ${ }^{503}$. Selbst die drohende Rege-

dadurch der Verantwortung für die unter dem Ermächtigungsgesetz zu treffenden Maßnahmen entzogen und bei der Neuwahl entsprechend entlastet sein würden. “ AdR Marx, Nr. 7, S. 36.

$499 \mathrm{Vgl}$. auch den detaillierten Artikel von Graf Westarp für NPZ, 2. 12. 1923, S. 1f., "Wochenschau“; sowie FZ, 3. 12. 1923 mo, S. 2, „Die Deutschnationalen“. Wesentlichstes Interesse der DNVP, die sich angesichts der "vaterländischen“ Stimmungsmache im gesamten Reich in einer günstigen wahlpolitischen Situation fühlte, war vermutlich die möglichst rasche Herbeiführung von Neuwahlen.

500 Ausführlich zur sozialdemokratischen Diskussion vgl. Eilers, Ermächtigungsgesetz und militärischer Ausnahmezustand, S. 78-88; knappe Skizze in Winkler, Von der Revolution zur Stabilisierung, S. 680 .

501 AdR Marx, Nr. 4, S. 17.

502 Ebd., Nr. 5, S. 27.

503 Vgl. unten S. 487. 
lung der Arbeitszeit per Ermächtigungsverordnung war bei der SPD offenbar kein Thema mehr.

Stärker war, und dies entsprach dem vorherrschenden Parlamentarismusverständnis, das Bewußtsein von der Notwendigkeit parlamentarischer Kontrolle entwickelt. Regierung und Teile der SPD bemühten sich am 3. und 4. Dezember, eine Regelung zu finden, die der sozialdemokratischen Fraktion eine Zustimmung zum Ermächtigungsgesetz ermöglichen könnte. Die Debatte hierüber verband sich mit der Frage, in welcher Form der Reichsrat am Zustandekommen der Verordnungen zu beteiligen war. Der am 3. Dezember im Kabinett vorgebrachte Vorschlag, ähnlich wie bei dem Notgesetz vom Februar eine Zustimmungspflicht des Reichsrats vorzusehen und so über sozialdemokratisch mitregierte Länder eine Einflußmöglichkeit der SPD zu sichern, wurde rasch verworfen. Arbeitsminister Brauns regte statt dessen an, daß der Reichstagsausschuß zur Wahrung der Rechte der Volksvertretung ,in das Verfahren eingegliedert werden solle“504. Einen ähnlichen Vorschlag machte am 4. Dezember im Gespräch mit dem Reichskanzler auch die Spitze der SPD-Fraktion. Marx berichtete hierüber in der abendlichen Kabinettssitzung und schlug vor, die von der SPD geforderte „Zustimmung eines ständigen Ausschusses des Reichstags" durch eine bloße Anhörung zu ersetzen. Die letztgenannte Lösung fand nach einiger Diskussion die Billigung des Kabinetts, wobei freilich statt des Ausschusses zur Wahrung der Rechte der Volksvertretung ein neu zu schaffender fünfzehnköpfiger Sonderausschuß vorgesehen wurde. Neben einer Kontrollmöglichkeit war damit auch ein Rest an legislativer Mitwirkung des Reichstags in Aussicht gestellt. Im Zuge des hier nicht weiter zu verfolgenden Diskussionsprozesses mit dem Reichsrat wurde eine analoge Regelung in die Vorlage des Ermächtigungsgesetzes aufgenommen ${ }^{505}$. Reichstag wie Reichsrat erhielten zudem, wie von Anfang an vorgesehen, das Recht auf Außerkraftsetzung von Verordnungen.

Vor dem abendlichen Beschluß vom 4. Dezember zum Ermächtigungsgesetz hatte sich das Kabinett Marx im Reichstag vorgestellt. Eine kurze Regierungserklärung des neuen Reichskanzlers verzichtete gegen den Willen der koalierenden Parteien weitgehend auf programmatische Aussagen ${ }^{506}$. Statt dessen malte Marx den Zustand des Reichs und insbesondere seiner Finanzen in apokalyptischen Farben. Die Regierung sehe sich ,in der Finanzlage [...] vor eine Aufgabe von einer vielleicht in der Weltgeschichte nie dagewesenen Schwierigkeit gestellt“. Die Bevölkerung müsse „endlich in ihrer Gesamtheit davon durchdrungen werden, daß, wenn nicht Volk und Reich in einen hoffnungslosen Strudel der Vernichtung versinken sollen, jetzt die Stunde größten Opferns gekommen ist“507. Geschickt verstand es der rhetorisch ansonsten eher biedere Marx, das anstehende Ermächtigungsgesetz als den einzig gangbaren Weg darzustellen, der zu „Rettung und Besserung“ führe. „Angesichts des ungeheuren Zwanges der Zeit" seien „langwie-

${ }^{504}$ Kabinettssitzung vom Nachmittag des 3. 12. 1923; AdR Marx, Nr. 4, S. 17.

${ }^{505} \mathrm{Vgl}$. Frehse, Ermächtigungsgesetzgebung, S. 117-119.

506 Verh. RT 361, S. 12296-12298. Zur Haltung der „Parteiführer“ vgl. die Aussage von Marx in der

Kabinettssitzung vom 3. 12. 1923; AdR Marx, Nr. 5, S. 27-30, hier S. 29. Allgemein zur Rede von Marx vgl. auch Hehl, Marx. S. 256-258.

507 Verh. RT 361, S. 12996. 
rige Verhandlungen im Reichstage, wie sie die Beratung einschneidender Gesetze erfordern würde, nicht wünschenswert, ja geradezu unerträglich“. Eindringlich appellierte der Reichskanzler ,an die Vaterlandsliebe und das Pflichtgefühl der Volksvertreter [...] in schwerer Zeit einer Regierung, die glaubt, auf die Zustimmung weiter Kreise der Bevölkerung rechnen zu dürfen, außergewöhnliche Vollmachten geben zu dürfen" 508 .

Erstmals in der Weimarer Republik wurde auf ein gesondertes Vertrauensvotum für die neue Regierung verzichtet. Marx hatte dies zwei Tage zuvor im Kabinett angeregt und ergänzend gemeint, „die eventuelle Annahme des Ermächtigungsgesetzes könne man wohl als Vertrauensvotum für das Kabinett ansehen" 509 . Verfassungsrechtlich war dieses pragmatische Vorgehen durchaus in Ordnung, denn eine ausdrückliche Vertrauenserklärung des Reichstags nach Antritt einer neuen Regierung war in der Weimarer Verfassung nicht vorgesehen. Die Kompetenz des Parlaments zur Abberufung der Regierung blieb insofern unberührt, als die Möglichkeit eines Mißtrauensvotums jederzeit bestand. Durch die Verbindung von Vertrauensbeweis und Ermächtigungsgesetz wurde freilich implizit eine Neudefinition des parlamentarischen Regierungslagers vorgenommen, von der später noch zu sprechen sein wird.

Unter dem Eindruck des Teilerfolgs, den sie im Hinblick auf die Mitwirkung eines Reichstagsausschusses erzielt hatte, beschloß die SPD-Fraktion noch am Abend des 4. Dezember nach ,heftige[n] Kämpfe[n] “510 mit 73 zu 53 Stimmen ${ }^{511}$, sich im Reichstag für das Ermächtigungsgesetz auszusprechen - eine Entscheidung, die zuvor in Kabinett und Presse eher als unwahrscheinlich gegolten hatte ${ }^{512}$. Severing berichtet in seinen Erinnerungen über die harte Diskussion, die diesem Beschluß vorausging: "Jeder einzelne Mann wurde herbeigerufen. Es war ein Feilschen und Markten, wie ich es unerfreulicher bisher in keiner anderen Situation in diesem Gremium erlebt hatte. "513 Prominentester Gegner war kein geringerer als der Fraktionsvorsitzende Hermann Müller. Dieser begründete später seine Verweigerung mit dem bereits erwähnten Argument, die SPD sei in der Regierung Marx nicht vertreten und könne sie nicht „von innen heraus kontrollieren “514. Die aus diesem Motiv heraus resultierende Ablehnung ist insofern konsequent, als Breitscheid drei Monate zuvor die Zustimmung der SPD zum Ermäch-

$50 s$ Ebd., S. 12997.

${ }^{509}$ AdR Marx, Nr. 1, S. 3.

510 Zitat aus Bericht der Reichstagsfraktion, Sozialdemokratischer Parteitag 1924, S. 89. Vgl. auch die eindringliche Rechtfertigung Severings, Lebensweg 1, S. 455-458, sowie Winkler, Von der Revolution zur Stabilisierung, S. 680 , auch zum folgenden.

s11 So übereinstimmend in der Presse. Unklar bleibt, ob es zahlreiche Enthaltungen gab oder ob so viele SPD-Parlamentarier fehlten. Stichpunktartige Notizen zu dieser Fraktionssitzung liegen von Carl Giebel vor; ASD Bonn, Nl. Giebel, Kassette II, Mappe 3, B1. 277.

512 So Marx am Abend des 3. 12. 1923. Vgl. auch FZ, 4.12. 1923 mo, S. 1, „Ermächtigungsgesetz und Reichstag": „Es spricht einiges dafür, daß sie [die sozialdemokratische Fraktion] zwar gegen das Gesetz stimmen, aber seine Verabschiedung durch die bürgerliche Mehrheit nicht verhindern will.“

513 Severing, Lebensweg 1, S. 457.

514 Bericht der Reichstagsfraktion, Sozialdemokratischer Parteitag 1924, S. 89: „Ich bin der Überzeugung, daß man einer Regierung die weitestgehenden Vollmachten geben kann, wenn man selbst an der Regierung ist und sie von innen heraus kontrollieren kann. Der Fall war aber nicht gegeben, und wir konnten damals auch nicht wieder in die Regierung eintreten." 
tigungsgesetz für die Regierung Stresemann gerade auch mit der sozialdemokratischen Regierungspräsenz gerechtfertigt hatte ${ }^{515}$. Vermutlich gab es in der SPD zudem ein wachsendes grundsätzliches Unbehagen am „Verzicht des Parlaments auf seine Rechte" ${ }^{516}$. Die Mehrzahl der Ermächtigungsgegner stammte aber vom linken Parteiflügel, der auch schon die Große Koalition und die Vollmachten für die Regierung Stresemann bekämpft hatte und der sich durch das Scheitern der Koalition bestätigt sehen mußte ${ }^{517}$. Die sozialdemokratischen Befürworter argumentierten vor allem mit der Erwartung, daß durch eine Ablehnung der Gesetzesvorlage nur der weitere, für das parlamentarische System gefährliche und durch keinen Kontrollausschuß beeinflußbare Gebrauch des Artikels 48 gefördert würde ${ }^{518}$. Das Ermächtigungsgesetz stelle somit gewissermaßen das kleinere Übel dar ${ }^{519}$. Ausschlaggebend für die Fraktionsentscheidung waren aber wohl auch Befürchtungen um den Bestand der Großen Koalition in Preußen ${ }^{520}$, Sorgen um die Stabilität der Rentenmark ${ }^{521}$ sowie um mögliche innenpolitische Erschütterungen nach einer Reichstagsauflösung und vermutlich auch ein grundsätzliches Bemühen, "Gesamtinteressen des Volkes vor die Interessen der Partei“ zu stellen ${ }^{522}$. Nicht auszuschließen ist, daß die stark dramatisierende Regierungserklärung von Marx hier eine gewisse Wirkung entfaltet hat.

Die wichtigste Vorentscheidung für eine Bewilligung des Ermächtigungsgesetzes war demnach bereits gefallen, bevor am 5. Dezember die Reichstagsaussprache mit der ersten Lesung begann ${ }^{523}$. In den Ausführungen der Fraktionsredner standen die eigene Positionsbestimmung in der aktuellen Krisenlage, Schuldzuweisungen an den politischen Gegner und die Definition des Verhältnisses zur Regierung im Vordergrund. Das Thema „Ermächtigungsgesetz“ wurde dabei

515 Vgl. oben S. 290.

516 Severing, Lebensweg 1, S. 455 f.; Severing selbst betont die Gefahren „für Land und Volk“ bei einer Verweigerung.

517 Severing, ebd., S. 455, verweist auf das Argument, man habe mit dem Vertrauensvorschuß durch das Ermächtigungsgesetz für die Regierung Stresemann schlechte Erfahrungen gemacht.

518 Darauf deutet auch die stichpunktartige Mitschrift Giebels: „Ermächtigungsgesetz sofern wir Einfluß gewinnen [...] oder Art. 48!“; ASD Bonn, Nl. Giebel, Kassette II, Mappe 3, Bl. 277. Vgl. auch Severing, Lebensweg 1, S. 457, der in seiner Rede darauf hinwies, daß es nach 1925 einen bürgerlichen Reichspräsidenten geben werde. Es dürfe daher keine Präzedenzfälle für die weitere Ausdehnung des Art. 48 geben. Grundsätzlicher blieb Scheidemann am 5.12. 1923 im Reichstag: „In einer Entwicklung unseres verfassungsmäßigen Lebens zur Ausschaltung des Parlaments und zur vorwiegenden Inanspruchnahme des Art. 48 erblickt die Fraktion eine schwere Gefahr. Die Absicht, ihr vorzubeugen, war für ihren Beschluß mitentscheidend." Verh. RT 361, S. $12299 \mathrm{f}$. Ähnlich skizzierte Müller im Bericht der Reichstagsfraktion, Sozialdemokratischer Parteitag 1924, S. $89 \mathrm{f}$., die Argumentation der Fraktionsmehrheit. Vgl. auch Winkler, Von der Revolution zur Stabilisierung, S. 680.

519 Vo, 5. 12. 1923 mo, S. 2, „Das Ermächtigungsgesetz abgeändert“, stellte dazu prägnant fest: „Der Regierung die Pistole des Ermächtigungsgesetzes verweigern, hieß, ihr das Gewehr des Art. 48 in die Hand drücken."

520 Vgl. Severing, Lebensweg 1, S. 458.

521 Vgl. Müller im Bericht der Reichstagsfraktion, Sozialdemokratischer Parteitag 1924, S. 90: „Die Mehrheit der Fraktion sagte sich, daß die neue Rentenmark eben erst ins Leben getreten sei und daß diese Währung ein sehr zartes Pflänzchen sei, daß, wenn es zur Auflösung komme und außenund innenpolitisch Stürme in Deutschland kommen würden, die Rentenmark stark beeinträchtigt würde."

522 Severing, Lebensweg 1, S. 458.

523 Allgemein zum folgenden vgl. auch Eilers, Ermächtigungsgesetzgebung und Ausnahmezustand, S. 88-95. 
meist nur knapp angesprochen: Scheidemann, der von allen Rednern noch am ausführlichsten darauf einging, begründete die Zustimmung der SPD mit den Gefahren des Artikels 48524. Prälat Kaas bestritt im Namen der Zentrumsfraktion, daß die Ermächtigung die legislative parlamentarische Zuständigkeit einschränke, vielmehr sei sie ein „Akt der Selbstdisziplin“ und eine „Betätigung echten parlamentarischen Geistes"525. Scholz für die DVP, Haas für die DDP und Leicht für die BVP kündigten die Zustimmung ihrer Fraktionen nur en passant an ${ }^{526}$. Angesichts der bevorstehenden Verabschiedung eines legislativen Blankoschecks ist der weitgehende Verzicht auf eine parlamentarische Diskussion oder doch zumindest auf eine öffentliche Rechtfertigung höchst bemerkenswert. Mehr noch als in der tatsächlichen Entscheidung für das Ermächtigungsgesetz zeigte sich hier ein eklatanter Mangel an verfassungsrechtlichem Problembewußtsein.

Als einzige große Fraktion legte sich die DNVP auf eine Ablehnung fest. Nachdem die Fraktion ihren Kurs zunächst tagelang offen gelassen hatte, erfolgte gegen Mittag des 5. Dezember ein entsprechender Beschluß, der wohl auch auf die entgegengesetzte SPD-Entscheidung vom Vorabend reagierte ${ }^{527}$. Hergt, der ,in den jüngsten Abmachungen über das Ermächtigungsgesetz [...] ein Wiederaufleben der großen Koalition sah", begründete das Stimmverhalten der DNVP im Reichstag mit dem fehlenden Vertrauen seiner Fraktion gegenüber einer Regierung, die "dem Urteil des Volkes“ ausweiche und sich einer Reichstagsauflösung widersetze ${ }^{528}$. Angemerkt sei, daß bei einer Konstellation, in der die SPD das Ermächtigungsgesetz abgelehnt und die DNVP zugestimmt hätte, die notwendige qualifizierte Mehrheit nur dann zu erreichen war, wenn ein Teil der SPD im Plenum anwesend geblieben wäre ${ }^{529}$. Die bestehende Rechtslage erschwerte damit die Einbeziehung der DNVP in eine bürgerliche „Ermächtigungsmehrheit“. Hätte es für die legislative Delegation, wie in Frankreich üblich, nur einer einfachen Mehrheit bedurft, so wäre Ende 1923 eine Ablehnung der Ermächtigung durch die SPD und statt dessen ein Wechsel der DNVP in das informelle Regierungslager erheblich leichter gefallen. Dennoch ist festzuhalten, daß auch unter den gegebenen Umständen eine derartige Konstellation möglich war und zunächst auch diskutiert wurde.

Trotz scheinbar klarer Fronten war die Billigung des Ermächtigungsgesetzes noch keineswegs so gesichert, wie es zunächst schien ${ }^{530}$. Denn die Frage, ob der

524 Verh. RT 361, S. 12299 f. Vgl. Zitat in Anm. 518.

525 Ebd., S. 12300-12304, Zitat S. 12301.

526 Scholz ebd., S. 12304-12308, hier S. 12307; Haas S. 12308-12314, hier S. 123212; Leicht S. 1231412315 , hier S. 12315.

${ }^{527}$ Zur Haltung der DNVP-Fraktion vgl. die kurzen Hinweise in NPZ, 4. 12. 1923 ab, S. 1, „Die Parlamentskrisis“; NPZ, 5. 12. 1923 mo, S. 2, „Eine neue Fassung des Ermächtigungsgesetzes?“; NPZ, 5. $12.1923 \mathrm{ab}$, „Das geänderte Ermächtigungsgesetz“.

528 Ebd., S. 12307-12308, hier S. 12308.

529 So die Prognose in FZ, 4. 12. 1924 mo, S. 1, „Ermächtigungsgesetz und Reichstag“. Der Artikel rechnete mit einer notwendigen Mehrheit von nur 200 bis 210 Stimmen. DDP, Zentrum, DVP, DNVP und BVP verfügten zusammen über eine theoretische Mehrheit von 257 Stimmen. - Unter umgekehrten Vorzeichen verzichtete dann am 8.12. die DNVP mit ihrer Anwesenheit bei der Abstimmung auf den destruktiven Versuch, die Ermächtigung durch eine Unterschreitung des notwendigen Anwesenheits-Quorums zum Scheitern zu bringen.

530 Vgl. z. B. Vo, 5. 12. 1923 mo, „Die Erklärung des Kabinetts Marx“: „Das Ermächtigungsgesetz wird ihm bewilligt werden“: „Das Kabinett wird also freie Bahn haben und zeigen können, wo es 
Reichstag in der entscheidenden Schlußabstimmung die geforderte Präsenz von zwei Dritteln aller Abgeordneten erreichen würde (306 von 459), stand noch offen. $\mathrm{Zu}$ erwarten war insbesondere das Fernbleiben von SPD-Dissidenten sowie der DNVP-Fraktion. Hinzu kam, daß eine Reihe von Abgeordneten krank, beurlaubt oder aus sonstigen Gründen verhindert war. Ein Indiz für die prekäre Mehrheitslage war die in dritter Lesung am 6. Dezember vollzogene Abstimmung über den zentralen $₫ 1$ der Ermächtigungsvorlage, der mit $280 \mathrm{zu} 79$ Stimmen gebilligt wurde. Dabei fehlten 62 SPD-Parlamentarier, und einer stimmte sogar mit Nein ${ }^{531}$. Kurz vor der entscheidenden Schlußabstimmung waren etwa 370 Abgeordnete im Plenum anwesend. Falls nun KPD, Deutschvölkische und DNVP, die zuvor mit Nein votiert hatten, den Plenarsaal verließen, wäre das erforderliche Quorum verfehlt worden, und Reichskanzler Marx hätte umgehend die von Ebert bereits ausgefertigte Auflösungsurkunde zum Einsatz gebracht. In einem bizarren Schauspiel versuchte die ausschlaggebende DNVP-Fraktion, die übrigen Parteien im unklaren über ihr Verhalten zu lassen. Nach einem Pressebericht verzogen die Deutschnationalen „wie Sphinx keine Miene“ und warteten mit "steinernem Antlitz“ auf eine Handbewegung ihres Fraktionsvorsitzenden, um sie „zum Verbleiben oder zum Verlassen des Saales bei der Abstimmung zu veranlassen“ 532 . Ähnlich wie schon am 11. Oktober zogen die Regierungsfraktionen jetzt die Notbremse und setzten eine Vertagung der Sitzung durch.

Vor dem neuerlichen Zusammentreten des Reichstags am 8. Dezember mühten sich die Regierungsparteien, alle nur verfügbaren Abgeordneten nach Berlin zu holen. Die SPD-Fraktion proklamierte einen verschärften Fraktionszwang, der de facto erneut das traditionell geduldete Fernbleiben von der Abstimmung untersagte ${ }^{533}$. Nachdem die Reihen derart verdichtet waren, konnte aus Sicht der Koalition die Schlußabstimmung gewagt werden. Das Ermächtigungsgesetz wurde nun mit 313 zu 18 Stimmen bei einer Enthaltung gebilligt. Der größere Teil der DNVP-Fraktion war - offenbar nach einer informellen Zusage von Marx im Hinblick auf vorgezogene Neuwahlen - im Saal geblieben und hatte somit auf eine harte Obstruktionspolitik verzichtet ${ }^{534}$. Dasselbe galt überraschenderweise auch

den Hebel ansetzt, um dem leidenden Volke zu helfen. Es bedarf keiner besonderen Versicherung, daß die Sozialdemokratie alles unterstützen wird, was geeignet erscheint, dem Reich die notwendigen Mittel zu verschaffen; daß sie aber auf der Wacht sein wird, um zu verhüten, daß auf dem Wege der Verordnung die Last der breiten Massen noch drückender, die Rechte des arbeitenden Volkes noch mehr verkürzt werden."

531 Liste der namentlichen Abstimmung in Verh. RT 361, S. 12359-12361. Winkler, Von der Revolution zur Stabilisierung, S. 680, spricht nur von 50 Abgeordneten, was offenbar auf die in Arns, Die Linke in der SPD-Reichstagsfraktion, S. 197-199, zu findende Tabelle zurückgeht. Arns berücksichtigt allerdings nur den von ihm eingegrenzten linken Flügel der Fraktion. Mit Nein votierte der Abgeordnete Wilhelm Hoffmann(-Schmargendorf).

532 BT, 7. 12. 1923 mo, S. 1, „Die vertagte Gesamtabstimmung“.

533 Nach Vo, 7. 12. 1923 mo, S. 1, „Sitzung der sozialdemokratischen Fraktion“: „Die Mitglieder der Fraktion sind nur dann berechtigt, sich aus Gewissensgründen einer von der Fraktion beschlossenen Abstimmung fernzuhalten, wenn nicht durch diese Fernhaltung die Abstimmung der Fraktion in ihrem Erfolg beeinträchtigt wird. “ Nach Kastning, Sozialdemokratie, S. 136.

534 Nach BT, 9. 12. 1923 mo, S. 1. „Das Ermächtigungsgesetz angenommen“, hatten sich „etwa zwanzig bis dreißig [...] vorher heimlich seitwärts in die Büsche geschlagen“. Zur Vereinbarung mit Marx vgl. Huber, Verfassungsgeschichte 7, S. 454, im Anschluß daran auch Hehl, Marx, S. 259. Allerdings ist hier jeweils die Rede davon, daß die gesamte DNVP-Fraktion anwesend blieb. Eilers, Ermächtigungsgesetzgebung und Ausnahmezustand, geht auf diese Frage nicht ein. 
für die meisten KPD-Abgeordneten sowie die Splittergruppe der USPD. Die deutschnationale Teilkonzession war aber letztlich nicht entscheidend für die Annahme des Ermächtigungsgesetzes gewesen ${ }^{535}$, denn die magische Grenze von 306 Anwesenden, d.h. von zwei Dritteln aller Abgeordneten, war bereits durch die Zahl der an der Abstimmung Beteiligten deutlich übertroffen worden.

Die SPD war trotz aller Drohungen nicht in der Lage gewesen, ihre Abgeordneten durchgehend zu disziplinieren. Immerhin 42 SPD-Parlamentarier fehlten bei der Abstimmung, das ist etwa ein knappes Viertel der Fraktion; die meisten davon waren ehemalige Mitglieder der USPD ${ }^{536}$.

Tab. 10: Votum des Reichstags am 8. 12. 1923: Schlußabstimmung Ermächtigungsgesetz ${ }^{537}$

\begin{tabular}{lrrrrrrc}
\hline $\begin{array}{l}\text { Fraktion oder } \\
\text { Gruppe }\end{array}$ & Abg. & ja & nein & $\begin{array}{l}\text { ent- } \\
\text { halten }\end{array}$ & fehlend & $\begin{array}{l}\text { beurl. } \\
\text { krank } \\
\text { entsch. }\end{array}$ & $\begin{array}{l}\text { Kohä- } \\
\text { renz }\end{array}$ \\
\hline KPD & 16 & - & 11 & - & 5 & - & $69 \%$ \\
USPD & 2 & - & 2 & - & - & - & - \\
SPD & 171 & 128 & 1 & - & 41 & 1 & $75 \%$ \\
DDP & 39 & 39 & - & - & - & - & $100 \%$ \\
Zentrum & 66 & 63 & - & - & 1 & 2 & $98 \%$ \\
DVP & 66 & 60 & - & - & 5 & 1 & $92 \%$ \\
BVP & 20 & 19 & - & - & - & 1 & $100 \%$ \\
DHP & 4 & 3 & - & 1 & - & - & - \\
DNVP539 & 66 & - & - & - & 62 & 4 & $100 \%$ \\
DVFP & 3 & - & - & - & 3 & - & - \\
fraktionslos & 2 & 1 & - & - & 1 & - & - \\
\hline Gesamt & 459 & 313 & 18 & 1 & 118 & 9 & - \\
\hline
\end{tabular}

Wie erwähnt, betrachtete Marx die Verabschiedung des Ermächtigungsgesetzes vom 8. Dezember 1923 auch als Vertrauensvotum. Schon allein aus diesem Grund bedeutete das Ergebnis eine Neudefinition des parlamentarischen Regierungslagers. Obgleich der Charakter einer bürgerlichen Minderheitsregierung gewahrt blieb, stand die SPD-Fraktion durch ihre überwiegende Zustimmung zur Pauschalermächtigung doch mindestens mit einem Bein in der Regierungsmehrheit, so daß die Politik der Großen Koalition nun eine informelle Fortsetzung fand. Demonstrativ wurden nun freilich oppositionelle Töne angeschlagen. Ausdrücklich betonte Scheidemann am 5. Dezember im Reichstag, daß die SPD-Fraktion „keine

535 In der Literatur wird dies teilweise angenommen; so z.B. in Huber, Verfassungsgeschichte 7 , S. 454.

536 Vgl. Liste der namentlichen Abstimmung in Verh. RT 361, S. 12359-12386. Davon war ein Abgeordneter krank gemeldet, 41 fehlten unentschuldigt. Die von Arns, Die Linke in der SPD-Reichstagsfraktion, S. 199, und Winkler, Von der Revolution zur Stabilisierung, S.680, angegebene Zahl von 39 fehlenden SPD-Abgeordneten ist zu korrigieren. Hoffmann(-Schmargendorf) stimmte erneut gegen die Ermächtigung, was nun mit einem Parteiausschlußverfahren geahndet wurde.

537 Berechnung nach Liste der namentlichen Abstimmung in Verh. RT 361, S. 12359-12386.

${ }_{538}$ Einschließlich Hospitanten.

539 Einschließlich der Bayerischen Mittelpartei. 
Mitverantwortung für die Beschlüsse eines Kabinetts übernehmen [könne], dem sie nicht angehört". Sie behalte sich daher "sachliche Stellungnahmen zu allen Maßnahmen der Regierung vor". In einem zentralen Punkt deutete Scheidemann auch eine inhaltliche Alternative an: Bereits mehrfach hätten SPD-Vertreter in Gesprächen mit Regierungsmitgliedern zum Ausdruck gebracht, „daß ihrer Meinung nach die von der Regierung vorbereiteten steuerpolitischen Maßnahmen unzulänglich sind und eine einseitige Überlastung der minderbemittelten Volksschichten bewirken müssen" 540 .

Am Ende der Plenarsitzung vom 8. Dezember wurde beschlossen, daß der Wiederzusammentritt durch den Reichstagspräsidenten festgelegt werden sollte ${ }^{541}$. Durch diese Vertagung auf unbestimmte Zeit zog sich das Parlament weitgehend von der politischen Bühne zurück. Dem pauschalen legislativen Funktionsverzicht folgte so die nahezu vollständige Suspendierung der parlamentarischen Tätigkeit, die sich jetzt fast ausschließlich auf den - nach der Reichstagssitzung erstmals zusammentretenden - Fünfzehnerausschuß beschränkte. Weiterhin bestand allerdings die Möglichkeit, daß auf Antrag von einem Drittel der Mitglieder der Reichstag einberufen werden mußte und daß dann eine Mehrheit die Aufhebung einer Verordnung veranlassen konnte.

Bezeichnend für die im bürgerlichen Regierungslager herrschende Stimmungslage, die von einer gewissen Erleichterung über die Abgabe der legislativen Bürde an die Regierung gekennzeichnet war, scheint eine Äußerung des Zentrumsabgeordneten Becker(-Arnsberg) während der kurzen Diskussion um die Vertagung: "Der Sinn des Ermächtigungsgesetzes ist doch, daß wir in der nächsten und übernächsten Woche, vielleicht auch nach der Weihnachtswoche keine Sitzungen zu halten brauchen. Sonst wäre ja das ganze Ermächtigungsgesetz überflüssig gewesen. “ ${ }^{442}$ Unter der vom Protokoll verzeichneten „Zustimmung in der Mitte“ ${ }_{543}$ wurde so die Pauschalvollmacht für die Regierung - zumindest in der Außendarstellung - auch zum Urlaubsschein für das Parlament.

Die Pause in den Plenarverhandlungen sollte fast zweieinhalb Monate dauern. Erst am 20. Februar 1924, nach dem regulären Ablauf der Ermächtigung, versammelte sich der Reichstag wieder. Auch der Ausschußbetrieb wurde mangels legislativer Tätigkeit nahezu vollständig eingestellt. Der besonders wichtige Haushaltsausschuß hatte ohnehin seit dem 12. Oktober nicht mehr getagt; erst am 18. Februar trat er wieder zusammen. Lediglich die als „45. Ausschuß“ konstituierte Sonderkommission („Fünfzehnerausschuß“) befand sich in einer intensiven Beratungsaktivität, von der gleich noch genauer die Rede sein soll.

Bis zum 14. Februar 1924 wurden auf der Grundlage des Ermächtigungsgesetzes insgesamt 68, teils sehr umfangreiche Verordnungen erlassen ${ }^{544}$. Generell las-

\footnotetext{
540 Verh. RT 361, S. 12300.

${ }^{541}$ Ebd., S. $12381 \mathrm{f}$. Zuvor war ein DNVP-Antrag auf Einberufung des Reichstags bis spätestens zum 10. 1. 1924 gescheitert. Auf die schließlich beschlossene Lösung hatten sich Regierungsparteien und SPD bereits am 6.12. geeinigt, nachdem das ursprüngliche Verlangen der Regierung, eine Vertagung bis zum 31.1. 1924 zu beschließen, auf den Widerstand der SPD gestoßen war. Vgl. FZ, 7. 12 . $1923 \mathrm{mo} / 2$, S. 1 , „Neue Schwierigkeiten im Reichstag“.

542 Verh. RT 361, S. 12381.

${ }^{54} 3$ So ebd. das Protokoll.

544 Vgl. Liste in AdR Marx, Nr. 106, S. 369-373, geordnet nach Politikfeldern; chronologische Liste in
} 
sen sich dabei zwei Gruppen unterscheiden: Sozial- und finanzpolitische Verordnungen, die im weitesten Sinne der Neuordnung des Währungssystems einschließlich der notwendigen staatlichen Einsparungen und Einnahmeverbesserungen dienten, und Verordnungen allgemeinerer Natur, die mit dem ursprünglichen Anlaß des Ermächtigungsgesetzes nichts mehr zu tun hatten.

Im Mittelpunkt der Stabilisierungspolitik standen die zweite und die dritte "Steuernotverordnung" vom 19. Dezember 1923 und vom 14. Februar 1924, mit denen wieder ein leistungsfähiges Steuersystem geschaffen wurde ${ }^{545}$. Letztlich muß man hier von einem Sieg industrieller Interessen sprechen, die sich im bürokratischen Gesetzgebungsprozeß durchsetzen konnten. Während es bei der Neufestlegung diverser Steuern zu einer erheblichen Belastung breiter Bevölkerungsschichten kam, fand eine „Kapitalentlastung der Wirtschaft ${ }^{\text {“ }}$ statt $^{546}$. Innerhalb der Verordnung vom 14. Februar 1924 erfolgte zudem eine Weichenstellung in der Frage der Schuldenaufwertung. Notwendig geworden war sie nach einem Urteil des Reichsgerichts vom 28. November 1923, das mit dem Grundsatz „Mark gleich Mark" gebrochen hatte. Die nach einigen Kontroversen schließlich dekretierte Aufwertung privater Vorkriegsschulden lag bei einem Satz von $15 \%$ ihres Goldmarkbetrages. Die Aufwertung öffentlicher Schulden - darunter nicht zuletzt die Kriegsanleihen - wurde zur Schonung des Staatsetats zurückgestellt ${ }^{547}$.

$\mathrm{Daß}$ diese Maßnahmen vor allem in jenen Teilen des Mittelstandes, die von Vermögensverlusten betroffen waren, weitreichende politische Folgen hatten und zur weiteren Desintegration des deutschen Liberalismus beitrugen, ist bekannt ${ }^{548}$. Parlamentarismusgeschichtlich sei hierzu angemerkt, daß der anonyme Verordnungsweg, auf dem eine öffentliche Diskussion kaum noch stattfand, sicherlich nicht geeignet war, Verständnis für die verfolgte Politik zu wecken. Mit dem Verzicht auf die Gesetzgebungsfunktion des Reichstags war daher in einer extrem wichtigen Angelegenheit auch ein Abbau der parlamentarischen Öffentlichkeitsfunktion verbunden.

Weitere wichtige Projekte der Reichsregierung auf der Grundlage des Ermächtigungsgesetzes, die im Kontext der Stabilisierungspolitik standen, waren die Verordnung über Goldbilanzen vom 28. Dezember 1923549, die Verordnung über die

Frehse, Ermächtigungspolitik, Anhang, Teil III, S. 4-8. - Kurze Skizzierung der wichtigsten Verordnungen in Huber, Verfassungsgeschichte 6, S. 443; ders. Verfassungsgeschichte 7, S. 455-458 (allerdings mit zahlreichen fragwürdigen Wertungen). Ausführlich zum Verordnungswerk der Regierung Marx vgl. Eilers, Ermächtigungsgesetz und militärischer Ausnahmezustand, S. 98-105. Frehse, Ermächtigungsgesetzgebung, S. 129-132, geht nur knapp auf die inhaltliche Seite ein.

545 RGBI. 1923 I, S. 1205-1228; RGBl. 1924 I, S. 74. Vgl. AdR Marx, S. XXVII; Feldman, Great Disorder, S. 816-821; Winkler, Von der Revolution zur Stabilisierung, S. 694 f.; Huber, Verfassungsgeschichte 7, S. 456. Die erste Steuernotverordnung war bereits am 7.12. 1923 auf dem Wege des Art. 48 erlassen worden.

${ }^{546}$ Krohn, Helfferich contra Hilferding, S. 91.

${ }^{547} \mathrm{Zu}$ den Details der Regelung und zur fachlichen Seite der Diskussion vgl. v.a. Holtfrerich, Die deutsche Inflation, S. 315-327. Ebd. auch zur Modifizierung durch zwei Gesetze im Juli 1925. Ebd., S. 331, wird resümierend eher die Bedeutung der Aufwertung (nach der Verbesserung von 1925) betont, die etwa cinen analogen Vermögensverlust wie in Frankreich brachte. Kritischere Bewertung in Feldman, Great Disorder, S. $818 \mathrm{f}$.

548 Vgl. v.a. Jones, German Liberalism, S. 225-305; ders., In the Shadow of Stabilization.

${ }^{549}$ RGBl. 1923 I, S. 1253. 
Schaffung eines Unternehmens „Deutsche Reichsbahn“ vom 12. Februar 1924550, die Reichsschuldenordnung vom 13. Februar 1924551 sowie nicht zuletzt auch die Verordnung über die Arbeitszeit vom 21. Dezember 1923552. Das im Oktober nach heftigen Konflikten vereinbarte Gesetzgebungsverfahren zur Arbeitszeitregelung war damit auf unspektakuläre Weise hinfällig geworden ${ }^{553}$. Materiell sicherte die vom Reichsarbeitsministerium durchgesetzte Verordnung die Beibehaltung des Achtstundentages "nur ganz akademisch" 554 . Zugelassen waren weitgehende Ausnahmen, entweder aufgrund tariflicher Vereinbarung oder behördlicher Anordnung. Als regelmäßige Höchstgrenze wurde eine Arbeitszeit von 10 Stunden festgesetzt. Dieser am 1. Januar 1924 in Kraft tretende „Sieg der Unternehmer" führte schon bald zu schweren Arbeitskämpfen 555 .

Innerhalb kürzester Zeit diente die auf Hochtouren laufende Verordnungsmaschinerie auch dazu, in den Ministerien bereitliegende Projekte auf schnellem Wege in eine teils dauerhafte Gesetzgebung zu überführen. Genannt seien vor allem verschiedene Verordnungen zur Justizreform, darunter eine Neuregelung des Prozeßwesens ${ }^{556}$, sowie die - bis 1962 gültige! - Verordnung über die Fürsorgepflicht vom 13. Februar 1924557. Mit der im Text der legislativen Vollmacht genannten „Not von Volk und Reich“ hatten diese Verordnungen nur noch wenig zu tun. Das Ermächtigungsgesetz wurde somit zum Blankoscheck für ein bürokratisches Verordnungsregime, das sich von der ursprünglichen Motivation gelöst hatte.

Da die im Regierungslager stehenden Parteien kaum noch an der Gesetzgebung beteiligt waren, baute sich auch in deren Reihen teilweise eine deutliche Distanz zur Regierungspolitik auf. So kam eine Entschließung auf dem DVP-Parteitag im März 1924 zu dem harschen Urteil: „Die III. Steuernotverordnung bringt breite Volksschichten um die Früchte langjähriger Arbeit und Sparsamkeit und zerschlägt den Mittelstand." 558 Auf grundsätzliche Kritik scheint das Verordnungsregime allerdings nur in der DDP gestoßen zu sein. Der Parteiausschuß verfaßte am 27. Januar 1924 eine Protestresolution, die „lebhafte[n] Widerspruch“ dagegen erhob, „dass das Ermächtigungsgesetz seinem Zwecke zuwider dazu ausgenutzt wird, Gerichtsverfassung und Gerichtsverfahren in einem ganz einseitigen und

${ }^{550}$ RGBI. 1924 I, S. 57-59. Die Verordnung diente v.a. der Entlastung des Reichshaushalts. Vgl. AdR Marx, S. XXVI; Huber, Verfassungsgeschichte 7, S. $456 \mathrm{f}$.

551 RGBl. 1924 I, S. 95. Vgl. Huber, Verfassungsgeschichte 7, S. 456.

552 RGBl. 1923 I, S. 1249-1251.

${ }_{553}$ Vgl. auch Winkler, Von der Revolution zur Stabilisierung, S. 684.

${ }^{554} \mathrm{FZ}, 23.12 .1923 \mathrm{mo} / 2$, S. 2, „Die Regelung der Arbeitszeit“. Einblicke in die Verordnungspraxis gibt BA Berlin, R 3901, Nr. 1730.

555 Winkler, Von der Revolution zur Stabilisierung, S. 684 (Zitat): AdR Marx, S. XXX.

556 Verordnung über die Gerichtsverfassungs- und Strafrechtspflege vom 4.1. 1924, RGBl 1924 I, S. 15; Verordnung zur Entlastung des Reichsgerichts vom 15. 1. 1924, ebd., S. 29; Verordnung über Vermögensstrafen und Bußen vom 6. 2. 1924, ebd., S. 44; Verordnung über das Verfahren in bürgerlichen Rechtsstreitigkeiten vom 13. 2. 1924, ebd., S. 135.

557 Ebd., S. 100.

558 So in einer Entschließung des DVP-Parteitags im März 1924; BA Koblenz, R 45 II, Nr. 28, Bl. 137. Vgl. auch ebd.: „Der in der III. Steuernotverordnung unternommene Versuch, die Aufwertung der Forderung der Hypothekengläubiger, der Pfandbriefinhaber, der Sparkassengläubiger, der Obligationäre und der Versicherungsgläubiger mit den Grundsätzen des Reichsgerichtsurteils vom 28. November 1923 in Einklang zu bringen, ist nach Ansicht des Parteitages völlig misslungen.“ 
bürokratischen Sinne rückwärts zu revidieren"559. Auch an der linksliberalen Basis artikulierten sich Widerstände. So fragte Mitte Februar eine Ortsgruppe bei Fraktionssekretär Erkelenz nach: „Wird weiter nach Mussolinischem Muster regiert oder nach der guten Weimarischen Verfassung? Regieren überhaupt noch die von uns gewählten Parlamentarier oder nur Wirtschaftspolitiker?" 560

Der Anfang Dezember von der SPD ausgehandelte Rest an parlamentarischer Mitwirkungs- und Kontrollmöglichkeit konzentrierte sich zunächst auf den hoffnungslos überforderten Fünfzehnerausschuß561. Die unter der Leitung des DVPFraktionsvorsitzenden Scholz stehende Kommission, die mit Spitzenvertretern der Parteien besetzt war, arbeitete zwar fleißig, sie kam in ihren insgesamt 20 Sitzungen bei der Fülle der vorliegenden Verordnungsentwürfe jedoch der gestellten Aufgabe schon bald nicht mehr nach. Von einer fachlich fundierten Beratung konnte mangels Zeit und auch infolge des weitgehenden Fehlens der eigentlichen Fraktionsexperten aus den regulären Ausschüssen ohnehin keine Rede sein. Der Ausschußvorsitzende klagte bereits am 19. Dezember in einem Schreiben an Reichskanzler Marx, daß „der durch das Gesetz gewollte Zweck der schleunigen vereinfachten Gesetzgebung in Frage gestellt wird, wenn dem Ausschuß nicht ausschließlich die Entwürfe von Verordnungen vorgelegt werden, die unbedingt auf Grund des Ermächtigungsgesetzes erlassen werden müssen“. Andere "Materien", so Scholz, seien „auf dem Wege der ordentlichen Gesetzgebung zur Erledigung zu bringen" 562 . Selbst der DVP-Fraktionsvorsitzende, ansonsten keineswegs ein Verteidiger parlamentarischer Verfahrensweisen, wurde offenbar durch die Eigendynamik des Verordnungsregimes überrascht. Abänderungsvorschläge des Fünfzehnerausschusses wurden bei den Verordnungen durchaus berücksichtigt, sie betrafen aber wohl lediglich Detailfragen. Insgesamt wird man daher im Hinblick auf das Verordnungsregime dem Urteil von Moritz Julius Bonn zustimmen müssen, der „von einer fast nur ornamentalen Kontrolle“ des Reichstags gesprochen hat ${ }^{563}$.

Lediglich in der ganz zum Schluß der Ermächtigungsfrist durch die dritte Steuernotverordnung vom 14. Februar geregelten Aufwertungsfrage kam der parlamentarische Einfluß wieder stärker zur Geltung. Allerdings geschah dies nicht über den Fünfzehnerausschuß, dessen Vorsitzender sich am 9. Februar in einer Parteiführerbesprechung darüber beklagte, daß die Vorlage von der Regierung zu spät in den Ausschuß gebracht worden sei ${ }^{564}$. Vielmehr gewannen nun die Partei-

${ }_{559}$ BA Koblenz, R 45 III, Nr. 12, Bl. 63. Vgl. auch Koch-Weser: „Weittragende Verordnungen auf Grund des Ermächtigungsgesetzes, z.T. wenig mit der Vermeidung der Inflation in stehend." Auf den 16. 5. 1924 datierter Nachtrag zu den tagebuchartigen Notizen; BA Koblenz, Nl. Koch-Weser, Nr. 30, Bl. 25.

560 BA Koblenz, Nl. Erkelenz, Nr. 126, Bl. 204. Inhaltlich richtete sich die Kritik an dem Verordnungsregime hier v.a. gegen den Beamtenabbau. - Allgemein zur gespannten innerparteilichen Situation der DDP Ende 1923/Anfang 1924 vgl. Jones, German Liberalism, S. 212 f.

561 Protokolle in BA Berlin, R 101, Nr. 1623-1624: „Verhandlungen des Ausschusses gemäß $₫ 1$ des Ermächtigungsgesetzes“. Vgl. zum Ausschuß auch Stürmer, Koalition und Opposition, S. 34; Frehse, Ermächtigungsgesetzgebung, geht nicht auf die Praxis des Fünfzehnerausschusses ein.

562 BA Berlin, R 1501, Nr. 17100, Bl. 201.

563 Bonn, So macht man Geschichte, S. 136. Bonn war einer der wenigen von der parlamentarischen Demokratie überzeugten Staatsrechtler der Weimarer Republik.

564 Protokoll der Besprechung in AdR Marx, Nr. 97, S. 343-345, hier S. 344. 
führerbesprechungen entscheidende Bedeutung für die Durchsetzung einer legislativen Restfunktion des Reichstags ${ }^{565}$. Gegenüber dem Fünfzehnerausschuß hatte dies zweifellos den Vorzug, daß Regierungs- und Fraktionsvertreter direkt miteinander verhandeln konnten. Ganz umgehen ließ sich die Mitsprache der Reichstagsparteien in einem so wichtigen und heiklen Problemfeld kaum, denn der Wiederzusammentritt des Parlaments stand unmittelbar bevor. Ohne Konsenslösung, in die zumindest partiell auch SPD und DNVP als Gegner und Befürworter einer Aufwertung 566 eingebunden werden mußten, drohte die sofortige Außerkraftsetzung und Abänderung der Verordnung durch einen Mehrheitsbeschluß des Reichstags. Scholz hatte im Namen des Fünfzehnerausschusses aus rechtlichen Bedenken sogar angeregt, daß die Materie aus der dritten Steuernotverordnung ausgenommen und einem regulären Gesetzgebungsverfahren unterworfen werden sollte ${ }^{567}$. Eine derartige Lösung scheiterte freilich daran, daß die von der Regierung als notwendig erachtete rasche Einigung infolge von Differenzen zwischen SPD und DNVP nicht zustande $\mathrm{kam}^{568}$. Im Zuge des Diskussionsprozesses mit den Parteiführern wurde vom Reichsfinanzministerium schließlich der Aufwertungssatz von den ursprünglich vorgesehenen 10 auf die bereits erwähnten $15 \%$ erhöht ${ }^{569}$.

In der rückblickenden Analyse erscheint die Bedeutung der Parteiführerbesprechungen in der Aufwertungsthematik als Indiz dafür, daß die parlamentarische Abgabe der legislativen Funktion unter den Bedingungen des Jahres $1924 \mathrm{zu}-$ letzt doch auf Grenzen stieß. Noch deutlicher war dies zuvor schon in einer Frage geworden, die mit der Stabilisierungsthematik nichts zu tun hatte. Der Versuch des Innenministeriums, auf dem Verordnungsweg zu einer Wahlrechtsreform zu kommen, war rasch am Widerstand der führenden Fraktionsvertreter gescheitert ${ }^{570}$. Die Gesetzgebungsgewalt des Reichstags war eben nur zeitweise suspendiert, spätere Änderungen von Verordnungen blieben immer möglich, und die Drohung mit der Reichstagsauflösung war noch kein so wirkungsvolles Instrument wie dann seit Mitte 1930. Problematisch wurde der Funktionsgewinn der Parteiführerbesprechungen freilich insofern, weil dies nur eine punktuelle Adhoc-Lösung darstellte und dazu beitrug, das in Form eines Reichstagsausschusses

565 V.a. Besprechung am 9. 2. 1924, Protokoll in AdR Marx, Nr. 97, S. 343-345. Von den weiteren Besprechungen, die nach ebd., S. 345 auf den 11.2. gelegt waren, sind keine Protokolle überliefert. Vgl. aber einen zusammenfassenden „Bericht über die Dritte Stcuernotverordnung“ des DDPAbgeordneten Hermann Fischer für seine Fraktion aus BA Koblenz, Nl. Dietrich, Nr. 70. Resümee in AdR Marx, Nr. 97, S. 345.

566 Die Sozialdemokratic, deren Basis von der Aufwertungsproblematik wenig betroffen war, teilte im Prinzip die Regierungsposition und wollte „lediglich die Inflationsgewinne vollständig abgeschöpft und sozial verwendet wissen“. Jung, Direkte Demokratie, S. 17.

567 Protokoll der Besprechung in AdR Marx, Nr. 97, S. 343-345, hier S. 344: „Im übrigen seien die Bedenken des Ausschusses gerade darin begründet, daß die Erledigung der Aufwertungsfrage in der vorgeschlagenen Weise auf Grund des Ermächtigungsgesetzes sich möglicherweise als nicht ausreichend gesichert erweisen könne gegenüber einer ablehnenden Haltung der Gerichte, und daß daher eine Erledigung im Wege der ordentlichen Gesetzgebung, wenn möglich sogar mit einer Zweidrittelmchrheit im Hinblick auf die verfassungsrechtlichen Bedenken dringend erwünscht sei."

568 Vgl. zusammenfassend AdR Marx, S. XXVIII.

569 Regierungsentwurf der dritten Steuernotverordnung ebd., Nr. 77 f., S. 291-294.

570 Vgl. zusammenfassend zur Wahlrechtsvorlage und zum späteren Scheitern eines regulären Gesetzgebungsverfahrens ebd., S. XVII. 
installierte Experiment eines formellen Mitwirkungs- und Kontrollorgans zu entwerten.

Am 15. Februar 1924 endete die Gültigkeit des Ermächtigungsgesetzes. Vier Wochen später erfolgte die erste Reichstagsauflösung der Weimarer Republik, weil die Regierung die parlamentarische Aufhebung oder Abänderung erlassener Verordnungen fürchtete. Die im breiten Konsens begonnene Ermächtigungspolitik führte so am Ende der Legislaturperiode zu einem Grundsatzkonflikt zwischen einer heterogenen Reichstagsmehrheit und der Reichsregierung. Die Umstände dieser Entwicklung seien im folgenden etwas genauer betrachtet.

Wenige Tage nach Ablauf der Ermächtigung, am 20. Februar, trat auf Veranlassung des Reichstagspräsidenten erstmals seit zweieinhalb Monaten das Reichstagsplenum wieder zusammen. Pünktlich zu diesem Termin hatte die SPD zahlreiche Änderungs- oder Aufhebungsanträge zu den erlassenen Ermächtigungsverordnungen eingebracht ${ }^{571}$. Diese richteten sich zwar nicht grundsätzlich gegen die von den Sozialdemokraten im Prinzip begrüßte Stabilisierungspolitik, wohl aber gegen eine Fülle von Details, die jetzt auf parlamentarischem Wege korrigiert werden sollten ${ }^{572}$. Die SPD forderte zu diesem Zwecke eine Überweisung ihrer Anträge in die regulären Reichstagsausschüsse ${ }^{573}$. Die DNVP, die heftig gegen die als zu niedrig bewertete Aufwertungsregelung bei Vermögensschulden polemisierte, legte wenige Tage später ein pauschales Aufhebungsverlangen gegen die dritte Steuernotverordnung vor ${ }^{574}$, wobei im Gegensatz zur SPD eine möglichst umgehende Reichstagsauflösung angestrebt wurde. Die Parteien der Regierungskoalition hingegen waren soweit diszipliniert worden, daß sie entweder keine Änderungs- und Aufhebungsanträge stellten oder diese sehr schnell wieder zurückzogen ${ }^{575}$.

Aus Sicht der Regierung drohte jetzt eine unabsehbare und die Währungsstabilisierung gefährdende nachträgliche parlamentarische Diskussion ihrer Verordnungspolitik. Ernsthaft bedroht war diese allein durch die SPD-Anträge, die mit Unterstützung von KPD und DNVP jederzeit eine heterogene Reichstagsmehrheit erlangen konnten. Diese Lage war eine durchaus logische Folge der Konstellation vom 8. Dezember, als sich die SPD-Fraktion zwar aus verschiedenen Gründen entschlossen hatte, für das Ermächtigungsgesetz zu stimmen, allerdings jede inhaltliche Verantwortung für die Regierungspolitik abgelehnt hatte. Während

571 Drucks. Nr. 6470-6474, 6476 und 6479-6485 vom 20. 2. 1924, Nr. 6506 vom 22. 2. 1924; Verh. RT 380, S. 7735-7739, 7848. Vgl. auch Übersichtsliste des Reichsarbeitsministers Brauns mit Stellungnahmen zu Abänderungsanträgen der SPD; BA Berlin, R 3901, Nr. 1730 (ohne Paginierung).

572 Vgl. z. B. Müller am 19. 2. 1924 in einer Parteiführerbesprechung: „Es müßten eine Menge der erlassenen Verordnungen beanstandet werden, so z.B. die zahlreichen sozialpolitischen Verordnungen, die Personalabbauverordnung, Teile der dritten Steuernotverordnung usw." AdR Marx, Nr. 111, S. 381. Vgl. zu den Einwänden der SPD auch Frehse, Ermächtigungsgesetzgebung, S. $132 \mathrm{f}$.

573 Vgl. Bericht Brachts (Staatssekretär der Reichskanzlei) in der Ministerbesprechung vom 21.2. 1924; Protokoll in AdR Marx, Nr. 117, S. 393.

574 Antrag Nr. 6512 vom 22. 2. 1924: Verh. RT 380, S. 7849; ebd. Nr. 6513 auch ein Abänderungsantrag zur Verordnung über Gerichtsverfassung und Strafrechtspflege. Vgl. auch Frehse, Ermächtigungsgesetzgebung, S. 133.

575 Vgl. Protokolle von Parteiführerbesprechungen am 15. und 19.2.1924 in AdR Marx, Nr. 105 und 111 , hicr S. 365, 379f. Von Bedeutung war wohl v.a. ein umfangreicher Gesetzentwurf der DVP zur Abänderung der dritten Steuernotverordnung vom 25. 2. 1924, Antrag Nr. 6522; Verh. RT 380, S. $7852 \mathrm{f}$. 
des Verordnungsregimes war der eigene Einfluß nur minimal gewesen. Aus sozialdemokratischer Perspektive erschien es daher konsequent, sich jetzt aktiv für eine parlamentarische Modifizierung des Verordnungswerkes einzusetzen. In gewisser Weise handelte es sich um eine Art nachholende Kontrolle der Regierungstätigkeit. Gleichzeitig war die Chance gegeben, im Vorfeld der Reichstagswahlen inhaltliche Alternativen zur Regierungspolitik aufzuzeigen.

Im Reichskabinett äußerten sich zunächst unterschiedliche Meinungen zur parlamentarischen Diskussion erlassener Verordnungen. Stresemann stellte „zur Erwägung [...], ob das unbedingte Festhalten an der geschaffenen gesetzlichen Regelung hinsichtlich aller Verordnungen zu gelten habe. Es sei doch wohl denkbar, daß bei Verordnungen von geringerer Bedeutung Kompromisse dem Reichstag gegenüber geschlossen werden könnten. "576 Eine derartige Strategie deutete sich auch in diversen Parteiführergesprächen an, in denen der Reichskanzler jeweils „diejenigen Verordnungen“ bezeichnete, „welche von der Reichsregierung als unantastbar betrachtet würden" 577 . Marx zeigte sich vorübergehend kompromißbereit und räumte in der Kabinettssitzung vom 20. Februar ein, daß man „vom parlamentarischen Standpunkte aus betrachtet [...] das völlige Verbot der Ausschußberatungen als eine starke Beschneidung der Rechte der Volksvertretung ansehen" müsse ${ }^{578}$. In derselben Sitzung setzte sich dann aber, offenbar vor allem unter dem Einfluß von Arbeitsminister Brauns, Justizminister Emminger und Wirtschaftsminister Hamm, eine harte Linie durch ${ }^{579}$. Die Konfrontation mit der sozialdemokratischen Fraktion, deren Verhandlungsführer die Haltung der Regierung vehement als „Diktaturpolitik“ verurteilten ${ }^{580}$, war damit vorprogrammiert. Auch die Aussicht auf Aufhebung des militärischen Ausnahmezustands, wie sie Seeckt am 13. Februar Ebert vorgeschlagen hatte, konnte hier nicht für Entspannung sorgen ${ }^{581}$.

Der sich anbahnende parlamentarische Konflikt kam der Regierungskoalition vermutlich nicht einmal ungelegen, denn man war sich im Prinzip darüber einig, $\mathrm{daß}$ die noch bis zum 6. Juni dauernde Legislaturperiode vorzeitig beendet werden sollte. Da eine parlamentarische Stabilisierung der Regierung Marx oder auch eine neue Ermächtigungsmehrheit ${ }^{582}$ nicht in Sicht waren, erschien es naheliegend,

576 So in der Ministerbesprechung vom 15. 2. 1924. Protokoll in AdR Marx, Nr. 105, S. 365-369, hier S. 366. Ähnlich äußerten sich ebd. Postminister Höfle und Arbeitsminister Brauns.

577 Besprechung mit den Regierungsparteien, mit führenden Reichstagsabgeordneten der SPD und mit der DNVP, jeweils am 19. 2. 1924. Protokolle ebd., Nr. 110, 111, 113, S. 379-381, 384.

578 Ebd., Nr. 115, S. 389.

579 Die Genannten äußerten sich am klarsten in diesem Sinne. Marx resümierte zum Schluß, das Kabinett wolle daran festhalten, „daß Ausschußberatungen über die Notverordnungen nicht geduldet würden“. Ebd., S. 390.

580 So Wels in einer Besprechung des Reichskanzlers mit führenden SPD-Reichstagsabgeordneten am 19. 2. 1924; AdR Marx, Nr. 111, S. 381. Müller sprach ebd. von einer "schroff[en] und diktatorisch[en]" Haltung der Regierung. Dittmann wies auf die „bedenkliche außenpolitische Wirkung“ hin. Breitscheid, der gerade aus England zurückgekehrt war, bestätigte dies und drohte mit der „Wahlparole“ „Für die Demokratie, gegen die Diktatur“.

581 NPZ, 14. 2. 1924 ab, S. 1, „Aufhebung des Ausnahmezustandes“, behauptete, daß dem ein „Kuhhandelsgeschäft der Parteien" vorangegangen sei. Angeblich sei dies der Preis gewesen, um einen Verzicht der SPD auf Aufhebung der neuen Steuernotverordnung zu erreichen. Seeckt hat darauf am 23. 2. 1924 eine Unterredung mit Westarp. IfZ München, Nl. Seeckt, Stück 130.

582 Kurzzeitig war eine neue Ermächtigung im Gespräch. Vgl. etwa Marx am 28. 2. 1924 in einer Parteiführerbesprechung; AdR Marx, Nr. 124, S. 411. 
den Zustand der Unsicherheit zu beenden und die anstehenden Neuwahlen einige Monate vorzuziehen ${ }^{583}$. Die DNVP forderte ohnehin schon seit längerem die Reichstagsauflösung. Über Wochen hinweg entspann sich nun eine Diskussion über den günstigsten Wahltermin ${ }^{584}$, die sich mit der Suche nach einem geeigneten Motiv für die Reichstagsauflösung verband.

Nachdem die Entscheidung über die vorliegenden Änderungs- und Aufhebungsanträge zurückgestellt worden war, beschäftigte sich ${ }^{585}$ der Reichstag seit dem 26. Februar zunächst mit einer Aussprache über die Regierungspolitik der zurückliegenden Monate im allgemeinen und über die erlassenen Verordnungen im besonderen. Reichskanzler Marx und einzelne Minister mühten sich dabei ansatzweise auch um eine inhaltliche Begründung der getroffenen Maßnahmen ${ }^{586}$. Der SPD-Fraktionsvorsitzende Müller betonte in einer sehr grundsätzlichen Rede das Recht und auch die Pflicht des Parlaments zu einer Modifizierung einzelner Verordnungen ${ }^{577}$. Im übrigen erwies sich der Reichstag während dieser Tage in legislativer Hinsicht durchaus als funktionsfähig. So wurden ein „Etatnotgesetz“"588 zur vorläufigen Regelung des Haushalts 1924 sowie eine Gesetzesvorlage zur Errichtung einer Golddiskontbank ${ }^{589}$ gebilligt. Eine in der Vorlage versteckte großzügige Kreditermächtigung für die Reichsregierung war auf sozialdemokratische Initiative hin zuvor im Haushaltsausschuß entschärft worden ${ }^{590}$.

Zwischenzeitlich gingen im Kabinett und in Parteiführerbesprechungen die Beratungen über eine Reichstagsauflösung und über den Umgang mit den parlamentarischen Wünschen nach Diskussion und Modifizierung erlassener Verordnungen weiter. Zeitweise war dabei eine Lösung im Gespräch, die in ihrem ersten Schritt den parlamentarischen Gepflogenheiten in Frankreich entsprochen hätte. Die Regierung, so erörterte das Kabinett am 26. und 27. Februar, solle nach einer kurzen Plenaraussprache über die Ergebnisse des Ermächtigungsgesetzes den mit der Vertrauensfrage verbundenen Antrag auf Schluß der Debatte stellen und so

${ }^{583}$ Als überzogen erscheint daher die Deutung von Arns, Regierungsbildung, S. 185, der in der breiten Bereitschaft zur Reichstagsauflösung ein weiteres Indiz für mangelndes Verantwortungsbewußtsein der Parteien sieht.

${ }^{58+}$ Dabei spielte auch das Argument eine Rolle, bis nach den französischen Kammerwahlen am 11. 5. 1924 zu warten, um durch das deutsche Wahlergebnis keine Vorlage für die französische Rechte zu geben. Vgl. z. B. Marx in der Ministerbesprechung vom 6. 3. 1924; AdR Marx, Nr. 131, S. 433.

585 Vgl. die zynische Äußerung von Scholz in der Parteiführerbesprechung vom 14. 2. 1924: „Am besten würde es sein, wenn der Reichstag mit der Beratung des Etats für 1924 beschäftigt werden könne." Ebd., Nr. 104, S. 362.

586 Verh. RT 361, S. 12465-12580 (26.-29. 2. 1924).

587 Sitzung vom 26. 2. 1924; ebd., S. 12469-12480, va. S. 12479, nach einer generellen Rechtfertigung der Ermächtigung: „Aber diese Zeit der Ermächtigung ist abgelaufen. Jetzt handelt es sich darum, daß nach Ablauf dieser Ermächtigung der normale Weg der Gesetzgebung wieder frei ist und daß infolgedessen das Parlament die Pflicht hat, diesen Weg zu betreten. Das Gegenteil wäre die Abdankung des Parlamentarismus."

588 „Gesetz über dic vorläufige Regelung des Reichshaushalts für das Rechnungsjahr 1924“. Vgl. hierzu AdR Marx, Nr. 105, S. 365, Anm. 4. - Annahme am 13. 3. 1923 ohne namentliche Abstimmung; Verh. RT 361, S. 12824.

589 Beratung am 11. und 13. 3. 1924, Annahme am 13.3. ohne namentliche Abstimmung. Ebd.

590 Vgl. Gesetzentwurf vom 21. 2. 1924; Verh. RT 380, Drucks. Nr. 6498. Beratung des Entwurfes am 28. und 29. 2 im Haushaltsausschuß; Protokoll der 292. und 293. Sitzung; BA Berlin, R 101, Nr. 1363, Bl. 600-604, 648f. Der Sozialdemokrat Hertz äußerte dabei „schwerste Bedenken, daß durch dieses Ermächtigungsgesetz die Reichsregierung eine Blankovollmacht erhalte und der Reichstag keine Möglichkeit habe, auf den Etat den notwendigen Einfluß zu nehmen“. 
jeder speziellen Diskussion um einzelne Verordnungen eine Absage erteilen. Sollte der Antrag abgelehnt werden, dies war der geplante - in Frankreich de facto unmögliche ${ }^{591}$ - zweite Schritt, würde die von Ebert bereits zugesagte Auflösung erfolgen. Im übrigen war es keineswegs sicher, daß die Vertrauensfrage scheitern würde, denn die SPD-Führung hatte wohl nur geringes Interesse an frühzeitigen Neuwahlen. Der DVP-Fraktionsvorsitzende Scholz plädierte in einer Besprechung am 19. Februar daher nachdrücklich für ein derartiges Vorgehen, das auch vom Ältestenrat des Reichstags befürwortet worden war ${ }^{592}$. Da es in diesem Fall nicht zur Auflösung durch den Reichspräsidenten kommen würde, sprach sich Scholz für eine Art Selbstauflösung des Reichstags durch einen Mehrheitsbeschluß über die vorzeitige Beendigung der Legislaturperiode aus ${ }^{593}$.

Als Problem erwies sich allerdings, daß mit dem Scheitern der Vertrauensfrage der Rücktritt der Regierung verbunden war ${ }^{594}$. Auch wenn dies aus den Kabinettsprotokollen nicht direkt hervorgeht, fürchtete man vermutlich die dann erforderliche Bildung einer bis zu den Neuwahlen amtierenden Interimsregierung. Nur so ist es zu erklären, daß Innenminister Jarres, sekundiert von seinem Staatssekretär Zweigert, am 26. Februar in der Ministerrunde einen verfassungsrechtlich verwegenen Plan vortrug: Jarres behauptete, „daß nach richtiger Auslegung der Verfassung die Annahme eines Mißtrauensvotums von seiten des Reichstags die Tätigkeit der Regierung an sich nicht unterbreche. Die Folge der Annahme eines solchen Antrages sei vielmehr, daß die Regierung gemäß Art. 54 RV verpflichtet sei, zurückzutreten. Beim Herrn Reichspräsidenten liege alsdann die Entscheidung über Annahme des Rücktrittsgesuches, bezw. könne der Herr Reichspräsident den zurückgetretenen Reichskanzler sofort neu berufen und ihm die Ermächtigung zur Auflösung des Reichstages erteilen." 595

Reaktionen anderer Regierungsmitglieder auf diesen klar gegen die Logik des parlamentarischen Systems gerichteten Vorschlag sind in dem vorliegenden Kabinettsprotokoll nicht verzeichnet. Auch ist nicht bekannt, inwieweit in diesem Sinne bei Ebert vorgefühlt wurde. Daß der Reichspräsident hier Zustimmung signalisiert haben könnte, dürfte allerdings auszuschließen sein ${ }^{596}$. In den folgenden Kabinettsberatungen tauchte der Plan jedenfalls nicht mehr auf. Vielmehr setzte sich nun in Rücksprache mit den Spitzen der Regierungsfraktionen die Auffassung durch, daß die Regierung auf einen Vertrauensantrag verzichten solle ${ }^{597}$. Man

591 Vgl. oben S. 30 f. zur Tabuisierung der Kammerauflösung seit 1877.

592 AdR Marx, Nr. 111, S. 379 f. Ebd., S. 380, auch Einschätzung der SPD: „Die Opposition werde ein Mißtrauensvotum nicht riskieren, daher könne man unbedenklich die Vertrauensfrage stellen."

593 Parteiführerbesprechung am 28. 2. 1924, ebd., Nr. 124, S. 412; Parteiführerbesprechung am 5. 3. 1924, ebd., Nr. 130, S. 431.

594 So zumindest nach dem in der Regierungskoalition vorherrschenden Verständnis. Anders Anschütz, Verfassung, S. 190. Hinweise darauf, daß diese Auffassung unter den führenden Politikern bekannt war, fanden sich nicht.

${ }^{595}$ AdR Marx, Nr. 122, S. 407. Dieses Vorhaben scheint bislang in der Literatur noch nicht beachtet worden zu sein.

596 Vgl. Anm. 601 zu Eberts Bemühen um eine verfassungspolitisch korrekte Lösung.

597 Vgl. v.a. Marx in Parteiführerbesprechung am 5. 3. 1924: „Der Reichskanzler äußerte Bedenken dagegen, die Ablehnung eines Regierungsantrages am Schluß der Debatte als Auflösungsgrund zu nehmen." AdR Marx, Nr. 130, S. 432; ähnliche Äußerungen kamen von Scholz und Fehrenbach, Koch-Weser stimmte zu; ebd., S. 431 f. - Die Annahme von Arns, Regierungsbildung, S. 185, man habe von einem Vertrauensvotum Abstand genommen, weil es - gemäß der Forderung Eberts (vgl. 
einigte sich bereits am 5. März auf ein Verfahren, wie es dann gut eine Woche später im Prinzip auch praktiziert wurde: Auflösung nach einer bloßen Erklärung der Reichsregierung, daß sie sich angesichts der parlamentarischen Lage dazu gezwungen sehe ${ }^{598}$.

Am 13. März war es schließlich so weit. Bevor die Anträge der Opposition zur Abstimmung gestellt werden konnten, gab Marx eine kurze Regierungserklärung ab. Dabei betonte er, daß „die auf Grund des Ermächtigungsgesetzes erlassenen Verordnungen ein einheitliches Ganzes darstellen“. Das „Werk der Gesundung“ dürfe nicht gefährdet werden, daher müsse „die Reichsregierung das Verlangen stellen, daß zur Zeit selbst jede Einzelberatung über die zu den Verordnungen vorliegenden zahlreichen Anträge im Plenum unbedingt vermieden wird“. Der Regierung sei es nicht gelungen, die Oppositionsparteien durch Verhandlungen von ihrem Standpunkt zu überzeugen ${ }^{599}$. Da die „Mehrheit des Reichstags darauf besteh[e], einen Weg zu beschreiten, der nach Überzeugung der Reichsregierung für das Volk verderblich ist, [halte] sich die Regierung [...] für verpflichtet, die weiteren Verhandlungen über die Notverordnungen zu verhindern und die Entscheidung des Volkes selbst anzurufen". Der Reichskanzler verlas zuletzt das Ebertsche Auflösungsdekret: „Nachdem die Reichsregierung festgestellt hat, daß ihr Verlangen, die auf Grund der Ermächtigungsgesetze vom 13. Oktober und 8. Dezember [...] ergangenen und von ihr als lebenswichtig bezeichneten Verordnungen zur Zeit unverändert fortbestehen zu lassen, nicht die Zustimmung der Mehrheit des Reichstags findet, löse ich auf Grund des Art. 25 der Reichsverfassung den Reichstag auf." 600

Auffallend ist, daß die Erklärung des Reichskanzlers und die Verordnung des Reichspräsidenten in ihren Begründungen leicht voneinander abweichen. Während Marx das Gewicht auf das seiner Sicht nach fatale und daher von der Regierung zu verhindernde Vorhaben der Opposition legte, bezog sich das Ebertsche Dekret primär auf die fehlende Mehrheit der Regierung, um die erlassenen Verordnungen unverändert fortbestehen zu lassen. Möglicherweise resultierte diese Akzentverschiebung aus dem Bemühen Eberts, eine verfassungspolitisch absolut korrekte Auflösungsformel zu finden ${ }^{601}$. Freilich richtete sich auch der gewählte Text, der seltsamerweise auf einen Vorschlag von Reichswehrminister Geßler zu-

Anm. 601) - „als ein möglicherweise nicht genügend ,einwandfreier ' Auflösungsgrund erscheinen mochte", ist offensichtlich verfehlt. Ebert hatte für diesen Fall - gemäß Kabinettsprotokoll vom 27. 2. 1924; AdR Marx, Nr. 123, hier S. 410 - die Auflösung klar zugesagt. Verfassungsrechtlich wäre ein derartiges Vorgehen zweifellos korrekt gewesen. Die politischen Implikationen eines verlorenen Vertrauensvotums werden von Arns jedoch nicht beachtet, wie überhaupt die Thematik nur en passant erwähnt wird.

598 AdR Marx, Nr. 130, S. 432. Die Zustimung Eberts war allerdings nach Aussage von Marx noch offen. Vgl. ebd. „Die Frage sei, ob der Herr Reichspräsident unter solchen Umständen die Auflösungsorder erteilen würde."

599 Verh. RT 361, S. 12828.

600 Drucks. Nr. 6620; Verh. RT 380, S. 7952; auch Poetzsch, Staatsleben 1, S. 161.

601 Vgl. v.a. Protokoll der Parteiführerbesprechung vom 6.3. 1924 mit Bericht des Reichskanzlers; AdR Marx, Nr. 132, hier S. 442f.: „Die Frage der Auflösung habe er schon des öfteren mit dem Reichspräsidenten besprochen. Dieser sei der Ansicht, daß eine konkrete Tatsache für die Auflösung vorliegen müsse und daß bei der Auflösung alles zu vermeiden sei, was nach einer Verletzung des Ermächtigungsgesetzes, der Geschäftsordnung des Reichstages oder der Reichsverfassung aussehen könne." Ahnlich bereits Marx in Ministerbesprechung vom 6.3. 1924; ebd., Nr. 131, S. 433. Demnach forderte Ebert einen „einwandfreien Grund“ für die Auflösung. 
rückging602, noch deutlich gegen das im Ermächtigungsgesetz vom 8. Dezember ausdrücklich verbürgte Recht des Reichstags. Hinzu kam, daß gar nicht festgestellt worden war, ob die Regierung im Plenum tatsächlich keine Mehrheit für ihr „Verlangen“ finden konnte. Vielmehr gründete sich dieses Urteil allein auf die vorherigen informellen Gespräche mit den Parteiführern sowie auf die gleichzeitige Annahme eines disziplinierten Abstimmungsverhaltens der Oppositionsparteien.

Die Reichstagsauflösung vom 13. März 1924 weist eine gewisse Ähnlichkeit zur bekannteren Auflösung durch Reichspräsident Hindenburg am 18. Juli 1930 auf. Beide Male richtete sich die präsidentielle Gewalt des Artikels 25 gegen die verfassungsmäßige Wahrnehmung des parlamentarischen Rechts, Verordnungen, die auf dem Weg der „vereinfachten Gesetzgebung" durch die Regierung erlassen worden waren, aufzuheben bzw. abzuändern. 1930 basierten diese Verordnungen allerdings auf Artikel 48 und nicht wie 1924 auf einem Ermächtigungsgesetz. Unterschiedlich war auch der Zeitpunkt der Auflösung: 1924 präventiv vor einem parlamentarischen Beschluß, 1930 unmittelbar danach. Infolge dieser Differenzen, aber auch infolge des Termins kurz vor Ablauf der regulären Legislaturperiode war die verfassungsrechtliche Problematik 1924 sicher weniger markant. Dennoch kann man hier einen schwerwiegenden Präzedenzfall für die spätere Kombination der Artikel 48 und 25 sehen ${ }^{603}$. Und wie die oben zitierten Überlegungen von Innenminister Jarres zeigen, war auch die Verbindung zu Artikel 54 und dem präsidentiellen Recht auf Berufung des Reichskanzlers nicht mehr weit. Die Eigendynamik des Verordnungsregimes hatte so in kürzester Zeit in die Nähe einer präsidentiellen Überformung des parlamentarischen Systems geführt.

Unmittelbar nachdem Marx das Auflösungsdekret verlesen hatte, stellte Reichstagspräsident Löbe unter Bezug auf Artikel 25 der Verfassung fest, daß „unsere Aufgabe an diesem Orte abgeschlossen“ ist. Im Anschluß daran dankte er allen Mitarbeitern der Reichstagsverwaltung und nutzte die Gelegenheit noch zu einem „allgemeine[n] politische[n] Wort", das bezeichnend ist für den Tiefpunkt, auf dem sich das öffentliche Ansehen des deutschen Parlaments inzwischen befand 604: Der Feststellung, daß „dieser Reichstag [...] vielfach angegriffen, gescholten, ich darf sagen: geschmäht worden" ist, konnte der Reichstagspräsident nur die Hoffnung auf ein "gerechteres Urteil“ „kommende[r] Geschlechter“ entgegensetzen ${ }^{605}$.

${ }^{602}$ Dies geht aus einer Bemerkung von Franz Bracht, Staatssekretär in der Reichskanzlei, in der Ministerbesprechung vom 11.3. 1924 hervor. Ebd., Nr. 139, S. 449. Die ursprüngliche Vorlage ist nicht überliefert. Ebd. wird von Bracht auch erwähnt, daß die Formulierung noch mit Geßler und Staatssekretär Meissner abgestimmt werden soll.

${ }^{603}$ Auf die mangelhafte Beachtung in der Forschung hat bereits Abramowski, Die Reichsregierung im Spannungsfeld, S. 66, aufmerksam gemacht. Arns, Regierungsbildung, S. 185, geht nur ganz knapp auf diese Thematik ein. Bei Eilers, Ermächtigungsgesetz und militärischer Ausnahmezustand, ist der Präzedenzfall nicht erkannt. Statt dessen wird ebd., S. 153, die „Schuld an der Auflösung des Parlaments" bei SPD und DNVP gesucht.

${ }^{604}$ Vgl. hierzu resümierend z.B. VZ, 4. 4. 1924 mo, S. 1, „Zwischen den Reichstagen“. Der Autor, der Sozialdemokrat Max Cohen-Reuß, spricht ein vernichtendes Urteil über den alten Reichstag. Vor allem sei die Stabilisierung „ohne das deutsche Parlament geschehen“: „Das ist wahrlich ein Armutszeugnis allerersten Ranges."

605 Verh. RT 361, S. 12829. Löbe wies auch auf die europäische Dimension der Parlamentarismuskritik hin. Auch zitiert bei Eilers, Ermächtigungsgesetz und militärischer Ausnahmezustand, S. $150 \mathrm{f}$. 


\section{Resümee: Funktionaler Rückzug des Reichstags obne Alternative?}

In den Amtszeiten der beiden Kabinette Stresemann und des ersten Kabinetts Marx überstand die Weimarer Republik eine extrem schwierige Krisensituation. Vor allem drei wesentliche Herausforderungen waren dabei zu bestehen: der Abbruch des Ruhrkampfes, die Überwindung der Hyperinflation mit Umstellung auf ein neues Währungssystem und die Abwehr systemgefährdender Machenschaften auf der politischen Rechten.

Diese unbestreitbaren Erfolge wurden mit den Mitteln eines von parlamentarischer Mitwirkung und Kontrolle nur noch wenig beeinflußten Ausnahme- und Verordnungsregimes erzielt. Die seit der Regierungsbildungskrise vom Herbst 1922 verstärkt auftretenden funktionalen Defizite des Reichstags steigerten sich nun zu einem weitgehenden Rückzug aus dem politischen Geschehen.

Die parlamentarischen Grundfunktionen erlebten während der Kanzlerschaft Stresemanns seit dem positiven Auftakt, als sich die führenden Fraktionen rasch über die Regierungsbildung einigten, einen breiten Niedergang. Die Große Koalition brachte zunächst eine Suspendierung der Alternativfunktion mit sich. Die regierungstragende Funktion wurde schon bald durch wachsende innere Gegensätze im breiten Regierungslager gelähmt. Stresemann konnte zwar die schwere, wesentlich von seiner eigenen Partei initiierte Koalitionskrise vom Oktober 1923 überwinden und ein neues Kabinett der Großen Koalition bilden. Die damit verbundene Schwächung der Sozialdemokratie und die wiederholten Zugeständnisse des Kanzlers an den rechten Flügel seiner Partei mußten aber geradezu ein Herausbrechen der SPD aus der Koalition zur Folge haben. Gleichzeitig scheiterte die vom rechten Flügel der DVP angestrebte Einbeziehung der DNVP in die Regierungsverantwortung, so daß die Erosion der Großen Koalition nicht durch eine neu akzentuierte Kabinettsbildung nach rechts kompensiert werden konnte.

Die Schwäche im Bereich der regierungstragenden Funktion aber beschleunigte den weiteren Verzicht des Reichstags auf seine legislative und damit eng verbunden auch auf seine Kontrollfunktion. Bereits das weite Ermächtigungsgesetz vom 13. Oktober 1923 ist ohne die innere Schwäche des Regierungslagers nicht zu erklären ${ }^{606}$. Auch der vom Reichstag nach Zerbrechen der Koalition geduldete expansive legislative Einsatz des Artikels 48 steht in diesem Zusammenhang. Die Pauschalermächtigung für die Regierung Marx vom 8. Dezember und die anschließende Suspendierung des parlamentarischen Betriebes spiegelten dann eine Situation, in der es nicht gelungen war, eine Mehrheitsregierung zu bilden. Im Hinblick auf die parlamentarische Alternativfunktion gab es in dieser Phase trotz des Regierungsaustritts der SPD jedoch nur wenig Belebung, denn die sozialdemokratische Reichstagsfraktion fügte sich in die „Ermächtigungsmehrheit“ der Regierung Marx ein.

Bis Mitte Februar 1924, als erstmals die Aufhebung legislativer Verordnungen durch eine heterogene Reichstagsmehrheit drohte, erfolgte der funktionale Rückzug des Reichstags überwiegend im Einklang zwischen den Reichsregierungen und einer - zunächst tatsächlichen, später dann informellen - Großen Koalition. 
In den letzten Wochen der Legislaturperiode bis zur Reichstagsauflösung vom 13. März 1924 deutete sich aber dann bereits eine auf die Endphase der Weimarer Republik vorausweisende Konfrontation von Regierung und Reichstagsmehrheit an. Die Eigendynamik des parlamentarischen Funktionsverlustes führte so schließlich zu einem Punkt, an dem Reichsregierung und Reichspräsident den wieder auflebenden legislativen Gestaltungsanspruch des Reichstags mit der Auflösung sanktionierten.

Dieser Konflikt ist auch ein Anzeichen dafür, daß sich in bestimmten Situationen doch noch ein parlamentarischer Selbstbehauptungswille regte. Bereits die Bildung der Regierung Stresemann kann als Gegenreaktion auf den Prozeß der Entparlamentarisierung während der Regierungszeit Cunos gedeutet werden. Ein analoger Wille zur parlamentarischen Regierungsbildung setzte sich dann auch Anfang Oktober durch, als Stresemann eigentlich ein parteiunabhängiges Kabinett zusammenstellen wollte. Vor allem aber bewährte er sich Anfang Dezember 1923, als die Parteien der bürgerlichen Mitte Eberts Bemühungen um ein „Fachkabinett" Albert zurückwiesen und sich zunächst auf Stegerwald und dann auf Marx als Kanzlerkandidaten verständigten. Dieses Bestehen auf einer parlamentarisch verankerten Regierungsbildung 607 - offensichtlich ein Lerneffekt aus dem fehlgeschlagenen "Experiment" Cuno ${ }^{608}$ - kontrastiert freilich damit, daß eine wirkliche Kooperation zwischen Regierung und Regierungslager dann jeweils vernachlässigt wurde. Die parlamentarische Stützung der Regierung blieb so auf die Bewilligung pauschaler Ermächtigungsgesetze beschränkt. Überraschen kann dieser Befund freilich nicht, entspricht er doch ziemlich genau dem verbreiteten Leitbild einer parlamentarisch möglichst ungestörten Regierung.

Bei der Gesetzgebungsfunktion ist zumindest in den Reihen der Sozialdemokratie ein begrenzter parlamentarischer Gestaltungsanspruch zu erkennen. So bemühte sich die SPD-Fraktion bei der Formulierung des Ermächtigungsgesetzes Anfang Dezember, durch Schaffung eines besonderen Ausschusses ein Minimum an parlamentarischer Kontrolle und legislativer Mitwirkung zu wahren. Nach Ablauf des Ermächtigungsgesetzes wollte die SPD dann mit den Kompetenzen der parlamentarischen Gesetzgebung nachträglich in das geschaffene Verordnungswerk eingreifen.

Bereits diese Indizien weisen darauf hin, daß der Prozeß der Funktionslähmung keineswegs ohne Alternativen war. Wenn nun im folgenden verschiedene „kontrafaktische“ Möglichkeiten einer abweichenden Entwicklung angeführt werden, so ist damit, dies sei gegen Mißverständnisse ausdrücklich betont, keinerlei Bewertung verbunden. Es geht hier nicht um Besserwisserei, wie sich die Zeitgenossen parlamentarismustheoretisch „korrekt" hätten verhalten sollen, sondern

607 In der Literatur wird dies bislang nicht angemessen gewürdigt. Dies gilt auch für Arns, Regierungsbildung. In seiner zusammenfassenden Bewertung der "Kanzlerbestellungen“ erfolgt ebd., S. 205, lediglich die allgemeine Aussage, daß es hier zu keinem "kontinuierlichen Abbau parlamentarischer Prinzipien“ kam.

608 Explizite Hinweise auf den Fall Cuno ließen sich im parlamentarischen Verhandlungsprozeß nicht feststellen. Zumindest für das Umfeld der DDP charakteristisch scheint aber die Kritik an Ebert in FZ, 27. 11. 1923 ab, S. 1, „Frankfurt, 27. November": „Aber er hat mit einem ähnlichen Experiment schon einmal Erfahrungen gemacht: mit Cuno, der eine Wiederholung des Falles Michaelis war. Das sollte warnen." 
darum, das zeitgenössische Potential einer funktional aktiveren parlamentarischen Entwicklung aufzuzeigen.

Die inneren Probleme der Großen Koalition hätten sich zweifellos erheblich reduzieren lassen, wenn Stresemann, wie auch zeitgenössisch vielfach gefordert ${ }^{609}$, gegenüber dem rechten Flügel seiner Partei weniger nachgiebig gewesen wäre. Eine entschiedenere Reaktion gegen den innerparteilichen „Putschversuch“ Ende September/Anfang Oktober hätte zwar möglicherweise zum Bruch innerhalb der DVP geführt, vielleicht aber auch eine Konsolidierung der Regierungsmehrheit bewirkt und so verhindert, daß man schließlich Zuflucht in einer Pauschalermächtigung suchte. Eine andere Sachsen- und Bayernpolitik des Kanzlers hätte dann die SPD von jenem Druck entlastet, der schließlich zum Bruch der Großen Koalition und zum sozialdemokratischen Mißtrauensantrag gegen Stresemann führte. Das Scheitern der Koalition aber war ein Impuls für die weitere Eskalation des legislativen Funktionsverzichts.

Unbestritten ist, daß sich mit guten Gründen auch Kritik am Verhalten der SPD üben läßt. Allerdings muß hier immer auch bedacht werden, welche Folgen eine noch stärkere Anpassung an die im wesentlichen von den bürgerlichen Koalitionspartnern bestimmte Politik für das Wahlverhalten der Arbeiterschaft besessen hätte. Je mehr sich die SPD an die bürgerliche Mitte anlehnte, desto mehr mußte die systemfeindliche linke Alternative der Kommunisten an Attraktivität gewinnen. Der Entschluß der SPD, sich nicht mehr an der Regierung zu beteiligen und durch das beantragte Mißtrauensvotum eine demonstrative Oppositionsrolle einzunehmen, schuf auf der Linken zumindest ansatzweise wieder eine systemloyale parlamentarische Alternative. Vielleicht wäre hier bei einer mutigeren, eine eigene Führungsrolle anstrebenden Politik der SPD auch die Möglichkeit einer Weimarer Koalition wieder stärker in die Diskussion gekommen.

Eine ganz andere Richtung hätte die politische Entwicklung genommen, wenn die SPD das Experiment der Großen Koalition bereits Anfang Oktober für gescheitert erklärt und sich nicht mehr an einer neuen Regierung Stresemann beteiligt hätte. Eventuell wären dann bei der DNVP jene Kräfte gestärkt worden, die den Eintritt in eine bürgerliche Koalitionsregierung befürworteten, während umgekehrt die Bereitschaft bei DDP und Zentrum zu einer Kooperation mit den Deutschnationalen vielleicht gewachsen wäre. Der so geschaffene Bürgerblock hätte eine ausreichende parlamentarische Mehrheit besessen, um die anstehenden legislativen Aufgaben auf dem regulären Wege zu bewältigen, während der SPD nun eine klare parlamentarische Oppositionsrolle zugefallen wäre. Dasselbe gilt für die Situation Anfang Dezember, als nach dem Rücktritt Stresemanns über eine bürgerliche Mehrheitskoalition unter Einschluß der DNVP verhandelt wurde. Eine Einbeziehung der DNVP in die legislative Durchführung der Währungsstabilisierung und insbesondere in die Aufwertungsentscheidung hinsichtlich der Vermögensschulden hätte zudem den kaum zu überschätzenden Vorteil besessen,

${ }^{609} \mathrm{Vgl}$. z.B. das Resümec in FZ, 24. 11. 1923 ab, S. 1, „Frankfurt, 24. November“. „Aber Herr Dr. Stresemann, der wirklich der Kanzler der Großen Koalition hatte sein wollen, ist daran gescheitert, daß er von den Worten nicht zu den Taten schritt." 
daß die Partei nicht aus der Opposition heraus demagogische Kritik an diesen Maßnahmen hätte üben können.

Erscheint ein formeller Regierungseintritt der DNVP zu diesem Zeitpunkt als eine schwierig zu realisierende Option, so wäre eine losere Bindung an das Regierungslager eher zu praktizieren gewesen. Wie Anfang Dezember der mißlungene Kabinettseintritt Schieles zeigte, war die Einbeziehung einzelner Persönlichkeiten der DNVP zu diesem Zeitpunkt offenbar kein gangbarer Weg. Die in anderen Situationen der Weimarer Republik mehrfach versuchte Personalisierung der Regierungsbildung wurde hier ähnlich wie bereits beim Scheitern des Kabinettseintritts der DVP im November 1922 durch die modernere Logik des parteiengestützten Systems gebrochen. Hingegen bestanden Anfang Dezember 1923 durchaus Aussichten auf eine von der DNVP tolerierte bürgerliche Minderheitsregierung. Tagelang hatte die DNVP-Fraktion in ihrer Haltung gegenüber dem Ermächtigungsgesetz geschwankt, und offenbar gab erst die sozialdemokratische Fraktionsentscheidung für eine Zustimmung den Ausschlag für die ablehnende $\mathrm{Hal}$ tung der DNVP. Nochmals sei daran erinnert, daß eine Ermächtigungsmehrheit auch mit DNVP-statt SPD-Unterstützung möglich gewesen wäre, wenn ein Teil der SPD-Fraktion im Plenarsaal geblieben wäre. Mit einem derartigen Verhalten hätte die SPD einen eher moderaten Oppositionskurs eingeschlagen.

Eine konsequente Ablehnung des zweiten großen Ermächtigungsgesetzes durch die SPD hätte erfordert, daß die Fraktion am 4. Dezember vor der Abstimmung den Saal verläßt, um die für eine qualifizierte Mehrheit nach Artikel 76 der Reichsverfassung notwendige Anwesenheit von zwei Dritteln der Abgeordneten zu vereiteln. Dies hätte die Reichstagsauflösung, Neuwahlen innerhalb von $60 \mathrm{Ta}$ gen und die Fortsetzung des auf Artikel 48 gestützten Verordnungsregimes bedeutet. Hinsichtlich der Legislativfunktion wäre eine derartige Lösung zweifellos noch problematischer gewesen als das Ermächtigungsgesetz, vom Standpunkt der Alternativfunktion hätte sie der SPD erheblichen oppositionellen Spielraum für den Wahlkampf verschafft.

Auch unterhalb der eben skizzierten Handlungsebene gab es mehrfach Möglichkeiten zur stärkeren Wahrung parlamentarischer Funktionen. Daß die beiden Ermächtigungsgesetze jeweils zu Pauschalvollmachten wurden, erscheint ebenso wenig zwangsläufig wie die Ausnutzung der zweiten Ermächtigung zu Gesetzgebungsprojekten, die mit den ursprünglichen Motiven der Delegation nichts mehr zu tun hatten. Eine enge materielle Begrenzung der Ermächtigungen - verwiesen sei hier auf das französische Beispiel610 - hätte es unmöglich gemacht, daß der parlamentarische Betrieb über Monate hinweg fast ganz eingestellt wurde.

Die Ursachen, warum die hier angedeuteten Optionen nicht realisiert wurden, waren im einzelnen vielgestaltig. Zwei Faktoren lassen sich allerdings immer wieder erkennen: das trotz aller praktischen Probleme wirkungsvolle Leitziel einer Großen Koalition und die hohe deutsche Bereitschaft zur parlamentarischen Selbstbeschränkung. Letztere fällt insbesondere dann auf, wenn man sie mit dem ausgeprägten Selbstbewußtsein der französischen Parlamentarier vergleicht. 